\title{
EFFECT OF PRESSURE VARIATION ON POLYMER FLOODING
}

by

\section{Ahmad Ali Manzoor}

B.Sc. in Chemical Engineering, Bahauddin Zakariya University, Pakistan, 2011

\author{
A thesis presented to \\ Ryerson University
}

in partial fulfillment of the

requirements for the degree of

Master of Applied Science

in the program of

Chemical Engineering

Toronto, Ontario, Canada, 2018

CAhmad Ali Manzoor, 2018 


\section{Author's Declaration}

I hereby declare that I am the sole author of this thesis. This is a true copy of the thesis, including any required final versions, as accepted by my examiners.

I authorize Ryerson University to lend this thesis to other institutions or individuals for the purpose of scholarly research.

I further authorize Ryerson University to reproduce this thesis by photocopying or by other means, in total or in part, at the request of other institutions or individuals for the purpose of scholarly research.

I understand that my thesis may be made electronically available to the public. 


\title{
EFFECT OF PRESSURE VARIATION ON POLYMER FLOODING \\ Master of Applied Science
}

2018

\author{
Ahmad Ali Manzoor \\ Chemical Engineering \\ Ryerson University
}

\begin{abstract}
Chemical-based enhanced oil recovery (EOR) techniques utilize the injection of chemicals, such as solutions of polymers, alkali, and surfactants, into oil reservoirs for incremental recovery. The injection of a polymer increases the viscosity of the injected fluid and alters the water-to-oil mobility ratio which in turn improves the volumetric sweep efficiency. This research study aims to investigate strategies that would help intensify oil recovery with the polymer solution injection. For that purpose, we utilize a lab-scale, cylindrical heavy oil reservoir model. Furthermore, a dynamic mathematical black oil model is developed based on cylindrical physical model of homogeneous porous medium. The experiments are carried out by injecting classic and novel partially hydrolyzed polyacrylamide solutions (concentration: 0.1-0.5 wt \%) with $1 \mathrm{wt} \%$ brine into the reservoir at pressures in the range, 1.03-3.44 MPa for enhanced oil recovery. The concentration of the polymer solution remains constant throughout the core flooding experiment and is varied for other subsequent experimental setup. Periodic pressure variations between 2.41 and $3.44 \mathrm{MPa}$ during injection are found to increase the heavy oil recovery by $80 \%$ original-oil-in-place (OOIP). This improvement is approximately $100 \%$ more than that with constant pressure injection at the maximum pressure of $3.44 \mathrm{MPa}$. The experimental oil recoveries are in fair agreement with the model calculated oil production with a RMS\% error in the range of 5-10\% at a maximum constant pressure of $3.44 \mathrm{MPa}$.
\end{abstract}




\section{Acknowledgements}

For their boundless gifts and blessings, I thank Majeeda Begum and Manzoor Hussain.

For making incredible things happen when they seemed most impossible I thank my wife Affairah Ahmad.

For his consistent encouragement, sage advice, support and guidance I thank my supervisor Dr.

Simant R. Upreti, without his kind patience I wouldn't have managed to accomplish this. For his illuminating guidance and creative input, I thank Dr. Philip Chan.

For being there for the good times and especially for the bad and being my przyjaciel I thank Dr. Khurram Shahzad Baig, Dr. Arjang, Mohammed Awad, Saadullah Baloch, Nafay Akhtar Tareen, Jawad Khan, and Waleed Ahmed.

For being amazing comrades in the lab, for having humor, and for helpful technical support during performing the experiments I thank Mr. Ali Hemmati and Mr. Daniel Boothe. Also, I express my sincere thanks to Mr. Tondar Tajrobehkar for his technical assistance.

For their thought provoking conversations about purpose and fulfilment I thank Mr. Niaz Ahmed Qureshi, Ms. Nadia Manzoor, Shazia Manzoor, Sadia Manzoor, and Louise Lichacz.

For being my family away from family and sharing so many good meals I thank my uncle Muhammad Iqbal Malik and Ms. Hoor Jehan Qureshi.

Financial support of this research work from the Department of Chemical Engineering, Ryerson University is gratefully acknowledged. 


\section{Dedication}

TO MY FAMILY 


\section{Table of Contents}

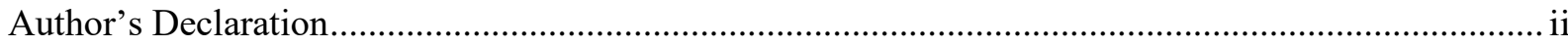

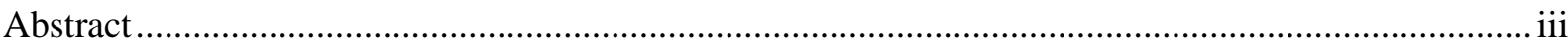

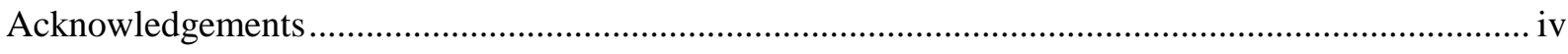

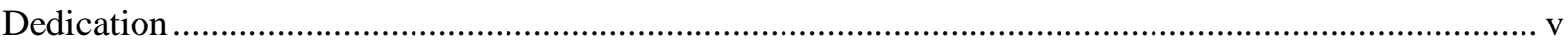

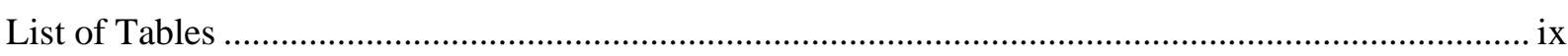

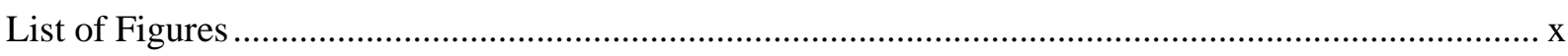

List of Symbols and Nomenclature.............................................................................................

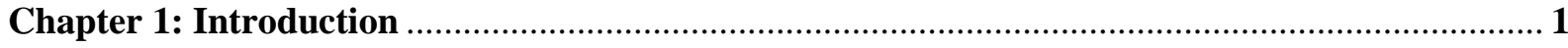

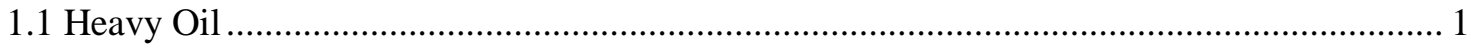

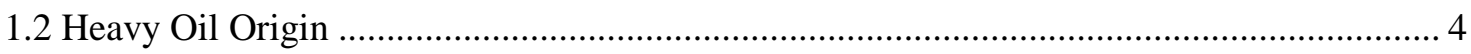

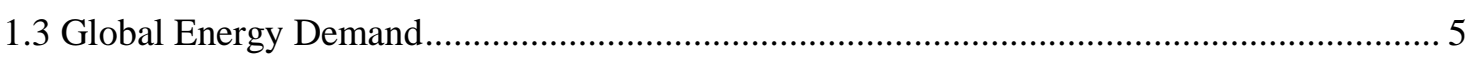

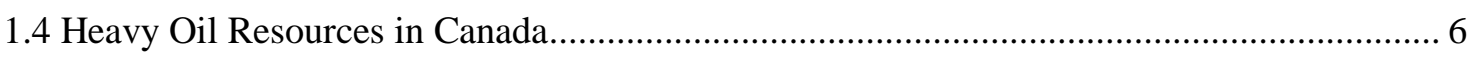

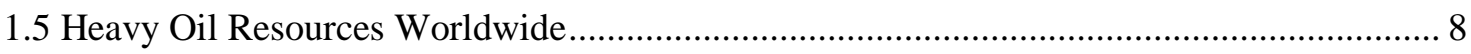

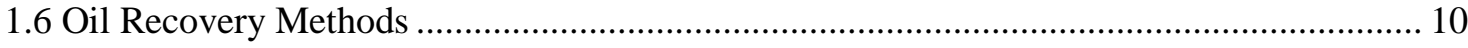

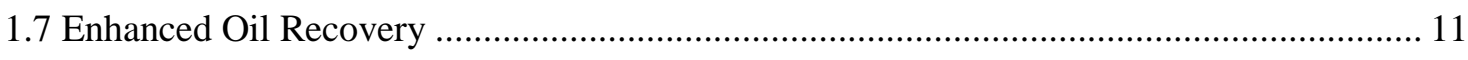

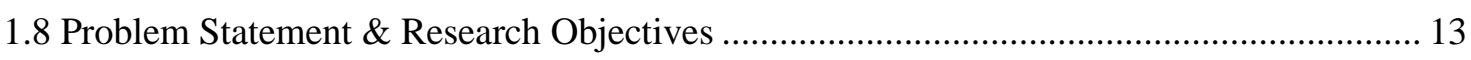

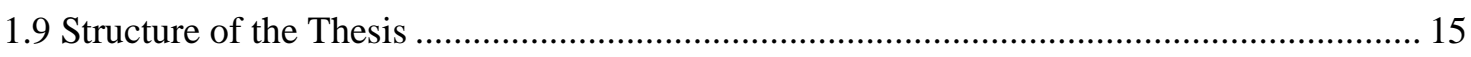

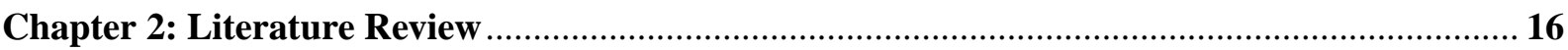

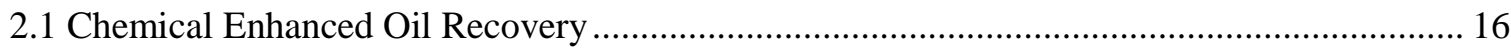

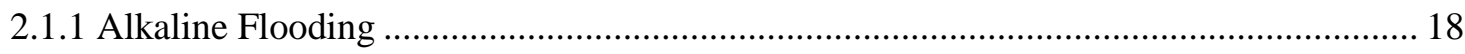

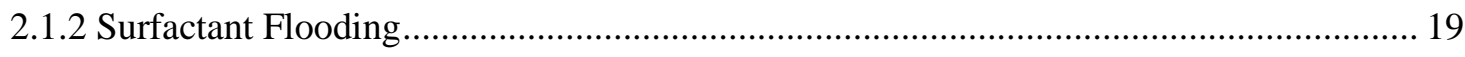

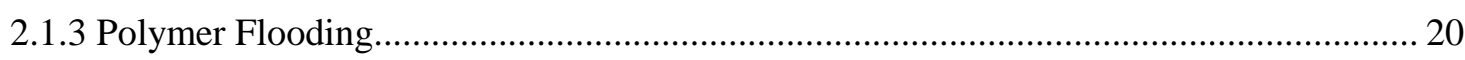

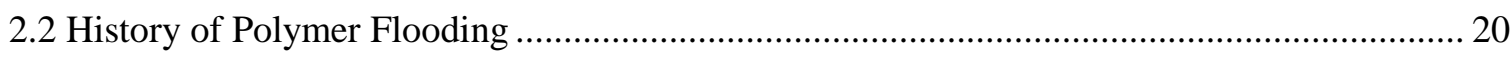

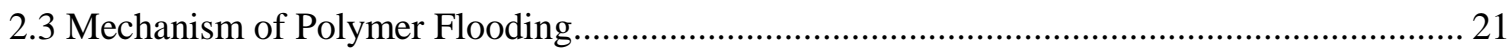

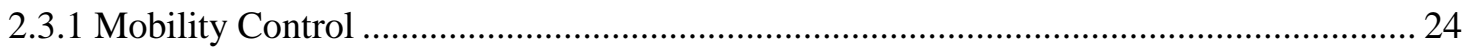

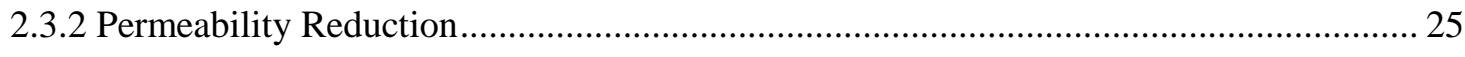

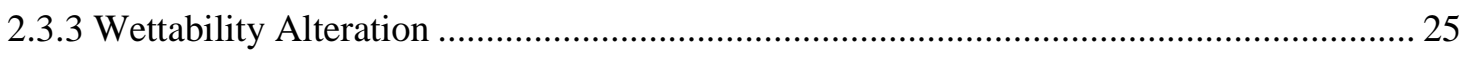

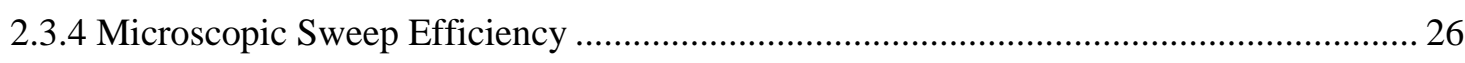

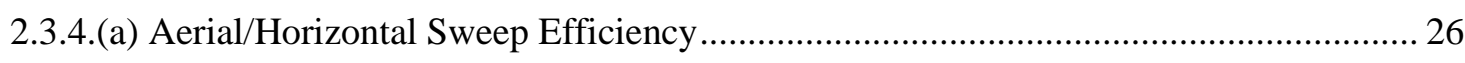

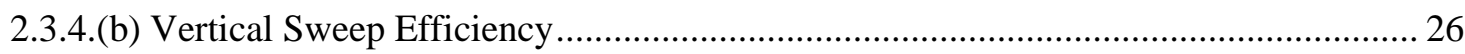

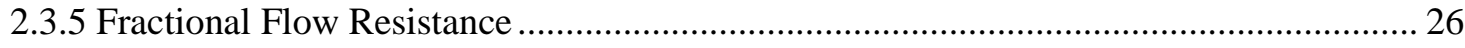

2.4 Viscoelastic Behavior of Polymer Solutions in Porous Media .............................................. 27

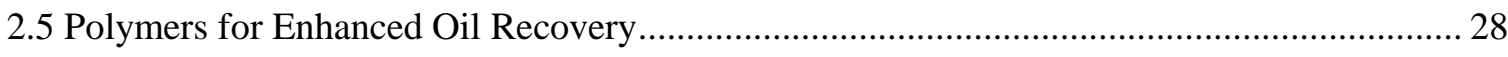


2.5.1 Partially Hydrolyzed Polyacrylamide (HPAM). 29

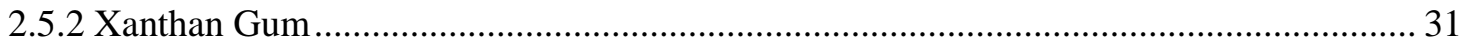

2.6 Factors Affecting Polymers Performance in Heavy Oil Reservoirs ...................................... 32

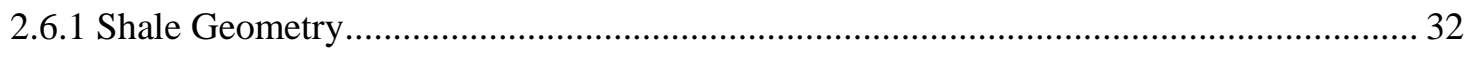

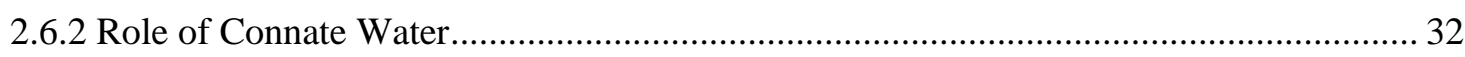

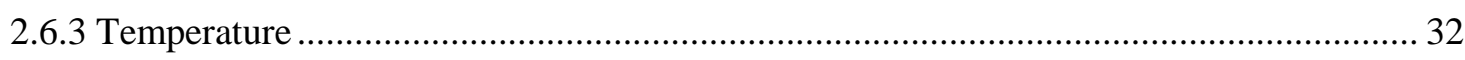

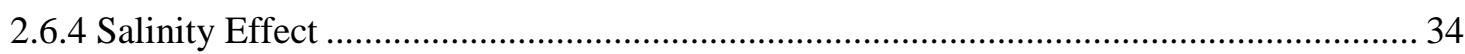

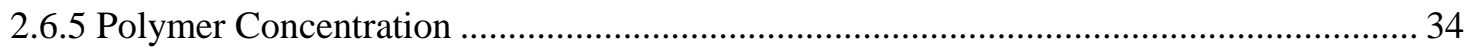

2.7 Screening Criteria of Polymer Flooding for EOR Process ……............................................ 35

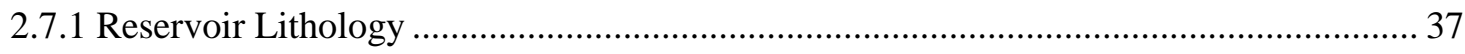

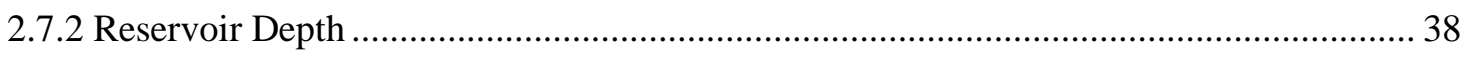

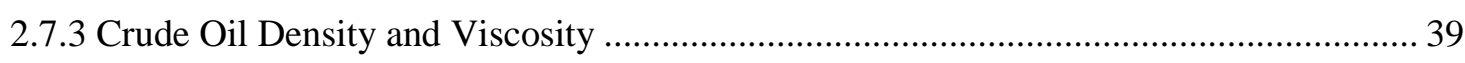

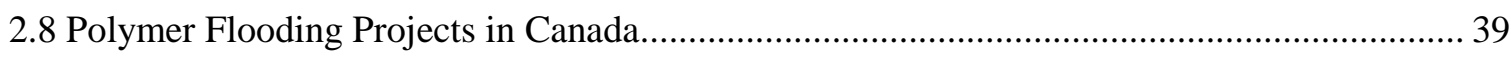

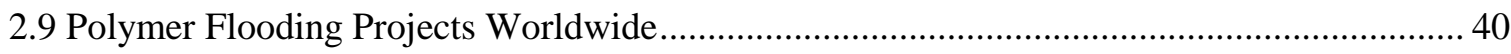

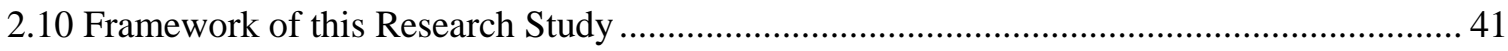

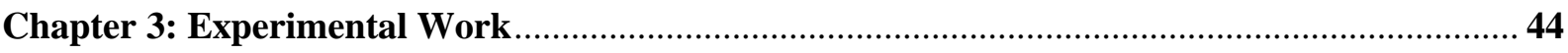

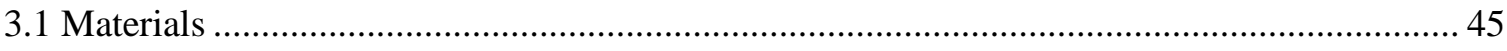

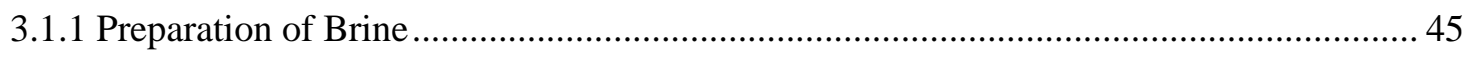

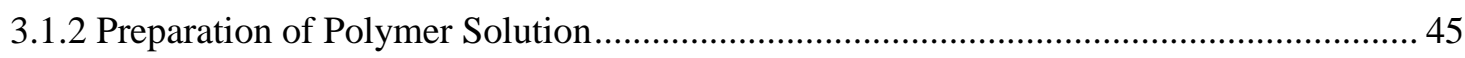

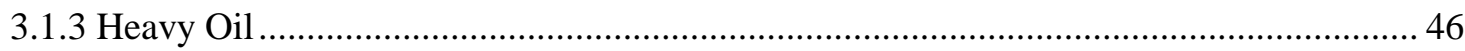

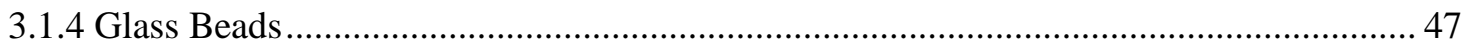

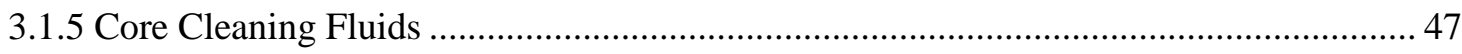

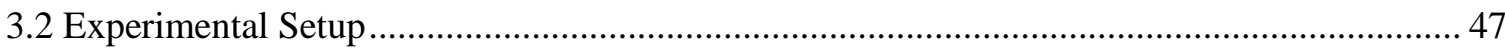

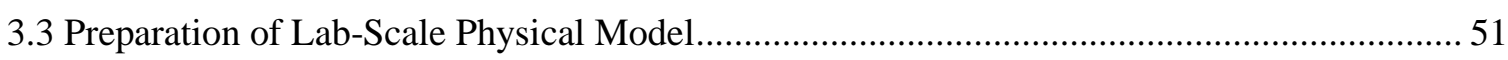

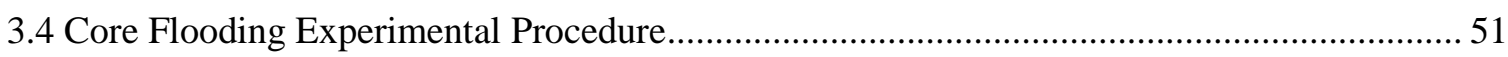

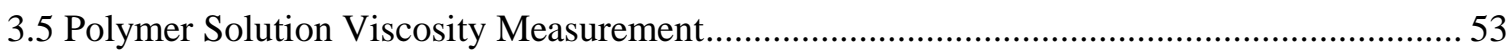

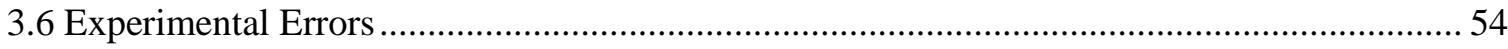

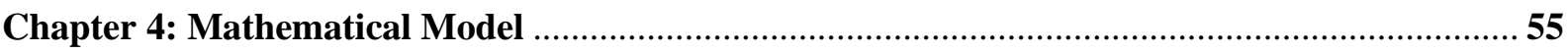

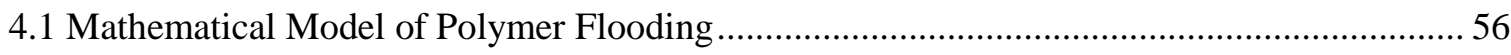

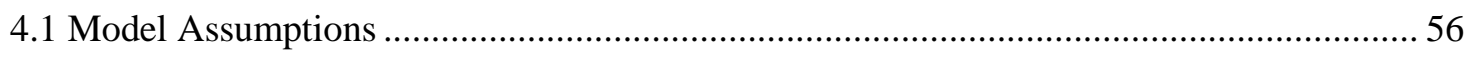

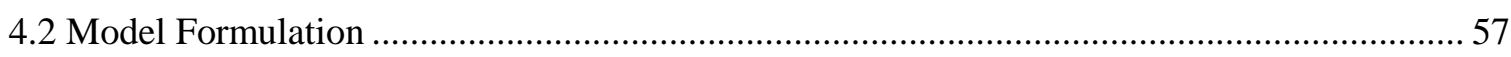

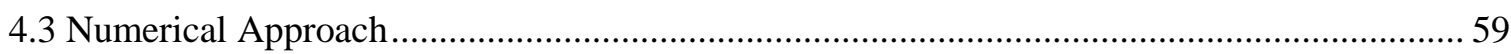

4.3.1 Finite Difference for conversion of PDE to ODE for Oleic Phase Equation ................... 60

4.3.2 Finite Difference for conversion of PDE to ODE for Aqueous Phase Equation .............. 61

4.3.3 Finite Difference for conversion of PDE to ODE for Pressure Equation .......................... 62

4.3.4 Finite Difference for conversion of PDE to ODE for Polymer Concentration .................. 64 
Chapter 5: Results and Discussion 69

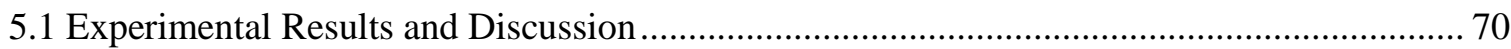

5.1.1 Effect of Polymer Concentration on Solution Viscosity …….......................................... 70

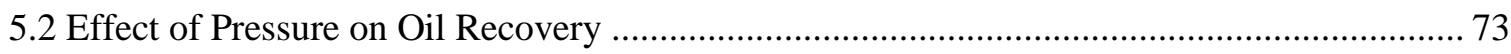

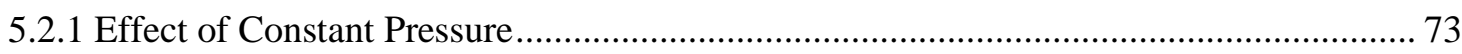

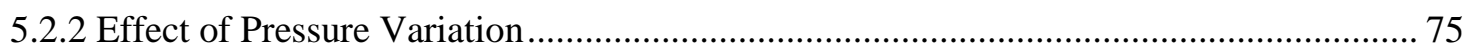

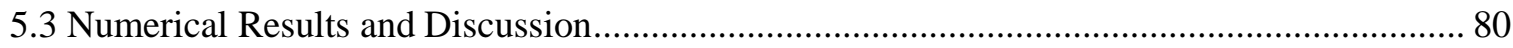

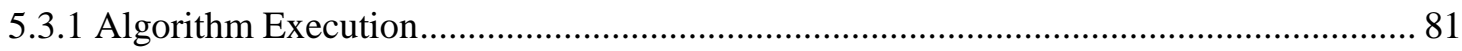

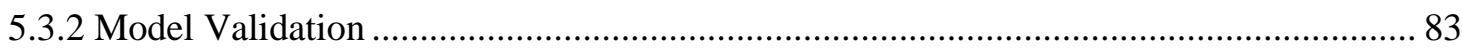

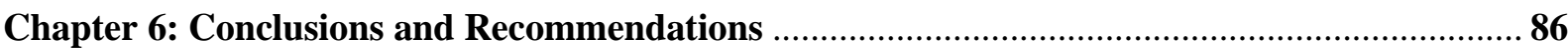

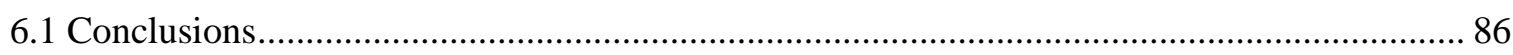

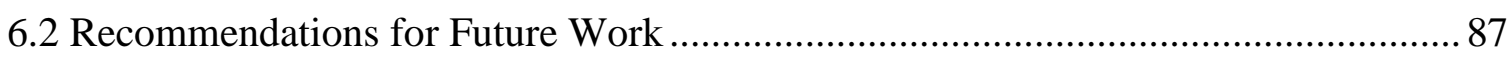

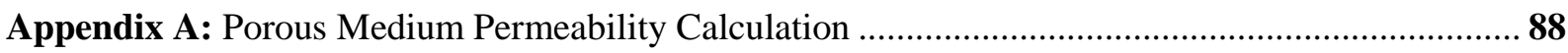

Appendix B: Parameters Used in the Power Law Model …............................................................... 89

Appendix C: Parameters Obtained from the Flow Curve of FLOPAAM 3630 (4000 ppm) at Various

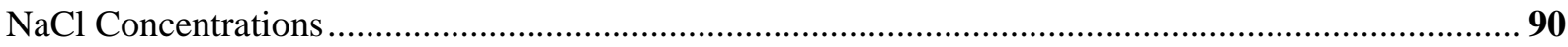

Appendix D: Derivation of Polymer Flooding Model ..................................................................... 91

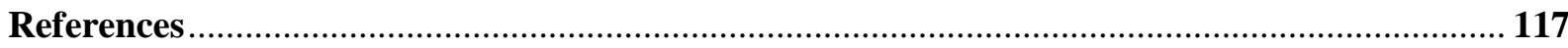




\section{List of Tables}

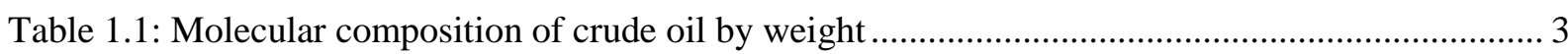

Table 1.2: Chemical composition of Arabian heavy crude oil............................................................ 4

Table 1.3: World's most 5 leading countries with largest accumulation of crude oil reserves from

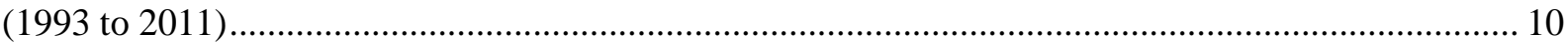

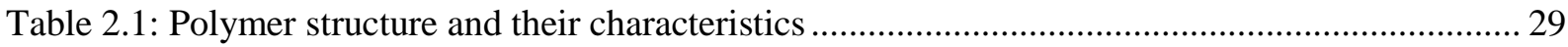

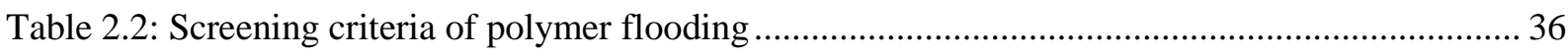

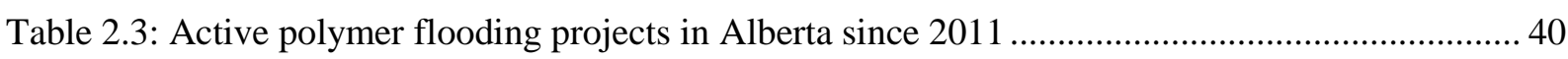

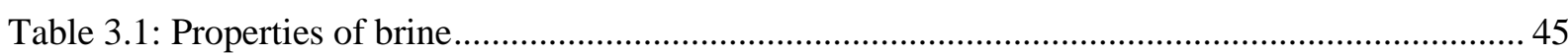

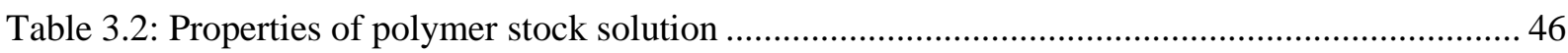

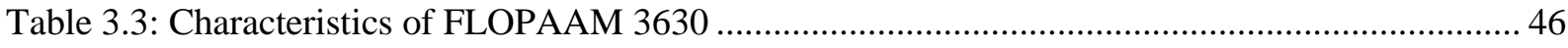

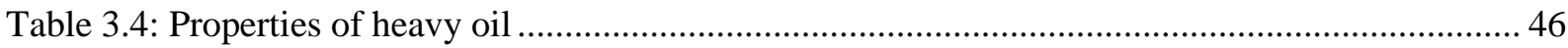

Table 3.5: Glass beads specifications used as a packing material in this experimental work................ 47

Table 3.6: Specification of the instruments used in this research study and the instrument's operational

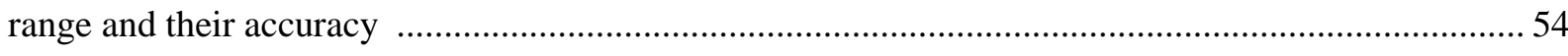

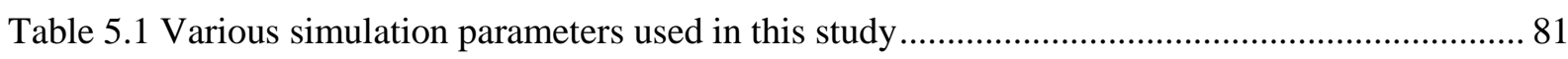




\section{List of Figures}

Figure 1.1: Heavy oil components (left) versus conventional oil components (right) ........................... 2

Figure 1.2: Deposits of heavy oil in Western Canadian bank ............................................................. 5

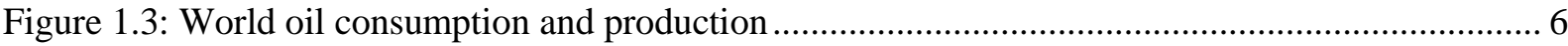

Figure 1.4: Canadian crude oil production from 2015-2030 .............................................................. 8

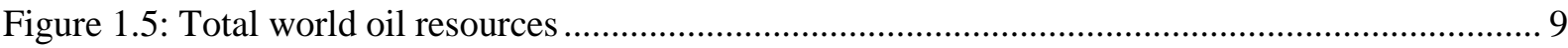

Figure 1.6: Schematic illustration of oil recovery from primary to tertiary recovery techniques.......... 12

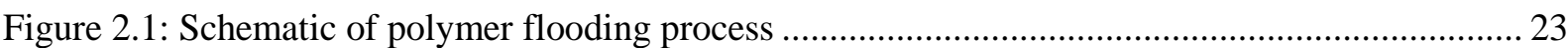

Figure 2.2: Schematic illustration of favorable and unfavorable mobility ratio impact on displacement

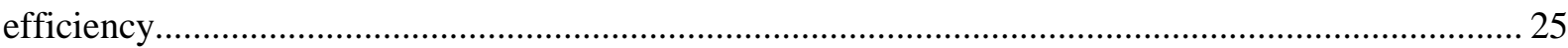

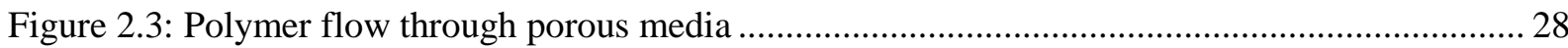

Figure 2.4: Chemical structure of partially hydrolyzed polyacrylamide (HPAM) ................................ 30

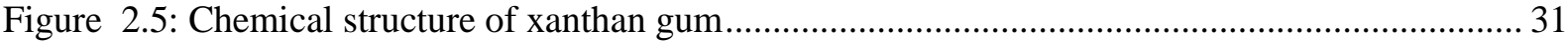

Figure 2.6: Temperature versus viscosity POMOA 75 (Polyacrylamide with $0.75 \mathrm{~mol} \%$ Octylacrylate

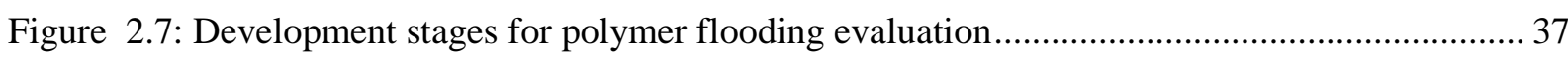

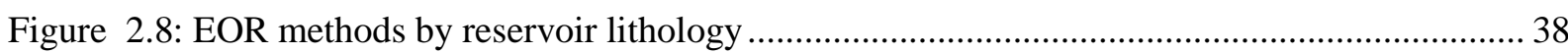

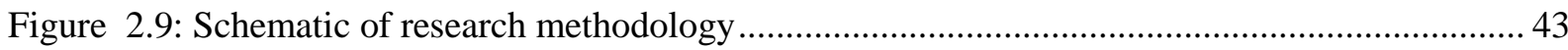

Figure 3.1: Schematic diagram of polymer flooding experimental setup ............................................. 49

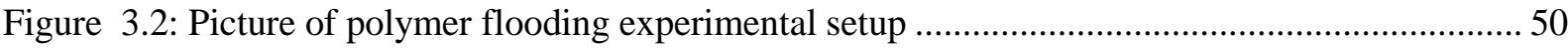

Figure 3.3 Picture of glass beads, mixture of heavy oil \& glass beads, and preparation of physical

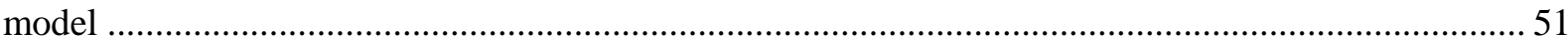

Figure 4.1: Physical reservoir model with differential element and the arrangement of grid points ..... 59

Figure 5.1: Effect of concentration of HPAM with $1 \mathrm{wt} \%$ brine on shear viscosity versus shear rate at

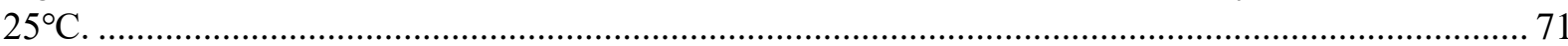

Figure 5.2: Effect of brine on polymer solution concentration (4000 ppm), shear viscosity versus shear

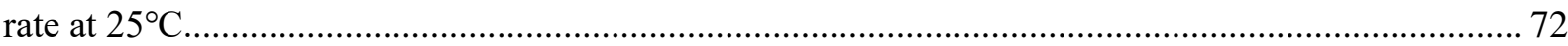

Figure 5.3: Heavy oil recovery versus time with polymer concentrations (0.1-0.5 wt \%) at constant

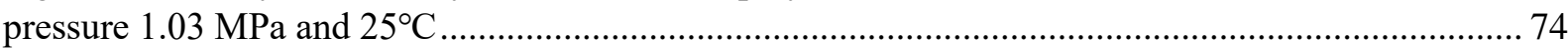

Figure 5.4: Overall oil recovery versus polymer concentration (0.1-0.5 wt \%) at constant pressure 1.03

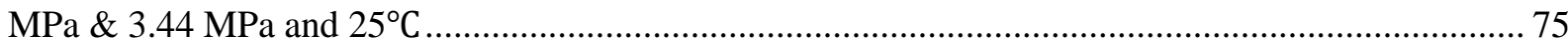

Figure 5.5: Heavy oil recovery versus time for $0.1 \mathrm{wt} \%$ polymer concentration at $25^{\circ} \mathrm{C}$, and at constant (3.44 MPa) as well as periodically varying injection pressure in the range of 2.41-3.44 MPa.

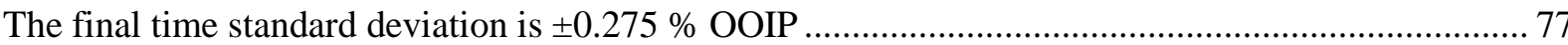

Figure 5.6: Heavy oil recovery versus time for $0.2 \mathrm{wt} \%$ polymer concentration at $25^{\circ} \mathrm{C}$, and at constant (3.44 MPa) as well as periodically varying injection pressure in the range of 2.41-3.44 MPa. The final time standard deviation is $\pm 0.124 \%$ OOIP

Figure 5.7: Heavy oil recovery versus time for $0.3 \mathrm{wt} \%$ polymer concentration at $25^{\circ} \mathrm{C}$, and at constant pressure (3.44 MPa) as well as periodically varying injection pressure in the range of 2.41 3.44 MPa. The final time standard deviation is $\pm 0.168 \%$ OOIP. 
Figure 5.8: Heavy oil recovery versus time for $0.4 \mathrm{wt} \%$ polymer concentration at $25^{\circ} \mathrm{C}$, and at constant pressure (3.44 MPa) as well as periodically varying injection pressure in the range of 2.413.44 MPa. The final time standard deviation is $\pm 0.154 \%$ OOIP

Figure 5.9: Heavy oil recovery versus time for $0.5 \mathrm{wt} \%$ polymer concentration at $25^{\circ} \mathrm{C}$, and at constant pressure (3.44 MPa) as well as periodically varying injection pressure in the range of 2.41 3.44 MPa. The final time standard deviation is $\pm 0.147 \%$ OOIP

Figure 5.10: Overall oil recovery versus polymer concentrations $(0.1-0.5 \mathrm{wt} \%)$ with periodic pressure (3.44 to $2.41 \mathrm{MPa}$ ) and $25^{\circ} \mathrm{C}$..... 80

Figure 5.11: Model Validation at 3.44 MPa using $0.1 \mathrm{wt} \%$ polymer concentration 83

Figure 5.12: Model Validation at 3.44 MPa using $0.2 \mathrm{wt} \%$ polymer concentration .84

Figure 5.13: Model Validation at 3.44 MPa using $0.3 \mathrm{wt} \%$ polymer concentration 84

Figure 5.14: Model Validation at 3.44 MPa using $0.4 \mathrm{wt} \%$ polymer concentration .85

Figure 5.15: Model Validation at 3.44 MPa using $0.5 \mathrm{wt} \%$ polymer concentration 85 


\section{List of Symbols and Nomenclature}

\begin{tabular}{|c|c|}
\hline$A$ & area, $m^{2}$ \\
\hline$B_{o}$ & oil formation volume factor, res $\mathrm{m}^{3} / \mathrm{std} \mathrm{m}^{3}$ \\
\hline$B_{w}$ & water formation volume factor, res $\mathrm{m}^{3} / \mathrm{std} \mathrm{m}^{3}$ \\
\hline$b_{r k}$ & permeability reduction factor \\
\hline$C_{o}$ & compressibility factor of oil, $1 / \mathrm{MPa}$ \\
\hline$C_{T}$ & total compressibility, $1 / \mathrm{MPa}$ \\
\hline$C_{w}$ & compressibility factor of water, $1 / \mathrm{MPa}$ \\
\hline $\mathrm{C}$ & polymer concentration \\
\hline$D$ & diffusion coefficient of solvent in medium, $\mathrm{m}^{2} / \mathrm{s}$ \\
\hline$f_{\mathrm{a}}$ & effective pore volume coefficient \\
\hline $\mathrm{K}$ & absolute permeability of the medium, D \\
\hline$K_{\text {ro }}$ & oil relative permeability \\
\hline$K_{\text {rw }}$ & water relative permeability \\
\hline$K_{\text {rwro }}$ & oil relative permeability at irreducible water saturation \\
\hline$K_{\text {rocw }}$ & water relative permeability at residual oil saturation \\
\hline$n_{o}$ & index of oil relative permeability \\
\hline$n_{w}$ & index of water relative permeability \\
\hline$P$ & pressure, $\mathrm{MPa}$ \\
\hline $\mathrm{R}_{\mathrm{k}}$ & permeability reduction factor \\
\hline$S_{o}$ & oil saturation \\
\hline$S_{w}$ & water saturation \\
\hline$S_{\text {or }}$ & irreducible water saturation \\
\hline$S_{w c}$ & residual water saturation \\
\hline$t_{o}$ & scaled time, $\mathrm{s}$ \\
\hline
\end{tabular}


length of the cylindrical core, $\mathrm{m}$

Greek Symbols

$\begin{array}{ll}\varphi & \text { porosity of the medium } \\ \mu_{o} & \text { oil viscosity, } \mathrm{cP} \\ \mu_{p} & \text { polymer solution viscosity, } \mathrm{kg} / \mathrm{m} \cdot \mathrm{s} \\ \rho & \text { density of oil, } \mathrm{kg} / \mathrm{m}^{3}\end{array}$

Abbreviations

API American Petroleum Institute

ASP Alkaline/Surfactant/Polymer Flooding

CAPP Canadian Association of Petroleum Producers

D Darcy

EOR Enhanced Oil Recovery

IOR Improved Oil Recovery

IFT Interfacial Tension

PF Polymer Flooding

PV Pore Volume

OOIP Original Oil in Place 


\section{Introduction}

The focus of this chapter is to provide the background information on heavy oil as a global energy need. Emphasis is given to the information relevant to heavy oil and its origin, and heavy oil recovery methods. Therefore, the purpose of this chapter is to provide a brief but thorough overview of general aspects of heavy oil, heavy oil properties, classification of heavy oil, heavy oil reservoirs worldwide and enhanced oil recovery (EOR) techniques.

\subsection{Heavy Oil}

The world's current primary energy source is petroleum. It can be broken down into conventional oil and non-conventional oil (Abukhalifeh, 2010). The conventional oil consists of crude oil and the non-conventional oil incorporate heavy oil and bitumen. Figure 1.1 demonstrates the components of conventional oil versus heavy oil. Due to the recent depletion of light crude oil reserves, geologists and researchers have focused their efforts on exploring heavy crude oil reserves by implementing enhanced oil recovery techniques in order to meet the growing energy demand. Heavy oil reserves contain more barrels of oil approximately ten 
trillion barrels which are almost three times more than the light oil reserves (Salama and Kantzas, 2005; Lie et al., 2014). Moreover, the enormous amount of heavy oil resources present in the world enlightens itself to be explored.

Heavy oil is essentially a type of crude oil that has a higher density and specific gravity than that of conventional light crude oil (Ancheyta, Jorge, 2016). They have high resistances to flow and have heavy molecular compositions. According to World Petroleum Congress heavy oils generally, have specific gravity less than $22.3^{\circ}$ API. Conversely, extra heavy crude oil generally has an API gravity of less than 10 degree (i.e. density greater than $1000 \mathrm{~kg} / \mathrm{m}^{3}$ ). It is also important to note that heavy crude oil is related to bitumen from oil sands. Bitumen is categorized as the heaviest and thickest form of petroleum. It is also known as extra heavy crude oil due to these characteristics.

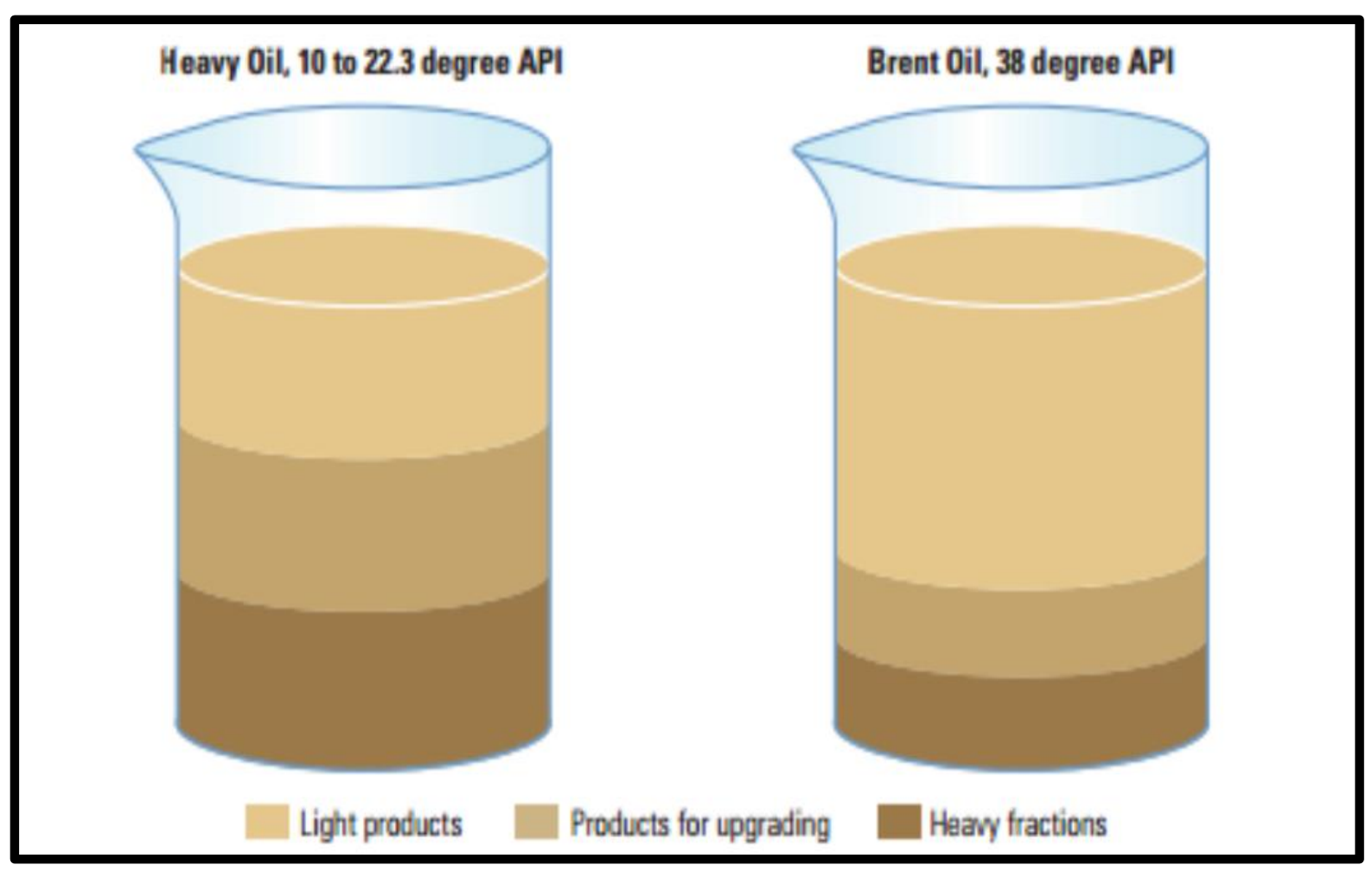

Figure 1.1 Heavy oil components (left) versus conventional oil components (right) (Oilfield review, 2016)

More specifically, heavy oil has a viscosity greater than 1.0 Pa s (1000 cP) and a high specific gravity, while bitumen viscosity is higher than $10 \mathrm{~Pa} \mathrm{~s}(10,000 \mathrm{cP})$ with API gravity of $10^{\circ}$ or less. On the other hand, condensates have a gravity of about $70^{\circ}$ API (Schumacher, 1980). According to Veil et al. (2009), the heavy oil differs from bitumen, extra heavy oil, and condensates on the basis of flow pattern under reservoirs condition. Bitumen exhibits solid like behavior and does not have sufficient mobility to flow under natural drive mechanisms at 
ambient conditions. Geologists and petroleum engineers have pessimistic opinions regarding heavy crude oil and natural bitumen. According to them, heavy oil has a close similarity to natural bitumen from oil sands. They further categorize natural bitumen as extra heavy crude oil based on the low density, while other classifications differentiate each other based on the extent of the degree of biodegradation.

The molecular composition also plays a pivotal role in differentiating heavy oil among lighter grade oils. Regarding the molecular composition of crude oil, it primarily contains low hydrogen-to-carbon ratios, alkanes, cycloalkanes, aromatic hydrocarbons, high asphaltene, sulfur, nitrogen, and heavy-metal contents such as nickel, iron, copper, and vanadium. Table 1.1 shows the general molecular composition of crude oil and it may vary depending on the type of formation and reservoir lithology (Speight, 1999).

Table 1.1 Molecular composition of crude oil by weight

\begin{tabular}{c|c|c|c}
\hline \multicolumn{4}{c}{ Molecular Composition by Weight \% } \\
\hline Element & Weight \% & Hydrocarbons & Weight \% \\
Carbon & $83-87$ & Paraffins & 30 \\
Hydrogen & $10-14$ & Naphthenes & 49 \\
\hline Nitrogen & $0.1-2$ & Aromatics & 15 \\
Oxygen & $0.1-1.5$ & Asphaltics & 6 \\
Sulfur & $0.5-6$ & Note: Hydrocarbon values are average \\
Metals & $<0.1$ & values. \\
\hline
\end{tabular}

Heavy oil is considered asphaltic (Meyer \& Emil, 2003). As mentioned previously, this is due to its content of asphaltenes. Asphaltenes are essentially very large molecules that make up most of the sulfur and metals in the oil. This is the characteristic of heavy crude oil, which can be observed in Table 1.2 
Table 1.2 Chemical composition of Arabian heavy crude oil (Juárez, 2016)

\begin{tabular}{|c|c|c|c|c|c|c|c|}
\hline \multicolumn{8}{|c|}{ Chemical Composition (Arabian Heavy Oil $27^{\circ}$ API) } \\
\hline \multirow[t]{2}{*}{ Compounds } & \multirow[t]{2}{*}{ Wt $\%$} & \multicolumn{4}{|c|}{ Crude Oil (wt \% of the total) } & \multicolumn{2}{|c|}{$\operatorname{AR}\left(345^{\circ} \mathrm{C}+\right)$} \\
\hline & & $\mathbf{S}$ & $\mathbf{N}$ & $\mathbf{V}$ & $\mathbf{N i}$ & $\mathbf{N i}$ & $\mathbf{V}$ \\
\hline Saturates & 0.2 & 6.7 & - & - & - & - & 0.2 \\
\hline Aromatics & 29.6 & 8.4 & 3.4 & 10.4 & 5.2 & 1.6 & 29.6 \\
\hline Resins & 46.3 & 43.8 & 25.2 & 28.0 & 14.2 & 11.8 & 46.3 \\
\hline Asphaltenes & 23.9 & 41.1 & 71.4 & 61.6 & 80.6 & 86.6 & 29.3 \\
\hline
\end{tabular}

\subsection{Heavy Oil Origin}

Like other forms of petroleum, the formation of heavy oil originated with plants millions of years ago. When the plants and plankton that fed off the heavy oil perished, the sediments containing their remains were buried at the bottom of inland seas. Over time, heat and pressure were able to convert the carbohydrates into hydrocarbons that lead to the formation of heavy oil and bitumen. In very fine-grained sedimentary rocks, oil formation usually takes place and these rocks are also known as black shale (Meyer \& Attanasi, 2003). Furthermore, after the oil has formed, it experiences pressure from overlying rocks. This causes it to migrate through permeable rock layers until it is trapped in reservoirs of porous rocks (sandstone \& limestone).

Another interpretation is that of foreland basins. Heavy oil initially arises as conventional oil, which moves towards the shallower oil traps (Oilfield Review, 2016) and disintegrates into heavy oil by bacterial and thermal degradation process. Enormous shallow deposits at the flanks of foreland basins are where most of the world's heavy oil exists. These basins are formed during the creation of mountains, from the down-wrapping of Earth's crust. Marine sediments in these basins become source rock for hydrocarbons that moves upward and dip into sediments and gradually wear away from young mountain chains. Geologically heavy oil has been found in young Pleistocene, Pliocene, and Miocene formations and in older Cretaceous, Mississippian, and Devonian formations. Figure 1.2 shows the heavy oil deposits in different formations in Western Canadian sedimentary basin. 


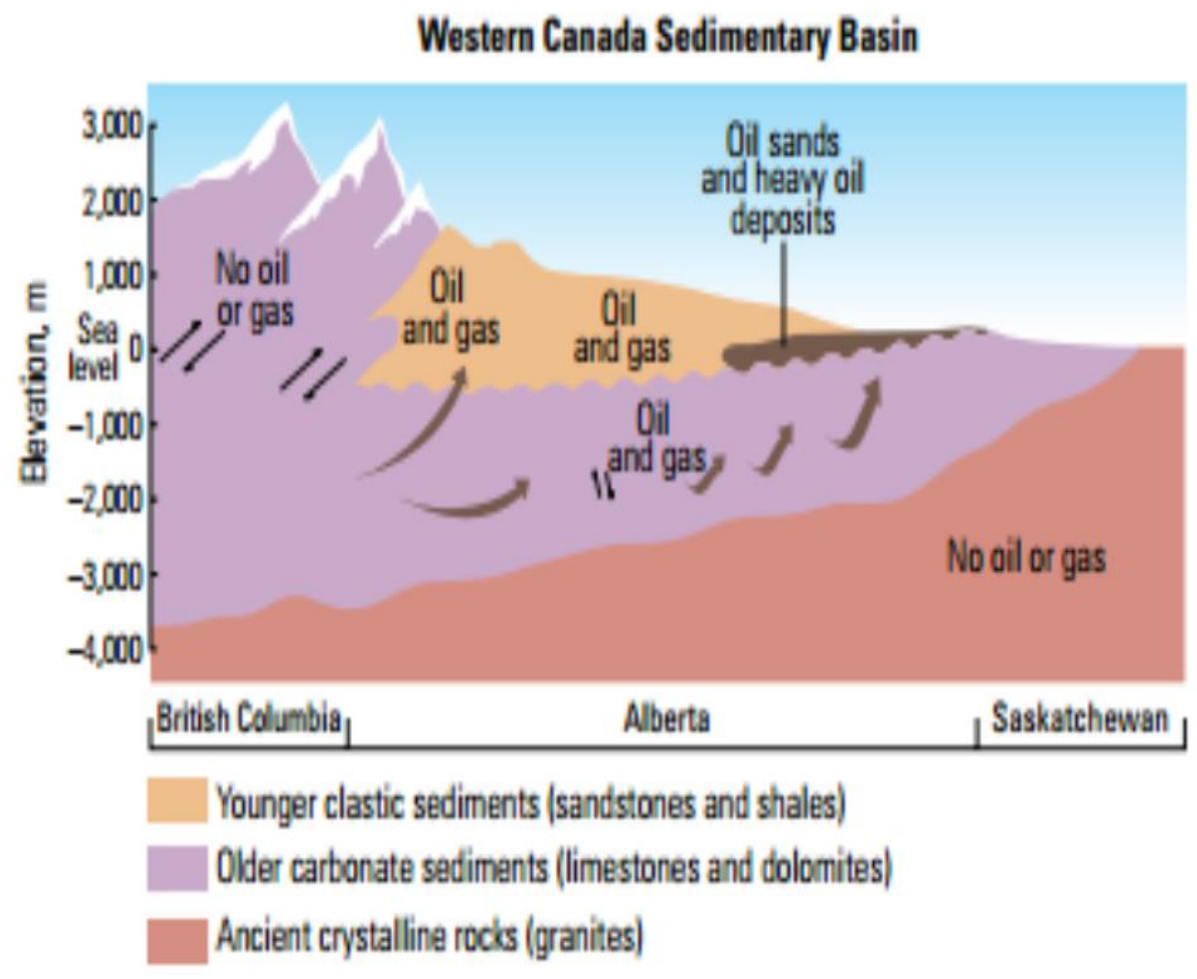

Figure 1.2 Deposits of heavy oil in Western Canadian bank (Oilfield review, 2016)

\subsection{Global Energy Demand}

As we have witnessed today, that energy plays an important role in our lives. The rapidly growing energy demand is an important issue and many world economies are working hard to maintain the momentum of supplying the source of energy in an efficient and more economical way. Still, the energy requirement remains vast and all our modern industrial societies ranging from food sector to the power industry consume a large amount of energy. The worldwide energy demand rose to about $1 / 3^{\text {rd }}$ from 2000 to 2014 to meet the needs of 7 billion people each day. The world's oil consumption rate is approximately 95 million barrels of oil per day. This is surreal when one brings their attention to the translation of this value. The value of 95 million barrels of oil is enough to power a car for 100 billion miles, or the equivalent of 4 million times around the world (ExxonMobil, 2016).

According to the world energy forum, the world oil reserves have widely grown up to $60 \%$ than it was twenty years ago and the oil production rate has escalated to $25 \%$. Still, oil is a major global leading fuel that covers up to $32.9 \%$ of the world's energy consumption. If we take into consideration all the unconventional oil resources such as shale oil, extra-heavy oil, oil sands and bitumen, still the global oil reserves are four times bigger than the current reserves. In 
addition, oil is a primary and mature global source of energy which is supplied to all modern industrial societies. This emerging source of energy is in abundant amount because of the up gradation done in Canadian Oil Sands as well as major changes undertaken in the OPEC countries: Iran, Venezuela, and Qatar (World Energy Council, 2013).

Figure 1.3 below shows the region with significant oil production and consumption from 1991 to 2016. According to the British Petroleum stats, the liquid fuel consumption shows a continual increase in consumption annually specifically in Asia Pacific and North America. As the oil demand increases more attention should be paid to the oil production from unconventional oil resources in order to overcome the uncertainties in oil supplies from the conventional oil reserves. A large proportion of massive crude oil reserve exists in the United States and Canada that needs to be explored in order to meet the rising oil demand as well as to optimize the operational efficiency.

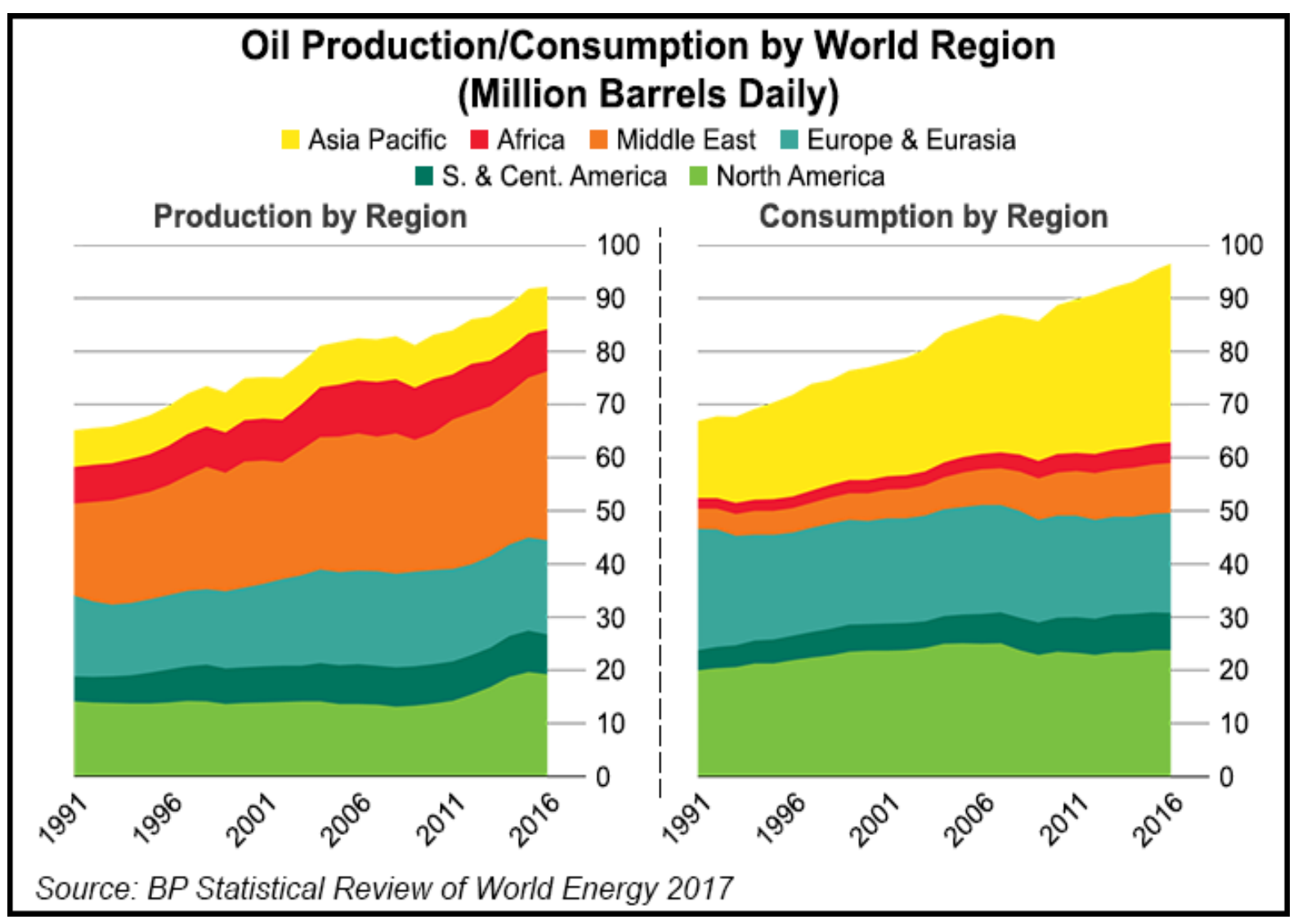

Figure 1.3 World oil consumption and production (BP statistical review, 2017)

\subsection{Heavy Oil Resources in Canada}

Oil remains world's mature global source of energy which plays a dominant role in emerging economies to sustain the upheaval demand in global energy consumption. Due to the rapid exhaustion of mature oil fields worldwide, it becomes a key issue for the researchers, geologists, 
and petroleum engineers to explore massive new oil reservoirs or upgrade the old ones by applying enhanced oil recovery techniques. Despite this fact, there are enormous heavy oil resources in Western Canada more specifically in Alberta and Saskatchewan. The East Coast Offshore contains 233 million $\mathrm{m}^{3}$ of the unconventional oil reserves. Some of these unconventional oil reservoirs also exist in other regions of the world including United States, Venezuela, Middle East, Asia Pacific, and China.

There is no doubt that Canada also plays a vital role in the oil production from oil sands deposits. According to the report in 2008 by the Reserves Committee of the Canadian Association of Petroleum Producers (CAPP); Canada has 765 million $\mathrm{m}^{3}$ of conventional crude oil reserves and 2508 million $\mathrm{m}^{3}$ of oil sands and natural bitumen reserves. In early 2012, Canada had approximately 173.6 billion barrels of proven oil reserves and holds the third largest amount of these proven oil reserves in the world after Saudi Arabia and Venezuela (oil and gas journal, 2017). Alberta and Saskatchewan contains a large amount of Western Canada's conventional oil reserves while the oil reserves on the Eastern offshore counts for almost 233 million $\mathrm{m}^{3}$ of crude oil.

Natural Resources Canada states that the oil sands will remain an important part of the Canadian economy and forecast incremental oil production of 2.5 million barrels per day within the next 25 years. Natural Resources Canada also funds research and development for the oil sands by providing \$200M annually to support such research.

Figure 1.4 below shows the projected Canadian crude oil production from 2015-2030 by CAPP, states that the Canadian oil production will continue to grow up to $5.1 \mathrm{million} \mathrm{bbl} / \mathrm{d}$ through 2030 which is 1.2 million bbl/d more production as compared to 3.85 million $\mathrm{bbl} / \mathrm{d}$ in 2016 (CAPP, 2017) from oil sands while the conventional oil production will remain relatively flat. Based on these observations, the Canadian Oil Sands will continue to be a strong industry for a long-time period and more pipelines will need to be constructed in Canada. 


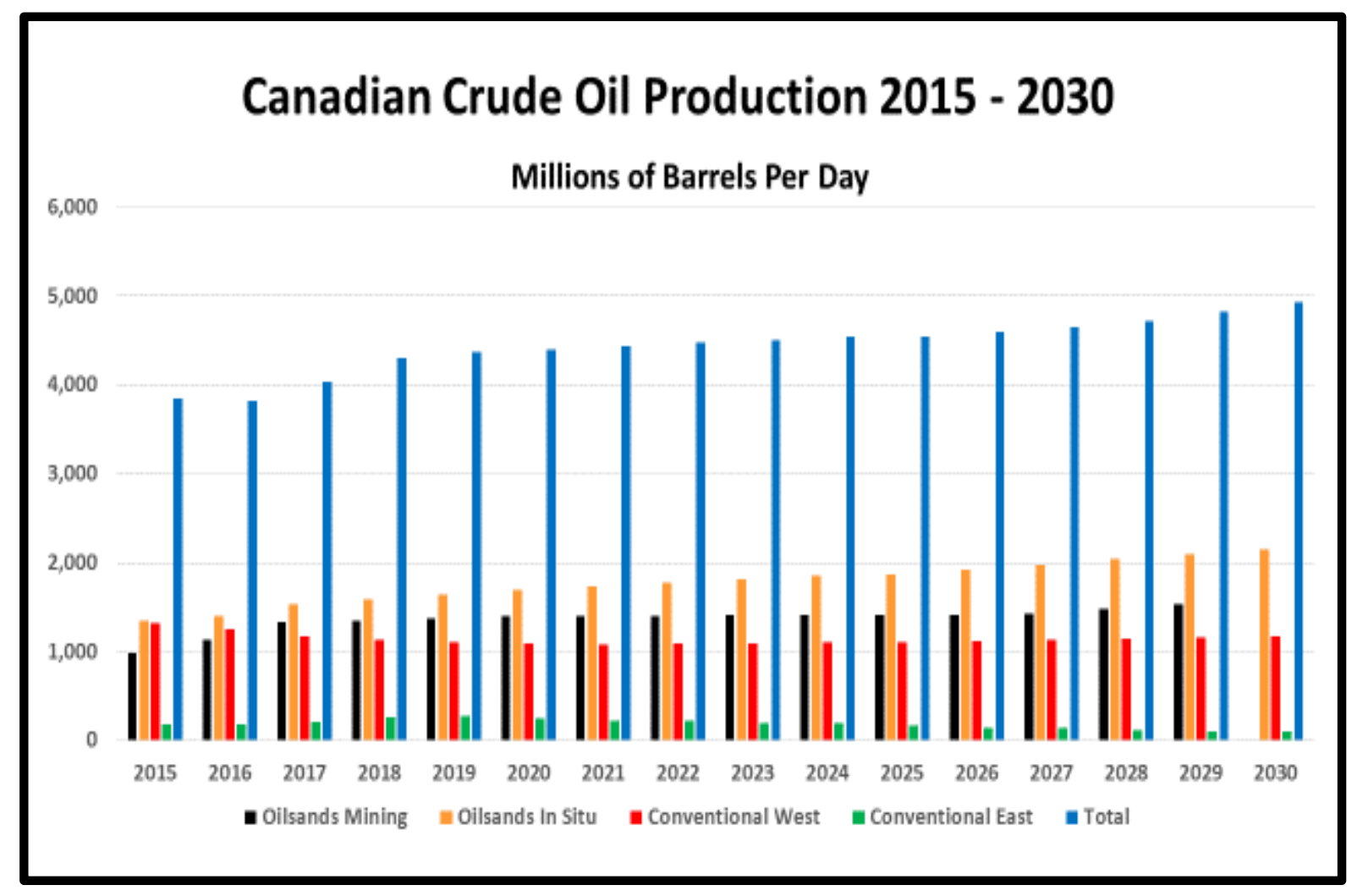

Figure 1.4 Canadian crude oil production from 2015-2030 (CAPP, 2017)

\subsection{Heavy Oil Resources Worldwide}

The recovery of residual oil from unconventional reservoirs through enhanced oil recovery techniques and the significant rate of oil production are always considered a controversial topic. How much oil left behind in the conventional oil reservoirs and how much still remain to be explored is a matter of heated debate.

In 1980, Schumacher stated that United States had 5.2 billion barrels of proved reserves containing 51.3 billion bbl of oil with API gravity ranging from $20^{\circ}$ to $25^{\circ}$ and 55.3 billion bbl of crude oil with API gravity less than $20^{\circ}$. According to the British Petroleum statistical review, the recoverable world oil reserves at the end of 2011 were estimated to be 13,39,617 million barrels and an official estimate of 22 billion barrels for oil sand are under the stage of operational development. Heavy oil reservoirs in the United States have also gained much popularity in the $19^{\text {th }}$ century based on several factors; as these reservoirs contains a large amount of OOIP left behind in the reservoirs after primary and secondary production techniques and due to the presence of more than 2,000 heavy oil reservoirs. 
The total world's heavy oil and tar sand resources are 8 trillion barrels with largest accumulation approximately 3 trillion barrels being in Canada and Venezuela 2 trillion barrels (Farouq et al., 2003). In 2003, Meyer \& Attanasi reported that the Western Hemisphere contains $69 \%$ of the world's recoverable heavy oil and $82 \%$ of world's recoverable bitumen. Conversely, the Eastern Hemisphere contains $85 \%$ of the world's light oil reserves. According to them the accumulation of extra-heavy oil in the Venezuelan Faja del Orinoco heavy-oil belt is $1.5 \times 10^{12} \mathrm{bbl}$ of the world's extra heavy oil. Together they make up 3600 billion barrels of oil in place. According to the current stats, together with heavy oil, extra-heavy oil, oil sands and bitumen accounts for $70 \%$ of the world's total oil resources (Oilfield review Schlumberger, 2016).

Figure 1.5 below shows the total world oil resources consisting of heavy oil and extra heavy oil that makes up about $40 \%$ of the world's current total oil resources of 1.4 to 2.1 trillion $\mathrm{m}^{3}$ (9 to 13 trillion bbl).

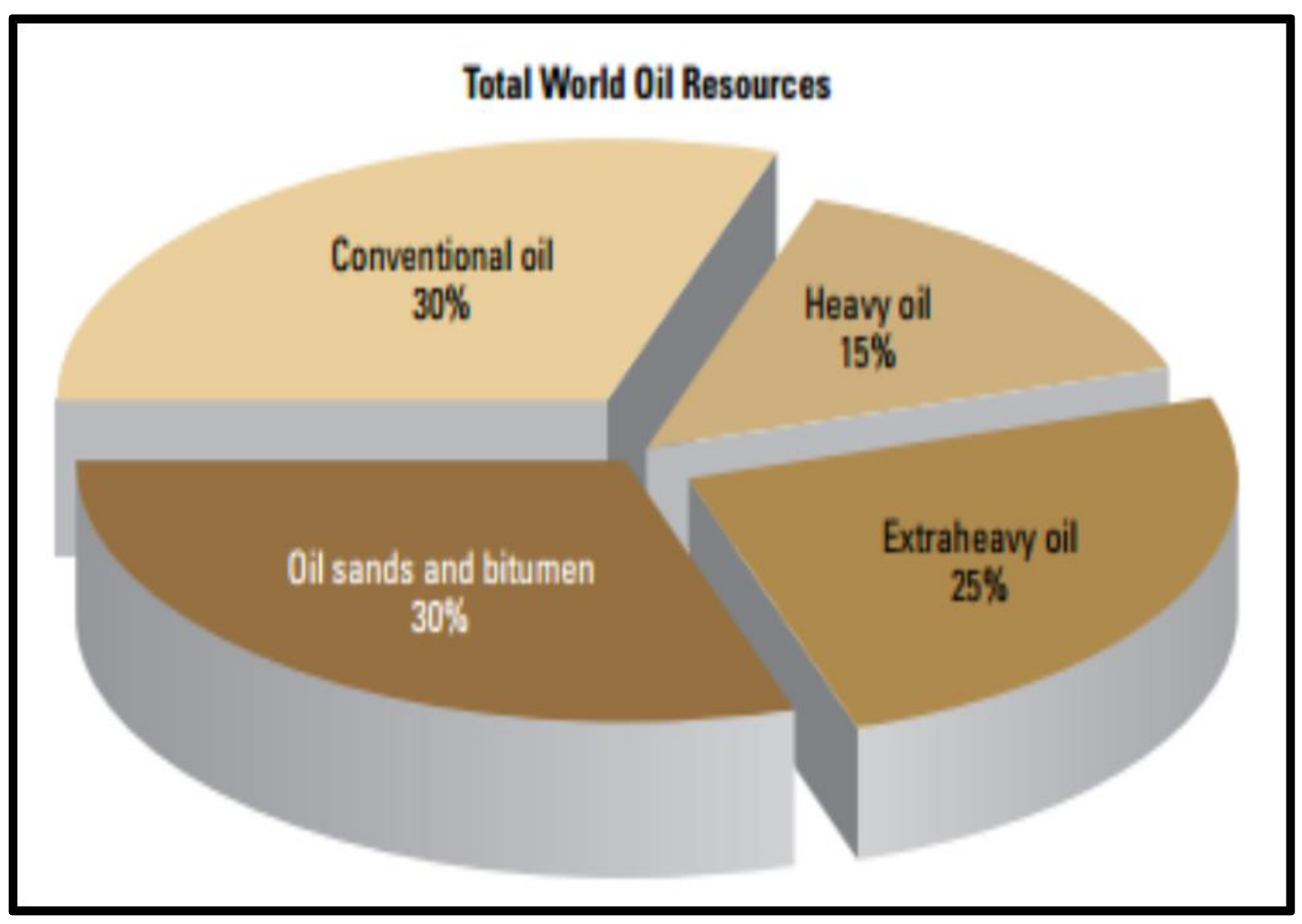

Figure 1.5 Total world oil resources (Oilfield review Schlumberger, 2016)

Table 1.3 below reports the top five leading with world's largest oil resources from 1993 to 2011 (World Energy Council, 2013). Over the past 2 decades, despite the fact that there is an immense increase in energy consumption but this fact cannot be denied that the crude oil reserves have continued to grow as well. According to the World Energy Council, the fact and 
figures interpret that since the beginning of the 1990s the heavy and extra-heavy crude oil reserves in Canadian oil belt and Venezuelan tar sands have contributed together $389 \mathrm{~Gb}$ of oil reserves to the world's available heavy oil resources. The contribution mentioned is four times more than the rest of the global oil reserves. Venezuela with the availability of $296 \mathrm{~Gb}$ of oil reserves outstrips Saudi Arabia with total available oil reserves of $265 \mathrm{~Gb}$.

Table 1.3 World's most 5 leading countries with largest accumulation of crude oil reserves from (1993 to 2011)

\begin{tabular}{c|c|c|c|c|c}
\hline \multicolumn{2}{c}{ Reserves (Mt) } & \multicolumn{2}{c}{ Production (Mt) } & R/P \\
\hline Country & 2011 & 1993 & 2011 & 1993 & Years \\
\hline Venezuela & 40,450 & 9,842 & 155 & 129 & $>100$ \\
Saudi Arabia & 36,500 & 35,620 & 526 & 422 & 69 \\
Canada & 23,598 & 758 & 170 & 91 & $>100$ \\
Iran & 21,359 & 12,700 & 222 & 171 & 96 \\
Iraq & 19,300 & 13,417 & 134 & 29 & $>100$ \\
Rest of world & 82,247 & 68,339 & 2766 & 2338 & 30 \\
\hline Global Total & $\mathbf{2 2 3 , 4 5 4}$ & $\mathbf{1 4 0 , 6 7 6}$ & $\mathbf{3 9 7 3}$ & $\mathbf{3 1 7 9}$ & $\mathbf{5 6}$ \\
\hline
\end{tabular}

\subsection{Oil Recovery Methods}

There are three main methods of recovering the heavy oil from the reservoir and are classified as;

- Primary production (natural flow \& artificial lift) the main driving force in this technique is the natural energy i.e. pressure exerted by gas and water present at the depth of the reservoir that forces the oil to move forward through the rock surface towards the producing well, where it is hauled up to the surface. Under the primary method, only about $10 \%$ of the original oil in place (OOIP) in a heavy oil reservoir can be recovered (SEM, 1998).

- Secondary recovery methods (water flooding \& pressure maintenance) utilizes the artificial energy injection into the reservoir due to the lack of sufficient energy (underground pressure) required to move the oil towards the surface. Mainly water flooding is carried out as the secondary recovery technique which is accomplished by injecting a large amount of water through a subsurface pump into the reservoir for pressure maintenance, as well as the displacement of oil is also carried out by the 
displacing fluid (water). Under secondary recovery method, the recovery is between 10$30 \%$ of original oil in place (OOIP).

- Tertiary recovery refers to the recovery followed by secondary recovery techniques. It utilizes the injection of fluids such as chemicals, miscible gases and the injection of thermal energy (injection of heat) to increase the fluid mobility. The addition of heat is used to lower the viscosity of the oil and to improve its ability to flow easily to the wellbore.

\subsection{Enhanced Oil Recovery (EOR)}

It is more important to distinguish between the two terms IOR and EOR that are more frequently used in petroleum industry. The term improved oil recovery (IOR) stipulates the recovery of oil from any mode of operation. On the other hand, enhanced oil recovery (EOR) is a unique term and is considered as a subsection of improved oil recovery (Sheng, James, 2011). According to oil and gas regulatory bodies, enhanced oil recovery is the recovery of hydrocarbons by implementing chemical injection techniques, thermal recovery methods or by any other relevant method (Schumacher, 1980). Thomas (1999) defined enhanced oil recovery on the basis of residual oil saturation $\left(\mathrm{S}_{\mathrm{or}}\right)$. A technique used to recover oil left behind in the reservoirs due to the capillary forces and recover oils that have high viscosity and API gravity (extra-heavy oils and tar sands) can be recovered by lowering the oil saturation below the residual oil saturation $\left(\mathrm{S}_{\mathrm{o}}<\mathrm{S}_{\mathrm{or}}\right.$ ). According to (Taber et al., 1997), enhanced oil recovery is the recovery of oil apart from the primary recovery techniques. According to (Alvarado et al., 2010), enhanced oil recovery techniques are characterized by the oil displacement mechanism.

Enhanced oil recovery techniques are categorized into three main types;

1. Thermal processes which utilizes heat energy to recover the oil from the reservoirs. Steam flooding, steam stimulation, and in-situ combustion falls into this category.

2. Chemical processes which involves the injection of chemical agents (surfactants, polymers, and alkali's). Polymer flooding, Alkaline flooding, Surfactant flooding and the synergetic effect of all three together belongs to this class.

3. Miscible displacement processes which involve the injection of miscible gases. Such processes contain carbon dioxide injection, hydrocarbon displacement, flue gas injection and solvent injection (W. Fred Ramirez, 1987). 
In enhanced oil recovery process, the main driving force is the injected fluid that tends to move the oil from oil bank to the production site. The displacing fluid interacts with porous rock and oil within the reservoir and reduces the interfacial tension (IFT), and viscosity of the displaced fluid. Furthermore, it improves the oil sweep efficiency (Sheng, James, 2011). EOR methods are generally applied to heavy oil reservoirs where the oil viscosity is significantly high as well as in order to extract the residual oil in the reservoir. Figure 1.6 illustrates the progression of oil production from primary recovery to tertiary oil recovery. The recovery by IOR is usually 30 $50 \%$ while enhanced oil recovery techniques show a better oil recovery percentage in the range of $>50 \%$ and up to $80 \%$ (Al-Mutairi and Kokal, 2011).

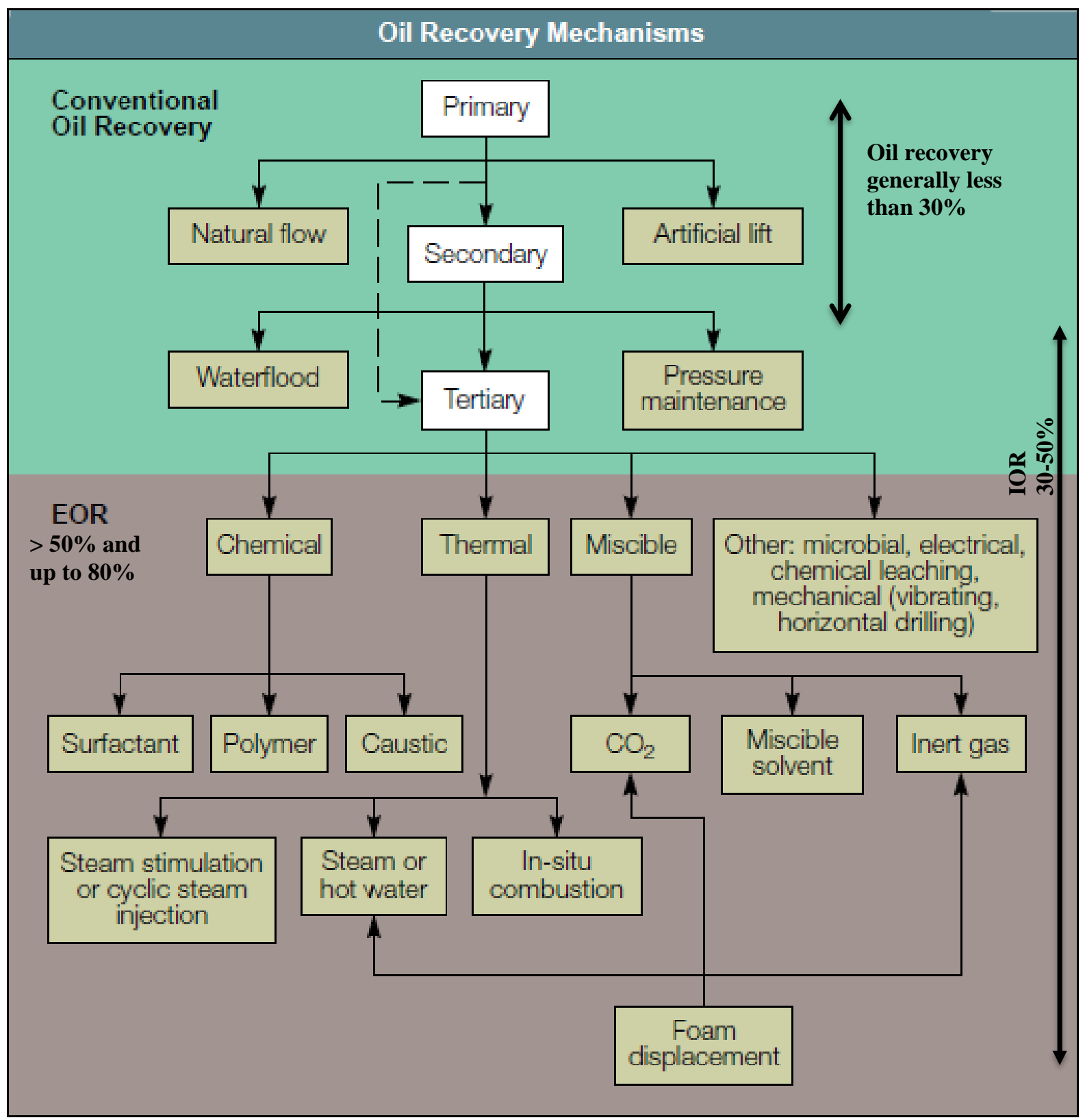

Figure 1.6 Schematic illustration of oil recovery from primary to tertiary recovery techniques (Donaldson et al., 1989; Al-Mutairi and Kokal, 2011) 
It is well recognized that EOR projects are strongly influenced by crude oil prices. The initiation of EOR depends on the decision of investors to manage EOR risk assessment and economic exposure and also the availability of appealing investment option. The averaged recovery factor from oil reservoirs is about one third which makes the consideration of leaving the crude oil underground (IEA, 2015). The recovery factor can be improved by practicing the advanced/tertiary IOR technologies and EOR techniques, as well as by conducting the fully detailed geological surveys (Oil \& Gas Journal, 2015).

Besides the direct relation between EOR projects to oil pricing, there are other factors which need to consider such as process complexity, technology-heavy, capital investment and financial risks. The financial risks are usually related to oil price fluctuations. Another challenge related to EOR projects is the long dead time required for such projects, it may take several decades from the start of the project to generate laboratory data and conducting simulation studies- to the first pilot plant and finally commercialization. Enhanced oil recovery techniques appear to be a potential candidate, as the environmental risks associated with them are very low. These techniques are not toxic or hazardous in nature if carried out with cautions.

\subsection{Problem Statement and Research Objectives}

The utilization of polymer flooding to enhance heavy oil recovery is an ongoing process. During the past few years, polymer flooding technique has gained much attraction of the geologists and reservoir engineers due to the exhaustion of the mature oil fields and the boom in the market requirement of the crude oil globally. A large amount of oil approximately $7.0 \times 10^{12}$ barrels still left behind in the reservoirs due to the immature conventional oil recovery techniques (Thomas, 2008). Most of the heavy oil reservoirs in the world are thin oil reservoirs and their thickness is just a few meters. Thermal and miscible enhanced oil recovery techniques are not a good option to carry out in these reservoirs due to the technical, economic, and environmental constraints. Primary production technique, particularly, water flooding is mainly carried out in thin oil reservoirs and the oil recovery rate ranged between $1-2 \%$ to $20 \%$ of the OOIP. The main drawback associated with this method is the large portion of the oil remains unsweet due to the viscous fingering effect (Oefelein and Walker, 1964; Adams, 1982; Kasraie et al., 1993; Ko et al., 1995).

Under the light of these technological challenges and concerns, it is extremely important to pursue polymer flooding technique that would give better displacement efficiency and oil recovery. With the addition of water soluble polymers, the viscosity of the displacing fluid increases and results in the favorable mobility ratio of water-to-oil. The pivotal difference 
between water flooding and polymer flooding is the controlled mobility ratio of displacing fluid to displaced fluid (viscous oil).

Polymer flooding is an interesting process and the commercial use of the polymers to increase oil recovery depends on the economic incentive program that plays a major role in the successful implementation of chemical enhanced oil recovery. Partially hydrolyzed polyacrylamides (HPAMs) are most widely used because of their availability on large scale and low manufacturing cost (Needham and Doe, 1987; Wang et al., 2008). It is well known that synthetic polymers are susceptible to chemical, mechanical, and biological degradation.

Therefore, it is necessary for the researchers to investigate the polymer flooding technique in depth to explore the new ways to increase the oil recovery by modifying the injection strategies. Furthermore, in order to make polymer flooding process technically viable and economically feasible, it requires a thorough investigation of low injection of large viscous polymer slugs in horizontal wells (Zaitoun et al., 1998; Wassmuth et al., 2007; Seright., 2010). Numerous researches have been conducted on polymer flooding on laboratory and pilot field scale to analyze the potential and overview the key concepts to modify the technology for its successful implementation.

For this purpose, the objectives of this study were defined as follows:

1 To conduct polymer flooding experiments using lab scale physical reservoir model of uniform porosity and permeability to obtain preliminary experimental data.

2 To develop a best polymer injection strategy as a solvent for heavy oil recovery under controlled temperature and pressure conditions in polymer injection process. To that end, core flooding experiments are carried out with pressure ranges between 1.03-3.44 MPa.

3 To evaluate the technical potential of polymer flooding in finding new way to enhance heavy oil recovery of polymer solution injection using pressure variation with time. The periodic pressure variation is expected to periodically change the flow velocity and pore volume size of the displacing fluid resulting in incremental oil recovery.

4 To validate the model with experimental results that provide the base data required for core flood simulations. 


\subsection{Structure of the Thesis}

Following is the outline of this thesis:

- Chapter 1: This chapter provides a brief description of heavy oil, heavy oil recovery methods, heavy oil resources in Canada and worldwide, enhanced oil recovery techniques, problem statement and list of research objectives.

- Chapter 2: This chapter provides a literature review on chemical enhanced oil recovery techniques. Polymer flooding, polymers for enhanced oil recovery, viscoelastic behavior of polymers in porous media, and screening criteria of polymer flooding.

- Chapter 3: This chapter provides the details of experimental setups used for polymer flooding. Experimental methods and procedures are thoroughly discussed.

- Chapter 4: This chapter presents the mathematical model describing polymer flooding process. The mathematical model consists of partial differential equations that determines the oleic and aqueous phase saturations, pressure and concentration of polymers used in heavy oil recovery. It further includes the scaled polymer flooding model and method of discretization of PDE's into ODE's.

- Chapter 5: This chapter reports the experimental and numerical simulation results in detail which are further analyzed and discussed in details.

- Chapter 6: This chapter summarizes the contributions of this research study. The future key research areas and recommendations are further presented. 


\section{2}

\section{Literature Review}

This chapter reviews the different chemical flooding techniques, history of polymer flooding, and current status of polymer flooding. This chapter further focuses on oil recovery mechanism that elaborates the displacement mechanism of oil by using the polymeric solutions within the oil reservoir. Emphasis will be given to the screening criteria of polymer flooding, and types of polymers used for oil recovery. Factors affecting polymer flooding process, and flow behavior of polymers within the porous media, are also summarized and discussed. Polymer flooding projects in Canada and worldwide are also reviewed. The main objective of this chapter is to provide the basis to continue polymer flooding as a potential candidate for heavy oil recovery.

\subsection{Chemical Enhanced Oil Recovery}

Chemical flooding is a technique which involves the injection of chemicals to recover more oil by carrying out the following of these processes listed below: 
1. Adding polymers to provide a favorable mobility ratio between injected water and oil (Mobility control).

2. Reducing the interfacial tension (IFT) by using surfactants and alkalis.

Chemical EOR consists of alkaline flooding, surfactant-polymer flooding (micro-emulsion flooding), and polymer augmented water flooding (polymer flooding) (Prince, 1980). The mobility process targets on achieving a controlled mobility ratio which results in improving the macroscopic displacement efficiency of oil. The addition of polymers in aqueous phase also increases the water phase relative permeability and reduces the viscous fingering affect by thickening the aqueous phase. The reduction of interfacial tension between displacing (water) and displaced fluid (oil) is related to the capillary number. The addition of surfactant reduces the IFT, the ratio of viscous to local capillary forces increases the residual oil saturation decreases and ultimately the oil recovery increases (Lake, 1989). Currently, the synergetic effect of ASP is a research topic and this technique shows great field potential of more oil recovery as the alkali injection tends to lower the surfactant and polymer adsorption. The reaction of crude oil and alkali generate soap which has low salinity while the surfactants have high salinity. The mixture of soap generated and surfactant together yields a limit that lowers the interfacial tension (Gurgel et al., 2008; Rafiq Islam et al., 2010). Following factors need to be in consideration when implementing Chemical EOR such as the cost of chemicals used, water treatment, reservoir type, and environmental hazards associated with the consumed chemicals.

In 1980, most of the chemical EOR projects were conducted on a pilot scale in the US and none of these projects were successful at that time economically. These projects were successfully implemented in China in the 1990s (Zhang et al, 1999). In light oil reservoirs, chemical EOR process encounters certain limitations due to lack of knowledge, and availability of compatible chemicals which withstand high temperature and high salinity environments. According to the vision gain analysis, chemical EOR techniques have a great potential and produced 377,685 bbl/d of crude oil in 2014, with a total spending of \$2,261M (vision gain, 2014).

The rate of success of chemical enhanced oil recovery processes depends on the production rate i.e. the amount of oil produced per unit mass of chemicals injected. In 2006 Chang et al. reported that by using polymer flooding in heterogeneous reservoirs with good reservoir characteristics, the recovery factor can be increased up to $14 \%$ of original oil in place (OOIP). Similarly, by conducting the ASP, the recovery rate can be reached up to $25 \%$ of OOIP. Moreover, the 
effectiveness of chemical enhanced oil recovery depends on the reservoir characteristics such as:

- Reservoir temperature

- Reservoir lithology

- Reservoir permeability

- Crude oil properties such as composition and viscosity

- Formation salinity.

\subsubsection{Alkaline Flooding}

In the early $19^{\text {th }}$ century, the alkaline flooding technique came into existence when Squires reported that the oil displacement efficiency can be improved by injecting alkali into the water. In 1920 in Canada, the first patent on alkaline flooding technique was issued under the name of Flyeman. He introduced a technique using $\mathrm{Na}_{2} \mathrm{CO}_{3}$ to separate bitumen from tar sands (Okoye, 1982; Ma, 2005). According to Sheng (2013), alkaline flooding is considered as one of the cheapest recovery methods as compared to other implemented methods. In alkaline flooding, the addition of alkali in displacing fluid makes it chemically basic. Most commonly used alkalis are Sodium hydroxide, sodium carbonate, and sodium orthosilicate.

In alkaline flooding, the alkali reacts with the acidic component in a crude oil to generate soap, which lowers the water-oil interfacial tension (IFT). The use of alkali also increases the efficiency of oil recovery process by a rapid decrease in emulsification (formation of stable oilin-water emulsions or unstable water-in-oil emulsions) and wettability alteration (Mungan, 1981). The nature of these emulsion phases depends on temperature, $\mathrm{pH}$, electrolyte type, and hardness concentration. The reaction equation of alkali is given as;

$$
\mathrm{HA}+\mathrm{OH}^{-} \rightarrow \mathrm{A}^{-}+\mathrm{H}_{2} \mathrm{O}
$$

where $H A$ is a pseudo-acid component and $A^{-}$is the soap component. Alkaline flooding is used as a potential candidate to enhance heavy oil recovery due to its characteristic features such as cost-effective surface facilities, process efficiency, and recovery mechanism. There are eight recovery mechanisms for alkaline flooding and these include emulsification with entrainment, emulsification with entrapment, emulsification (i.e., spontaneous or shear-induced) with coalescence, wettability reversal (i.e., oil-wet to water-wet or water-wet to oil-wet), wettability gradients, disruption of rigid films, and low interfacial tension (Johnson et al, 1976). 


\subsubsection{Surfactant Flooding}

The term "surfactant" most commonly refers to the surface active agents (detergents). Surfactants are usually organic compounds that are amphiphilic in nature possessing both hydrophobic and hydrophilic properties. This dual property makes surfactants to adsorb at the interface where they reduce the interfacial tension.

Surfactant flooding is a multiple-slug process that uses the wetting agents to reduce the liquid surface tension and allow it to spread widely within the carbonate reservoirs. The surfactant also reduces the interfacial tension between the two fluids (displacing fluid and displaced fluid). The purpose of surfactant slug is to displace the residual oil and form a flowing oil-water bank outside the reservoir (Speight, 2009). Surfactant flooding has been considered as a simplest and cost-efficient EOR method that yields the additional oil recovery through oil solubilization and mobilization which in turn decreases the interfacial tension and capillary forces inside the pore (Healy and Reed, 1974).

The main mechanism behind surfactant flooding is low interfacial-tension (IFT) effect. The interfacial-tension (IFT) between oil and water is related to emulsions formation and its stability. During spontaneous emulsification process, more emulsion will be produced due to the lower interfacial-tension (Rudin et al., 1992). Interfacial-tension (IFT) can be reduced from 20-30 to $10^{-3} \mathrm{mN} / \mathrm{m}$. In other words, a capillary number can be increased practically more than 1000 times by adding surfactants. Capillary Number is defined as the ratio of the viscous forces and local capillary forces. A capillary number for water flooding is about $10^{-7}$ to $10^{-5}$. To decrease the residual oil saturation, the capillary number should be greater than $10^{-7}$, usually in the range of $10^{-5}$ to $10^{-4}$. The low interfacial-tension between oil and water leads to the mobilization of oil droplets that are trapped in the porous rocks, which in turn merge with the downstream oil to form oil bank (Sheng, James, 2013).

There are two different types of surface active agents used for EOR

i. Anionic surfactants

ii. Cationic surfactants

Anionic surfactants are most commonly used in EOR processes because they show low adsorption on sandstone reservoirs because these rocks have negatively charged surface (Sheng, James, 2011). Surfactant flooding processes are generally carried out in sandstone reservoirs with conventional oil properties of (API gravity $25^{\circ}$ or higher). Surfactant flooding techniques are not implemented alone; they are carried out with its variants such as alkali surfactant (AS), 
polymer surfactant (PS), and alkaline surfactant polymer (ASP) (Alvarado, 2010). In surfactant flooding process, surfactant retention is a major factor that reduces the ultimate oil recovery factor within the reservoir rock. There are certain factors influencing the surfactant retention capacity including temperature, effluent $\mathrm{pH}$, type of reservoir rock (i.e., carbonate or sandstone), solvent concentration, the molecular weight of surfactant mixture, total acid number (TAN), mobility ratio, permeability, the salinity of polymer and surfactant solution (Kamari, 2015).

\subsubsection{Polymer Flooding}

Polymer flooding is one of the most incipient methods for chemically enhanced oil recovery. This technique is widely carried out in heavy oil reservoirs that contain a large amount of residual oil that cannot be further extracted by using the conventional water flooding. Due to the presence of high viscosity crude oil in these reservoirs, the mobility ratio between water and oil show a poor impact on the volumetric sweep efficiency. The injection of polymeric solution provides the favorable mobility ratio between water-oil and results in better microscopic and macroscopic displacement efficiency of oil (Lake, 1989; Maitin, 1992; Sheng et al., 2015).

Polymer flooding is generally carried out in heterogeneous reservoirs; these formations mineralogy, organic content, natural fractures, and other properties vary from area to area. This method increases the heavy oil recovery but it does not reduce the residual oil saturation. The use of polymers reduces the recycling water requirement and also decreases the effective permeability of the rock near the borehole wall. According to (Wang, 1999), liquid polymers are used as a displacing fluid because they are easy to handle and mix with the water. Polymer concentration is usually in the range of $0.00025 \mathrm{~kg} / \mathrm{L}$ to $0.002 \mathrm{~kg} / \mathrm{L}$. A significant pore volume i.e. $40 \%$ of polyacrylamide solution is injected to control the mobility ratio oil and displacing fluid (Schumacher, 1980).

\subsection{History of Polymer Flooding}

The idea to use polymer flooding to recover heavy oil and bitumen can be traced back more than half a century ago when Aronofsky (1952), Pye and Sandiford in (1964), and Knight and Rhudy (1977) injected water soluble polymers in a horizontal and vertical orientations to enhance the oil recovery factor. They found that the addition of the polymers reduces the wateroil mobility ratio but the results in both the orientations show a minimal difference due to a small density difference between displacing fluid and oil. They further carried out core flooding experiments with two different oils having viscosities of $220 \mathrm{cP}$ and $1140 \mathrm{cP}$ and reported that 
the more oil was recovered by using the higher molecular weight polymer. Since then polymer flooding became one of the most promising enhanced oil recovery (EOR) techniques.

Later, Manning et al. (1983) reported that a few number of pilot tests were conducted in the Lansdale field in Mississippi but none of these tests were successful because of the conflicting results in viscosities, one at $1494 \mathrm{cP}$ and the other one at $120 \mathrm{cP}$. At that time polymer flooding was considered to be the best option for reservoirs having a viscosity of $100 \mathrm{cP}$ only.

In order to verify that the oil recovery increases with the injection of polymers, Zaitoun et al. (1998) conducted the core flooding experiments in a homogeneous Cartesian reservoir model and reported some interesting results of the process. They used a partially hydrolyzed polyacrylamide having a molecular weight of $13.6 \times 10^{6}$ daltons. They investigated the effect of increasing the polymer concentration against the shear rates. They further measured some of the auxiliary components in the polymer flooding such as polymer adsorption, permeability reduction, and mobility reduction on the basis of polymer concentration. Based on their findings they suggested that incremental oil recovery does not depend on the polymer solution injection. It changes slightly with polymer viscosity, which means usually a lower concentration polymer slug is required at the initial stage within the reservoir.

Hovendick (1987) performed the simulation studies on reservoirs and stated that the injection time plays a key role in incremental oil recovery. This means if the time span of the polymer flood injection following by water flooding is decreased the ultimate oil recovery increases and his findings were already in line with the Zaitoun et al. results.

In 2007 Wang and Dong studied the effect of reservoir lithology on oil recovery. They conducted experiments in heterogeneous sand packs formation and observed that the incremental oil recovery was less as compared to that with the homogeneous sand stone formation. Later their findings were verified and confirmed by the numerical simulation study of Kumar et al. (2005).

Wassmuth et al. (2007) performed their experimental studies on polymer flooding and stated that the use of polymeric solutions provides a favorable mobility ratio between water-oil as compared to the primary water flooding technique and reported that the oil recovery increases more than twice as compared to the conventional polymer flooding.

In 2008 Asghari and Nakutnyy worked on the experimental studies of polymer flooding to check its potential in highly viscous $(8400 \mathrm{cP}$ ) oil reservoirs. Their finding resembles with Wang and Dong (2007) outcomes that by increasing the polymer concentration the ultimate oil 
recovery increases. Polymer flooding showed an incremental oil recovery of $44 \%$ as reported by Manichand et al. (2010) who performed core flooding experiments in homogeneous sand packs.

Later many researchers (Zhang et al., 2010; Wassmuth et al., 2012; Levitt et al., 2013; Algharaib et al., 2014) measured the potential of polymer flooding by varying the oil viscosities from 100s cP to $1000 \mathrm{~s}$ cP. In 2015, researchers at the Colombian Petroleum Institute of Ecopetrol described a new methodology for the selection of polymer flooding, evaluation of polymer flooding, experimental evaluation and numerical simulation. The primary objective was to improve sweep efficiency in unconventional oil reservoirs. They implemented the polymer flooding pilot test in the Southern part of Colombia by CPI. The pilot plant consists of two injection wells with irregular patterns and one production well. The polymer solution injection began in mid-2015 and after more than a year later the total cumulative polymer injection reached 1.5 million barrels which was distributed equally between both the injectors with a varying range of polymer concentration between $200-1500 \mathrm{ppm}$ and with variability in injection rate from 2000-3200 BPD per irregular pattern. The results had shown a tremendous increase in oil production that exceeded 63000 barrels with a reduction of water cut of up to $10 \%$.

In 2015, Solatpour conduction an experimental study to investigate the potential of different types of polymers and the synergetic effect of ASP technology to enhance heavy oil recovery from thin heavy oil fields in Western Canada. He conducted nine sets of polymer flooding using oil-saturated sand-packs with various concentrations of FLOPAAM 3530S (0.1-0.2 wt\% and $0.4 \mathrm{wt} \%), 0.4 \mathrm{wt} \%$ FLOCOMB 3525C, $0.5 \mathrm{wt} \% \mathrm{Na}_{2} \mathrm{CO}_{3}$ and different surfactants with varying concentrations.

All the experimental work done by the great researchers on polymer flooding revealed the fact that success of this technique depends on many factors like reservoir formation, reservoir depth, reservoir temperature and pressure, reservoir salinity, reservoir characteristics such as rock porosity, permeability, and oil composition and viscosity.

\subsection{Mechanism of Polymer Flooding}

In the early 1900s, the primary oil recovery method (water flooding) was mainly carried out on a large scale to extract the oil from the reservoirs as well as to maintain the reservoir pressure (Uren and Fahmy, 1927). The problems associated with this technique were the poor mobility ratio between water-to-oil in a heavy oil reservoir and the reservoir heterogeneity. 
In order to have the favorable mobility ratio between water-oil, Pye and Sandiford (1964) came up with the idea of injecting water soluble polymers in water that acts as a thickening agent. It increases the viscosity of the displacing fluid and results in a better sweep efficiency. Donaldson et al. (1989) defined the mobility ratio as the ratio of relative permeability of oil and water divided by its viscosity. Figure 2.1 shows the schematic of polymer flooding process;

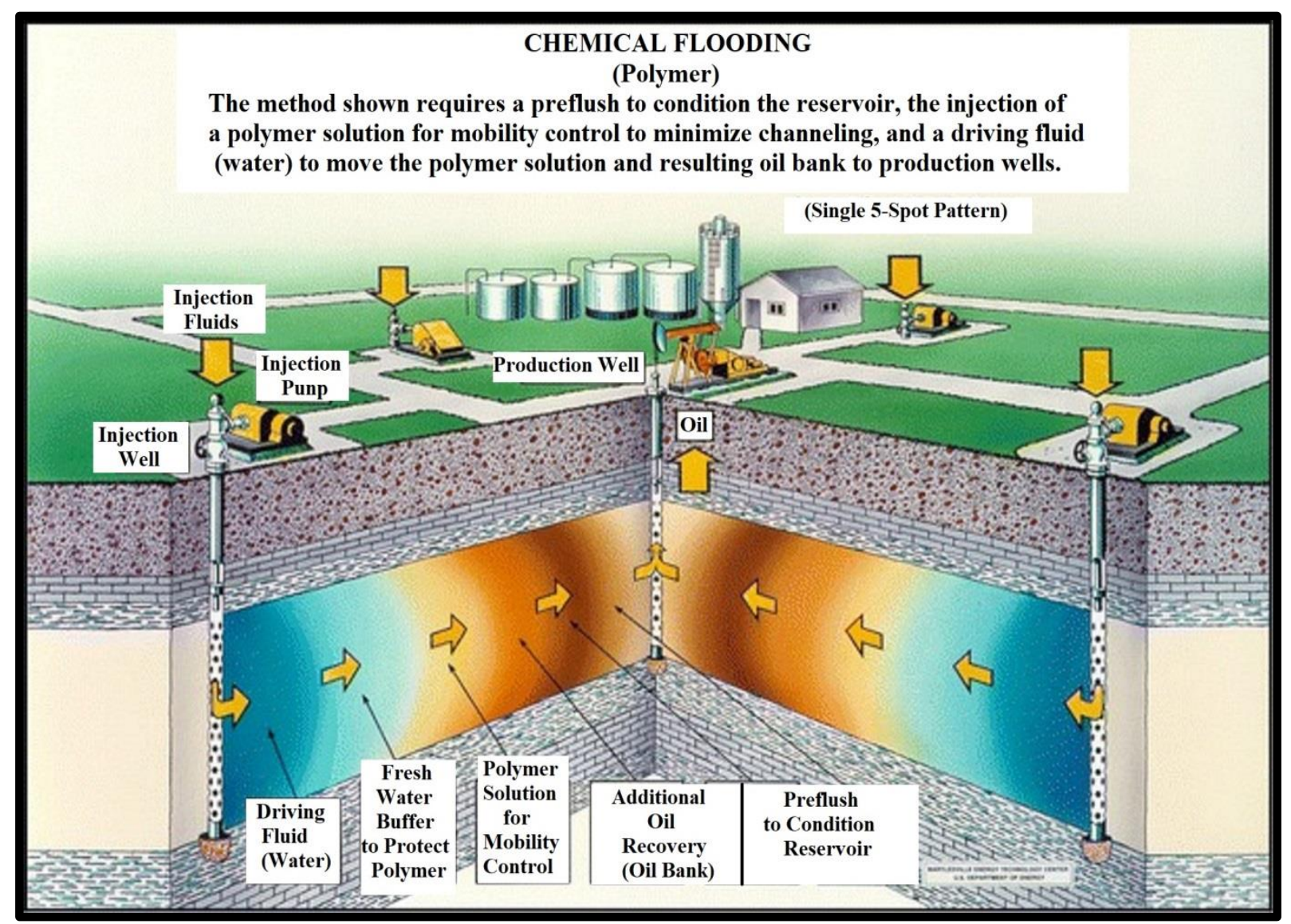

Figure 2.1 Schematic of Polymer Flooding Process (Lindley, 2001). Picture edited by

\section{Author for quality purposes}

In order to understand the oil displacement mechanism by polymer flooding, it is important to first understand the key concepts related to the process. There are three main mechanisms associated with polymer flooding such as;

- Mobility control,

- Permeability reduction,

- Fractional flow, and

- Sweep efficiency (microscopic displacement efficiency and volumetric sweep efficiency). 


\subsubsection{Mobility Control}

The mobility ratio (M) is defined as the mobility of water to the mobility of oil (Speight, 2009). The mobility ratio of water to oil $\left(\lambda_{0}\right)$ is reduced by the addition of polymer which results in more oil recovery.

$$
M=\frac{\lambda_{w}}{\lambda_{o}}=\frac{k_{r w} / \mu_{w}}{k_{r o} / \mu_{o}}=\frac{k_{r w} \mu_{o}}{k_{r o} \mu_{w}}
$$

In order to grasp the full knowledge of polymer flooding process, one should have to thoroughly understand the concept of mobility ratio and its effects on the process. The mobility of oil acts as a lead role throughout the process and is summarized as the effective permeability of rock to the oil divided by the viscosity of the oil $(\lambda=k / \mu)$.

where $\lambda$ denotes the mobility of oil in $(\mathrm{md} / \mathrm{cP}), k$ is the effective relative permeability of rock to the displaced fluid (oil) in (md), $\mu$ is the viscosity of displaced fluid in centipoise (cP). The overall value of mobility ratio should be less than one. The ranges of mobility ratio (M) describe the different conditions within the reservoir. As the oil moves faster than water within the reservoir the mobility ratio is $(\mathrm{M}<1)$ describes the favorable condition. If both oil and water flows at the same speed than the mobility ratio is $(M=1)$ shows the favorable displacement within the reservoir. On the other hand, if the velocity of water is greater than oil the mobility ratio becomes $(M>1)$ which indicates unfavorable displacement (Speight, 2009). In 2008 Kumar et al. investigated water flooding potential with unfavorable mobility ratios. They deduced that viscous fingering had a strong impact on fluid displacement and it reduces the overall oil recovery. They further proposed that the addition of polymer improves water mobility and the reservoir sweep efficiency which in turn enhances the oil recovery. Mobility reduction is one of the most important key factors that improve the sweep efficiency by the addition of high molecular weight polymers. Figure 2.2 below shows a schematic illustrating the displacement efficiency improvement at low mobility ratio $(\mathrm{M}<1)$ and low displacement efficiency due to viscous fingering and channeling with mobility ratio $(M>1)$. 


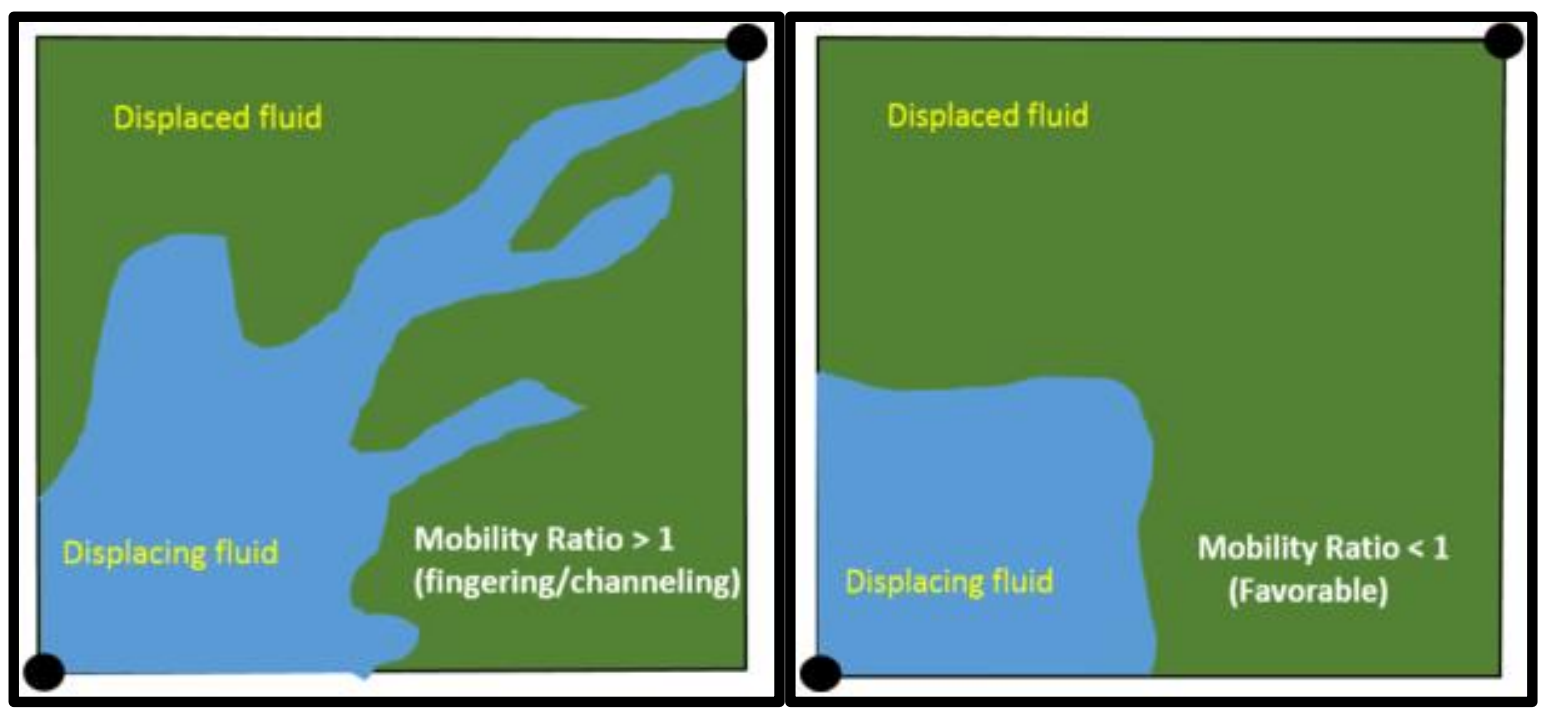

Figure 2.2 Schematic illustration of favorable and unfavorable mobility ratio impact on displacement efficiency (Green and Willhite, 1998; S. Aldourasry, 2015)

\subsubsection{Permeability Reduction}

Another phenomenon associated with the viscosity increase of the displacing fluid is the reduction of the water relative permeability. This is mainly caused by the entrapment of polymer molecules within the low permeable zones (Mungan, 1964; Szabo, 1975). Polymer adsorbs on the rock surface within the reservoir and this layer formation on the rock surface causes the continuous shrinking and swelling of polymer and reduces the effective permeability. In the presence of oil, the swelling is negligible and polymeric solution reduces the mobility within low oil saturation zones and results in incremental oil recovery (Sparlin, 1976).

\subsubsection{Wettability Alteration}

Wettability plays an important role in oil recovery factor. It commonly refers to the hydrophobic and hydrophilic nature of the particles within the reservoir. The oil reservoirs show a wide range of wettability's such as water-wet, oil-wet, and mixed-wet. The adsorption and deposition of polymers on the rock surfaces alters the wettability of the reservoir. In oil-wet reservoirs, the water flooding decreases the oil relative permeability and increases the water relative permeability that causes the viscous fingering effect. While in water-wet reservoirs the water relative permeability decreases and the oil relative permeability increases which in turn increases the oil recovery factor (Anderson, 1987). 


\subsubsection{Microscopic Sweep Efficiency}

The success of polymer flooding depends on the microscopic displacement efficiency of the residual oil which can be improved by the solubilization and mobilization of the trapped polymer molecules within the pore throats of the reservoir. Displacement efficiency is the measure of the quantity of oil displaced by the displacing fluid and strongly depends on the pore size distribution of the reservoir. There are two types of volumetric displacement efficiencies; aerial and vertical sweep efficiency and is the ratio of area swept by the front in the horizontal and vertical direction of the swept layers to the total area (Clifford and Sorbie, 1985; Cosse, 1993).

\section{a) Aerial/ Horizontal Sweep Efficiency}

It is defined as the ratio of the horizontal area swept by the fluid to the total area. The aerial sweep efficiency depends on the type of well pattern, injection patterns, time of flood, volume or capacity of the flood, and mobility ratio. Aerial sweep efficiency increases by maintaining the proper pressure distribution and by deliberately managing and choosing the proper injectionproduction pattern.

\section{b) Vertical Sweep Efficiency}

It is defined as the ratio of the vertical area swept by the fluid to the total area. Vertical sweep efficiency depends on the reservoir heterogeneity such as permeability, fractures, and drains. This vertical reservoir heterogeneity blocks the displacing fluid pathways and reduces the sweep efficiency and recovery factor. According to Sorbie (1991), vertical reservoir heterogeneity causes the early water breakthrough, even if the mobility ratio is appropriate for the flooding which leads to the poor sweep efficiency.

\subsubsection{Fractional Flow Resistance}

Another mechanism associated with polymer flooding is the viscoelastic behavior of the polymer solutions that causes the additional resistance in the flow path of the fluids. This improves the microscopic and macroscopic displacement efficiency during polymer flooding that results in an additional heavy oil recovery. The polymers used for enhanced oil recovery such as polyacrylamide, xanthan gum, and glucose they exhibit elastic behaviors. Polymer solutions when passes through the porous media show the viscoelasticity due to the presence of shear stresses between oil and polymer solution. When polymer solution passes through small pores exhibits greater elastic viscosity and higher frictional flow resistance, which results in the 
better displacement of immobilized residual oil trapped by the capillary forces and rock geometry (Wang et al., 2000).

\subsection{Viscoelastic Behavior of Polymer Solutions in Porous Media}

During polymer flooding, the polymeric solutions exhibit viscoelastic behavior. It mainly depends on the type of polymer, variation in the polymer concentration, polymer adsorption and mechanical entrapment of the polymer molecules within the pore throats. The flow resistance caused by the high viscous polymer solutions can increase the volumetric sweep efficiency (Garrouch and Gharbi, 2006).

Several studies have been conducted to determine the rheological properties of polymer solutions flowing through a porous media. It is known that the pore size distribution within the reservoir is so small that it does not permit the free flow of the non-Newtonian fluids. The low flow velocity means Reynolds number in most areas of the reservoir is below unity. It is a fact that the flow areas inside the well are not uniform which in turns do not allow the stream lines to flow in a linear and straight pattern. Mostly the path through the pore space is tortuous which give rise to the inertial forces due to the variations of the flow directions but nevertheless, these inertial forces are negligible as compared to the viscous forces. This internal resistance to flow is directly proportional to the flow rate and is generalized as Darcy's Law (Chatiz and Morrow, 1984). Due to low Reynolds number (creeping flow), these inertial forces overcome the viscous forces and the velocity distribution curve is determined by the pore size of the reservoir. Thus, the velocity distribution at the center is high while it is zero at the wall of the pores. 


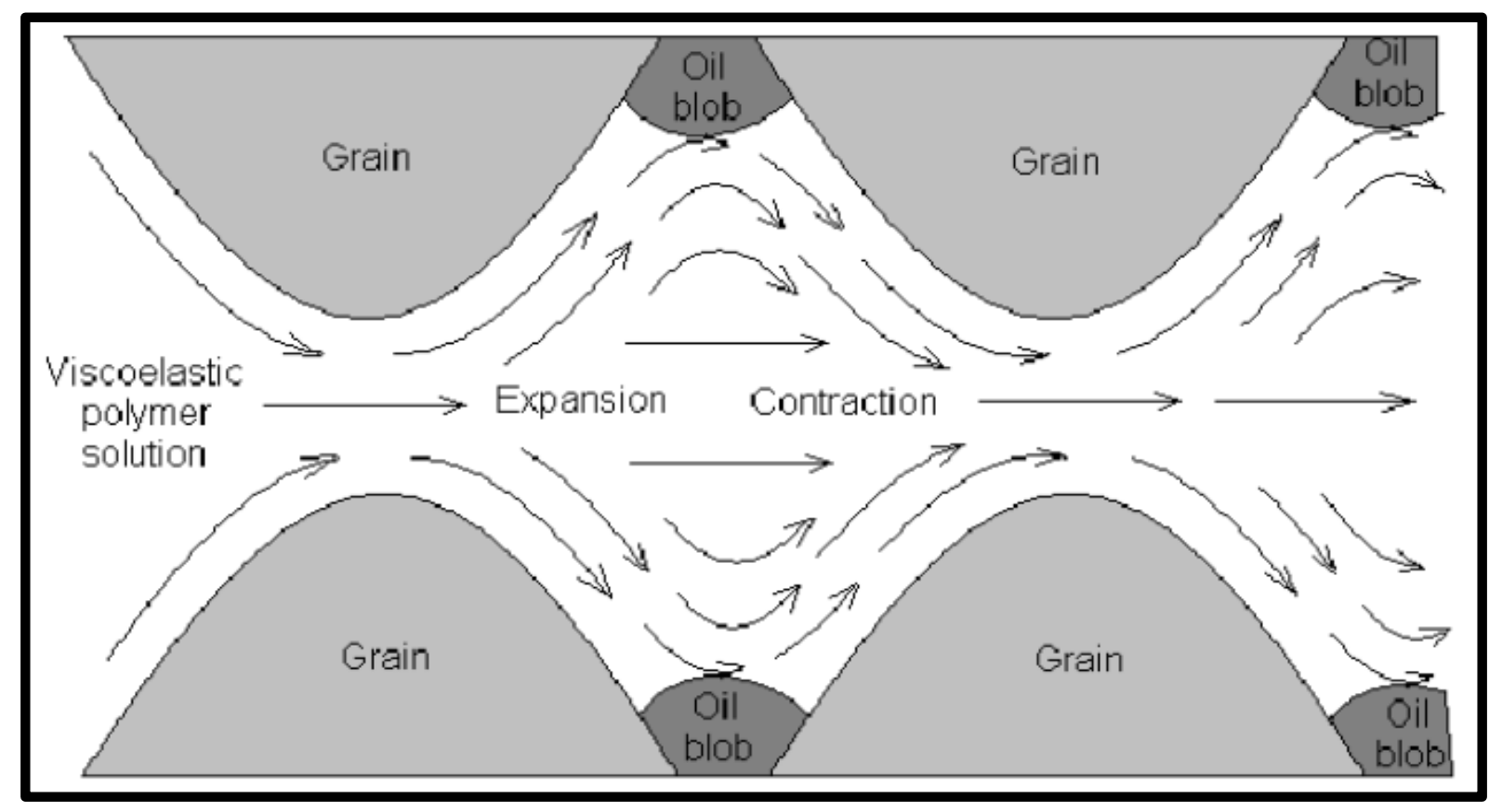

Figure 2.3 Polymer flow through porous media (Urbissinova, 2010)

Wang et al. (2007, 2011) performed an experimental study to investigate the pulling effect mechanism and found that the viscoelastic polymer due to the normal stress between the displacing fluid and oil generates an additional shear stress on the oil droplets to strip them out of the dead end pores. The viscoelastic property of the driving fluid and greater shear stress yields an additional oil recovery.

\subsection{Polymers for Enhanced Oil Recovery}

A polymer is a naturally occurring or synthetic compound having large chain molecules which are linked together by thousands of low molecular weight molecules of different repeating units called monomers. They have a wide range of application varying from oil industry to the manufacturing of paints and polishes (Schumacher, 1980). There are two main types of polymers which are most currently used in polymer flooding;

- Synthetic Polymers (Partially Hydrolyzed Polyacrylamide)

- Biopolymers (Xanthan gum)

There are other different types of polymers which are not commonly used in polymer flooding are natural polymers and their derivatives such as guar gum, sodium carboxymethylcellulose, and hydroxyl ethyl cellulose (HEC) (Sheng, James, 2011). The polymers used for EOR should have the following characteristics, (a) tendency to enhance the viscosity of the solution, (b) stability at high temperature, (c) negatively charged hydrophilic group that reduces the polymer 
adsorption on the rock surfaces, and (d) chemical stability (Sheng, James, 2011). The Table 2.1 below shows some of the characteristics of polymers used for heavy oil recovery:

Table 2.1 Polymer structure and their characteristics (Zhao, 1991)

\begin{tabular}{|c|c|c|}
\hline Structure & Characteristics & Sample Polymers \\
\hline -o- in the backbone & $\begin{array}{l}\text { Low temperature resistance, } \\
\text { Thermally degraded at } \\
\text { elevated } \mathrm{T} \text {, only suitable at } \\
\quad<80^{\circ} \mathrm{C}\end{array}$ & $\begin{array}{l}\text { Polyoxyethylene, sodium } \\
\text { alginate, sodium } \\
\text { carboxymethyl cellulose, } \\
\text { HEC, xanthan gum }\end{array}$ \\
\hline Carbon chain in the group & $\begin{array}{l}\text { Good thermal stability, Less } \\
\text { degradation at }<110^{\circ} \mathrm{C}\end{array}$ & $\begin{array}{c}\text { Polyvinyl, sodium } \\
\text { polyacrylate, polyacrylamide, } \\
\text { HPAM }\end{array}$ \\
\hline - $\mathrm{COO}^{-}$in hydrophilic group & $\begin{array}{c}\text { Good viscosity increasing } \\
\text { agent, less adsorption on } \\
\text { sandstones, less chemical } \\
\text { stability }\end{array}$ & $\begin{array}{l}\text { Sodium alginate, sodium } \\
\text { carboxymethyl cellulose, } \\
\text { HPAM, xanthan gum }\end{array}$ \\
\hline $\begin{array}{l}-\mathrm{OH} \text { or }-\mathrm{CONH}_{2} \text { in } \\
\text { hydrophilic group }\end{array}$ & $\begin{array}{l}\text { Good chemical stability, but } \\
\text { no repulsion between chain } \\
\text { links, less viscosifying } \\
\text { powder, high adsorption on } \\
\text { sandstone rocks }\end{array}$ & $\begin{array}{c}\text { Polyvinyl, HEC, } \\
\text { polyacrylamide, HPAM }\end{array}$ \\
\hline
\end{tabular}

\subsubsection{Partially Hydrolyzed Polyacrylamide (HPAM)}

Polyacrylamides and copolymers (acrylic acid and acrylamide) are water-soluble polymers which are most frequently used for EOR processes. HPAM is a straight chain polymer which contains acrylamide molecules as monomers. Partially hydrolyzed polyacrylamide is widely preferred in EOR operations due to the cheap price and high oil recovery factor. Polyacrylamides undergo partial hydrolysis due to which the amide groups $\left(\mathrm{CONH}_{2}\right)$ convert into the carboxylic group $\left(\mathrm{COO}^{-}\right)$. The molecular structure of HPAM is given below 


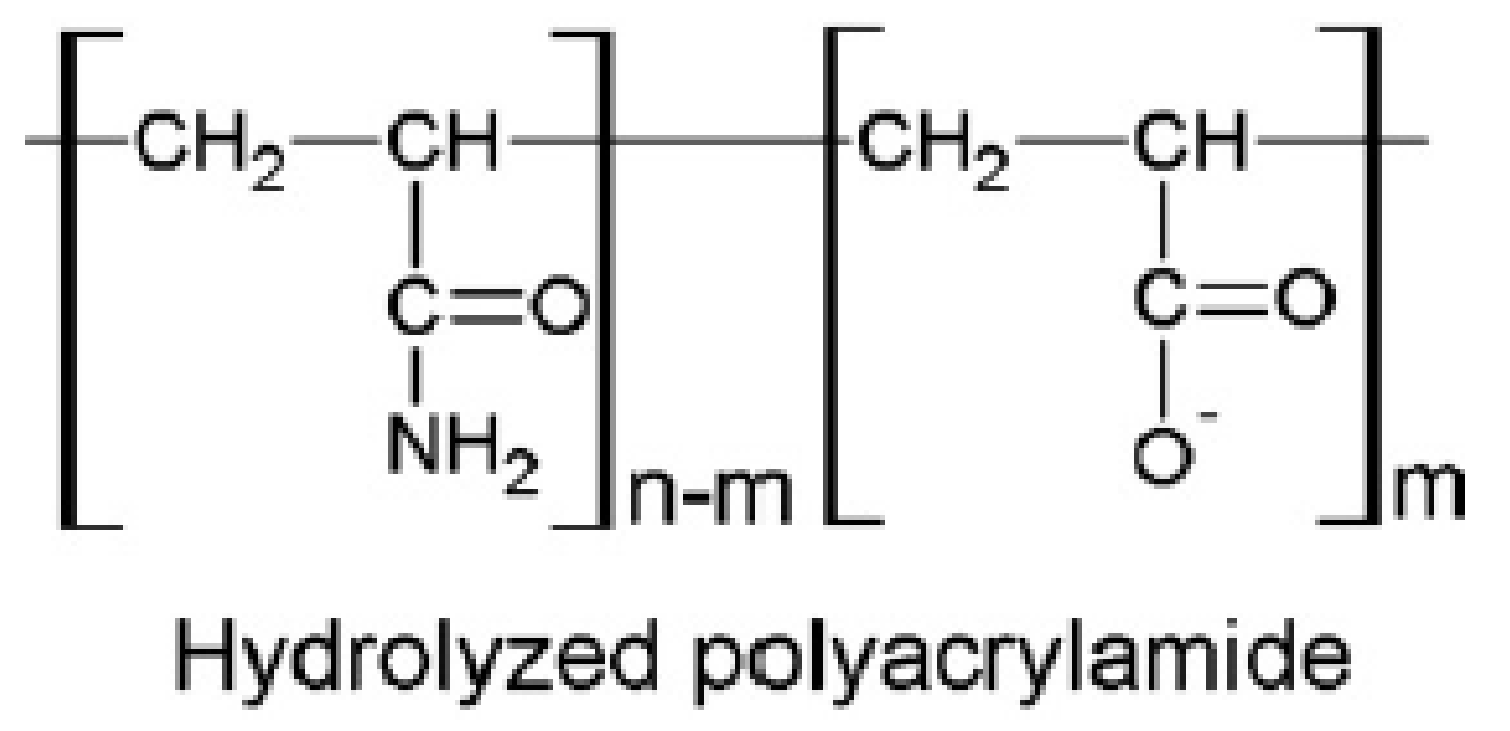

Figure 2.4 Chemical structure of partially hydrolyzed polyacrylamide (HPAM) (Wever et al., 2011)

HPAM solution shows higher viscoelastic properties than xanthan gum (Wang et al., 2006) and these viscoelastic properties improve the microscopic displacement efficiency. The high molecular weight PAM increases the viscosity of polymer solutions. High molecular weight PAM is easily disintegrated by high shear rate due to the breakage of carbon chain in the polymer backbone. The viscosity of polyacrylamide is inversely proportional to the salinity and hardness. PAM is not suitable under the extreme conditions of high temperature, high salinity, high heterogeneity, and hydrolysis.

According to (Sorbie, 1991), the polymer molecules flowing through a porous media can adsorb onto the pore walls. Due to the polymer adsorption, the relative permeability and the flow velocity of the aqueous zone reduces and is known as permeability reduction effect. Polymer adsorption shows an inverse relation with permeability, meaning if the permeability of the polymer passing paths increases the polymer adsorption decreases, while polymer adsorption increases with salinity (Sheng, James, 2011). The Langmuir-type isotherm can be used to describe the polymer adsorption and it is given as;

$$
\widehat{C}_{p}=\left[C_{p}, \frac{a_{p}\left(C_{p}-\hat{C}_{p}\right)}{1+b_{p}\left(C_{p}-\hat{C}_{p}\right)}\right]
$$

where $C_{p}$ is the concentration of polymer before adsorption, $C_{p}-\hat{C}_{p}$ is the equilibrium concentration between rock and polymer solution, $a_{p} \& b_{p}$ are empirical constants. As the polymer concentration increases the adsorption of polymer on rock surface decreases because 
the water soluble polymers have an adsorption layer on the rock surface. This adsorption layer becomes thicker as the polymer concentration increases which is due to the increase in adsorption rate. When the polymer concentration increases above the critical point, the molecular interaction becomes more attractive and stronger in liquid, while the adsorption on the rock surface becomes less prominent. This is the reason why the adsorbed molecules leave the rock surface and dissolve again into the liquid, which results in an overall decrease in adsorption (Li, 2006; Sheng, James, 2011).

\subsubsection{Xanthan Gum}

Xanthan gum (corn sugar gum) is a biopolymer which is most commonly utilized in enhanced oil recovery processes. It is highly resistant to mechanical degradation and their molecular weight ranges from 1 million to 15 million. Xanthan gum usually occurs in dry powder form as well as in concentrated broth. These biopolymers show less sensitivity to salinity as compared to polyacrylamides. The structure of xanthan gum is shown in the following figure (Sheng, James, 2011);

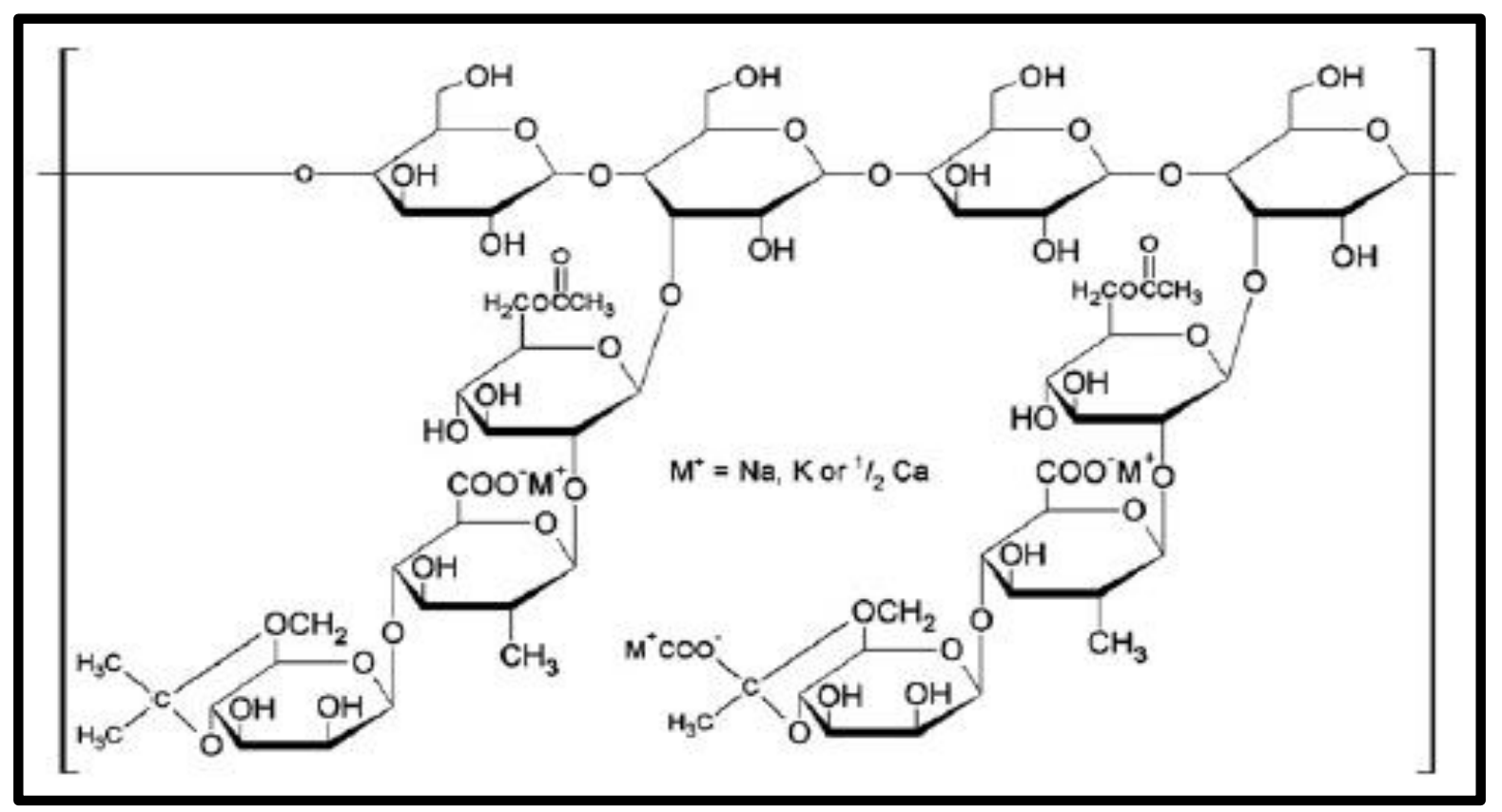

Figure 2.5 Chemical structure of xanthan gum (Wever et al., 2011)

The major drawback of xanthan gum is its biological degradation due to the presence of bacteria. Aerobic and anaerobic microorganisms degrade the xanthan gum that results in the reduction of the solution viscosity (Wever et al., 2011). 


\subsection{Factors Affecting Polymers Performance in Heavy Oil Reservoirs}

There are numerous factors that affect the performance of polymer in unconventional oil reservoirs and special consideration must be given to these factors when conducting polymer flooding. List of these factors and their effects on the process are discussed below:

\subsubsection{Shale Geometry}

Most of the heavy oil reservoirs contain discontinuous shale streaks which act as a barrier to fluid flow. These discontinuous shale streaks are randomly distributed within the reservoir and decrease the fluid flow along the radial axis due to the presence of tortuous track. These discontinuous barriers can also decrease the relative permeability. Due to the presence of viscous and gravitational forces the oil is initially bypassed and drains out from the shale which leads to the premature breakthrough of displacing fluids (polymer solution).

Moreover, the presence of these discontinuous shale streaks also changes the viscous, capillary, and gravitational flow and increases the dispersive cross flow. Geometrical characteristics like shale's orientation, length, spacing, the distance of shale from the production well, and shale density increases the ultimate oil recovery decreases (Mohammadi et al., 2012).

\subsubsection{Role of Connate Water}

In petroleum reservoirs, the oil contains a small amount of water which is equally dispersed within the oil phase. This uniformly dispersed water is deposited on the rock sediments in ancient times, is known as connate water. The connate water has a significant effect on the fluid flow or displacement mechanism within the porous media. In 1984, Paterson et al. observed that when connate water is trapped in porous media it changes the wettability and stuck between the pores in an irregular manner. This residual water than contacts with solid surface and forms a thin film around it. Connate water gives the fewer resistance areas for the displacing fluid to pass through the porous media which results in the overall reduction of breakthrough recovery of polymer processes (Mohammadi et al., 2012).

\subsubsection{Temperature}

In polymer flooding, the temperature is one of the most critical parameters that need to be controlled during the process. As it is known that the polymers are very sensitive to temperature and the high temperature increases the rate of decomposition reactions. According to the Arrhenius equation, the viscosity of a polymer solution decreases with the increase in temperature at a low shear rate. 


$$
\mu_{p}=A_{p} \exp \left[-\frac{E_{a}}{R T}\right]
$$

where $E_{a}$ is the activation energy of polymer solution, $R$ is the universal gas constant, and $\mathrm{T}$ is the temperature. This relation clearly shows that as the temperature increases the viscosity of polymer reduces briskly. Due to high temperature the polymer molecules moves apart, and the frictional flow resistance between these molecules decreases which in turn reduces the viscosity (Sheng, James, 2011).

In 1997, Zhou and Huang conducted an experimental study to determine the effect of temperature on polymer viscosity. The polymer used was (PAMOA75) polyacrylamide with $0.75 \mathrm{~mol} \%$ Octylacrylate (OA) having a polymer concentration of $2800 \mathrm{mg} / \mathrm{L}$. They found that viscosity of polymer solution is slightly increased when the temperature is below $35^{\circ} \mathrm{C}$, and the viscosity starts reducing as the temperature exceeds $50{ }^{\circ} \mathrm{C}$. When the temperature reaches 70 ${ }^{\circ} \mathrm{C}$, the viscosity of a polymer becomes constant and at this point, the viscosity is almost similar to that of $20{ }^{\circ} \mathrm{C}$. Thus, $70{ }^{\circ} \mathrm{C}$ is considered as a temperature screening limit for synthetic polymers (Littman, 1988).

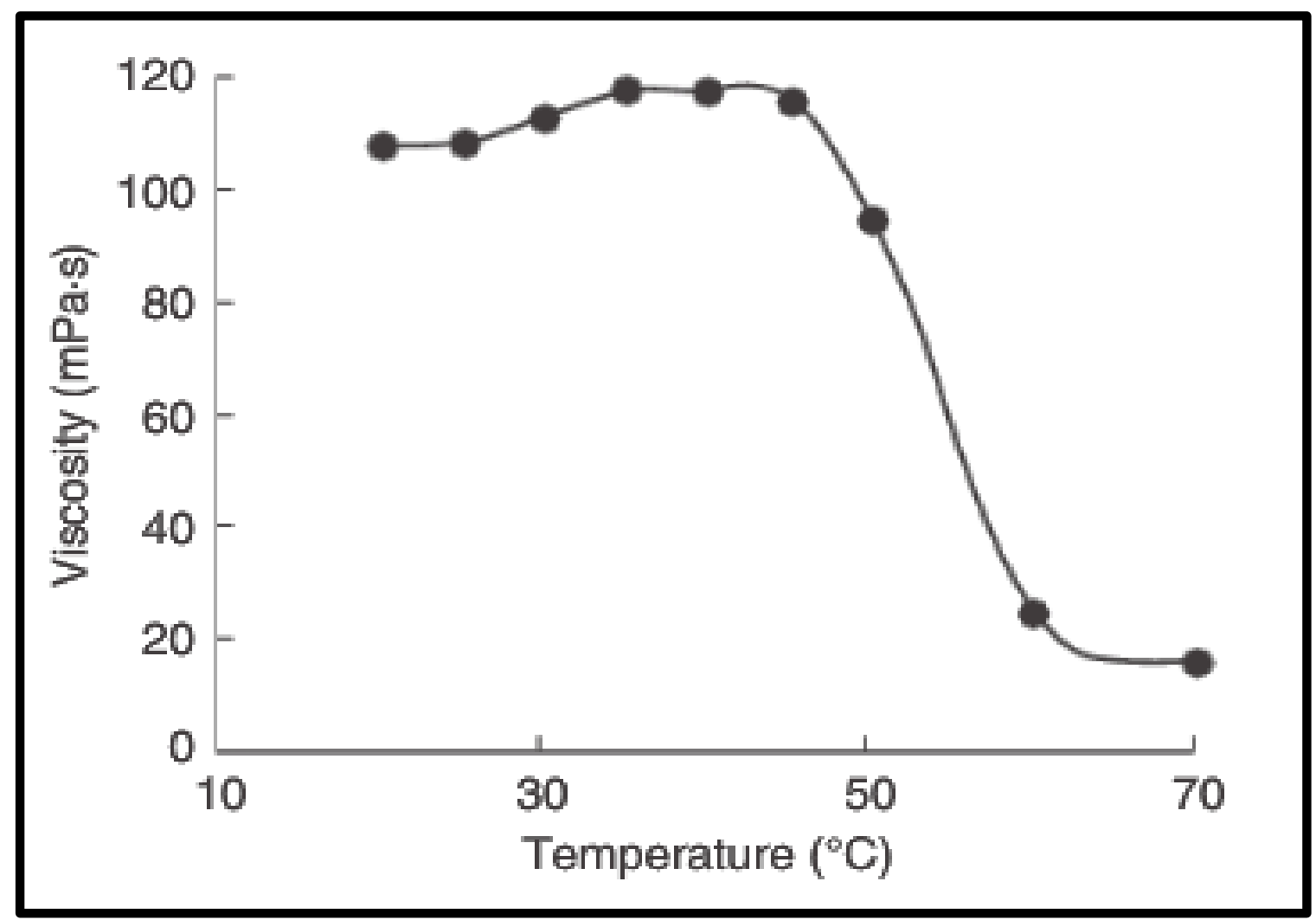

Figure 2.6 Temperature versus viscosity POMOA 75 (Polyacrylamide with 0.75 mol\% Octylacrylate (Zhou Huang, 1997; Sheng, James, 2011) 


\subsubsection{Salinity Effect}

Salinity is generally expressed in terms of total dissolved solids (TDS). TDS is the amount of inorganic salts (usually calcium, magnesium, potassium, sodium bicarbonates, chlorides, and sulfates) and organic substances dissolved in liquid. Generally, the amount of anions in liquid represents salinity and $\mathrm{NaCl}$ is the main salt in saline water which represents the salinity in terms of $\mathrm{Cl}^{-}$ions. High salinity content in reservoir fluids reduces the viscosity of polymers. Inorganic ions like $\mathrm{Na}^{+}, \mathrm{Ca}^{2+}$, and $\mathrm{Mg}^{2+}$ have a huge impact on the characteristics of polymers in aqueous solution. The viscosity of a polymer solution decreases with the increase of the concentration of inorganic ions (Sheng, James, 2011). Overall, the presence of high concentration of divalent ions precipitates the polymers in a chemical slug.

Polyacrylamide is not feasible under the severe conditions of high salinity in heavy oil reservoirs due to the hydrolysis, and shear degradation. Hydrolysis of PAM replaces some of the amide groups to carboxyl groups which bring more negative charges on the polymer chains and this addition of negative charges has a strong shielding effect on the electrostatic forces among the polymer chains. This reduces the viscosity of polymer solution with the increase of the concentration of divalent ions. In contrast with PAM, biopolymers like xanthan gum show high resistance to reservoir salinity as these polymers are highly rigid and act as a semi-rigid rod. Xanthan gum has high stability in the presence of divalent ions and they are highly thermal resistant as well as exhibits high shear resistance in porous media (Littman, 1988).

\subsubsection{Polymer Concentration}

The concentration of polymer solution is one of the most significant parameters that determine the polymer solution viscosity and the size of polymer slug. In 2009, Lee conducted an experiment to study the effect of polymer concentration on the performance of polymer flooding process. It was observed that with the injection of higher concentration polymer solution the oil recovery increases, the mobility ratio of water-oil decreases and the sweep efficiency increases. The study shows that the incremental oil recovery obtained by polymer flooding was $21 \%$ more than by water flooding and the mobility ratio of water-oil is $60 \%$ lower than water flood. The higher polymer concentration increases the slug viscosity which makes the injection of displacing fluid more impractical due to plugging problems and handling issues (Lee, 2009). 


\subsection{Screening Criteria of Polymer Flooding for EOR Process}

Screening of suitable elements is required for the successful implementation of polymer flooding for enhanced oil recovery process. Different staged processes are required for EOR project evaluation and development. The first one is conventional screening, which gives the information about reservoir properties such as reservoir geometry, reservoir rock, reservoir depth and temperature, and reservoir salinity. After screening all these parameters and decision to carry out polymer flooding process in a heavy oil reservoir, the next step is to screen and evaluate the polymers required for EOR polymer flooding. This screening method gives the information related to polymer viscosity, thermal stability, and polymer concentration. The screening chart containing different development stages for polymer evaluation is given on the next page (Kamisnky et al., 2007).

A detailed staged process of polymer flooding for the successful field-scale implementation of the project requires;

- Detailed study of the technological and economic aspects of the polymer flooding projects

- Better reservoir characteristics

- Preliminary laboratory tests

- Pilot scale operations

- Pilot design and injection strategies

- Numerical simulation of the model and history matching with pilot scale reservoir simulation studies

- Optimization of the polymer flooding project by improving the injection pattern, and injection rate.

Table 2.2 shows the criteria to conduct polymer flooding project real world oil reservoirs with following properties. These screening parameters are used to evaluate and implement the success of the field scale operation. 
Table 2.2 Screening criteria of polymer flooding (Saboorian-Jooybari, 2016)

\begin{tabular}{c|c|c|c|c|c}
\hline \multicolumn{1}{c}{ Variable } & Units & $\begin{array}{c}\text { Carcoana } \\
\mathbf{( 1 9 8 2 )}\end{array}$ & $\begin{array}{c}\text { Taber et al. } \\
(\mathbf{1 9 9 7})\end{array}$ & $\begin{array}{c}\text { Al-Adasani } \\
\text { \& Bai } \\
(\mathbf{2 0 1 0})\end{array}$ & $\begin{array}{c}\text { Dickson et } \\
\text { al. (2010) }\end{array}$ \\
\hline Depth & $\mathrm{ft}$ & $<6562$ & $<9000$ & $700-9460$ & $800-9000$ \\
\hline Porosity & $\%$ & $\mathrm{NR}$ & $\mathrm{NR}$ & $\mathrm{NR}$ & $\mathrm{NR}$ \\
Permeability & $\mathrm{md}$ & $>50$ & $>10$ & $1.8-5500$ & $>100$ \\
Oil viscosity & $\mathrm{cP}$ & $50-80$ & $10-100$ & $0.4-4000$ & $10-1000$ \\
Oil gravity & ${ }^{\circ} \mathrm{API}$ & $\mathrm{NR}$ & $>15$ & $13-42.5$ & $>15$ \\
\hline $\begin{array}{c}\text { Oil saturation } \\
\text { Temperature }\end{array}$ & $\%$ & $>50$ & $>50$ & $34-82$ & $>30$ \\
\hline $\begin{array}{c}\text { Salinity } \\
\text { Oil mobility }\end{array}$ & $\mathrm{ppm}$ & $<180$ & $<200$ & $<237$ & $<170$ \\
\hline $\begin{array}{c}\text { Oil/polymer } \\
\text { viscosity } \\
\text { ratio }\end{array}$ & $\mathrm{md} / \mathrm{cP}$ & $\mathrm{NR}$ & $\mathrm{NR}$ & $\mathrm{NR}$ & $\mathrm{NR}$ \\
\hline
\end{tabular}




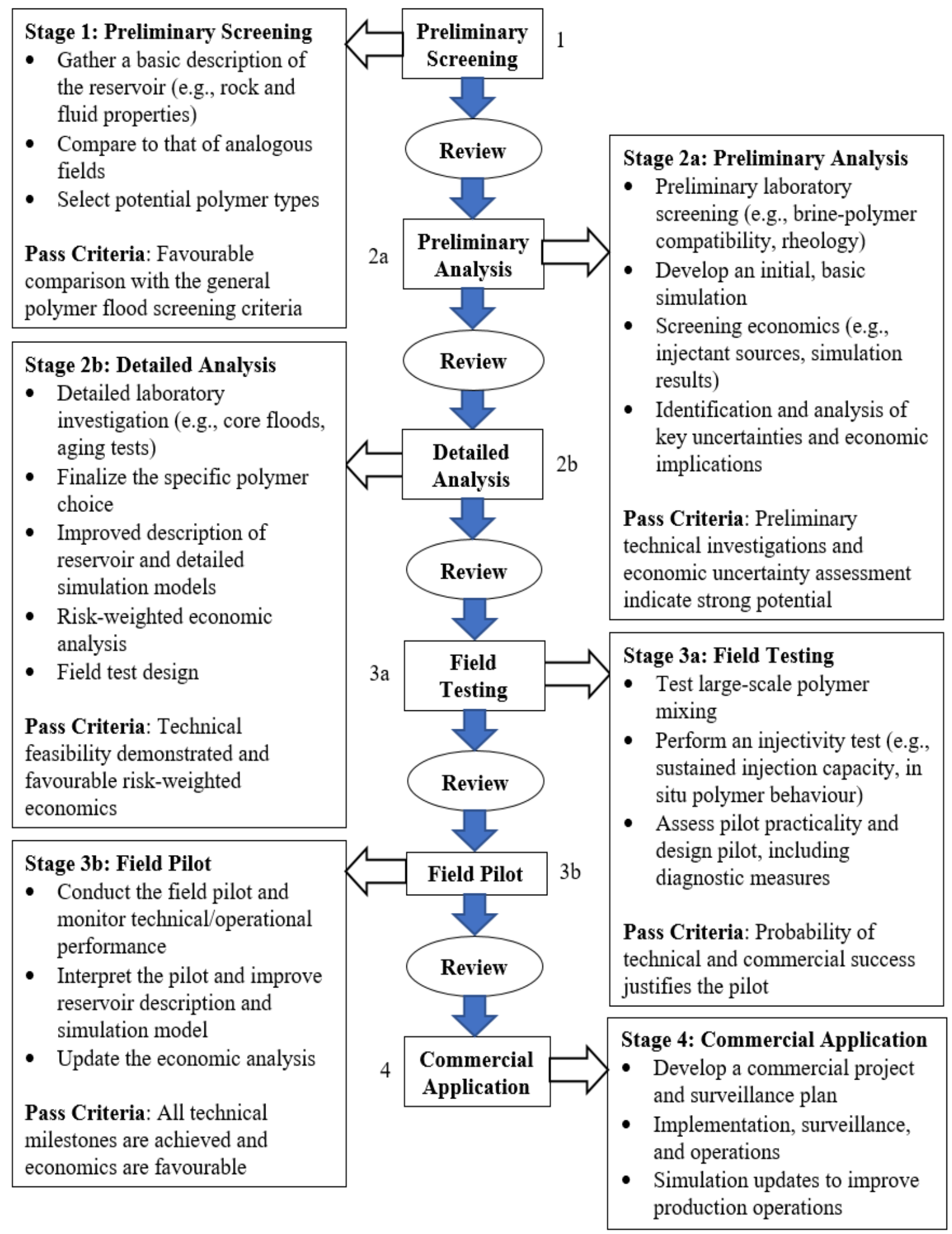

Figure 2.7 Development stages for polymer flooding evaluation (Kamisnky et al., 2007)

\subsubsection{Reservoir Lithology}

Reservoir lithology is one of the most promising screening factors for EOR process. It is well known that a number of successful polymer flooding projects have been implemented in high permeability carbonates and sandstone reservoirs particularly dealing with low conventional 
oils. In contrast, reservoir lithology is a limiting factor to polymer flooding in heavy oil reservoirs. High permeability and porosity in a reservoir gives the high-performance efficiency and the high permeability above $1 \mu \mathrm{m}^{2}$ are a desirable value and this value should not be less than $0.5 \mu \mathrm{m}^{2}$ in order to obtain high efficiency (Saboorian-Jooybari et al., 2016). In reservoirs, certain types of minerals especially clays and gypsums are present which reduces the efficiency of polymer flooding process by reducing the polymer viscosity, adsorption, and clay swelling. Hence, it is highly recommended that a detailed feasibility study have to be conducted when implementing the EOR process. The figure below shows the EOR thermal, gas injection, and chemical projects implanted in sandstone, carbonate, and other (turbidity formations) (Alvarado and Manrique, 2010).

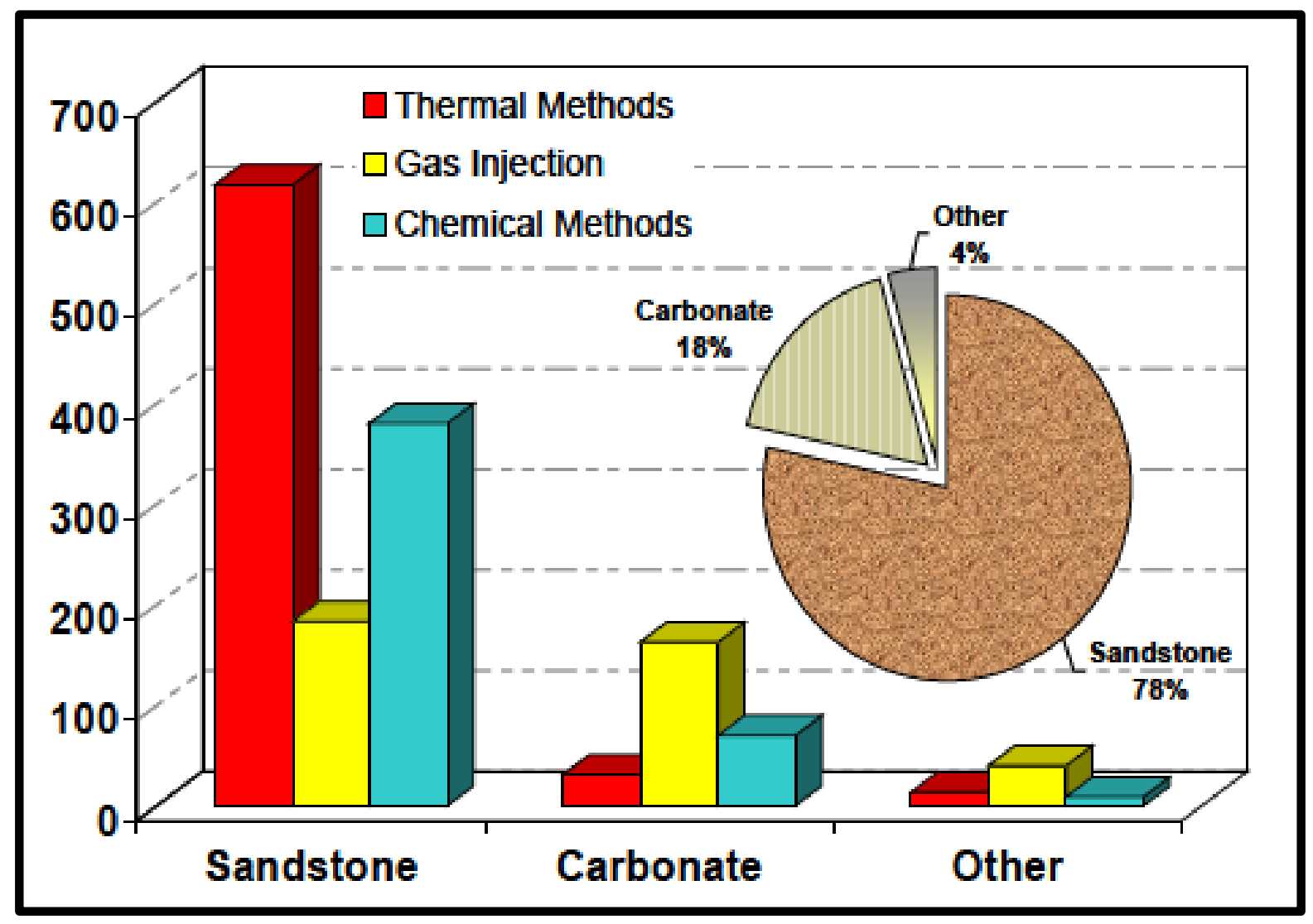

Figure 2.8 EOR methods by reservoir lithology (Alvarado and Manrique, 2010)

\subsubsection{Reservoir Depth}

Reservoir depth is a primary factor that has a direct effect on the reservoir temperature and pressure. Effects of temperature and pressure are related to polymer stability and injectivity while the reservoir depth is related to financial risks and costs which are relatively very high in deep formations. Reservoir depth is also used for evaluating drilling, completion, and operational costs. According to Taber et al. (1997), reservoir depth less than $9000 \mathrm{ft}$ is 
recommended whereas other ranges of 800-9000 and 700-9460 ft are also considered for depth screening criterion based on the projects implemented in medium to light oil reservoirs (Saboorian-Jooybari et al., 2016).

Reservoir depth is related to the injection pressure and the injection pressure is significantly higher in polymer flooding. The limiting factor for injection pressure is at which the reservoir would fracture. Hence, for polymer flooding processes carried out at low depth, the high injection pressure may fracture the reservoir. In the case of temperature, the reservoir depth is directly proportional to the temperature, the greater the depth, the higher the temperature. For polymer flooding, the maximum temperature limit is $70^{\circ} \mathrm{C}$ but for another polymer like xanthan, the maximum temperature limit is $90{ }^{\circ} \mathrm{C}$. According to the Arrhenius equation, the viscosity and the decomposition reaction of a polymer solution decreases with the increase in temperature at a low shear rate.

\subsubsection{Crude Oil Density and Viscosity}

Properties of crude oil are also one of the most important screening factors for the successful implementation of polymer flooding for EOR process. Oil composition is very important to alkalis and surfactants but not critical to a polymer. The average oil viscosity of $5400 \mathrm{cP}$ is recommended as a screening criterion for polymer flooding in heavy oil reservoirs. Oil gravity is related to oil viscosity, the lower limit for oil gravity is between 11-13 ${ }^{\circ} \mathrm{API}$ in heavy oil reservoirs (Sheng et al., 2015).

\subsection{Polymer Flooding Projects in Canada}

There is no doubt that Canada has a vast amount of heavy oil resources in the world. Most of these heavy oil reservoirs are found in Western Canadian belt and the production of oil from these unconventional reservoirs is mainly heavy oil, extra-heavy oil, and bitumen (Miller et al., 2000; Mohammadpoor et al., 2012). As previously discussed, that the recovery of heavy oil from these reservoirs is very low due to the conventional oil recovery techniques. Thus, it requires carrying out advanced oil recovery techniques (polymer flooding).

Polymer flooding technique can be traced back in the early sixties. The first polymer flooding project in Canada was started in Taber South Mannville in Southern Alberta in 1967. The porosity of the reservoir was $27-30 \%$ and the absolute permeability was 1000 milli Darcy. The thickness of the reservoir was $3.2 \mathrm{~m}$ and contains the total dissolved solids in the range of 25,000-29,000 ppm (Lozanski and Martin, 1970; Shaw and Stright, 1977). 
The Pelican Lake heavy oil field located in Alberta, Canada was discovered in 1978. After the continuous efforts of two years, the production of heavy oil started from this reservoir. The lithology of the reservoir was sandstone, and formation of the field was Wabiskaw "A". The rate of oil production in this reservoir increases from 43 barrels of oil per day to 700 barrels of oil per day after implementing polymer flooding (Delamaide, 2014).

Most of the other polymer flooding projects include Rapdan (1986) in Southwest Saskatchewan. The rate of oil production from this reservoir increased from 8 cubic meters per day to 28 cubic meters per day. The East bodo project in Alberta contains 13 producers and 1 injector (Wassmuth et al., 2009). Polymer flooding project carried out in a heavy oil reservoir in the Tambaredjo oil field in Suriname had 9 producers and 3 injectors (Moe Soe Let et al., 2012). Table 2.3 below lists a number of polymer flooding projects active in Alberta since 2011.

Table 2.3 Active polymer flooding projects in Alberta since 2011 (Singhal, 2011)

\begin{tabular}{c|c|c|c}
\hline \multicolumn{1}{c}{ Company } & Formation & Field Name & Injection Type \\
\hline $\begin{array}{c}\text { Black pearl } \\
\text { Resources Ltd. }\end{array}$ & Bluesky A & Mooney & Polymer Flood \\
\hline $\begin{array}{c}\text { Harvest operations } \\
\text { Corp. }\end{array}$ & Upper Mannville U & Suffield & Polymer Flood \\
Cenovus Energy & Sparky JJ & Viking-Kinsella & Chemical Flood \\
Cenovus Energy & Upper Manville H & Countess & Polymer Flood \\
Harvest operations & Mainwright B & Viking-Kinsella & Polymer Flood \\
Corp. & Mannville B & Taber South & Polymer Flood \\
Husky Oil operations & Othabasca Oil Sands & Oil Sands Area & Polymer Flood \\
CNRL & Area & Oil Sands Area & Polym \\
Murphy Oil & $\begin{array}{c}\text { Peace River Oil Sands } \\
\text { Company Ltd. }\end{array}$ & Area & \\
\hline
\end{tabular}

\subsection{Polymer Flooding Projects Worldwide}

In the early 1960s, the first polymer flooding project was conducted in two fields of the USA (Albrecht and West Cat Canyon). The process was carried out with an injection of very small slug sizes of partially hydrolyzed polyacrylamide during water flooding. The pilot pattern consists of one injector and seven producers which increase the oil recovery rate from 100 STB/Day to 300 STB/Day after employing polymer flooding. The net estimated production rate was 95,000 STB with only 2600 lbs of the polymer being injected (Saboorian-Jooybari et al., 
2016). Most of the polymers flooding projects in heavy oil reservoir were carried out in China, few of them in USA, Canada, India, and Venezuela.

The success of polymer flooding projects also depends on the properties of polymers being injected in heavy oil reservoirs. Polymer flooding was first implemented on sandstone reservoirs. The first commercial production from the heavy oil reservoir was carried out in early 1960. Mostly, the polymer flooding is employed in China because of the extensive research studies and technological advancement has been done by China. Moreover, the resources for polymer flooding are available at low prices in China. Daqing oil field in northern China is the largest oil field in the world; the reservoir lithology is sandstone with zone thickness of 328 to $393 \mathrm{ft}$. The viscosity of the oil is in the range of $9-10 \mathrm{cP}$, the reservoir temperature is $113{ }^{\circ} \mathrm{F}$, and the overall ultimate oil recovery is about $15 \%$ (Lu et al., 2006).

Bohai Bay in China is one of the biggest viscous oil fields in the world and was discovered in 1987. After the six years of successful research studies, the field was put into commercial production in 1993. The incremental oil recovery from Bohai Bay field was 145,000 STB and this successful implementation has motivated the researchers to carry out more pilot tests and from 2005 to 2010 up to 52 pilot tests were conducted (Kang et al., 2011).

\subsection{Framework of this Research Study}

This research work contains both experimental and mathematical modeling (numerical simulation) parts of polymer flooding for an aqueous and oleic-phase multicomponent system that describes the displacement process in one-dimensional porous media. The components include oil, brine, and polymer. The oleic phase contains heavy oil, while the aqueous phase consists of brine and partially hydrolyzed water soluble polymer components. To that end, different set of experiments are carried out in a homogeneous physical reservoir model with uniform porosity and absolute permeability. The determination of the parameters (porosity, pore volume, permeability, heavy oil viscosity, and polymer solution viscosity) involved in polymer flooding process is achieved through one-dimensional injection experiments to provide adequate and reliable data to simulate polymer EOR process.

A detailed mathematical model consisting of partial differential equations for oleic and aqueous phase saturation, pressure and polymer concentration is developed. The model deals with several phenomena essential to flooding such as the effect of brine-polymer interactions on the viscosity, adsorption, periodic pressure variation, and polymer concentration on flooding performance. The control variables are the injection pressure and injection polymer 
concentration. These variables have direct influence on heavy oil recovery and will result in more mass of oil produced experimentally as these variables results in better sweep efficiency by controlling the mobility ratio between water-oil. The model has undetermined concentration and pressure function. Incorporating these functions into the complete model will predict the calculated mass of oil produced which should be equal to the experimental mass value obtained from the experiments. The necessary initial and boundary conditions are derived which would determine the extremal functional value to validate the proposed mathematical model with the experimental results obtained and illustrate the effectiveness of the polymer flooding model. Figure 2.7 shows a schematic of research methodology. 


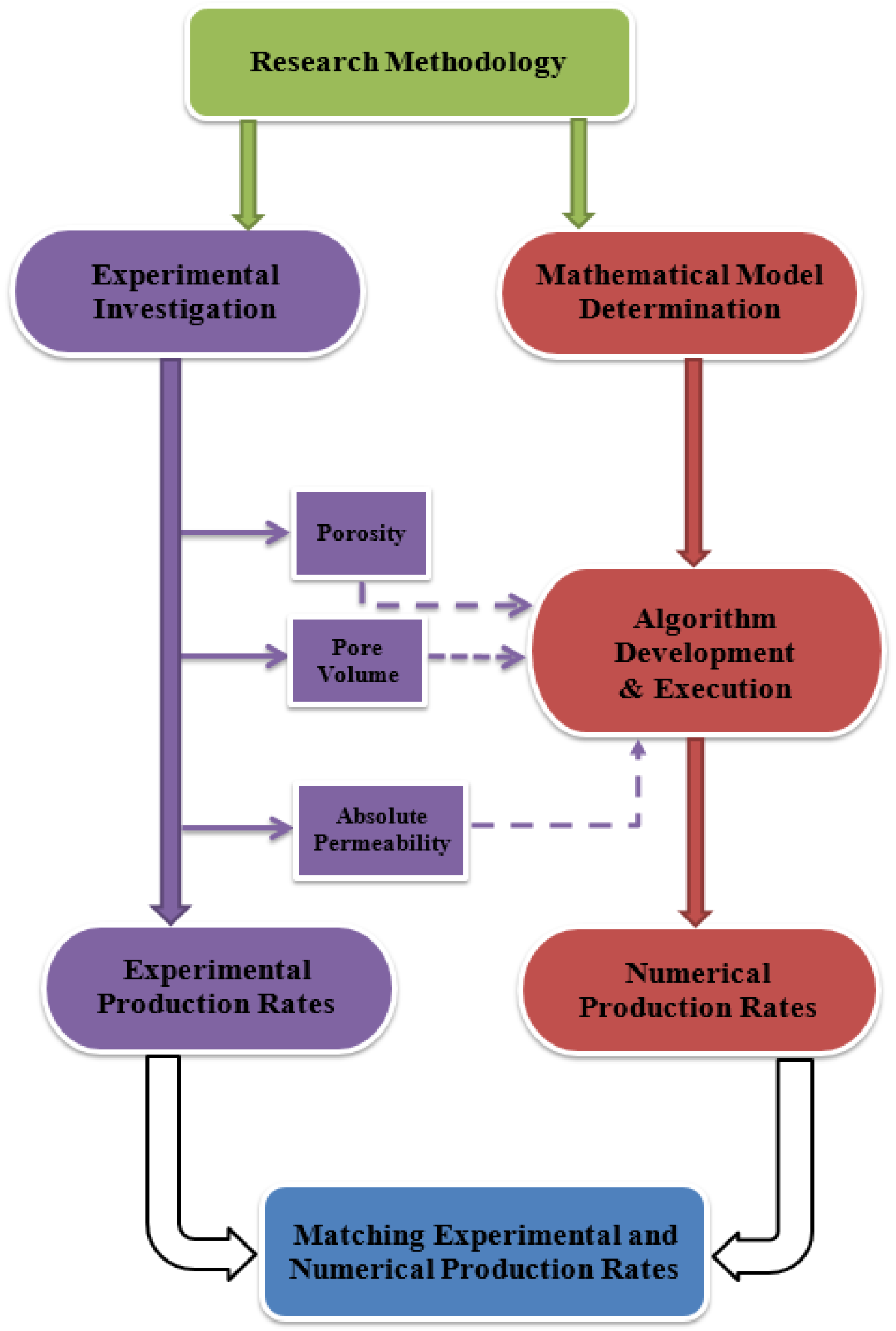

Figure 2.9 Schematic of research methodology 


\section{Experimental Work}

This chapter includes the detailed description of the experimental setup and procedures used to conduct 1-dimensional (axial) core flooding experiments with water soluble polymer. This chapter further explains the characteristics of different fluids used in this study, as well as the method of preparation of brine and polymer solution. The entire core flooding experiments are carried out on a laboratory scale physical reservoir model having a homogeneous porous media throughout the experiments to simulate the real world reservoir characteristics. Details of experimental determination of porosity, absolute permeability, pore volume, polymer, residual oil saturation, adsorption, and viscosity of polymer solutions are also incorporated. Data obtained from the polymer flooding experiments were used to analyze its technical feasibility, cumulative oil recovery, displacement efficiency, and field injection strategy as a function of pressure and polymer concentration. 


\subsection{Materials}

In this study the fluids utilized for the core flooding experiments are described in the section below;

\subsubsection{Preparation of Brine}

House hold table salt $(\mathrm{NaCl})$ was dissolved in tap water in order to create the solution which was used as the aqueous phase. Salt was added at $1 \mathrm{wt} \%(10,000 \mathrm{ppm})$; the solution was then stirred for 15 minutes using a magnetic stirrer at high speed. Once the salt had been dissolved the solution was then allowed to sit for at least 1 hour to ensure the air bubbles disappear. The brine was used for saturating the core and as a component in the polymer solution. Another purpose of using brine instead of fresh water was to mimic the real reservoir conditions.

Table 3.1 Properties of Brine used in this study

\begin{tabular}{cccc}
\hline \multicolumn{4}{c}{ Brine Preparation } \\
\hline Wt\% & Water & Salt & Brine \\
& $(\mathrm{g})$ & $(\mathrm{g})$ & $(\mathrm{g})$ \\
1 & 990 & 10 & 1000 \\
\hline
\end{tabular}

\subsubsection{Preparation of Polymer Solution}

The polymer FLOPAAM 3630 used in this study was supplied by SNF FLOERGER® in odorfree, white granular powder form. FLOPAAM 3630 is an anionic in nature and water soluble partially hydrolyzed polyacrylamide with a degree of hydrolysis $25-35 \mathrm{~mol} \%$. The average molecular weight of FLOPAAM 3630 was in the range of 15-25 MDalton. It is well known that polymers degrade over time, so a freshly prepared polymer solution was utilized in each run. First, polymer stock solution (5000 ppm concentration) was prepared. Initially, the $1 \mathrm{wt} \%$ brine was stirred using an overhead stirrer at 500 RPM in order to achieve a vortex. The HPAM polymer powder was then added gently at a constant rate to ensure that fish eyes or lumps would not form. The solution was stirred for 2 hours. Following stirring, the solution was allowed to settle down for 24 hours to ensure that no air bubbles were present. Using this $5000 \mathrm{ppm}$ stock solution, various desired polymer concentration ( 0.1 to $0.5 \mathrm{wt} \%)$ solutions were obtained through dilution. It was ensured that the polymer solution preparation method was done precisely and accurately to validate its efficiency over heavy oil recovery experiments. Preparation of FLOPAAM 3630 was done following the procedure provided by SNF 
FLOERGER®. Tables 3.2 and 3.3 below shows the characteristics of the polymer used in this research study.

Table 3.2 Properties of the polymer stock solution used in this study

\begin{tabular}{cccc}
\hline \multicolumn{4}{c}{ Mother Solution Preparation } \\
\hline $\begin{array}{c}\text { Initial Concentration } \\
(\mathrm{ppm})\end{array}$ & $\begin{array}{c}\text { FLOPAAM 3630 } \\
(\mathrm{g})\end{array}$ & $\begin{array}{c}\text { Brine } \\
(\mathrm{g})\end{array}$ & $\begin{array}{c}\text { Polymer Solution } \\
(\mathrm{g})\end{array}$ \\
5000 & 1.101018442 & 198.899 & 200 \\
& 5.50509221 & 994.495 & 1000 \\
\hline
\end{tabular}

Table 3.3 Characteristics of FLOPAAM 3630 used in this research study

\begin{tabular}{|c|c|c|c|c|c|}
\hline \multicolumn{6}{|c|}{ Polymer Properties } \\
\hline $\begin{array}{l}\text { Product } \\
\text { Name }\end{array}$ & $\begin{array}{l}\text { Relative } \\
\text { Density }\end{array}$ & $\begin{array}{l}\text { Active } \\
\text { Content }\end{array}$ & Ionic Nature & $\begin{array}{l}\text { Molecular } \\
\text { Weight }\end{array}$ & $\begin{array}{l}\text { Degree of } \\
\text { Hydrolysis }\end{array}$ \\
\hline $\begin{array}{l}\text { FLOPAAM } \\
3630\end{array}$ & $0.6-0.9$ & 0.90825 & anionic & $\begin{array}{l}15-25 \\
\text { MDalton }\end{array}$ & $25-35 \%$ \\
\hline
\end{tabular}

\subsubsection{Heavy Oil}

The heavy oil used in the present study was obtained from the Saskatchewan Research Council (SRC), Regina, Canada, having a viscosity of $14,500 \mathrm{mPa} s$ at $20^{\circ} \mathrm{C}$. The properties of the heavy oil are given in Table 3.4

Table 3.4 Properties of Heavy Oil used in this experimental study

\begin{tabular}{c|cc}
\hline \multicolumn{3}{c}{ Heavy Oil Properties } \\
\hline Density $\left(\mathbf{k g} / \mathbf{m}^{3}\right) @ 25^{\circ} \mathrm{C}$ & Viscosity (mPa s) & Mol Weight $(\mathrm{kg} / \mathrm{kmol})$ \\
977 & 14500 & 496 \\
\hline \multicolumn{3}{c}{ SARA (wt \%) } \\
\hline Saturates & 29 & \\
Aromatics & 31 & \\
Resins & 22 & \\
Asphaltene & 14 & \\
\hline
\end{tabular}




\subsubsection{Glass Beads}

The porous media used in the laboratory scale physical reservoir model for the experiment was glass beads to mimic the real reservoir characteristics. The glass beads were obtained from FlexO-Lite (supplied by BALLOTINI impact beads, Potters Industries LLC, Malvern, PA.). The specification of the packing material is shown in Table 3.5.

Table 3.5 Glass beads specifications used as a packing material in this experimental work (Abukhalifeh, 2010)

\begin{tabular}{|c|c|c|c|c|c|c|c|c|}
\hline $\begin{array}{c}\text { U.S } \\
\text { Sieve }\end{array}$ & $\begin{array}{c}\text { Product } \\
\text { (Flex- } \\
\text { O-Lite) }\end{array}$ & $\begin{array}{c}\text { Diameter } \\
\text { Max } \\
(\mathbf{m m})\end{array}$ & $\begin{array}{c}\text { Diameter } \\
\text { Min } \\
(\mathbf{m m})\end{array}$ & $\begin{array}{c}\text { U.S } \\
\text { sieve } \\
\text { size } \\
\text { Min } \\
95 \% \\
\text { Pass }\end{array}$ & $\begin{array}{c}\text { U.S } \\
\text { sieve } \\
\text { size } \\
\text { Max } \\
10 \% \\
\text { Pass }\end{array}$ & $\begin{array}{c}\text { Max } \\
3 \% \\
\text { Pass }\end{array}$ & $\begin{array}{c}\text { Min \% } \\
\text { True } \\
\text { Spheres }\end{array}$ & $\begin{array}{c}\text { Max \% } \\
\text { Sharp } \\
\text { Particles }\end{array}$ \\
\hline $30-40$ & BT 4 & 0.594 & 0.419 & 30 & 40 & 45 & 70 & 3 \\
\hline
\end{tabular}

\subsubsection{Core Cleaning Fluids}

Chemicals such as methanol, toluene, and varsol were used for the cleaning of cylindrical core. Methanol (dehydrating agent) was used for the removal of brine from the packed cylindrical core. The use of Methanol was strongly recommended by the two researchers Mwangi (2010) and Shetty (2011) over the strong dehydrating agents such as Acetone as it is incompatible with synthetic rubber and fluoropolymer elastomer Viton ${ }^{\circledR}$ seals. Varsol acts as oil thinner that helps to remove heavy oil from the core.

\subsection{Experimental Setup}

Figure 3.1 shows the schematic of the experimental setup that consists of different units such as tank unit for liquid holdup, injection \& delivery unit, cylindrical core unit, back pressure regulator, and data acquisition unit. The experimental apparatus designed in such a way that resembles the real world reservoir and recover the heavy oil from cylindrical core reservoir model by injecting the polymer solution of different concentrations at room temperature and varying pressures. The picture of the experimental setup is shown in figure 3.2. The setup consists of a tank to hold the polymer solution. It also consists of a Teledyne-ISCO syringe pump, transfer vessel, flow meters, valves, and joints that act as an injection and delivery unit. The Teledyne-ISCO 260D syringe pump consists of a single column that is connected to the flow valves that meters the continuous transfer of polymer solution from a tank to the sand pack 
holder. The maximum pressure rating of the pump is $7500 \mathrm{psi}$ and the flow rate range is 0.001 to a maximum of $107 \mathrm{ml} / \mathrm{min}$. The accuracy of the flow rate is $0.5 \%$ of set point. The maximum leakage rate of Teledyne-ISCO 260D syringe pump is $0.5 \mathrm{ul} / \mathrm{min}$. The capacity of the pump is $266 \mathrm{ml}$ and can bear a load (pressure $\times$ area) of 10147. The flow tubes, valves, and joints are made of aluminum and can withstand pressures of up to $5000 \mathrm{psi}$.

The displacing fluid from syringe pump is then delivered to the core unit which is a physical reservoir model (Swagelok $®$ steel sand pack holder). The core is cylindrical and measures 2.5 $\mathrm{cm}$ in diameter and $30 \mathrm{~cm}$ in length. At the inlet and outlet of the core is a stainless steel 200mesh screen present in order to ensure uniform distribution of the injected fluid through the porous media. The design of the core ensures the good reliability, adaptability, and compliance of the polymer flooding tests. The physical model is prepared from Fort Kent heavy oil (supplied by Saskatchewan Research Council, Saskatoon, Saskatchewan, Canada) having a viscosity of $14,500 \mathrm{mPa} \mathrm{s}$ at $20^{\circ} \mathrm{C}$ and glass beads (size range $0.594-0.419 \mathrm{~mm}$ ) supplied by (BALLOTINI impact beads, Potters Industries LLC, Malvern, PA). The physical model simulates homogeneous sand packed reservoir with a porosity of $38 \%$ and an average absolute permeability ranging from 8-9 Darcy.

Two pressure transducers (DP24-E, 4-20 mA, Omega Inc., Laval, Quebec, Canada) are installed at the inlet and outlet of the physical model for continuous monitoring and recording of differential pressure across the horizontally placed cylindrical core. The pressure transducer diaphragms are calibrated before the start of the experiment to ensure the accurate pressure changes in the system. 


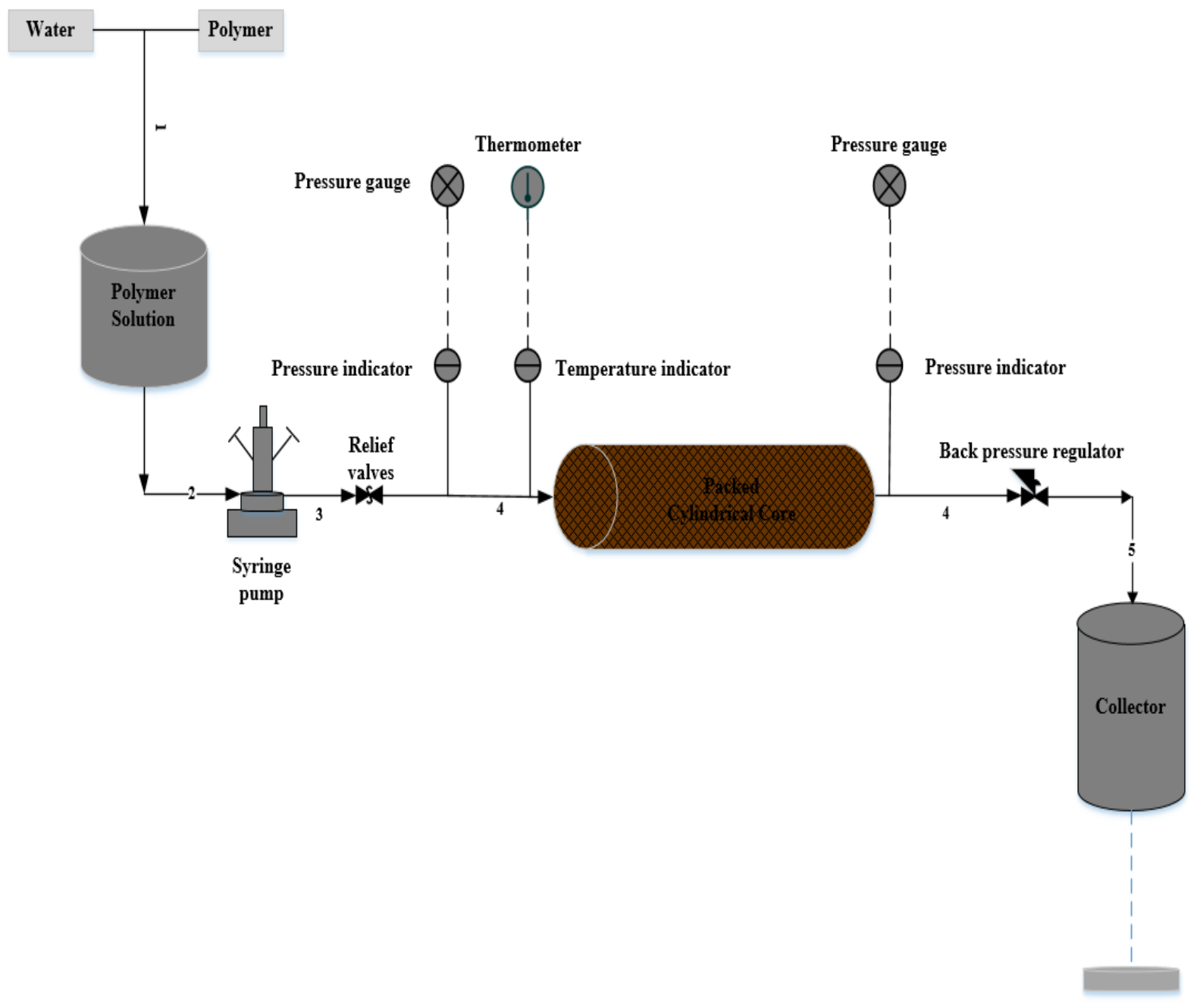

Figure 3.1 Schematic diagram of the polymer flooding experimental setup. The list of equipment in order are (1) tank, (2) syringe pump, (3) relief valves, (4) packed cylindrical core, and (5) collector.

The core unit is connected with a back pressure regulator (BPR) in which air is supplied from the air cylinder as shown in the schematic diagram. The purpose of supplying air is to provide constant system pressure resistance to the outlet of the core holder in order to maintain the same reservoir conditions. The back pressure regulator used in this study is manufactured by EQUILIBAR, with a maximum allowable pressure of 3000 PSIG. The tail end of the back pressure regulator is connected to the graduated beaker which is placed on the top of the weighing scale to collect and measure the heavy oil produced. The air coming out from the BPR vented to the atmosphere.

The instruments used in the experimental set up are connected via data acquisition unit that includes a personal computer in which all the analog input signals are transmitted. The input signals are transformed into the digital values interfaced with LabView ${ }^{\circledR}$ signal express version 7.1 software provided by National Instruments. The Data Acquisition System was used for the 
graphical user interface and online monitoring of the following inputs: (i) the temperature cylindrical core (ii) pressure difference across the core (iii) inlet flow rate of the polymer solution.

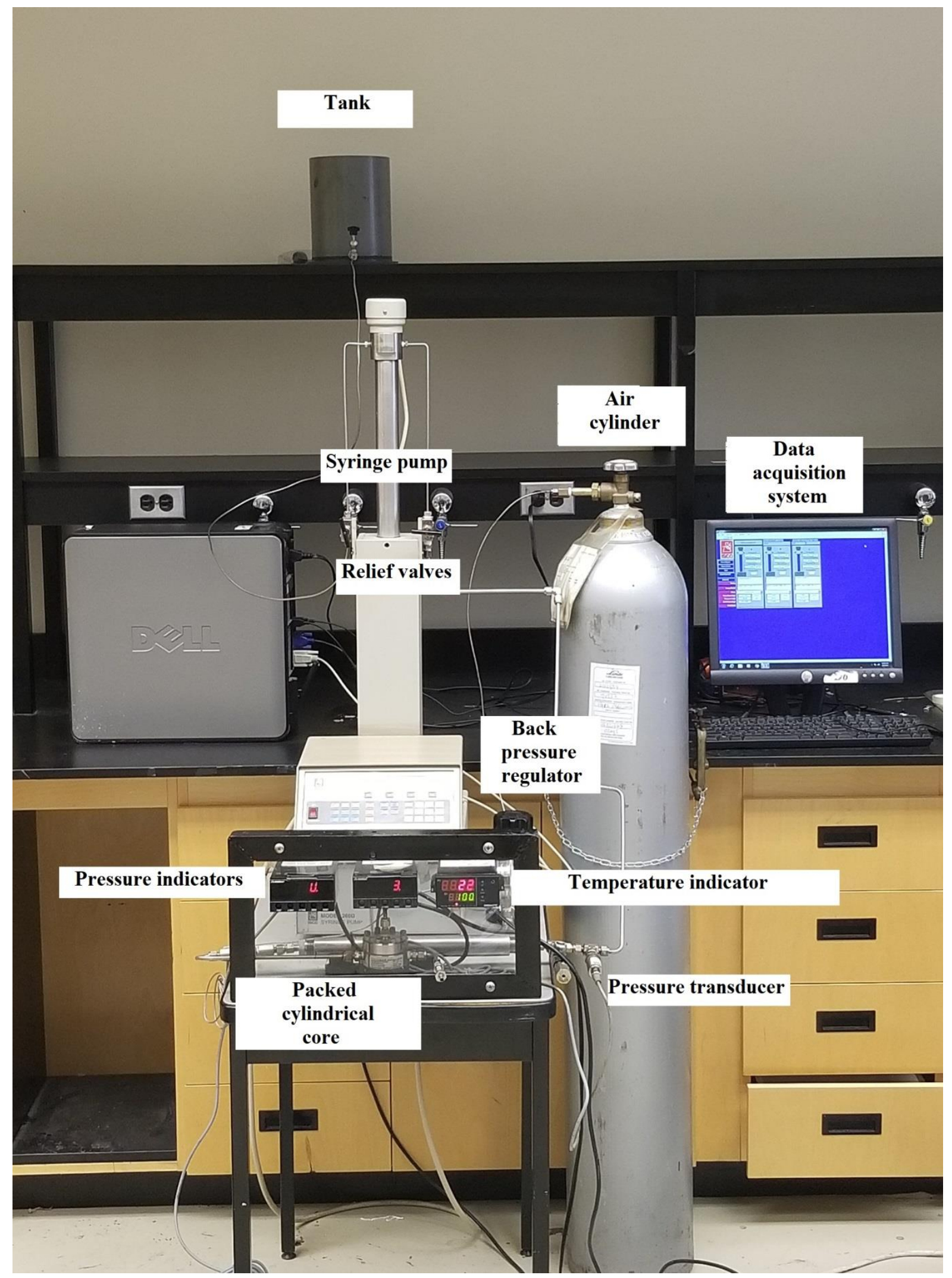

Figure 3.2 Picture of Polymer Flooding experimental set 


\subsection{Preparation of Lab-Scale Physical Model}

The physical model was prepared by mixing heavy oil with glass beads. The heavy oil used in the core flooding experiments has a viscosity of $14,500 \mathrm{mPa}$ at $20^{\circ} \mathrm{C}$. First, a known quantity of heavy oil (about $150 \mathrm{~g}$ ) was gently poured into the metallic container. The glass beads of known size $(0.594-0.419 \mathrm{~mm})$ were slowly mixed with the oil. The mixture containing heavy oil and glass beads were then stirred using a stirrer to ensure the uniform distribution of the glass beads within the oil.

The mixture was then allowed to settle down so that any bubbles that trapped during the physical model preparation would disappear and the maximum residence time was 45 min. After the glass beads were completely saturated with heavy oil, the mixture was moved into the cylindrical core and stainless steel mesh screen was fitted into the inlet and outlet ports of the physical model so that the injected fluid was uniformly distributed. Figures 3.3 a, b, c show the picture of glass beads with heavy oil for the preparation of physical model to perform experiments.

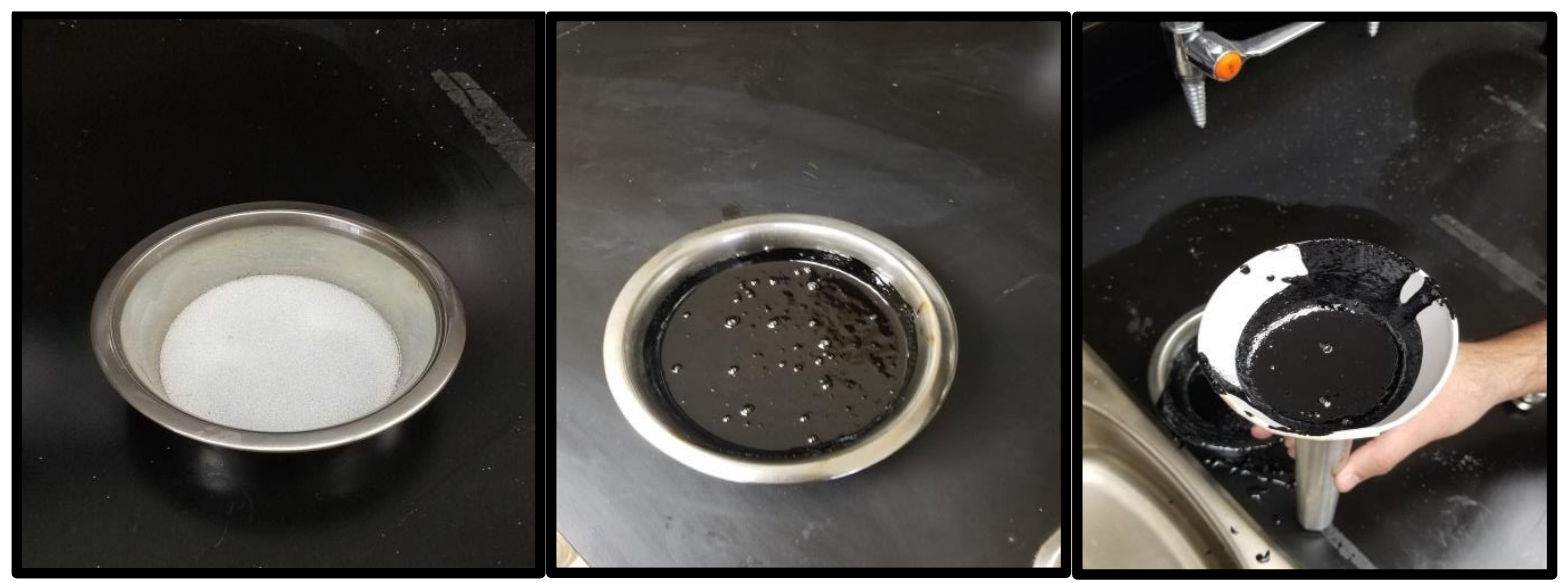

Figure 3.3.a,b,c Picture of glass beads, mixture of heavy oil \& glass beads, and preparation of physical model

\subsection{Core Flooding Experimental Procedure}

Before conducting each experiment, the cylindrical core was thoroughly cleaned with deionized water and varsol to ensure the removal of residues left behind from the previous run. The de-ionized water at constant flow rate $(1.0 \mathrm{ml} / \mathrm{min})$ was injected through high-pressure syringe pump to avoid the effect of polymer adsorbed within the porous media. The core cleaning was done to make sure all the experiments were run under the similar conditions. The 
core holder was then filled with fresh glass beads with size ranging from 0.594-0.419 $\mathrm{mm}$ that simulates the homogeneous unconsolidated sandstone porous media. After preparing the glass beads pack holder, the cylindrical core was connected to the mechanical vibrator for more than 30 minutes to ensure the tight packing. Then the glass beads packed holder was saturated with a known concentration of brine $(10,000 \mathrm{ppm})$ for wettability restoration. After the core holder was completely saturated with brine formation, the porosity, pore volume and absolute permeability with respect to brine were determined. The method used for the pore volume and porosity determination was fluid saturation method. First, the bulk volume of the core was measured by multiplying the length of the physical model with the area of the cylindrical core $(L \times A)$. Then the pore volume was determined by simply saturating the glass beads pack using $10000 \mathrm{ppm} \mathrm{NaCl}$ then injected $30000 \mathrm{ppm}$ brine at $0.5 \mathrm{ml} / \mathrm{min}$ and collected the effluent samples every 2 minutes (sample size of about $1 \mathrm{~mL}$ ). This method was continuously carried out until the exact volume of each test tube recorded; simultaneously the salinity was also measured using a salt refractometer (range 0-100 ppt) that gives the TDS of the measured sample. At first, the salinity was $10000 \mathrm{ppm}$, and then it increased when the $30000 \mathrm{ppm} \mathrm{NaCl}$ solution break through. The flood was stopped when the measured salinity became constant at $30000 \mathrm{ppm}$. Then plotted the cumulative volume of all tubes versus the normalized salinity, from the area above the curve we obtained the pore volume $\left(37.79 \mathrm{~cm}^{3}\right)$. The porosity of the porous media was measured to be (0.38) from the formula given below;

For absolute permeability determination, the brine was injected at a constant flow rate (1.0 $\mathrm{ml} / \mathrm{min}$ ) until the core was completely saturated. A constant pressure was supplied to the back pressure regulator. After the stabilized core pressure established across the each end of the core, the absolute permeability of the porous medium to $1 \mathrm{wt} \%$ brine was calculated by using Darcy's equation given as;

$$
K=\frac{Q \mu L}{A \Delta P} \times 1.01325 \times 10^{12}
$$

where $Q$ is the volumetric flow rate of the brine through the porous media, $A$ is the crosssectional area of the fluid flow through the media, $\mu$ is the viscosity of the brine, and $\Delta P$ is the differential pressure across the length of the core $L$. The corresponding values of all these parameters are listed in the appendix for a specific size range of glass beads $0.594-0.419 \mathrm{~mm}$. By substituting all these values in the equation above gives the absolute permeability of 8.75 Darcy. 
For core flooding concentration effect a mixture of heavy oil containing glass beads was transferred into the horizontally positioned cylindrical core at room temperature until the level was just below the mesh. The initial oil was generated in this manner; the core was then reconnected to the pump system while the feed tank was filled with the desired concentration (0.1-0.5 wt \%) of polymer solution which was injected into the porous media through the highpressure syringe pump. For all polymer concentrations, the pump was run in a constant injection mode at an injection pressure 1.03 MPa. Once the polymer injection began, time was started and the polymer injection flow rate was recorded every minute. Time of initial oil breakthrough as well as polymer break through was recorded. When the cylinder was emptied it was manually filled with the polymer at a flow rate of $75 \mathrm{ml} / \mathrm{min}$. This procedure was repeated until negligible oil cut (approximately 3\%) was obtained. A digital balance was placed below the emulsion collection beaker in order to approximate the mass of collected oil and polymer of each sweep. When the emulsion collection was completed, it was allowed to settle for some time such that the polymer and oil would separate themselves. The oil collected was measured once again and an oil recovery percentage was calculated. This same procedure was repeated for polymer concentrations of $0.2-0.5 \mathrm{wt} \%$. For each run, through of the experiment, a fresh glass beads pack holder was obtained through thorough cleaning of the system and holder initially using varsol as oil thinner and passing water through the system continuously until the water being output was almost pure. A similar procedure as described above was applied by keeping the maximum pressure at $3.44 \mathrm{MPa}$ and changing the polymer solution concentrations. Moreover, the periodic pressure variation from (2.41-3.44 MPa) was also studied by repeating the core flooding experimental procedure. The performance of polymer flooding process and the effects of concentration and pressure variations on heavy oil recovery were evaluated in a homogeneous glass beads packed reservoir.

\subsection{Polymer Solution Viscosity Measurement}

The steady state rheological evaluations of 0.1-0.5 wt \% HPAM polymer solutions in $1 \mathrm{wt} \%$ brine were carried out with a CVO 150 controlled stress rheometer (Malvern Instruments Ltd., Westborough, MA) with a C25 coaxial cylindrical geometry, using a software-driven protocol (Bohlin Software Package, Malvern Instruments Ltd., Westborough MA) in Fluid Mixing Technology Lab in Ryerson University. The solutions were centrifuged for 20 minutes at 2,200 rpm to remove any air bubbles present. After removing bubbles, the samples were put at rest for 12 hours prior to conducting the rheological measurements. Sample temperatures were controlled and maintained at $25 \pm 0.1{ }^{\circ} \mathrm{C}$ by a Peltier temperature-control system. Viscosity 
measurements were carried out at shear rates varying from $1 \mathrm{~s}^{-1}$ to $150 \mathrm{~s}^{-1}$. Steady shear behavior of partially hydrolyzed polymeric solutions was examined via stepped-flow protocol over the shear stress range of 10-25 Pa. After performing rheological measurements, to analyze data a plot of shear stress as a function of the shear rate was developed for all polymer solution samples with constant concentration of $1 \mathrm{wt} \%$ brine as an aqueous phase.

\subsection{Experimental Errors}

Table 3.6 shows the specification of the instruments used in this research study and the instrument's operational range and their accuracy.

\begin{tabular}{cccc}
\hline Instrument & Operational Usage & Range & Accuracy \\
\hline Pressure Transducer & $\begin{array}{c}\text { Pressure drop across } \\
\text { the core }\end{array}$ & $0-3000 \mathrm{psig}$ & $\pm 0.01 \%$ full scale \\
$\begin{array}{c}\text { Resistance } \\
\text { Temperature } \\
\text { Detector }\end{array}$ & $\begin{array}{c}\text { Temperature across } \\
\text { the physical model }\end{array}$ & $\begin{array}{c}0-250^{\circ} \mathrm{C} \\
0-2500 \mathrm{psig}\end{array}$ & $0.1 \%$ full scale \\
$\begin{array}{c}\text { Back Pressure } \\
\text { Regulator }\end{array}$ & Pressure vessel & $0-100^{\circ} \mathrm{C}$ & $0.5 \%$ \\
$\begin{array}{c}\text { Syringe Pump } \\
\text { Mlow metering }\end{array}$ & $0-3000 \mathrm{psig}$ & $0.5 \%$ of set point \\
Measuring Scale & $\begin{array}{c}\text { Heavy oil weight } \\
\text { measurement }\end{array}$ & $0-107 \mathrm{ml} / \mathrm{min}$ & $0.1 \%$ full scale \\
\hline
\end{tabular}




\section{4}

\section{Mathematical Model}

In this chapter, mathematical model of polymer flooding to maximize heavy oil production is developed, which is the primary objective of this research study. The mathematical model of polymer flooding process is a multi-objective problem, which requires the simultaneous measurements of several parameters such as porosity, pore volume, and permeability during the recovery operation. The determination of these parameters can be made successful through one-dimensional injection experiments in a porous media. The experimental data obtained during the oil production by polymer flooding are used in the simulation of the developed mathematical model to determine the polymer concentration, pressure, water, and oil saturations. By incorporating these parameters into the mathematical model, the model predicted oil production recoveries should be match with the experimental values. Finally, a numerical algorithm is needed to obtain a reliable dimensionless solution as a function of injection pressure and polymer concentration in heavy oil. 


\subsection{Mathematical Model of Polymer Flooding}

As previously mentioned, the flow of polymeric solution in a porous media is considered to be a complex phenomenon; therefore, it is desired to develop a detailed mathematical model for the lab-scale replica of the process in our laboratory. The mathematical model consisting of partial differential equations describes the physical process and consists of various parameters and variables which are involved in our lab-scale process to quantify and analyze them. The main interest is to investigate the necessary conditions, specifically of the polymer concentration and pressure variations in a non-reactive environment that may be used for heavy oil recovery.

The mathematical model adapted for simulations is a black oil model consisting of the two phase flow (oleic and polymer solution) as a function of time and $z$-coordinates. Hence, the system constituting the oil, and water saturation, pressure and polymer concentration mass balance is a cylindrical differential element of thickness $\Delta z$, respectively, along the $z$-direction.

\subsubsection{Model Assumptions}

The following set of model assumptions are as follows;

1. The fluid flow is isothermal

Polymer flooding experiments were carried out at constant temperature with standard deviation of $0.01^{\circ} \mathrm{C}$.

2. Liquids are non-volatile.

3. There are only two fluid phases (oleic \& aqueous) and three species are involved throughout the process i.e. (oil, water, and polymer)

4. The heavy oil is insoluble in polymer solution and thermal equilibrium exists between oleic and aqueous phase.

5. No chemical and biological reaction takes places between the species.

6. Adsorption of polymer takes place on the solid matrix inside the cylindrical core, resulting from the bulk flow and dispersion mechanism of the mass transport.

7. The porous medium has uniform porosity and permeability. Thus, gravity and capillary pressure effects are negligible.

The glass beads used in this experimental work are uniformly sized spheres and have same particle size distribution within the physical reservoir model. Thus, the physical model has uniform permeability and no heterogeneities occur. 
8. The bulk flow along the $z$-direction is governed by the Darcy's law in a porous medium.

9. The density of the heavy oil is constant throughout the process.

\subsection{Model Formulation}

To determine the oleic, and water saturation, polymer concentration, and pressure we need the law of conservation of mass, and Darcy's law. Based on these assumptions, the conservation of mass equations for each component can be written as below. The detailed derivation of mathematical model can be found in Appendix D.

\section{Pressure Equation}

$$
\begin{aligned}
& \frac{\partial P}{\partial t}=\frac{K K_{\mathrm{ro}}}{\mu_{\mathrm{o}} \varphi C_{\mathrm{T}}}\left[\frac{\partial^{2} P}{\partial z^{2}}\right]+\left[\frac{K}{\mu_{\mathrm{o}} \varphi C_{\mathrm{T}}}\left(\frac{n_{o} K_{\mathrm{ro}, \mathrm{cw}}}{1-S_{\mathrm{wc}}-S_{\mathrm{or}}}\right)\left(\frac{S_{\mathrm{o}}-S_{\mathrm{or}}}{1-S_{\mathrm{wc}}-S_{\mathrm{or}}}\right)^{n_{o}-1} \frac{\partial S_{\mathrm{o}}}{\partial z} \frac{\partial P}{\partial z}\right]+ \\
& \frac{K K_{\mathrm{rw}}}{R_{\mathrm{k}} \mu_{\mathrm{p}} \varphi C_{\mathrm{T}}}\left[\frac{\partial^{2} P}{\partial z^{2}}\right]+\left[\frac{K}{R_{\mathrm{k}} \mu_{\mathrm{p}} \varphi C_{\mathrm{T}}}\left(\frac{n_{w} K_{\mathrm{rw}, \mathrm{ro}}}{1-S_{\mathrm{wc}}-S_{\mathrm{or}}}\right)\left(\frac{S_{\mathrm{W}}-S_{\mathrm{wc}}}{1-S_{\mathrm{wc}}-S_{\mathrm{or}}}\right)^{n_{w}-1} \frac{\partial S_{\mathrm{w}}}{\partial z} \frac{\partial P}{\partial z}-\right. \\
& \frac{K K_{\mathrm{rw}}}{R_{\mathrm{k}} \mu_{\mathrm{p}} \varphi C_{\mathrm{T}}} \frac{\partial C}{\partial z} \frac{\partial P}{\partial z}\left(\left(\frac{\left(R_{\mathrm{kmax}} b_{\mathrm{rk}}-b_{\mathrm{rk}}\right)}{R_{\mathrm{k}}\left(1+b_{\mathrm{rk}} \cdot C\right)^{2}}\right)+\right. \\
& \left.\left.\left(\frac{\left(\mu_{\mathrm{w}} a p_{1}+2 \mu_{\mathrm{w}} a p_{2} \cdot C+3 \mu_{\mathrm{w}} a p_{3} \cdot C^{2}\right)}{\mu_{\mathrm{p}}}\right)\right)\right]
\end{aligned}
$$

\section{Oleic Flow Equation}

$$
\begin{aligned}
& \frac{\partial S_{\mathrm{o}}}{\partial t}=\frac{K K_{\mathrm{ro}}}{\mu_{\mathrm{o}} \varphi}\left[\frac{\partial^{2} P}{\partial z^{2}}\right]+\left[\frac{K}{\mu_{\mathrm{o}} \varphi}\left(\frac{n_{\mathrm{o}} K_{\mathrm{ro}, \mathrm{cw}}}{1-S_{\mathrm{wc}}-S_{\mathrm{or}}}\right)\left(\frac{S_{\mathrm{o}}-S_{\mathrm{or}}}{1-S_{\mathrm{wc}}-S_{\mathrm{or}}}\right)^{n_{o}-1} \frac{\partial S_{\mathrm{o}}}{\partial z} \frac{\partial P}{\partial z}+\right. \\
& \left.\frac{K K_{\mathrm{ro}}}{\mu_{\mathrm{o}} \varphi} C_{\mathrm{o}} \frac{\partial^{2} P}{\partial z^{2}}\right]
\end{aligned}
$$

\section{Aqueous Flow Equation}

$$
\begin{aligned}
& \frac{\partial S_{\mathrm{w}}}{\partial t}=\frac{K K_{\mathrm{rw}}}{R_{\mathrm{k}} \mu_{\mathrm{p}} \varphi}\left[\frac{\partial^{2} P}{\partial z^{2}}\right]+ \\
& {\left[\frac{K}{R_{\mathrm{k}} \mu_{\mathrm{p}} \varphi}\left(\frac{n_{w} K_{\mathrm{rw}, \mathrm{ro}}}{1-S_{\mathrm{wc}}-S_{\mathrm{or}}}\right)\left(\frac{S_{\mathrm{w}}-S_{\mathrm{wc}}}{1-S_{\mathrm{wc}}-S_{\mathrm{or}}}\right)^{n_{w}-1} \frac{\partial S_{\mathrm{w}}}{\partial z} \frac{\partial P}{\partial z}+\frac{K K_{\mathrm{rw}}}{R_{\mathrm{k}} \mu_{\mathrm{p}} \varphi} C_{\mathrm{w}} \frac{\partial^{2} P}{\partial z^{2}}-\right.} \\
& \left.\frac{K K_{\mathrm{rw}}}{R_{\mathrm{k}} \mu_{\mathrm{p}} \varphi} \frac{\partial P}{\partial z} \frac{\partial C}{\partial z}\left(\frac{\left(R_{\mathrm{kmax}} b_{\mathrm{rk}}-b_{\mathrm{rk}}\right)}{R_{\mathrm{k}}\left(1+b_{\mathrm{rk}} \cdot C\right)^{2}}\right)+\left(\frac{\left(\mu_{\mathrm{w}} a p_{1}+2 \mu_{\mathrm{w}} a p_{2} \cdot C+3 \mu_{\mathrm{w}} a p_{3} \cdot C^{2}\right)}{\mu_{p}}\right)\right]
\end{aligned}
$$




\section{Polymer Concentration Equation}

$$
\begin{aligned}
& \frac{\partial C}{\partial t}=D f_{\mathrm{a}}\left[\frac{\partial^{2} C}{\partial z^{2}}\right]+\frac{D f_{\mathrm{a}} \varphi_{\mathrm{r}} C_{\mathrm{R}}}{\varphi} \frac{\partial C}{\partial z} \frac{\partial P}{\partial z}+\frac{K K_{\mathrm{rw}} C}{R_{\mathrm{k}} \mu_{\mathrm{p}} \varphi}\left[\frac{\partial^{2} P}{\partial z^{2}}\right]+ \\
& {\left[\frac{K C}{R_{\mathrm{k}} \mu_{\mathrm{p}} \varphi}\left(\frac{n_{w} K_{\mathrm{rw}, \mathrm{ro}}}{1-S_{\mathrm{wc}}-S_{\mathrm{or}}}\right)\left(\frac{S_{\mathrm{w}}-S_{\mathrm{wc}}}{1-S_{\mathrm{wc}}-S_{\mathrm{or}}}\right)^{n_{w}-1} \frac{\partial S_{\mathrm{w}}}{\partial z} \frac{\partial P}{\partial z}-\right.} \\
& \frac{K K_{\mathrm{rw}} C}{R_{\mathrm{k}} \mu_{\mathrm{p}} \varphi}\left(\frac{\partial C}{\partial z}\right)\left(\frac{\partial P}{\partial z}\right)\left(\left(\frac{\left(R_{\mathrm{kmax}} b_{\mathrm{rk}}-b_{\mathrm{rk}}\right)}{R_{\mathrm{k}}\left(1+b_{\mathrm{rk}} \cdot C\right)^{2}}\right)+\right. \\
& \left.\left.\left(\frac{\mu_{\mathrm{w}} a p_{1}+2 \mu_{\mathrm{w}} a p_{2} \cdot C+3 \mu_{\mathrm{w}} a p_{3} \cdot C^{2}}{\mu_{\mathrm{p}}}\right)\right)\right]
\end{aligned}
$$

where $P(t, z), S_{o}(t, z), S_{w}(t, z)$, and $C(t, z)$ is the pressure, concentration of the polymer solution, oil, and water phase saturation, which is a function of time, and length of the porous medium. $K$ is the absolute permeability, $K_{\mathrm{ro}}$ is the oil relative permeability, $K_{\mathrm{rw}}$ is the water relative permeability, $\varphi$ is the porosity of the porous medium, $\mu_{\mathrm{o}}$ is the viscosity of the heavy oil. The bulk flow of polymer solution is along $z$-direction governed by Darcy velocity, and diffusion is negligible along radial direction. Initially there is no polymer solution injection inside the cylindrical core and no heavy oil production at the beginning so that the initial length of cylindrical core is $Z_{\mathrm{o}}$. Thus, the initial conditions at $t=0$ are

$$
\begin{aligned}
& S_{o}(z, 0), S_{w}(z, 0), P(z, 0), C(z, 0)= \\
& S_{\text {o ini }}, S_{\text {w ini }}, P_{\text {ini }}, C_{\text {ini }} \text { at }\left\{\begin{array}{lll}
r=0, & \forall & 0 \leq z \leq Z \\
z=0, & \forall & 0 \leq r<R
\end{array}\right.
\end{aligned}
$$

The boundary conditions for $t \geq 0$ are

$$
\begin{aligned}
& S_{o}(z, t), S_{w}(z, t), P(z, t), C(z, t)= \\
& S_{\text {o ini }}, S_{\text {wini }}, P_{\text {ini }}, C_{\text {ini }} \quad \text { at }\left\{\begin{aligned}
r=0, & \forall 0 \leq z \leq Z(r, t) \\
z=0, Z(r, t) & \forall 0 \leq r<R
\end{aligned}\right. \\
& \frac{\partial S_{o}}{\partial r}=0, \frac{\partial S_{w}}{\partial r}=0, \frac{\partial P}{\partial r}=0, \frac{\partial C}{\partial r}=0 \quad \text { at } \quad r=0 \quad \forall \quad 0 \leq z<Z(r, t) \\
& \frac{\partial S_{o}}{\partial Z}=0, \frac{\partial S_{w}}{\partial Z}=0, \frac{\partial P}{\partial Z}=0, \frac{\partial C}{\partial Z}=0 \quad \text { at } \quad z=Z \quad \forall \quad 0 \leq r<R(z, t)
\end{aligned}
$$

At any time, the cumulative mass of produced oil from the final boundary of porous medium is given by 


\subsection{Numerical Approach}

The above mathematical model consists of non-linear partial differential equations that cannot be solved analytically. In this study, the problem is solved numerically using finite differences. We implement second order high accuracy central and backward finite-divided-difference formula along $z$-direction that results in the discretization of the partial differential equations into ordinary differential equations with time as independent variable. With $N_{\mathrm{j}}$ grid points along $z$-direction as shown in Figure 4.1, the discretized finite-differenced ordinary differential equations are as follows:

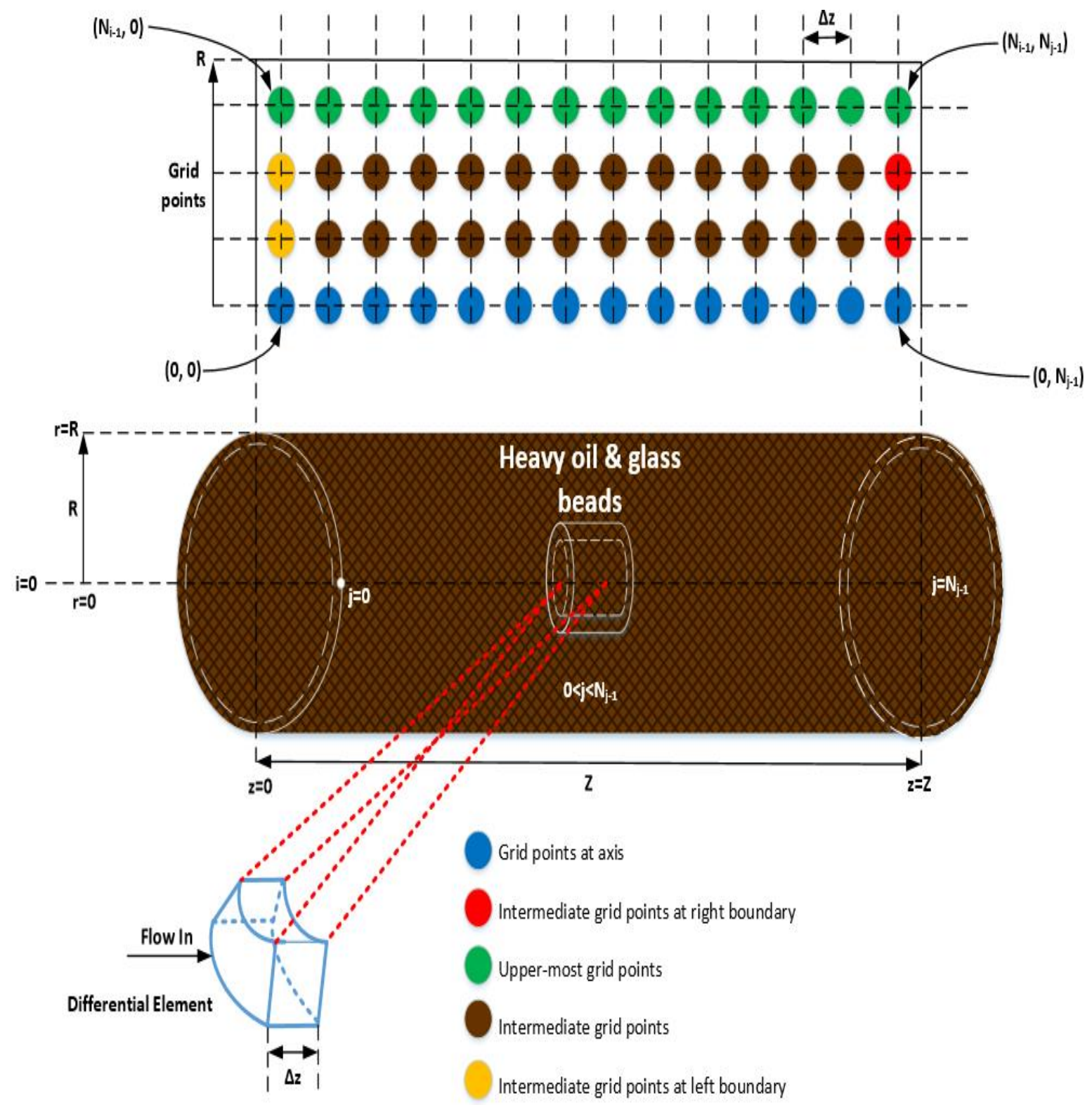

Figure 4.1 Physical reservoir model with differential element and the arrangement of grid points 


\subsubsection{Finite Difference for conversion of PDE to ODE for Oleic Phase Equation:}

The oleic phase equation is discretized by the central and backward finite-divided-difference formula for the conversion of PDE to ODE in a cylindrical porous media.

\section{For Intermediate Grid Points:}

For $0<j<\left(N_{j-1}\right)$;

$$
\begin{aligned}
& \frac{\partial S_{o(j)}}{\partial t}=\frac{K K_{r o}}{\mu_{o} \varphi}\left[\frac{P_{j+1}-2 P_{j}+P_{j-1}}{\Delta z^{2}}\right]+ \\
& {\left[\frac{K}{\mu_{o} \varphi}\left(\frac{n_{o} K_{r o, c w}}{1-S_{w c}-S_{o r}}\right)\left(\frac{S_{o}-S_{o r}}{1-S_{w c}-S_{o r}}\right)^{n_{o}-1} \frac{S_{o j+1}-S_{o j-1}}{2 \Delta z} \frac{P_{j+1}-P_{j-1}}{2 \Delta z}+\frac{K K_{r o}}{\mu_{o} \varphi} C_{o} \frac{P_{j+1}-2 P_{j}+P_{j-1}}{\Delta z^{2}}\right]}
\end{aligned}
$$

\section{For Axis Grid Points:}

when $j=0$;

$$
\begin{aligned}
& \frac{\partial S_{o(\mathbf{0})}}{\partial t}=\frac{K K_{r o}}{\mu_{o} \varphi}\left[\frac{P_{1}-2 P_{0}+P_{(\text {inlet })}}{\Delta z^{2}}\right]+ \\
& {\left[\frac{K}{\mu_{o} \varphi}\left(\frac{n_{o} K_{r o, c w}}{1-S_{w c}-S_{o r}}\right)\left(\frac{S_{o}-S_{o r}}{1-S_{w c}-S_{o r}}\right)^{n_{o}-1} \frac{S_{o_{1}}-S_{o_{(\text {inlet })}}}{2 \Delta z} \frac{P_{1}-P_{(\text {inlet })}}{2 \Delta z}+\right.} \\
& \left.\frac{K K_{r o}}{\mu_{o} \varphi} C_{o} \frac{P_{1}-2 P_{0}+P_{(\text {inlet })}}{\Delta z^{2}}\right]
\end{aligned}
$$

when $j=\left(N_{j}-1\right)$;

$$
\begin{aligned}
& \frac{\partial S_{o\left(N_{j-1}\right)}}{\partial t}=\frac{K K_{r o}}{\mu_{o} \varphi}\left[\frac{2 P_{\left(N_{j-1}\right)}-5 P_{\left(N_{j-2}\right)}+4 P_{\left(N_{j-3}\right)}-P_{\left(N_{j-4}\right)}}{\Delta z^{2}}\right]+ \\
& {\left[\frac{K}{\mu_{o} \varphi}\left(\frac{n_{o} K_{r o, c w}}{1-S_{w c}-S_{o r}}\right)\left(\frac{S_{o}-S_{o r}}{1-S_{w c}-S_{o r}}\right)^{n_{o}-1} \frac{3 S_{o\left(N_{j-1}\right)}-4 S_{o}\left(N_{j-2}\right)}{2 \Delta z}+S_{o}\left(N_{j-3}\right)\right.} \\
& \frac{K K_{r o}}{\mu_{o} \varphi} C_{o} \frac{2 P_{\left(N_{j-1}\right)}-5 P_{\left(N_{j-2}\right)}+4 P_{\left(N_{j-3}\right)}-P_{\left(N_{j-4}\right)}-4 P_{\left(N_{j-2}\right)}+P_{\left(N_{j-3}\right)}}{\Delta z^{2}}+
\end{aligned}
$$




\subsubsection{Finite Difference for conversion of PDE to ODE for Aqueous Phase Equation:}

The aqueous phase equation is discretized by the central and backward finite-divideddifference formula for the conversion of PDE to ODE in a cylindrical porous media.

\section{For Intermediate Grid Points:}

For $0<j<\left(N_{j-1}\right)$;

$$
\begin{aligned}
& \frac{\partial S_{w(j)}}{\partial t}=\frac{K K_{r w}}{R_{k} \mu_{p} \varphi}\left[\frac{P_{j+1}-2 P_{j}+P_{j-1}}{\Delta z^{2}}\right]+ \\
& {\left[\frac{K}{R_{k} \mu_{p} \varphi}\left(\frac{n_{w} K_{r w, r o}}{1-S_{w c}-S_{o r}}\right)\left(\frac{S_{w}-S_{w c}}{1-S_{w c}-S_{o r}}\right)^{n_{w}-1} \frac{S_{w j+1}-S_{w j-1}}{2 \Delta z} \frac{P_{j+1}-P_{j-1}}{2 \Delta z}+\right.} \\
& \frac{K K_{r w}}{R_{k} \mu_{p} \varphi} C_{w} \frac{P_{j+1}-2 P_{j}+P_{j-1}}{\Delta z^{2}}-\frac{K K_{r w}}{R_{k} \mu_{p} \varphi} \frac{P_{j+1}-P_{j-1}}{2 \Delta z} \frac{C_{j+1}-C_{j-1}}{2 \Delta z}\left(\frac{\left(R_{k m a x} b_{r k}-b_{r k}\right)}{R_{k}\left(1+b_{r k} \cdot C\right)^{2}}\right)+ \\
& \left.\left(\frac{\left(\mu_{w} a p_{1}+2 \mu_{w} a p_{2} \cdot C+3 \mu_{w} a p_{3} \cdot C^{2}\right)}{\mu_{p}}\right)\right]
\end{aligned}
$$

\section{For Axis Grid Points:}

when $j=0$;

$$
\begin{aligned}
& \frac{\partial S_{w(0)}}{\partial t}=\frac{K K_{r w}}{R_{k} \mu_{p} \varphi}\left[\frac{P_{1}-2 P_{0}+P_{(\text {inlet })}}{\Delta z^{2}}\right]+ \\
& {\left[\frac{K}{R_{k} \mu_{p} \varphi}\left(\frac{n_{w} K_{r w, r o}}{1-S_{w c}-S_{o r}}\right)\left(\frac{S_{w}-S_{w c}}{1-S_{w c}-S_{o r}}\right)^{n_{w}-1} \frac{S_{w_{1}}-S_{w_{(i n l e t)}}}{2 \Delta z} \frac{P_{1}-P_{(\text {inlet })}}{2 \Delta z}+\right.} \\
& \frac{K K_{r w}}{R_{k} \mu_{p} \varphi} C_{w} \frac{P_{1}-2 P_{0}+P_{(\text {inlet })}}{\Delta z^{2}}-\frac{K K_{r w}}{R_{k} \mu_{p} \varphi} \frac{P_{1}-P_{(\text {inlet })}}{2 \Delta z} \frac{C_{1}-C_{(\text {inlet })}}{2 \Delta z}\left(\frac{\left(R_{k m a x} b_{r k}-b_{r k}\right)}{R_{k}\left(1+b_{r k} \cdot C\right)^{2}}\right)+ \\
& \left.\left(\frac{\left(\mu_{w} a p_{1}+2 \mu_{w} a p_{2} \cdot C+3 \mu_{w} a p_{3} \cdot C^{2}\right)}{\mu_{p}}\right)\right]
\end{aligned}
$$

when $j=\left(N_{j}-1\right)$;

$$
\begin{aligned}
& \frac{\partial S_{w\left(N_{j-1}\right)}}{\partial t}=\frac{K K_{r w}}{R_{k} \mu_{p} \varphi}\left[\frac{2 P_{\left(N_{j-1}\right)}-5 P_{\left(N_{j-2}\right)}+4 P_{\left(N_{j-3}\right)}-P_{\left(N_{j-4}\right)}}{\Delta z^{2}}\right]+ \\
& {\left[\frac{K}{R_{k} \mu_{p} \varphi}\left(\frac{n_{w} K_{r w, r o}}{1-S_{w c}-S_{o r}}\right)\left(\frac{S_{w}-S_{w c}}{1-S_{w c}-S_{o r}}\right) n_{w}-1 \frac{3 S_{w_{\left(N_{j-1}\right)}}-4 S_{w_{\left(N_{j-2}\right)}}+S_{w_{\left(N_{j-3}\right)}}}{2 \Delta z} \frac{3 P_{\left(N_{j-1}\right)}-4 P_{\left(N_{j-2}\right)}+P_{\left(N_{j-3}\right)}}{2 \Delta z}+\right.} \\
& \frac{K K_{r w}}{R_{k} \mu_{p} \varphi} C_{w} \frac{2 P_{\left(N_{j-1}\right)}-5 P_{\left(N_{j-2}\right)}+4 P_{\left(N_{j-3}\right)}-P_{\left(N_{j-4}\right)}}{\Delta z^{2}}- \\
& \frac{K K_{r w}}{R_{k} \mu_{p} \varphi} \frac{3 P_{\left(N_{j-1}\right)}-4 P_{\left(N_{j-2}\right)}+P_{\left(N_{j-3}\right)}}{2 \Delta z} \frac{3 C_{\left(N_{j-1}\right)}-4 C_{\left(N_{j-2}\right)}+C_{\left(N_{j-3}\right)}}{2 \Delta z}\left(\frac{\left(R_{k m a x} b_{r k}-b_{r k}\right)}{R_{k}\left(1+b_{r k} \cdot C\right)^{2}}\right)+ \\
& \left.\left(\frac{\left(\mu_{w} a p_{1}+2 \mu_{w} a p_{2} \cdot C+3 \mu_{w} a p_{3} \cdot C^{2}\right)}{\mu_{p}}\right)\right]
\end{aligned}
$$




\subsubsection{Finite Difference for conversion of PDE to ODE for Pressure Equation:}

The pressure equation is discretized by the central and backward finite-divided-difference formula for the conversion of PDE to ODE in a cylindrical porous media.

\section{For Intermediate Grid Points:}

For $0<j<\left(N_{j-1}\right)$;

$$
\begin{aligned}
& \frac{\partial P_{(j)}}{\partial t}=\frac{K K_{r o}}{\mu_{o} \varphi C_{T}}\left[\frac{P_{j+1}-2 P_{j}+P_{j-1}}{\Delta z^{2}}\right]+ \\
& {\left[\frac{K}{\mu_{o} \varphi C_{T}}\left(\frac{n_{o} K_{r o, c w}}{1-S_{w c}-S_{o r}}\right)\left(\frac{S_{o}-S_{o r}}{1-S_{w c}-S_{o r}}\right)^{n_{o}-1} \frac{S_{o_{j+1}}-S_{o j-1}}{2 \Delta z} \frac{P_{j+1}-P_{j-1}}{2 \Delta z}\right]+} \\
& \frac{K K_{r w}}{R_{k} \mu_{p} \varphi C_{T}}\left[\frac{P_{j+1}-2 P_{j}+P_{j-1}}{\Delta z^{2}}\right]+ \\
& {\left[\frac{K}{R_{k} \mu_{p} \varphi C_{T}}\left(\frac{n_{w} K_{r w, r o}}{1-S_{w c}-S_{o r}}\right)\left(\frac{S_{w}-S_{w c}}{1-S_{w c}-S_{o r}}\right)^{n_{w}-1} \frac{S_{w_{j+1}}-S_{w_{j-1}}}{2 \Delta z} \frac{P_{j+1}-P_{j-1}}{2 \Delta z}-\right.} \\
& \left.\frac{K K_{r w}}{R_{k} \mu_{p} \varphi C_{T}} \frac{P_{j+1}-P_{j-1}}{2 \Delta z} \frac{C_{j+1}-C_{j-1}}{2 \Delta z}\left(\left(\frac{\left(R_{k m a x} b_{r k}-b_{r k}\right)}{R_{k}\left(1+b_{r k} \cdot C\right)^{2}}\right)+\left(\frac{\left(\mu_{w} a p_{1}+2 \mu_{w} a p_{2} \cdot C+3 \mu_{w} a p_{3} \cdot C^{2}\right)}{\mu_{p}}\right)\right)\right]
\end{aligned}
$$

\section{For Axis Grid Points:}

when $j=0$;

$$
\begin{aligned}
& \frac{\partial P_{(0)}}{\partial t}=\frac{K K_{r o}}{\mu_{o} \varphi C_{T}}\left[\frac{P_{1}-2 P_{0}+P_{(\text {inlet })}}{\Delta z^{2}}\right]+ \\
& {\left[\frac{K}{\mu_{o} \varphi C_{T}}\left(\frac{n_{o} K_{r o, c w}}{1-S_{w c}-S_{o r}}\right)\left(\frac{S_{o}-S_{o r}}{1-S_{w c}-S_{o r}}\right)^{n_{o}-1} \frac{S_{o_{1}}-S_{o_{(i n l e t)}}}{2 \Delta z} \frac{P_{1}-P_{(\text {inlet })}}{2 \Delta z}\right]+} \\
& \frac{K K_{r w}}{R_{k} \mu_{p} \varphi C_{T}}\left[\frac{P_{1}-2 P_{0}+P_{(\text {inlet })}}{\Delta z^{2}}\right]+ \\
& {\left[\frac{K}{R_{k} \mu_{p} \varphi C_{T}}\left(\frac{n_{w} K_{r w, r o}}{1-S_{w c}-S_{o r}}\right)\left(\frac{S_{w}-S_{w c}}{1-S_{w c}-S_{o r}}\right)^{n_{w}-1} \frac{S_{w_{1}}-S_{w(\text { inlet })}}{2 \Delta z} \frac{P_{1}-P_{(\text {inlet })}}{2 \Delta z}-\right.} \\
& \left.\frac{K K_{r w}}{R_{k} \mu_{p} \varphi C_{T}} \frac{P_{1}-P_{(\text {inlet })}}{2 \Delta z} \frac{C_{1}-C_{(\text {inlet })}}{2 \Delta z}\left(\left(\frac{\left(R_{k m a x} b_{r k}-b_{r k}\right)}{R_{k}\left(1+b_{r k} \cdot C\right)^{2}}\right)+\left(\frac{\left(\mu_{w} a p_{1}+2 \mu_{w} a p_{2} \cdot C+3 \mu_{w} a p_{3} \cdot C^{2}\right)}{\mu_{p}}\right)\right)\right]
\end{aligned}
$$


when $j=\left(N_{j}-1\right)$;

$$
\begin{aligned}
& \frac{\partial P\left(N_{j-1}\right)}{\partial t}=\frac{K K_{r o}}{\mu_{o} \varphi C_{T}}\left[\frac{2 P_{\left(N_{j-1}\right)}-5 P_{\left(N_{j-2}\right)}+4 P_{\left(N_{j-3}\right)}-P_{\left(N_{j-4}\right)}}{\Delta z^{2}}\right]+ \\
& {\left[\frac{K}{\mu_{o} \varphi C_{T}}\left(\frac{n_{o} K_{r o, c w}}{1-S_{w c}-S_{o r}}\right)\left(\frac{S_{o}-S_{o r}}{1-S_{w c}-S_{o r}}\right)^{n_{o}-1} \frac{3 S_{o\left(N_{j-1}\right)}-4 S_{o\left(N_{j-2}\right)}+S_{o\left(N_{j-3}\right)}}{2 \Delta z} \frac{3 P_{\left(N_{j-1}\right)}-4 P_{\left(N_{j-2}\right)}+P_{\left(N_{j-3}\right)}}{2 \Delta z}\right]+} \\
& \frac{K K_{r w}}{R_{k} \mu_{p} \varphi C_{T}}\left[\frac{2 P_{\left(N_{j-1}\right)}-5 P_{\left(N_{j-2}\right)}+4 P_{\left(N_{j-3}\right)}-P_{\left(N_{j-4}\right)}}{\Delta z^{2}}\right]+ \\
& {\left[\frac{K}{R_{k} \mu_{p} \varphi C_{T}}\left(\frac{n_{w} K_{r w, r o}}{1-S_{w c}-S_{o r}}\right)\left(\frac{S_{W}-S_{w c}}{1-S_{w c}-S_{o r}}\right) \frac{n_{w}-13 S_{w\left(N_{j-1}\right)}-4 S_{w\left(N_{j-2}\right)}+S_{w\left(N_{j-3}\right)}}{2 \Delta z} \frac{3 P_{\left(N_{j-1}\right)}-4 P_{\left(N_{j-2}\right)}+P_{\left(N_{j-3}\right)}}{2 \Delta z}-\right.} \\
& \frac{K K_{r w}}{R_{k} \mu_{p} \varphi C_{T}} \frac{3 P_{\left(N_{j-1}\right)}-4 P\left(N_{j-2}\right)}{2 \Delta z}+P_{\left(N_{j-3}\right)} \frac{3 C_{\left(N_{j-1}\right)}-4 C_{\left(N_{j-2}\right)}+C_{\left(N_{j-3}\right)}}{2 \Delta z}\left(\left(\frac{\left(R_{k m a x} b_{r k}-b_{r k}\right)}{R_{k}\left(1+b_{r k} \cdot C\right)^{2}}\right)+\right. \\
& \left.\left.\left(\frac{\left(\mu_{w} a p_{1}+2 \mu_{w} a p_{2} \cdot C+3 \mu_{w} a p_{3} \cdot C^{2}\right)}{\mu_{p}}\right)\right)\right]
\end{aligned}
$$




\subsubsection{Finite Difference for conversion of PDE to ODE for Polymer Concentration}

\section{Equation:}

The polymer concentration equation is discretized by the central and backward finite-divideddifference formula for the conversion of PDE to ODE in a cylindrical porous media.

\section{For Intermediate Grid Points:}

For $0<j<\left(N_{j-1}\right)$;

$$
\begin{aligned}
& \frac{\partial C_{(j)}}{\partial t}=D f_{a}\left[\frac{C_{j+1}-2 C_{j}+C_{j-1}}{\Delta z^{2}}\right]+\frac{D f_{a} \varphi_{r} C_{R}}{\varphi} \frac{P_{j+1}-P_{j-1}}{2 \Delta z} \frac{C_{j+1}-C_{j-1}}{2 \Delta z}+\frac{K K_{r w} C}{R_{k} \mu_{p} \varphi} \frac{P_{j+1}-2 P_{j}+P_{j-1}}{\Delta z^{2}}+ \\
& {\left[\frac{K C}{R_{k} \mu_{p} \varphi}\left(\frac{n_{w} K_{r w, r o}}{1-S_{w c}-S_{o r}}\right)\left(\frac{S_{w}-S_{w c}}{1-S_{w c}-S_{o r}}\right)^{n_{w}-1} \frac{S_{w_{j+1}}-S_{w_{j-1}}}{2 \Delta z} \frac{P_{j+1}-P_{j-1}}{2 \Delta z}-\right.} \\
& \left.\frac{K K_{r w} C}{R_{k} \mu_{p} \varphi} \frac{P_{j+1}-P_{j-1}}{2 \Delta z} \frac{C_{j+1}-C_{j-1}}{2 \Delta z}\left(\left(\frac{\left(R_{k m a x} b_{r k}-b_{r k}\right)}{R_{k}\left(1+b_{r k} \cdot C\right)^{2}}\right)+\left(\frac{\mu_{w} a p_{1}+2 \mu_{w} a p_{2} \cdot C+3 \mu_{w} a p_{3} \cdot C^{2}}{\mu_{p}}\right)\right)\right]
\end{aligned}
$$

\section{For Axis Grid Points:}

when $j=0$;

$$
\begin{aligned}
& \frac{\partial C_{(0)}}{\partial t}=D f_{a}\left[\frac{C_{1}-2 C_{0}+C_{(\text {inlet })}}{\Delta z^{2}}\right]+\frac{D f_{a} \varphi_{r} C_{R}}{\varphi} \frac{P_{1}-P_{(\text {inlet })}}{2 \Delta z} \frac{C_{1}-C_{(\text {inlet })}}{2 \Delta z}+ \\
& \frac{K K_{r w} C}{R_{k} \mu_{p} \varphi}\left[\frac{P_{1}-2 P_{0}+P_{(\text {inlet })}}{\Delta z^{2}}\right]+ \\
& {\left[\frac{K C}{R_{k} \mu_{p} \varphi}\left(\frac{n_{w} K_{r w, r o}}{1-S_{w c}-S_{o r}}\right)\left(\frac{S_{w}-S_{w c}}{1-S_{w c}-S_{o r}}\right)^{n_{w}-1} \frac{S_{w_{1}}-S_{w(\text { inlet })}}{2 \Delta z} \frac{P_{1}-P_{(\text {inlet })}}{2 \Delta z}-\right.} \\
& \left.\frac{K K_{r w} C}{R_{k} \mu_{p} \varphi} \frac{P_{1}-P_{(\text {inlet })}}{2 \Delta z} \frac{C_{1}-C_{(\text {inlet })}}{2 \Delta z}\left(\left(\frac{\left(R_{k \max } b_{r k}-b_{r k}\right)}{R_{k}\left(1+b_{r k} \cdot C\right)^{2}}\right)+\left(\frac{\mu_{w} a p_{1}+2 \mu_{w} a p_{2} \cdot C+3 \mu_{w} a p_{3} \cdot C^{2}}{\mu_{p}}\right)\right)\right]
\end{aligned}
$$


when $j=\left(N_{j}-1\right)$;

$$
\begin{aligned}
& \frac{\partial C_{\left(N_{j-1}\right)}}{\partial t}=D f_{a}\left[\frac{2 C_{\left(N_{j-1}\right)}-5 C_{\left(N_{j-2}\right)}+4 C_{\left(N_{j-3}\right)}-C_{\left(N_{j-4}\right)}}{\Delta z^{2}}\right]+ \\
& \frac{D f_{a} \varphi_{r} C_{R}}{\varphi} \frac{3 P_{\left(N_{j-1}\right)}-4 P_{\left(N_{j-2}\right)}+P_{\left(N_{j-3}\right)}}{2 \Delta z} \frac{3 C_{\left(N_{j-1}\right)}-4 C_{\left(N_{j-2}\right)}+C_{\left(N_{j-3}\right)}}{2 \Delta z}+ \\
& \frac{K K_{r w} C}{R_{k} \mu_{p} \varphi}\left[\frac{P_{\left(N_{j-1}\right)}-5 P_{\left(N_{j-2}\right)}+4 P_{\left(N_{j-3}\right)}-P_{\left(N_{j-4}\right)}}{\Delta z^{2}}+\right. \\
& {\left[\frac{K C}{R_{k} \mu_{p} \varphi}\left(\frac{n_{w} K_{r w, r o}}{1-S_{w c}-S_{o r}}\right)\left(\frac{S_{w}-S_{w c}}{1-S_{w c}-S_{o r}}\right)^{n_{w}-1} \frac{3 S_{\left.w_{(N-1}\right)}-4 S_{\left.w_{(N-2}\right)}+S_{w\left(N_{j-3}\right)}}{2 \Delta z} \frac{3 P_{\left(N_{j-1}\right)}-4 P_{\left(N_{j-2}\right)}+P_{\left(N_{j-3}\right)}}{2 \Delta z}-\right.} \\
& \frac{K K_{r w} C}{R_{k} \mu_{p} \varphi} \frac{\left.3 P_{\left(N_{j-1}\right)}-4 P_{\left(N_{j-2}\right)}+P_{\left(N_{j-3}\right)}\right)}{2 \Delta z} \frac{3 C_{\left(N_{j-1}\right)}-4 C_{\left(N_{j-2}\right)}+C_{\left(N_{j-3}\right)}}{2 \Delta z}\left(\left(\frac{\left(R_{k m a x} b_{r k}-b_{r k}\right)}{R_{k}\left(1+b_{r k} \cdot C\right)^{2}}\right)+\right. \\
& \left.\left.\left(\frac{\mu_{w} a p_{1}+2 \mu_{w} a p_{2} \cdot C+3 \mu_{w} a p_{3} \cdot C^{2}}{\mu_{p}}\right)\right)\right]
\end{aligned}
$$

\subsection{Scaling Analysis of Polymer Flooding Model}

The mathematical model consisting of partial differential equations describes the physical process. It consists of various variables and parameters which involved in the process are introduced into the mathematical model to quantify and analyze the physical and chemical quantities. Hence, all the variables and parameters in the mathematical model have some dimensions which are usually expressed in terms of units. Parameters involved in the model come as a result of constitutive equations as well as some algebraic equations and physical constraints. The scaling of the mathematical model is very essential in order to minimize the relative errors from the process. Scaling of mathematical model has numerous advantages and it involves the chain rule for differentiation to simplify the equations. With the help of scaling, one can easily transform the dimensional variables and parameters of the real process model into the dimensionless variables. Some of the advantages of the scaling of differential equations are listed below;

- With scaling we can have more command on the key parameters and variables of the physical process.

- With the proper utilization of scaling of the differential equations, the characteristic length and times of the problem can be specified to unity.

- Scaling can also reduce the number of parameters as compared to the ones in the original model. 
Due to the proper scaling of equations it is easy to understand which of the terms are important in the process and which are less important. In this way size of the original model will also be reduce and makes the mathematical model simpler.

\section{Scaled Oleic Flow Equation}

$$
\begin{aligned}
& \frac{\partial S_{\mathrm{o}}}{\partial t}=\frac{K K_{\mathrm{ro}}}{\mu_{\mathrm{o}} \varphi}\left[\frac{\partial^{2} P}{\partial z^{2}}\right]+\left[\frac{K}{\mu_{\mathrm{o}} \varphi}\left(\frac{n_{o} K_{r \mathrm{o}, \mathrm{cw}}}{1-S_{\mathrm{wc}}-S_{\mathrm{or}}}\right)\left(\frac{n_{o} K_{r \mathrm{o}, \mathrm{cw}}}{1-S_{\mathrm{wc}}-S_{\mathrm{or}}}\right)^{n_{o}-1} \frac{\partial S_{\mathrm{o}}}{\partial z} \frac{\partial P}{\partial z}+\frac{K K_{\mathrm{ro}}}{\mu_{\mathrm{o}} \varphi} C_{\mathrm{o}} \frac{\partial^{2} P}{\partial z^{2}}\right] \\
& \left\{\begin{array}{cc}
\tau=\frac{t}{t_{o}}, & \bar{z}=\frac{z}{\hat{z}} \\
\bar{P}=\frac{P}{\hat{P}}, & \bar{C}=\frac{C}{\hat{C}}
\end{array}\right\}
\end{aligned}
$$

Here, $\bar{Z}$ is the dimensionless axial coordinate, $\bar{P}$ is the dimensionless pressure, $\tau$ is the dimensionless time and $\bar{C}$ is the dimensionless concentration. With the above dimensionless variables, the oleic phase flow equation becomes;

$$
\begin{aligned}
& \frac{\partial S_{\mathrm{o}}}{\partial \tau} \frac{\partial \tau}{\partial t}=\frac{K K_{\mathrm{ro}}}{\mu_{\mathrm{o}} \varphi}[\underbrace{\frac{\partial^{2} P}{\partial z^{2}}}_{\alpha}]+[\frac{K}{\mu_{\mathrm{o}} \varphi}\left(\frac{n_{o} K_{r \mathrm{o}, \mathrm{cw}}}{1-S_{\mathrm{wc}}-S_{\mathrm{or}}}\right)\left(\frac{S_{o}-S_{o r}}{1-S_{w c}-S_{o r}}\right)^{n_{o}-1} \frac{\partial S_{\mathrm{o}}}{\partial \bar{z}} \frac{\partial \bar{z}}{\partial z} \frac{\partial \bar{P} \hat{P}}{\partial \bar{z}} \frac{\partial \bar{z}}{\partial z}+\frac{K K_{\mathrm{ro}}}{\mu_{\mathrm{o}} \varphi} C_{\mathrm{o}} \underbrace{\frac{\partial^{2} P}{\partial z^{2}}}_{\alpha}] \\
& \frac{\partial S_{\mathrm{o}}}{\partial \tau} \frac{1}{t_{o}}=\frac{K K_{\mathrm{ro}}}{\mu_{\mathrm{o}} \varphi}\left[\frac{1}{\hat{z}^{2}} \frac{\partial^{2} \bar{P} \hat{P}}{\partial \bar{z}^{2}}\right]+\left[\frac{K}{\mu_{\mathrm{o}} \varphi}\left(\frac{n_{o} K_{r \mathrm{o}, \mathrm{cw}}}{1-S_{\mathrm{wc}}-S_{\mathrm{or}}}\right)\left(\frac{S_{\mathrm{o}}-S_{\mathrm{or}}}{1-S_{\mathrm{wc}}-S_{\mathrm{or}}}\right)^{n_{o}-1} \frac{\partial S_{\mathrm{o}}}{\partial \bar{z}} \frac{1}{\hat{z}} \hat{P} \frac{\partial \bar{P}}{\partial \bar{z}} \frac{1}{\hat{z}}+\frac{K K_{r o}}{\mu_{o} \varphi} C_{o} \frac{1}{\hat{z}^{2}} \frac{\partial^{2} \bar{P} \hat{P}}{\partial \bar{z}^{2}}\right] \\
& \alpha=\frac{\partial^{2} P}{\partial Z^{2}} \rightarrow \frac{\partial^{2} \bar{P} \hat{P}}{\partial \bar{Z}^{-2} \hat{Z}^{2}} \\
& =\frac{\partial}{\partial \bar{z}}\left(\frac{\partial \bar{P}}{\underbrace{\bar{z}}_{\alpha}}\right) \\
& \therefore=\frac{\partial \alpha}{\partial \bar{z}} \\
& \alpha=\frac{\partial \bar{P}}{\partial \bar{Z}}=>\frac{1}{\hat{z}} \frac{\partial \bar{P}}{\partial \bar{Z}} \\
& \alpha=\frac{1}{\hat{z}} \frac{\partial \alpha}{\partial \bar{z}} \\
& \alpha=\frac{\hat{P}}{\hat{z}^{2}} \frac{\partial^{2} \bar{P}}{\partial \bar{z}^{2}} \\
& \frac{\partial S_{\mathrm{o}}}{\partial \tau}=\frac{K K_{\mathrm{ro}}}{\mu_{\mathrm{o}} \varphi} \frac{\hat{P} t_{o}}{\hat{z}^{2}}\left[\frac{\partial^{2} \bar{P}}{\partial \bar{z}^{2}}\right]+\left[\frac{K}{\mu_{\mathrm{o}} \varphi} \frac{\hat{P} t_{o}}{\hat{z}^{2}}\left(\frac{n_{o} K_{\mathrm{ro}, \mathrm{cw}}}{1-S_{\mathrm{wc}}-S_{\mathrm{or}}}\right)\left(\frac{S_{\mathrm{o}}-S_{\mathrm{or}}}{1-S_{\mathrm{wc}}-S_{\mathrm{or}}}\right)^{n_{o}-1} \frac{\partial S_{\mathrm{o}}}{\partial \bar{z}} \frac{\partial \bar{P}}{\partial \bar{z}}+\frac{K K_{\mathrm{ro}}}{\mu_{\mathrm{o}} \varphi} C_{\mathrm{o}} \frac{\hat{P} t_{o}}{\hat{z}^{2}} \frac{\partial^{2} \bar{P}}{\partial \bar{z}^{2}}\right]
\end{aligned}
$$




\section{Scaled Aqueous Phase Flow Equation}

$\frac{\partial S_{\mathrm{w}}}{\partial t}=\frac{K K_{\mathrm{rw}}}{R_{\mathrm{k}} \mu_{\mathrm{p}} \varphi}\left[\frac{\partial^{2} P}{\partial z^{2}}\right]+\left[\frac{K}{R_{\mathrm{k}} \mu_{\mathrm{p}} \varphi}\left(\frac{n_{w} K_{\mathrm{rw}, \mathrm{ro}}}{1-S_{\mathrm{wc}}-S_{\mathrm{or}}}\right)\left(\frac{S_{\mathrm{w}}-S_{\mathrm{wc}}}{1-S_{\mathrm{wc}}-S_{\mathrm{or}}}\right)^{n_{w}-1} \frac{\partial S_{\mathrm{w}}}{\partial z} \frac{\partial P}{\partial z}+\frac{K K_{\mathrm{rw}}}{R_{\mathrm{k}} \mu_{\mathrm{p}} \varphi} C_{\mathrm{w}} \frac{\partial^{2} P}{\partial z^{2}}-\right.$
$\left.\frac{K K_{\mathrm{rw}}}{R_{\mathrm{k}} \mu_{\mathrm{p}} \varphi} \frac{\partial P}{\partial z} \frac{\partial C}{\partial z} \frac{\left(1+b_{\mathrm{rk}} \cdot C\right)\left(R_{\mathrm{kmax}} b_{\mathrm{rk}}-b_{\mathrm{rk}}\right)-\left(R_{\mathrm{kmax}} b_{\mathrm{rk}}^{2} \cdot C-b_{\mathrm{rk} \cdot}^{2} \cdot C\right)}{R_{k}\left(1+b_{\mathrm{rk}} \cdot C\right)^{2}}+\left(\frac{\left(\mu_{\mathrm{w}} a p_{1}+2 \mu_{\mathrm{w}} a p_{2} \cdot C+3 \mu_{\mathrm{w}} a p_{3} \cdot C^{2}\right)}{\mu_{\mathrm{p}}}\right)\right]$

$\left\{\begin{array}{l}\tau=\frac{t}{t_{o}}, \bar{z}=\frac{z}{\hat{z}}, \\ \bar{P}=\frac{P}{\hat{P}}, \quad \bar{C}=\frac{C}{\hat{C}}\end{array}\right\}$

$\frac{\partial S_{\mathrm{w}}}{\partial \tau}=\frac{K K_{\mathrm{rw}}}{R_{\mathrm{k}} \mu_{\mathrm{p}} \varphi} \frac{\hat{P} t_{o}}{\hat{z}^{2}}\left[\frac{\partial^{2} \bar{P}}{\partial \bar{z}^{2}}\right]+\left[\frac{K}{R_{\mathrm{k}} \mu_{\mathrm{p}} \varphi} \frac{\hat{P} t_{o}}{\hat{z}^{2}}\left(\frac{n_{w} K_{\mathrm{rw}, \mathrm{ro}}}{1-S_{\mathrm{wc}}-S_{\mathrm{or}}}\right)\left(\frac{S_{\mathrm{w}}-S_{\mathrm{wc}}}{1-S_{\mathrm{wc}}-S_{\mathrm{or}}}\right)^{n_{w}-1} \frac{\partial S_{\mathrm{w}}}{\partial \bar{z}} \frac{\partial \bar{P}}{\partial \bar{z}}+\frac{K K_{\mathrm{rw}}}{R_{\mathrm{k}} \mu_{\mathrm{p}} \varphi} C_{\mathrm{w}} \frac{\hat{P} t_{o}}{\hat{z}^{2}} \frac{\partial^{2} \bar{P}}{\partial \bar{z}^{2}}-\right.$

$\left.\frac{K K_{\mathrm{rw}}}{R_{\mathrm{k}} \mu_{\mathrm{p}} \varphi} \frac{\hat{P} t_{o} \hat{C}}{\hat{z}^{2}} \frac{\partial \bar{P}}{\partial \bar{z}} \frac{\partial \bar{C}}{\partial \bar{z}}\left(\frac{\left(R_{\mathrm{kmax}} b_{\mathrm{rk}}-b_{\mathrm{rk}}\right)}{R_{\mathrm{k}}\left(1+b_{\mathrm{rk}} \cdot \hat{C} \bar{C}\right)^{2}}\right)+\left(\frac{\left(\mu_{\mathrm{w}} a p_{1}+2 \mu_{\mathrm{w}} a p_{2} \cdot \hat{C} \bar{C}+3 \mu_{\mathrm{w}} a p_{3} \cdot \hat{C}^{2} \bar{C}^{2}\right)}{\mu_{p}}\right)\right]$

\section{Scaled Pressure Equation}

$$
\begin{aligned}
& \frac{\partial P}{\partial t}=\frac{K K_{\mathrm{ro}}}{\mu_{\mathrm{o}} \varphi C_{\mathrm{T}}}\left[\frac{\partial^{2} P}{\partial z^{2}}\right]+\left[\frac{K}{\mu_{\mathrm{o}} \varphi C_{\mathrm{T}}}\left(\frac{n_{o} K_{\mathrm{ro}, \mathrm{cw}}}{1-S_{\mathrm{wc}}-S_{\mathrm{or}}}\right)\left(\frac{S_{\mathrm{o}}-S_{\mathrm{or}}}{1-S_{\mathrm{wc}}-S_{\mathrm{or}}}\right)^{n_{o}-1} \frac{\partial S_{\mathrm{o}}}{\partial z} \frac{\partial P}{\partial z}\right]+\frac{K K_{\mathrm{rw}}}{R_{\mathrm{k}} \mu_{\mathrm{p}} \varphi C_{\mathrm{T}}}\left[\frac{\partial^{2} P}{\partial z^{2}}\right]+ \\
& {\left[\frac{K}{R_{\mathrm{k}} \mu_{\mathrm{p}} \varphi C_{\mathrm{T}}}\left(\frac{n_{w} K_{\mathrm{rw}, \mathrm{ro}}}{1-S_{\mathrm{wc}}-S_{\mathrm{or}}}\right)\left(\frac{S_{\mathrm{w}}-S_{\mathrm{wc}}}{1-S_{\mathrm{wc}}-S_{\mathrm{or}}}\right)^{n_{w}-1} \frac{\partial S_{\mathrm{w}}}{\partial z} \frac{\partial P}{\partial z}-\frac{K K_{\mathrm{rw}}}{R_{\mathrm{k}} \mu_{\mathrm{p}} \varphi C_{\mathrm{T}}} \frac{\partial C}{\partial z} \frac{\partial P}{\partial z}\left(\left(\frac{\left(R_{\mathrm{kmax}} b_{\mathrm{rk}}-b_{\mathrm{rk}}\right)}{R_{\mathrm{k}}\left(1+b_{\mathrm{rk}} \cdot C\right)^{2}}\right)+\right.\right.} \\
& \left.\left.\left(\frac{\left(\mu_{\mathrm{w}} a p_{1}+2 \mu_{\mathrm{w}} a p_{2} \cdot C+3 \mu_{\mathrm{w}} a p_{3} \cdot C^{2}\right)}{\mu_{\mathrm{p}}}\right)\right)\right] \\
& \left\{\begin{array}{l}
\tau=\frac{t}{t_{o}}, \bar{z}=\frac{z}{\hat{z}}, \\
\bar{P}=\frac{P}{\hat{P}}, \bar{C}=\frac{C}{\hat{C}}
\end{array}\right\} \\
& \frac{\partial \bar{P}}{\partial \tau}=\frac{K K_{\mathrm{ro}}}{\mu_{\mathrm{o}} \varphi C_{T}} \frac{t_{o}}{\hat{z}^{2}}\left[\frac{\partial^{2} \bar{P}}{\partial \bar{z}^{2}}\right]+\left[\frac{K}{\mu_{\mathrm{o}} \varphi C_{T}} \frac{t_{o}}{\hat{z}^{2}}\left(\frac{n_{o} K_{\mathrm{ro}, \mathrm{cw}}}{1-S_{\mathrm{wc}}-S_{\mathrm{or}}}\right)\left(\frac{S_{\mathrm{o}}-S_{\mathrm{or}}}{1-S_{\mathrm{wc}}-S_{\mathrm{or}}}\right)^{n_{o}-1} \frac{\partial S_{\mathrm{o}}}{\partial \bar{z}} \frac{\partial \bar{P}}{\partial \bar{z}}\right]+\frac{K K_{\mathrm{rw}}}{R_{\mathrm{k}} \mu_{\mathrm{p}} \varphi C_{\mathrm{T}}} \frac{t_{o}}{\hat{z}^{2}}\left[\frac{\partial^{2} \bar{P}}{\partial \bar{z}^{2}}\right]+ \\
& {\left[\frac{K}{R_{\mathrm{k}} \mu_{\mathrm{p}} \varphi C_{\mathrm{T}}} \frac{t_{o}}{\hat{Z}^{2}}\left(\frac{n_{w} K_{\mathrm{rw}, \mathrm{ro}}}{1-S_{\mathrm{wc}}-S_{\mathrm{or}}}\right)\left(\frac{S_{\mathrm{w}}-S_{\mathrm{wc}}}{1-S_{\mathrm{wc}}-S_{\mathrm{or}}}\right)^{n_{w}-1} \frac{\partial S_{\mathrm{w}}}{\partial \bar{z}} \frac{\partial \bar{P}}{\partial \bar{z}}-\frac{K K_{\mathrm{rw}}}{R_{\mathrm{k}} \mu_{\mathrm{p}} \varphi C_{\mathrm{T}}} \frac{\hat{C} t_{o}}{\hat{z}^{2}} \frac{\partial \bar{C}}{\partial \bar{z}} \frac{\partial \bar{P}}{\partial \bar{z}}\left(\left(\frac{\left(R_{\mathrm{kmax}} b_{\mathrm{rk}}-b_{\mathrm{rk}}\right)}{R_{\mathrm{k}}\left(1+b_{\mathrm{rk}} \cdot \hat{C} \bar{C}\right)^{2}}\right)+\right.\right.} \\
& \left.\left.\left(\frac{\left(\mu_{\mathrm{w}} a p_{1}+2 \mu_{\mathrm{w}} a p_{2} \cdot \hat{C} \bar{C}+3 \mu_{\mathrm{w}} a p_{3} \cdot \hat{C}^{2} \bar{C}^{2}\right)}{\mu_{\mathrm{p}}}\right)\right)\right]
\end{aligned}
$$




\section{Scaled Polymer Component Flow Equation}

$\frac{\partial C}{\partial t}=D f_{\mathrm{a}}\left[\frac{\partial^{2} C}{\partial z^{2}}\right]+\frac{D f_{\mathrm{a}} \varphi_{\mathrm{r}} C_{\mathrm{R}}}{\varphi} \frac{\partial C}{\partial z} \frac{\partial P}{\partial z}+\frac{K K_{\mathrm{rw}} C}{R_{\mathrm{k}} \mu_{\mathrm{p}} \varphi}\left[\frac{\partial^{2} P}{\partial z^{2}}\right]+\left[\frac{K C}{R_{\mathrm{k}} \mu_{\mathrm{p}} \varphi}\left(\frac{n_{w} K_{\mathrm{rw}, \mathrm{ro}}}{1-S_{\mathrm{wc}}-S_{\mathrm{or}}}\right)\left(\frac{S_{\mathrm{w}}-S_{\mathrm{wc}}}{1-S_{\mathrm{wc}}-S_{\mathrm{or}}}\right)^{n_{w}-1} \frac{\partial S_{\mathrm{w}}}{\partial z} \frac{\partial P}{\partial z}-\right.$ $\left.\frac{K K_{\mathrm{rw}} C}{R_{\mathrm{k}} \mu_{\mathrm{p}} \varphi}\left(\frac{\partial C}{\partial z}\right)\left(\frac{\partial P}{\partial z}\right)\left(\left(\frac{\left(R_{\mathrm{kmax}} b_{\mathrm{rk}}-b_{\mathrm{rk}}\right)}{R_{\mathrm{k}}\left(1+b_{\mathrm{rk}} \cdot C\right)^{2}}\right)+\left(\frac{\mu_{\mathrm{w}} a p_{1}+2 \mu_{\mathrm{w}} a p_{2} \cdot C+3 \mu_{\mathrm{w}} a p_{3} \cdot C^{2}}{\mu_{\mathrm{p}}}\right)\right)\right]$

$\left\{\begin{array}{l}\tau=\frac{t}{t_{o}}, \bar{z}=\frac{z}{\hat{z}} \\ \bar{P}=\frac{P}{\hat{P}}, \bar{C}=\frac{C}{\hat{C}}\end{array}\right\}$

$\frac{\partial \bar{C}}{\partial \tau}=D f_{\mathrm{a}} \frac{t_{o}}{\hat{z}^{2}}\left[\frac{\partial^{2} \bar{C}}{\partial \bar{z}^{2}}\right]+\frac{D f_{\mathrm{a}} \varphi_{\mathrm{r}} C_{\mathrm{R}}}{\varphi} \frac{t_{o} \hat{P}}{\hat{z}^{2}} \frac{\partial \bar{C}}{\partial \bar{z}} \frac{\partial \bar{P}}{\partial \bar{z}}+\frac{K K_{\mathrm{rw}} \bar{C}}{R_{\mathrm{k}} \mu_{\mathrm{p}} \varphi} \frac{t_{o} \hat{P}}{\hat{z}^{2}}\left[\frac{\partial^{2} \bar{P}}{\partial \bar{z}^{2}}\right]+$

$\left[\frac{K \bar{C}}{R_{\mathrm{k}} \mu_{\mathrm{p}} \varphi} \frac{t_{o} \hat{P}}{\hat{z}^{2}}\left(\frac{n_{w} K_{\mathrm{rw}, \mathrm{ro}}}{1-S_{\mathrm{wc}}-S_{\mathrm{or}}}\right)\left(\frac{S_{\mathrm{w}}-S_{\mathrm{wc}}}{1-S_{\mathrm{wc}}-S_{\mathrm{or}}}\right)^{n_{w}-1} \frac{\partial S_{\mathrm{w}}}{\partial \bar{z}} \frac{\partial \bar{P}}{\partial \bar{z}}-\frac{K K_{\mathrm{rw}} \hat{C} \bar{C}}{R_{\mathrm{k}} \mu_{\mathrm{p}} \varphi} \frac{t_{o} \hat{P}}{\hat{z}^{2}}\left(\frac{\partial \bar{C}}{\partial \bar{z}}\right)\left(\frac{\partial \bar{P}}{\partial \bar{z}}\right)\left(\left(\frac{\left(R_{\mathrm{kmax}} b_{\mathrm{rk}}-b_{\mathrm{rk}}\right)}{R_{\mathrm{k}}\left(1+b_{\mathrm{rk}} \cdot \bar{C} \hat{C}\right)^{2}}\right)+\right.\right.$ $\left.\left.\left(\frac{\mu_{\mathrm{w}} a p_{1}+2 \mu_{\mathrm{w}} a p_{2} \cdot \bar{C} \hat{C}+3 \mu_{\mathrm{w}} a p_{3} \cdot \hat{C}^{2} \bar{C}^{2}}{\mu_{\mathrm{p}}}\right)\right)\right]$ 


\section{Results and Discussion}

In this chapter, the results of Polymer Flooding experiments carried out on a laboratory scale physical reservoir model having a homogeneous porous media and the numerical results will be presented and discussed. The effects of two main parameters on heavy oil recovery is investigated. The first parameter is the polymer concentration and the second parameter is the pressure. As mentioned previously, experiments were conducted using a laboratory scale physical model of heavy oil of $14,500 \mathrm{mPa}$ s viscosity at $20^{\circ} \mathrm{C}$ temperature and pressure in the range of 1.03-3.44 MPa with different polymer concentration solutions (0.1-0.5 wt \%). Under these conditions, the cumulative heavy oil production was recorded. To check the reproducibility of the oil production, polymer flooding experiments with periodic pressure injection were selected and repeated. The final time standard deviation from the repeated experiments were found to be in the range of $\pm 0.124-0.275 \%$ OOIP with different polymer concentration solutions. 


\subsection{Experimental Results and Discussion}

This section presents the results of different experiments carried out to recover heavy oil from physical reservoir models using polymer solution injection. First, we conducted experiments to determine the rheological properties of the polymer solutions which are in conjunction with the solution properties. Next, we performed experiments to determine the porosity and absolute permeability measurements. Lastly, we carried out experiments with different concentration polymer solutions (0.1-0.5 wt \%) at a constant pressure of $1.03 \mathrm{MPa}$. Then, we did experiments with different pressure injections in the range of 1.03-3.44 MPa with (i) constant maximum pressure 3.44 MPa and (ii) periodic pressure variations (2.41-3.44 MPa) with time. The maximum pressure injection of the displacing fluid was $3.44 \mathrm{MPa}$ in the experiments. All the experiments were conducted at room temperature $23^{\circ} \mathrm{C}$.

\subsubsection{Effect of Polymer Concentration on Solution Viscosity}

Figure 5.1 shows the steady-state shear viscosity of different concentrations $(0.1-0.5 \mathrm{wt} \%)$ of partially hydrolyzed polyacrylamide solution with $1 \mathrm{wt} \%$ brine against the shear rate at $25 \pm 0.1^{\circ} \mathrm{C}$. In a low shear rate region, the shear viscosities show an obvious increase with concentration. The apparent viscosities show the shear-thinning effect with an increasing shear rate up to $150 \mathrm{~s}^{-1}$ due to the presence of repulsive electrostatic or steric force between particles. The high shear rates break down the delicate structure of the polymeric solutions resulting in the uncoiling and aligning of the flexible polymer chains. The shear-rate dependence of apparent viscosity of the shear thinning polymer solution under a small range shear rates can be characterized by the Ostwald-de Waele power law equation as follows:

$$
\sigma=K \dot{\gamma}^{n}
$$

where $K$, the consistency index, and $n$, the power law index, are constants. The higher the consistency index, for a given power-law index, the higher is the apparent viscosity. For shear thinning fluids, $n$ ranges between 0 and 1 . The lower the power law index, the more is the shear-thinning resolution. By applying the regression analysis the coefficients ( $K$ and $n)$ in the power law model are determined and summarized in Appendix B, representing that $K$ increases and $n$ decreases when increasing polymer concentrations from $0.1-0.5 \mathrm{wt} \%$. The power law index was decreased from 0.7866 to 0.3015 while the consistency index (viscosity) showed an increase from 0.05394 to $2.29 \mathrm{~Pa}$ s. An increased consistency index $(K)$ proved a stability of suspension without sedimentation. The power law model fits very well for the apparent 
viscosity data at the regions for high shear rate values. Moreover, the dilute solutions of partially hydrolyzed polyacrylamide exhibit the extensional viscosities which would affect the pressure drop during the polymer flooding process and also reduce the drag turbulence in a porous media thereby permitting the oil to flow more efficiently. The relationship of viscosity and shear rate is fitted with Ostwald-de Waele power law Equation (28), which is one of the shear viscosity models that describes the viscosity behavior over the wide range of shear rates. The power law model is considered to fit the viscosity data in the regions above the critical values of shear rate for higher polymer concentrations $0.3-0.5 \mathrm{wt} \%$ with $\mathrm{r}^{2}$ coefficient ranging from 0.9843-0.9988. The polymer solution viscosity increases with an increase in polymer concentration which increases the sweep efficiency by reducing the mobility ratio of water-oil.

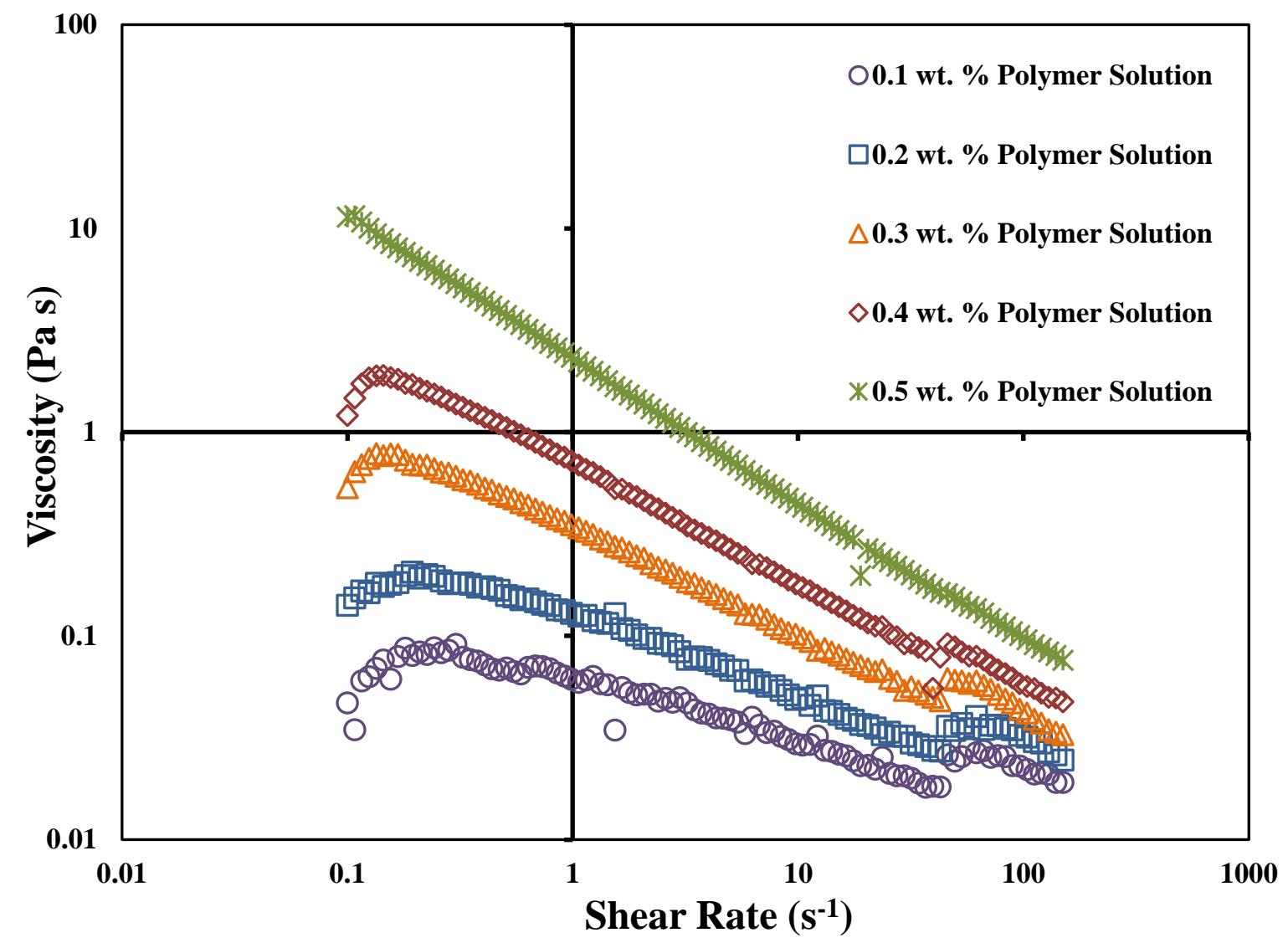

Figure 5.1 Effect of concentration of HPAM with 1 wt \% brine on shear viscosity versus shear rate at $25^{\circ} \mathrm{C}$. 
It was also noted that the addition of brine (2-3 wt \%) into polymer solution $(0.4 \mathrm{wt} \%)$ at $25^{\circ} \mathrm{C}$ decreased the viscosity of partially hydrolyzed polyacrylamide solution as shown in Figure 5.2. The increase in brine concentration from 0.2-0.3 wt \% showed a slight decrease in consistency index $(K)$, while the power law index increases. The values of power law index and consistency index obtained by applying the regression analysis are reported in Appendix C. For an optimum maximum polymer concentration $(0.4 \mathrm{wt} \%)$ the consistency index with increasing brine concentration $0.2-0.3$ wt \% is $0.5866-0.5805 \mathrm{~Pa} s$ with a corresponding power law index $(n)$ as 0.4767-0.4808. According to Samanta et al. (2011) and Nasr-El-Din et al. (1991) the reduction of polymer solution viscosity was due to the presence of $\mathrm{Na}^{+}$that attaches to the backbone (negative charges usually carboxyl groups) and reduces the electrostatic repulsion within the particles. This state of change of the polymer chain from stretched state to the shrinkage state reduces the hydraulic radius of the polymer chain molecules and the polymer chain entrapment, resulting in the reduction of polymer solution viscosity. Thus the higher concentration of inorganic ions decreases the apparent viscosity of the polymer solution. The addition of salt above the critical salinity shows the shielding effect of salt cations on the electrostatic resistance around the polymer molecules.

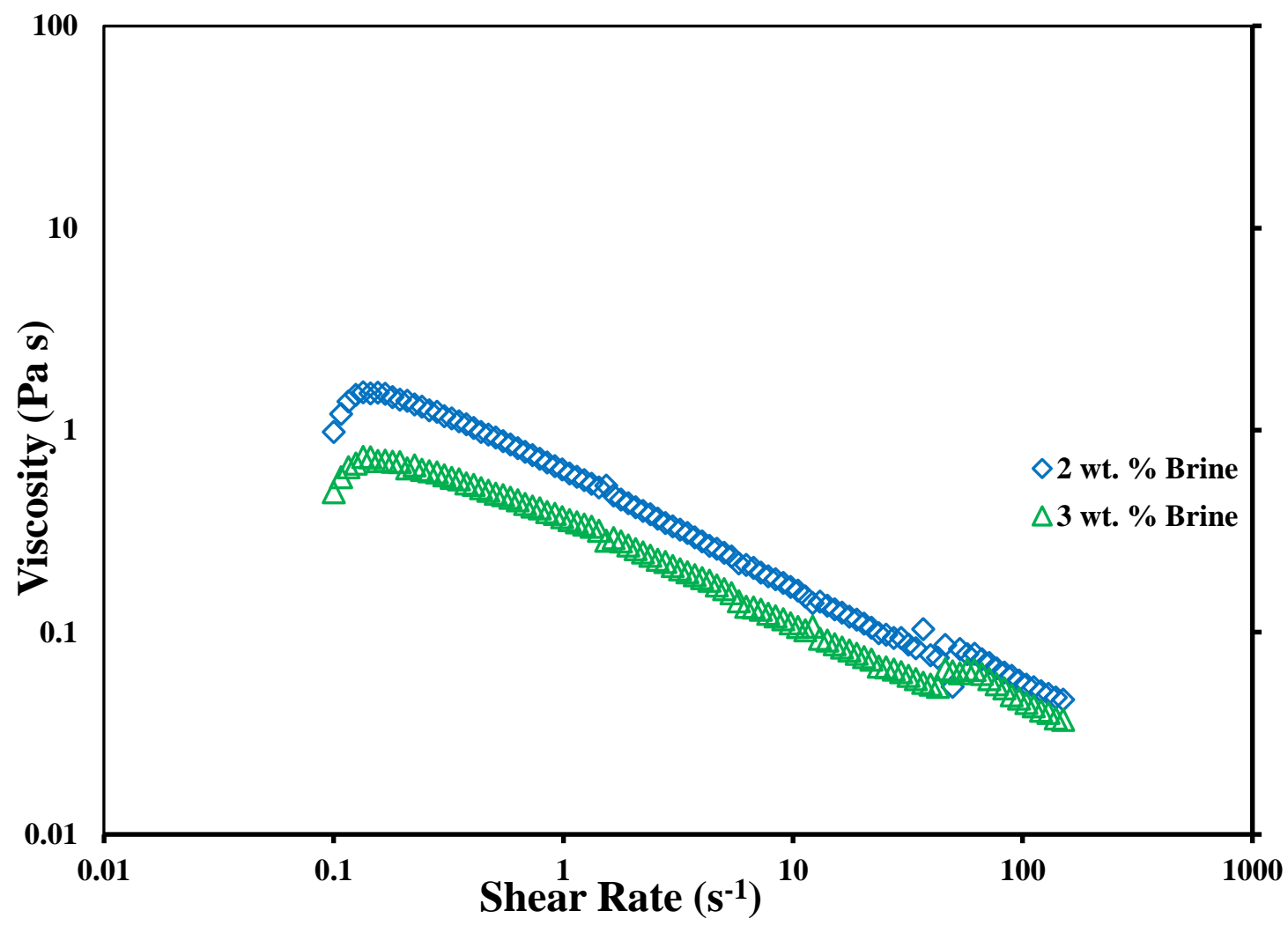

Figure 5.2 Effect of brine on polymer solution concentration (4000 ppm), shear viscosity versus shear rate at $25^{\circ} \mathrm{C}$. 


\subsection{Effect of Pressure on Oil Recovery}

In order to evaluate the impact of pressure on heavy oil recovery, we carried out a number of experiments keeping the pressure injection (i) constant and (ii) periodically varying with time.

\subsubsection{Effect of Constant Pressure}

We performed five different experiments at a constant injection pressure of $1.03 \mathrm{MPa}$ with different concentration polymer solutions $0.1,0.2,0.3,0.4$, and 0.5 wt \% with $8.75 \mathrm{D}$ permeability of the physical reservoir model. The results shown in Figure 5.3 depicts that the lowest concentration $(0.1 \mathrm{wt} \%)$ polymer solution achieved the highest breakthrough recovery $1.78 \%$ OOIP at a breakthrough time of 30 minutes. Apart from delayed in oil breakthrough, the final oil recovery obtained was $48.23 \%$ OOIP. While $0.2 \mathrm{wt} \%$ polymer solution achieved an earlier oil breakthrough recovery of $0.94 \%$ OOIP. With 0.1 wt $\%$ increase in polymer concentration from 0.1 to $0.2 \mathrm{wt} \%$, cumulative oil recovery shows an increase of approximately $6.38 \%$. On the other hand, a significant change in concentration from 0.2 to 0.3 wt $\%$ led to minimal increase of $1.62 \%$ OOIP. The results show a slight increase in oil recovery percentage with an increase in polymer concentration from $0.1 \mathrm{wt} \%$ to $0.3 \mathrm{wt} \%$. The general increase in cumulative oil recovery is a result of better displacement due to increased displaced fluid viscosity. Higher fluid viscosity allows for a decreased mobility ratio of the polymer-oil system as well as the increased surface tension between the polymer and oil. Furthermore, fingering is much less prominent which allow less of the displacing fluid to finger through the oil as opposed to pushing the oil.

Instead of oil recovery increasing with an increase in polymer solution concentration, it appeared to decrease significantly with polymer concentration shown by a $0.84 \%$ decrease in breakthrough recovery from 0.1 to $0.2 \mathrm{wt} \%$. Moreover, the final oil recoveries obtained with 0.4 wt $\%$ and with 0.5 wt $\%$ dropped to $5.45 \%$. 


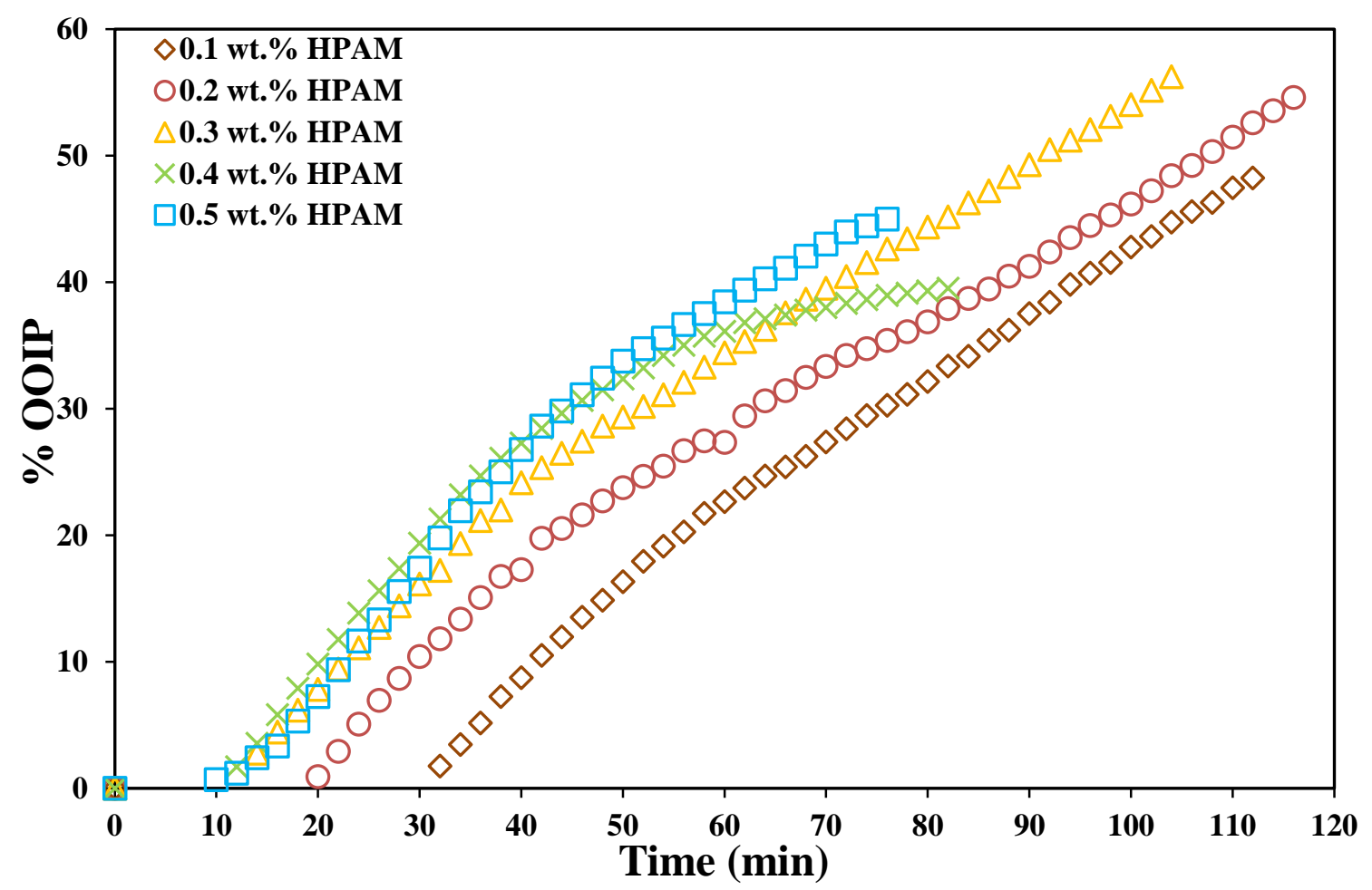

Figure 5.3 Heavy oil recovery versus time with polymer concentrations (0.1-0.5 wt \%) at constant pressure $1.03 \mathrm{MPa}$ and $25^{\circ} \mathrm{C}$.

Final cumulative oil recovery profiles are being delineated in Figure 5.4 at constant pressure injection of the polymer solution with pressure magnitudes of 1.03 and $3.44 \mathrm{MPa}$ respectively and with different concentrations (0.1-0.5 wt \%). The percentage recovery of heavy oil reaches its maximum value of $56.23 \%$ OOIP when the polymer solution of concentration $0.3 \mathrm{wt} \%$ was injected at a constant pressure magnitude of $1.03 \mathrm{MPa}$; with a slight increment in the concentration to $0.4 \mathrm{wt} \%$ at the same pressure level, the recovery percentage dropped to $39.54 \%$ OOIP. The oil recovery attained with highest polymer concentration $0.5 \mathrm{wt} \%$ is $44.99 \%$ OOIP. In contrast, the overall oil recoveries obtained with maximum constant pressure (3.44 MPa) were much less. It is clear from the experimental oil recoveries obtained with minimum and maximum constant pressure injection $1.03 \mathrm{MPa}$ and $3.44 \mathrm{MPa}$, the overall oil recoveries followed a different pattern. Maximum constant pressure injection $3.44 \mathrm{MPa}$ encountered the early polymer breakthrough that reduces the cumulative oil recovery with different polymer concentration solutions (0.1-0.5 wt \%). Moreover, the high pressure injection causes the compactness of the pore spaces inside the porous media that creates narrow paths for the polymer solution to flow freely and leads to the lower oil recovery. Higher concentration of the polymer solution is directly proportional to the viscosity and when these highly viscous displacing fluids pass through the porous media they exhibit a shear thinning behavior due to 
the coil-stretched transitions of polymer chains. These polymer chain coils deform when passes through the narrow pore spaces and loses its tendency to push more oil resulting in poor sweep efficiency even at maximum constant pressure $3.44 \mathrm{MPa}$.

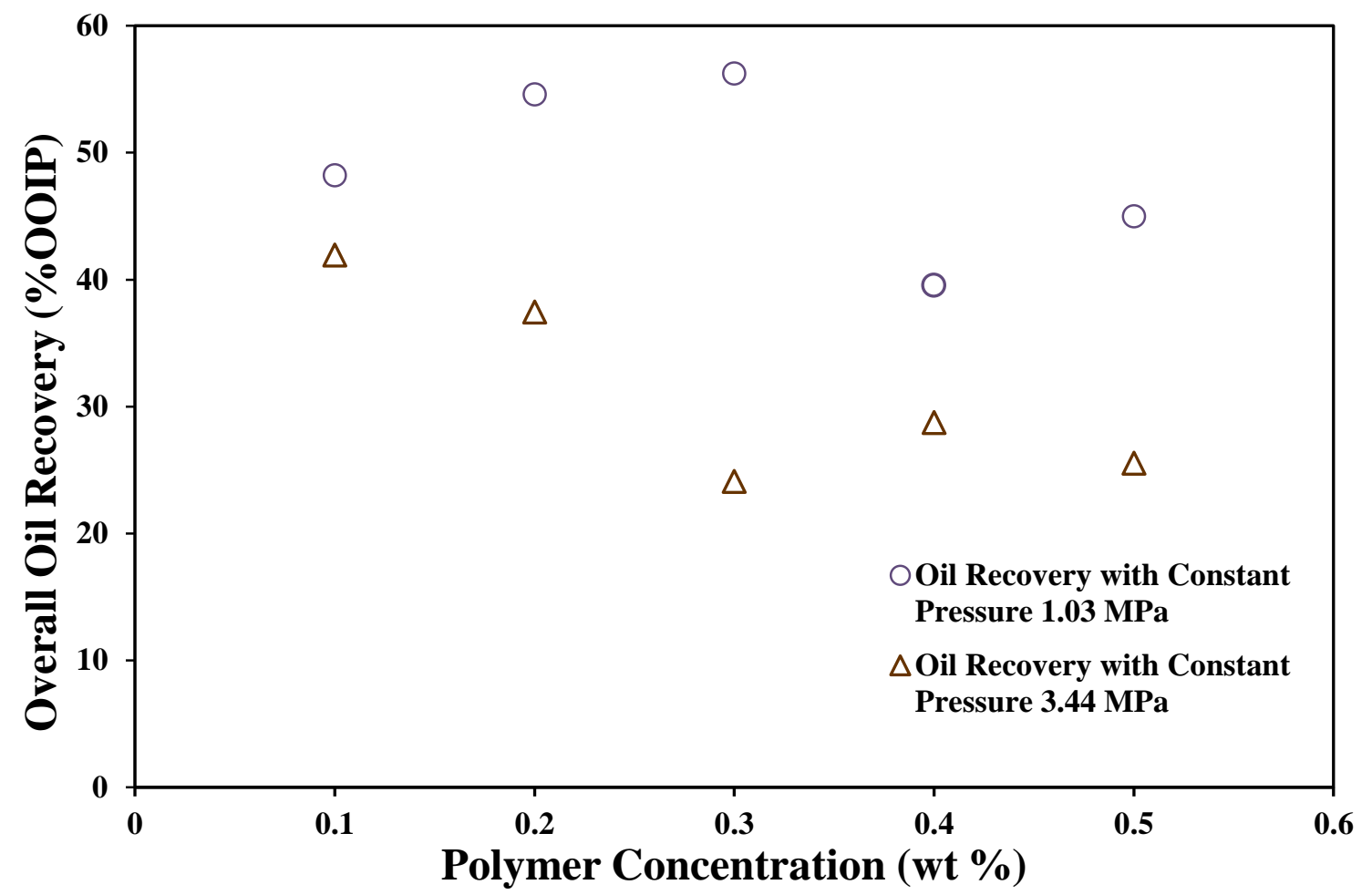

Figure 5.4 Overall oil recovery versus polymer concentration (0.1-0.5 wt \%) at constant pressure 1.03 MPa \& 3.44 MPa and $25^{\circ} \mathrm{C}$.

\subsubsection{Effect of Pressure Variation}

To study the effect of periodic pressure variation versus time with the polymer solution injection on heavy oil recovery, we performed experiments by varying the injection pressure between 2.41 and 3.44 MPa. Figures 5.5-5.9 shows the heavy oil recovery with different polymer concentration solutions at a maximum constant injection pressure $3.44 \mathrm{MPa}$ as well as with the periodic injection pressure variation. It can be clearly seen from the Figure 5.5-5.7, the periodic pressure variation between 2.41 and $3.44 \mathrm{MPa}$ enhances the oil recovery in comparison to a maximum constant pressure (3.44 MPa) by more than $100 \%$ with final recoveries ranging from $79.44 \%$ OOIP to $75.45 \%$ OOIP with polymer concentrations of 0.1 $0.3 \mathrm{wt} \%$. While the oil recovery achieved with various polymer concentrations $(0.1-0.3 \mathrm{wt} \%)$ showed a $13.2 \%$ decrease in oil production. It is evident that at maximum constant pressure 3.44 MPa the polymer flooding lost much of its effectiveness with a decrease in cumulative oil recovery from $41.92 \%$ to $28.72 \%$ OOIP. Figure 5.8 illustrates the highest cumulative oil 
recovery of $80.07 \%$ OOIP with 0.4 wt $\%$ polymer concentration. With 0.5 wt $\%$ polymer concentration solution the cumulative oil recovery slightly decreases to $4.62 \%$ by varying the pressure injection.

The pressure versus time for $0.1-0.3 \mathrm{wt} \%$ polymer concentrations shows early oil breakthrough due to the lower polymer solution viscosities but for higher concentrations 0.4$0.5 \mathrm{wt} \%$ the pressure versus time showed a delay in oil breakthrough time due to high viscosity which causes the higher internal resistance to the fluid flow even at higher pressure injections. However, as expected at higher injection pressure the oil breakthrough was attained early albeit a very small difference. The low recovery at constant $3.44 \mathrm{MPa}$ can be explained by the viscous fingering phenomena. In this scenario, the polymer was introduced to the oil at high pressure and instead of displacing the oil it can go through the oil, by passing it and creating an uneven or fingered profile. This leads to an inefficient sweep action which leaves significant volumes of unrecovered oil and moreover led to the early breakthrough of oil and polymer. Furthermore, to probe the impact of periodic pressure variation with different polymer concentration solutions, we performed experiments by injecting the polymeric solution using concentrations ranging between $0.1-0.5 \mathrm{wt} \%$ and with periodic variation of the solution injection pressure between 2.41 and 3.44 MPa. First we started the experiment with minimum constant pressure injection $(1.03 \mathrm{MPa})$ and when the oil breakthrough of the core we applied the periodic pressure variations between 2.41 $\mathrm{MPa}$ and $3.44 \mathrm{MPa}$. In comparison to a maximum constant pressure, the periodic pressure variations enhanced oil recovery more than $100 \%$ with a final value of $79.44 \%$ OOIP for $0.1 \mathrm{wt} \%$ polymer concentration solution injection, $79.18 \%$ OOIP with 2000 ppm polymer concentration solution, $75.45 \%$ OOIP with 0.3 wt \%, 80\% OOIP with 0.4 wt \% and $76.52 \mathrm{wt} \%$ OOIP by using $0.5 \mathrm{wt} \%$ polymer concentration solution as shown in Figure 5.10. Despite higher polymer concentration that would bring down oil recovery, periodic variation of pressure helps sustains the recovery close to $78 \%$.

The overall increase in heavy oil recovery with a periodic pressure variation may be attributed to the sudden change in the injection pressure of the displacing fluid within the physical reservoir model resulting in altering the fluid velocity as the polymer solution passes through the porous media. As the polymer solution passes through the small pore areas, the velocity increases due to the periodic variations causing a decrease in the static pressure, thereby, leading to higher oil recovery. The trends in the collected data indicate quite clearly that cumulative oil recovery can be improved by increasing the polymer concentration as well as increasing the injection pressure of the polymer. There is however an optimum polymer 
concentration as evidenced by the slowly decreasing oil recovery as polymer concentration was increased from 0.2 to $0.3 \mathrm{wt} \%$ and from 0.4 to $0.5 \mathrm{wt} \%$ as compared to a maximum constant pressure that slowed a large decrease in overall oil recovery.

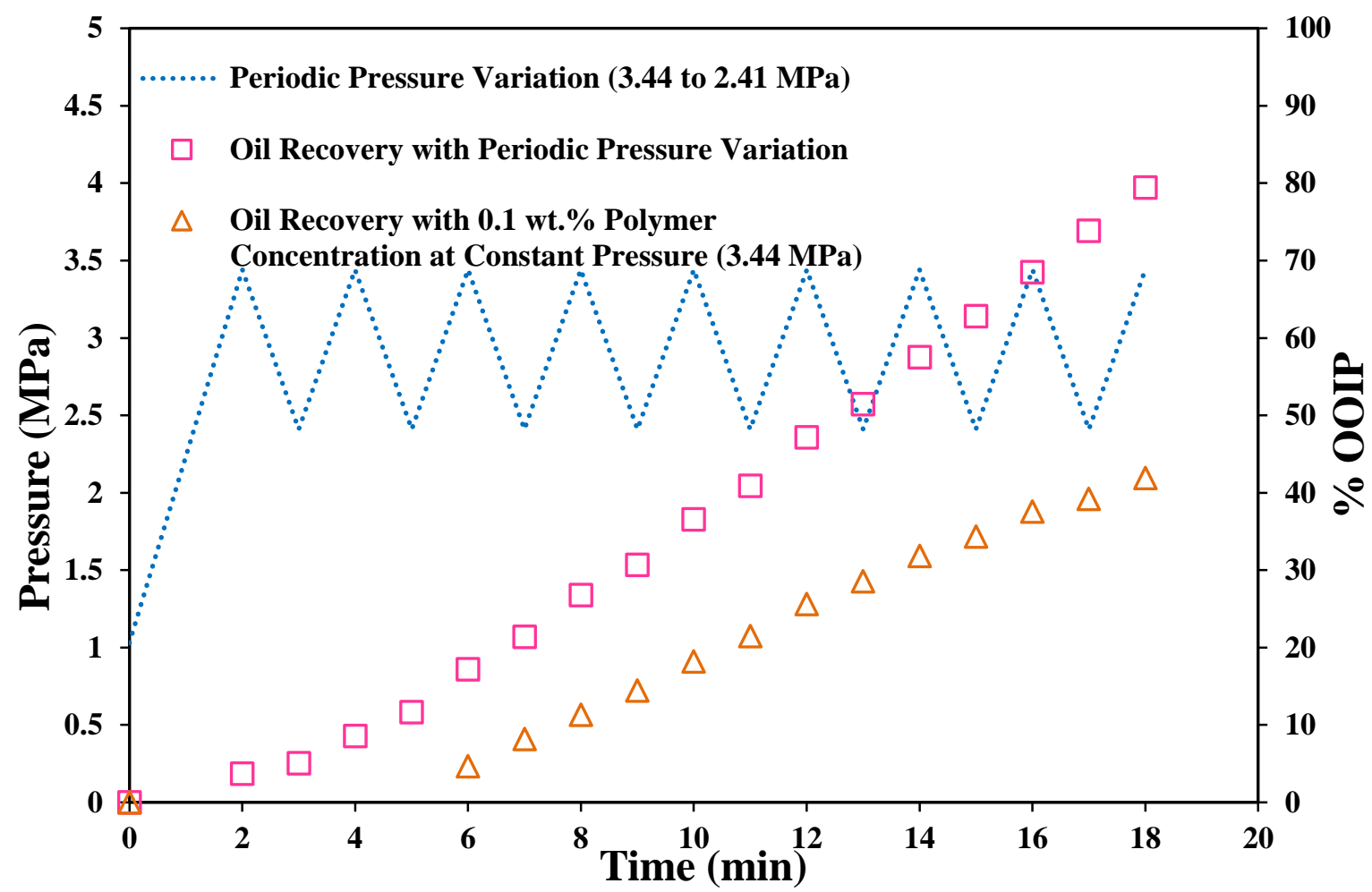

Figure 5.5 Heavy oil recovery versus time for $0.1 \mathrm{wt} \%$ polymer concentration at $25^{\circ} \mathrm{C}$, and at constant (3.44 MPa) as well as periodically varying injection pressure in the range of 2.41-3.44 MPa. The final time standard deviation is $\pm 0.275 \%$ OOIP. 


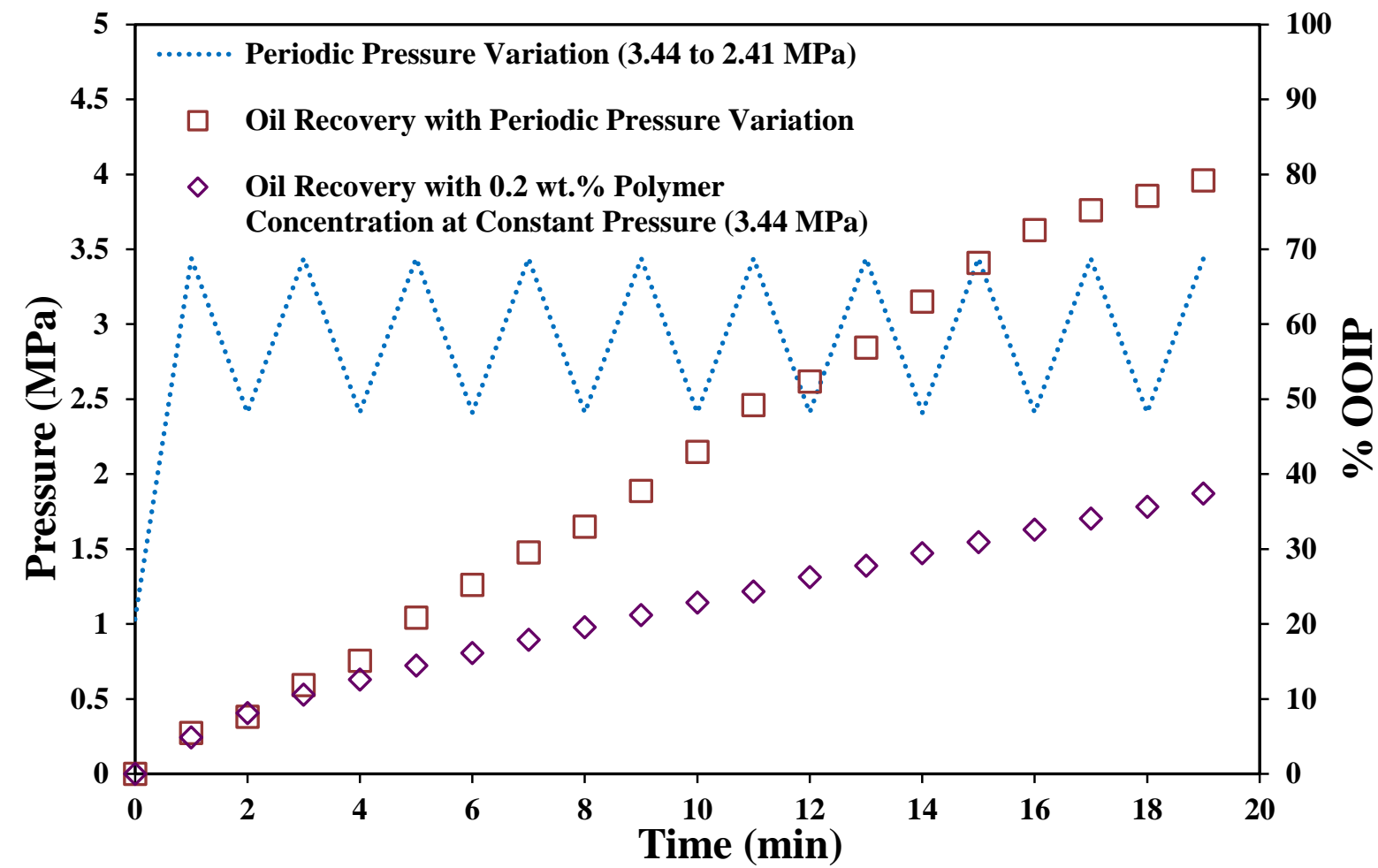

Figure 5.6 Heavy oil recovery versus time for $0.2 \mathrm{wt} \%$ polymer concentration at $25^{\circ} \mathrm{C}$, and at constant (3.44 MPa) as well as periodically varying injection pressure in the range of 2.41-3.44 MPa. The final time standard deviation is $\pm 0.124 \%$ OOIP.

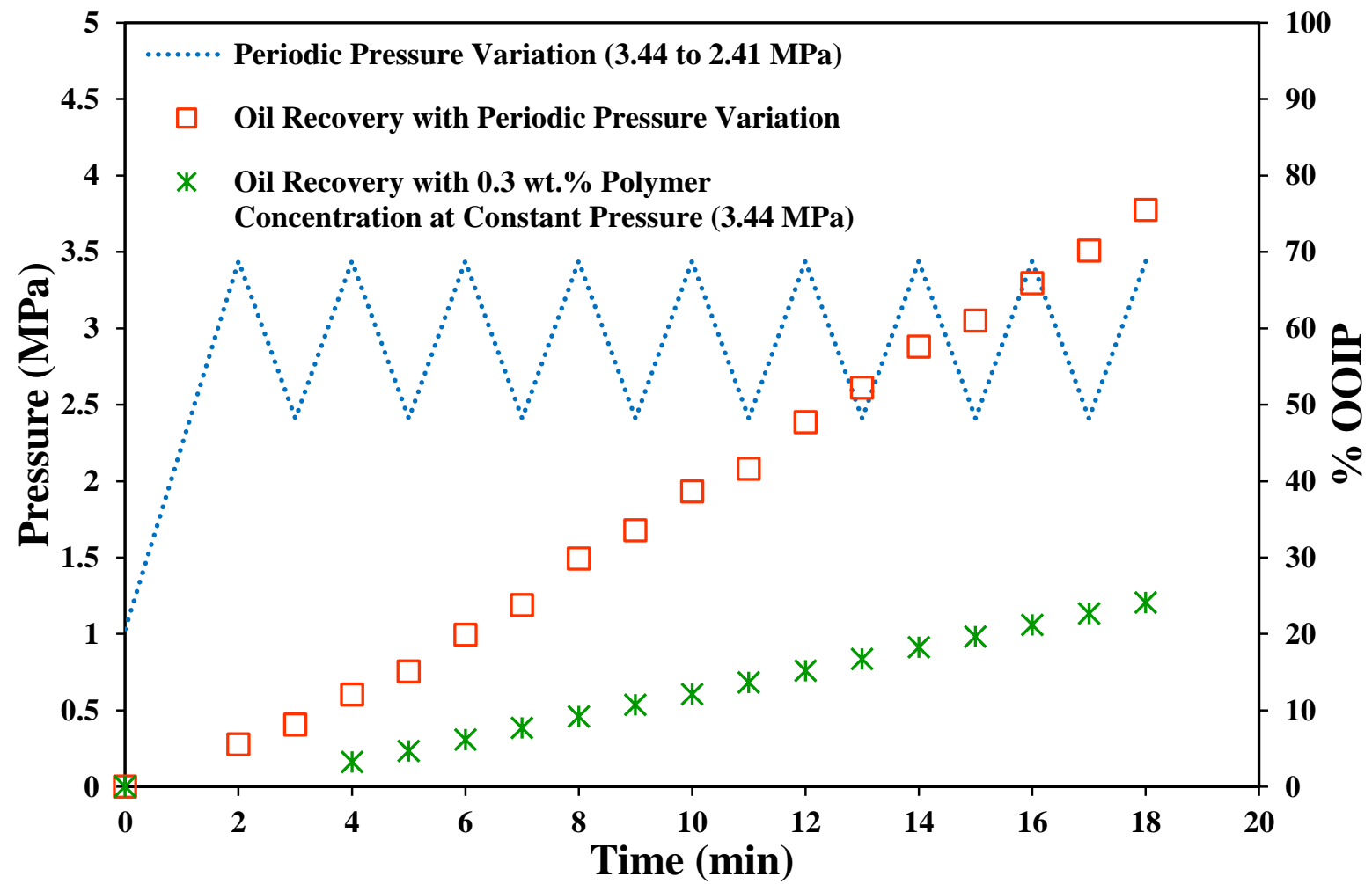

Figure 5.7 Heavy oil recovery versus time for $0.3 \mathrm{wt} \%$ polymer concentration at $25^{\circ} \mathrm{C}$, and at constant pressure (3.44 MPa) as well as periodically varying injection pressure in the range of 2.41-3.44 MPa. The final time standard deviation is $\pm 0.168 \%$ OOIP. 


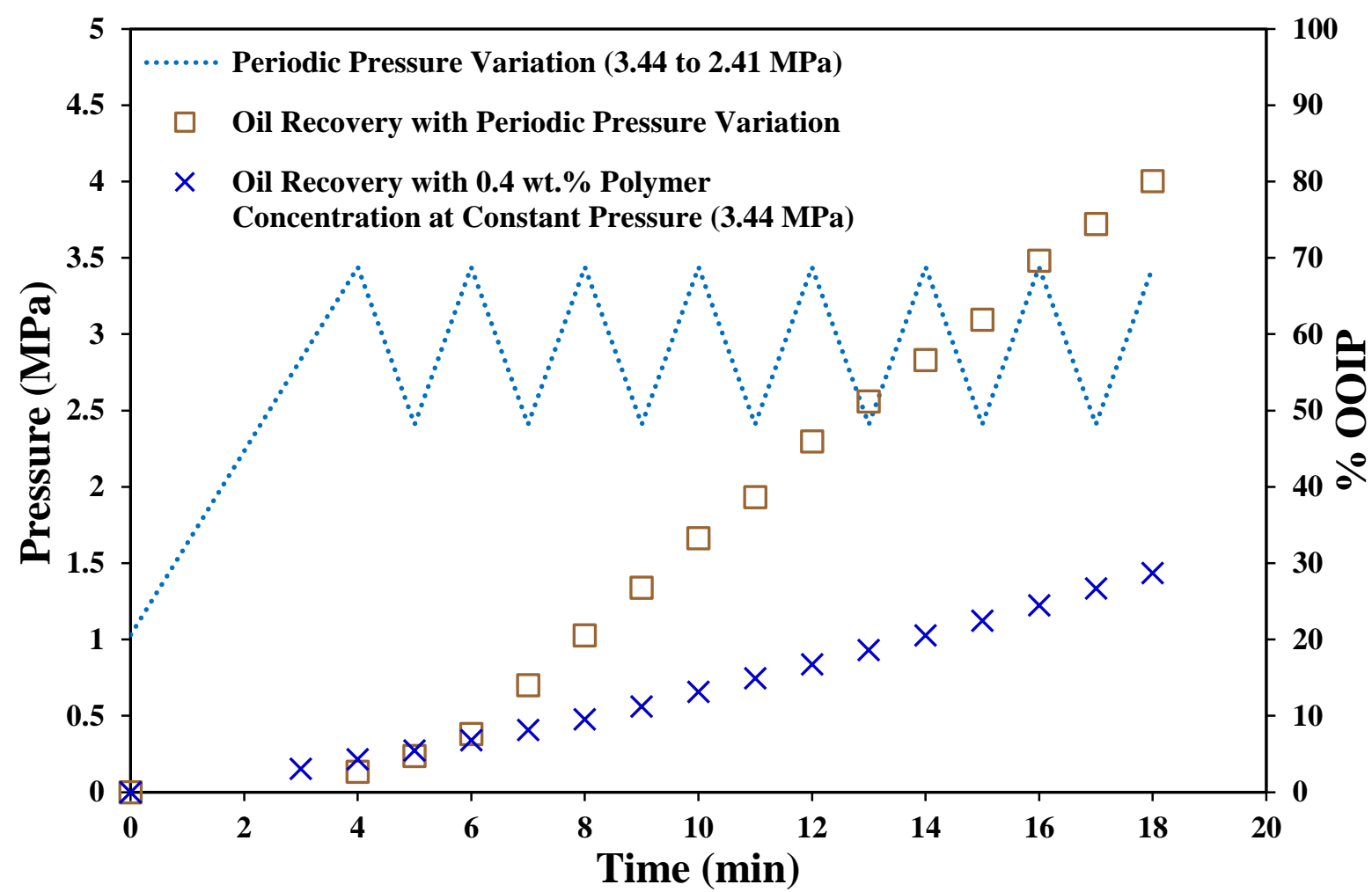

Figure 5.8 Heavy oil recovery versus time for $0.4 \mathrm{wt} \%$ polymer concentration at $25^{\circ} \mathrm{C}$, and at constant pressure (3.44 MPa) as well as periodically varying injection pressure in the range of 2.41-3.44 MPa. The final time standard deviation is $\pm 0.154 \%$ OOIP.

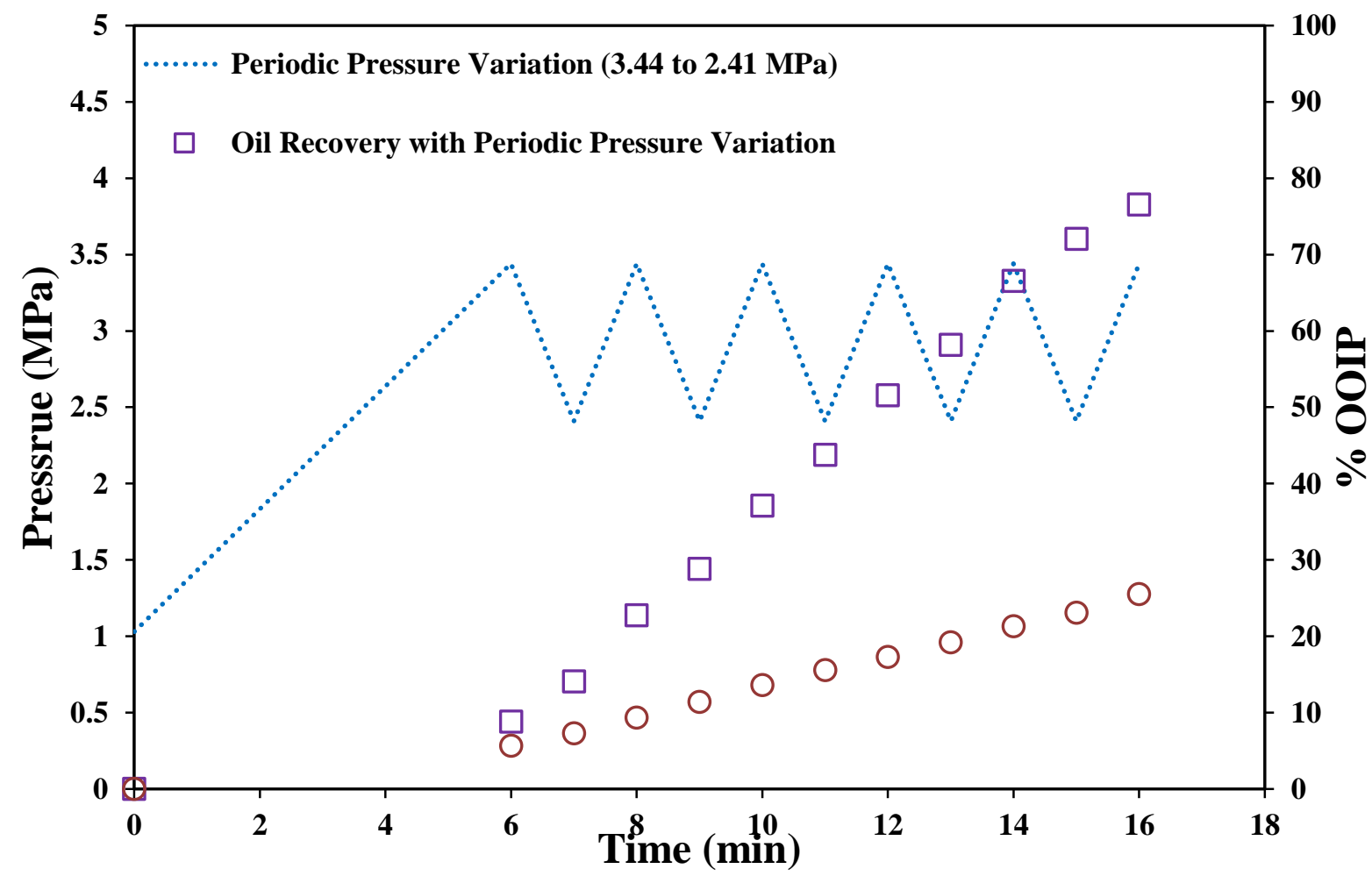

Figure 5.9 Heavy oil recovery versus time for $0.5 \mathrm{wt} \%$ polymer concentration at $25^{\circ} \mathrm{C}$, and at constant pressure (3.44 MPa) as well as periodically varying injection pressure in the range of 2.41-3.44 MPa. The final time standard deviation is $\pm 0.147 \%$ OOIP. 


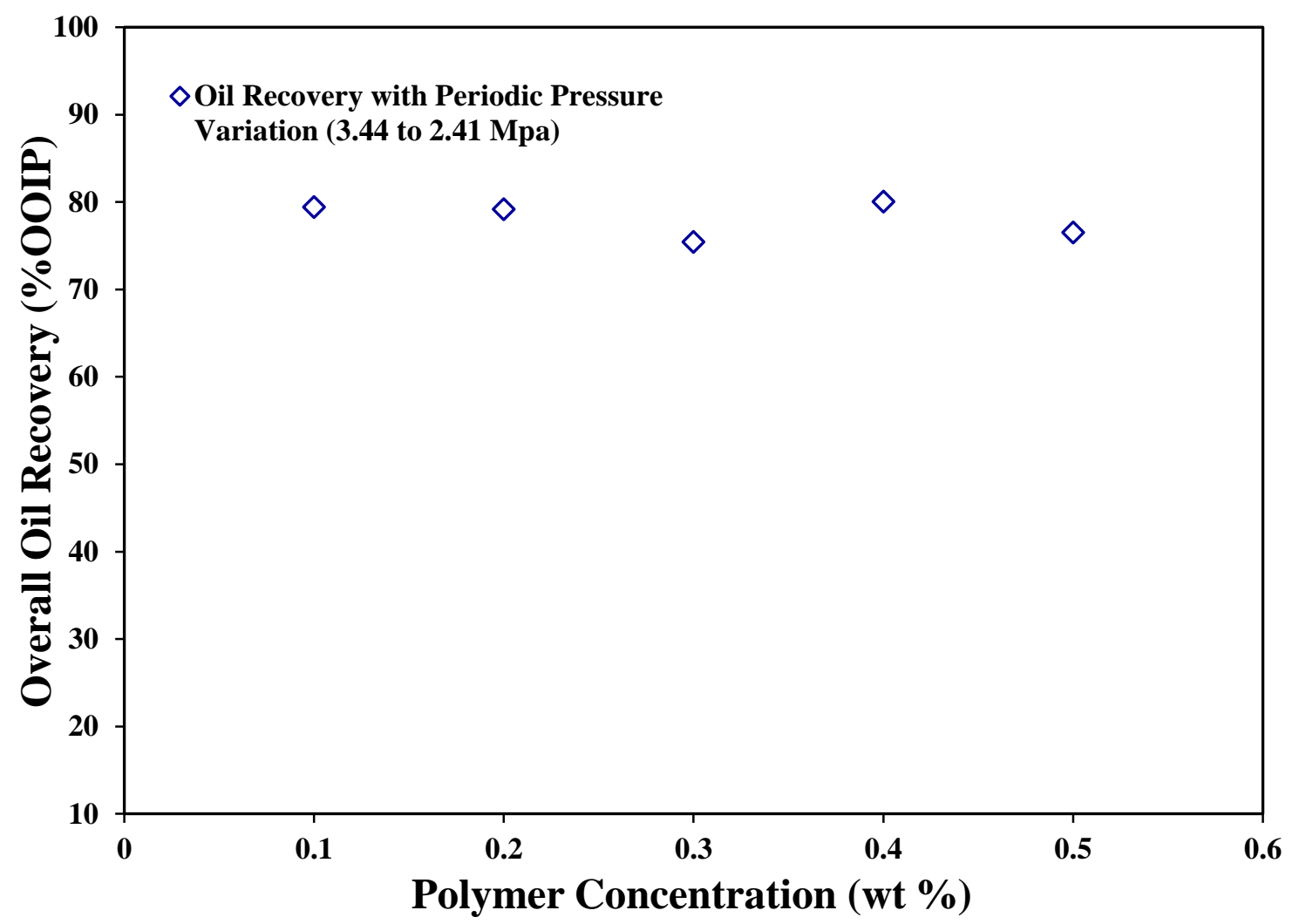

Figure 5.10 Overall oil recovery versus polymer concentrations $(0.1-0.5$ wt \%) with periodic pressure (3.44 to $2.41 \mathrm{MPa})$ and $25^{\circ} \mathrm{C}$.

\subsection{Numerical Results and Discussion}

In this section, the results of an extensive simulation study of polymer flooding process will be described and discussed. The main objective of the simulation work was to get the best possible matching between the model-predicted and the experimental polymer flooding production rates by adjusting the permeability function as well as the viscosity absorption parameter as the matching parameter. As previously mentioned, experiments were conducted using lab-scale homogeneous physical reservoir model having a uniform permeability at room temperature and pressure in the ranges of 1.03-3.44 MPa. Under these conditions, the cumulative mass of the produced oil was measured and recorded every 1 minute. To increase the confidence in the results of numerical simulation, the parameters involved in the simulation model were measured experimentally such as porosity, permeability, pore volume, oil saturation and aqueous phase saturation, and polymer solution viscosity. 


\subsubsection{Algorithm Execution}

The Equations (24) - (27) are solved simultaneously to obtain the calculated cumulative mass of produced oil. In the above mentioned equations, $S_{o}, S_{w}, C$ and $\mathrm{P}$ are the oil saturation, aqueous phase saturation, polymer concentration, and pressure at the node $(j)$ corresponding to the coordinate, $(z) . \Delta z$ is the distance between equispaced grid points respectively along $\mathrm{z}$ direction. In this work, they were numerically integrated using adaptive step-size control. Analytical jacobians of Equations (12) - (23) were employed for integration. To fix the number of grid points, $N_{j}$, the equations were integrated with a maximum number of grid point until the changes in solution became negligible. The algorithm was programmed to generate $m_{c a l}$ at the experimental time instants for its direct comparison with its experimental counterpart, $m_{\text {exp }}$. Table 5.3 lists the parameters used in the simulation of the mathematical model for physical model of $8.7 \mathrm{D}$ permeability with respect to brine and $1.5 \mathrm{D}$ with respect to heavy oil.

Table 5.1 Various Simulation Parameters used in this study

\begin{tabular}{|c|c|}
\hline Parameter & Value \\
\hline $\boldsymbol{N}_{\boldsymbol{j}}$ & 8 \\
\hline$\varnothing$ & 0.38 \\
\hline $\mathrm{K}\left(\boldsymbol{m}^{\mathbf{2}}\right)$ & $1.5 \mathrm{e}-10$ \\
\hline $\boldsymbol{\mu}_{\boldsymbol{o}}(\mathrm{Pa} \mathrm{s})$ & 14.5 \\
\hline $\boldsymbol{\rho}_{\boldsymbol{o i l}}\left(\boldsymbol{k g} / \boldsymbol{m}^{\mathbf{3}}\right)$ & 977 \\
\hline $\boldsymbol{S}_{\boldsymbol{o}}$ & 0.743 \\
\hline $\boldsymbol{S}_{\boldsymbol{w}}$ & 0.257 \\
\hline $\mathrm{Z}(\boldsymbol{m})$ & 0.3 \\
\hline $\mathrm{R}(\boldsymbol{m})$ & 0.125 \\
\hline $\mathrm{A}\left(\boldsymbol{m}^{\mathbf{2}}\right)$ & $4.9 \mathrm{e}-4$ \\
\hline $\boldsymbol{K}_{\boldsymbol{r o}}$ & 0.66 \\
\hline $\boldsymbol{n}_{\boldsymbol{o}}$ & 2 \\
\hline $\boldsymbol{K}_{\boldsymbol{r o c w}}$ & 0.9 \\
\hline $\boldsymbol{S}_{\boldsymbol{w c}}$ & 0.22 \\
\hline $\boldsymbol{S}_{\boldsymbol{o r}}$ & 0.25 \\
\hline $\boldsymbol{C}_{\boldsymbol{o}}(\mathbf{1} / \boldsymbol{P a})$ & $5 \mathrm{e}-12$ \\
\hline $\boldsymbol{K}_{\boldsymbol{r} \boldsymbol{w}}$ & $1.017 \mathrm{e}-3$ \\
\hline $\boldsymbol{R}_{\boldsymbol{k}}$ & 1.016 \\
\hline
\end{tabular}




\begin{tabular}{|c|c|}
\hline $\boldsymbol{n}_{\boldsymbol{w}}$ & 2.3447 \\
\hline $\boldsymbol{b}_{\boldsymbol{r} \boldsymbol{k}}$ & 0.2 \\
\hline $\boldsymbol{R}_{\boldsymbol{k m a x}}$ & 1.15 \\
\hline $\boldsymbol{\mu}_{\boldsymbol{w}}(\mathrm{Pa} \mathrm{s})$ & $0.458 \mathrm{e}-4$ \\
\hline $\boldsymbol{a p}_{\boldsymbol{1}}$ & 15.426 \\
\hline $\boldsymbol{a} \boldsymbol{p}_{\boldsymbol{2}}$ & 0.4228 \\
\hline $\boldsymbol{a} \boldsymbol{p}_{\mathbf{3}}$ & 0.2749 \\
\hline $\boldsymbol{C}_{\boldsymbol{T}}(\mathbf{1} / \boldsymbol{P a})$ & $4.8 \mathrm{e}-12$ \\
\hline $\mathrm{D}\left(\boldsymbol{m}^{2} / \boldsymbol{s}\right)$ & $5 \mathrm{e}-12$ \\
\hline $\boldsymbol{f}_{\boldsymbol{a}}$ & 1 \\
\hline $\boldsymbol{B}_{\boldsymbol{w}}$ & 1 \\
\hline $\mathrm{a}$ & 30 \\
\hline $\mathrm{b}$ & 3800 \\
\hline $\boldsymbol{\rho}_{\boldsymbol{r}}\left(\boldsymbol{k g} / \boldsymbol{m}^{\mathbf{3}}\right)$ & 2720 \\
\hline $\boldsymbol{C}_{\boldsymbol{f} \boldsymbol{w}}(\mathbf{1} / \boldsymbol{P a})$ & $1.22 \mathrm{e}-11$ \\
\hline $\boldsymbol{C}_{\boldsymbol{r} \boldsymbol{p}}(\mathbf{1} / \boldsymbol{P a})$ & $1.57 \mathrm{e}-11$ \\
\hline $\boldsymbol{C}_{\boldsymbol{R}}(\mathbf{1} / \boldsymbol{P a})$ & $9.38 \mathrm{e}-12$ \\
\hline
\end{tabular}

By using the parameters listed above we run the simulation with different permeability values and observed that the predicted production follows experimental production very close during the operation time of about 18 minutes for a maximum constant pressure of $3.44 \mathrm{MPa}$ by varying the polymer solution concentration from $0.1-0.5 \mathrm{wt} \%$. At very high values of permeability $(\mathrm{K})$, the integration of the set of differential equations, i.e. Equation (24) - (27) became very time consuming and took 45 minutes as the step size of integration became prohibitively small. The reason is that the permeability $(\mathrm{K})$ appears in the above mentioned set of ordinary differential equations. A higher value of permeability as such increases the stiffness of the whole set of equations requiring smaller step sizes for integration.

Predicted oil production versus time for the optimal values of permeability $(\mathrm{K})$ is compared with the experimental oil production. It is observed that the predicted production follows experimental production very closely during the operation time of about 18 minutes for a maximum constant pressure of $3.44 \mathrm{MPa}$. 


\subsubsection{Model Validation}

The numerical model was validated first to ensure consistent numerical results before being used to predict the oil production using various physical models. Using the permeability value $\mathrm{K}=1.5 \mathrm{e}^{10}{ }^{10} \mathrm{~m}^{2}$ and $\mathrm{P}_{\max }=3.44 \mathrm{e}^{6} \mathrm{~Pa}$ with different polymer concentration solutions $1000-5000$ ppm, the simulated production rates were compared with the experimental ones obtained from the data set of experiments conducted for the same physical model at the same operating conditions but with different polymer concentrations. Figures (5.11)-(5.15) shows the experimental and calculated production rates agree very well.

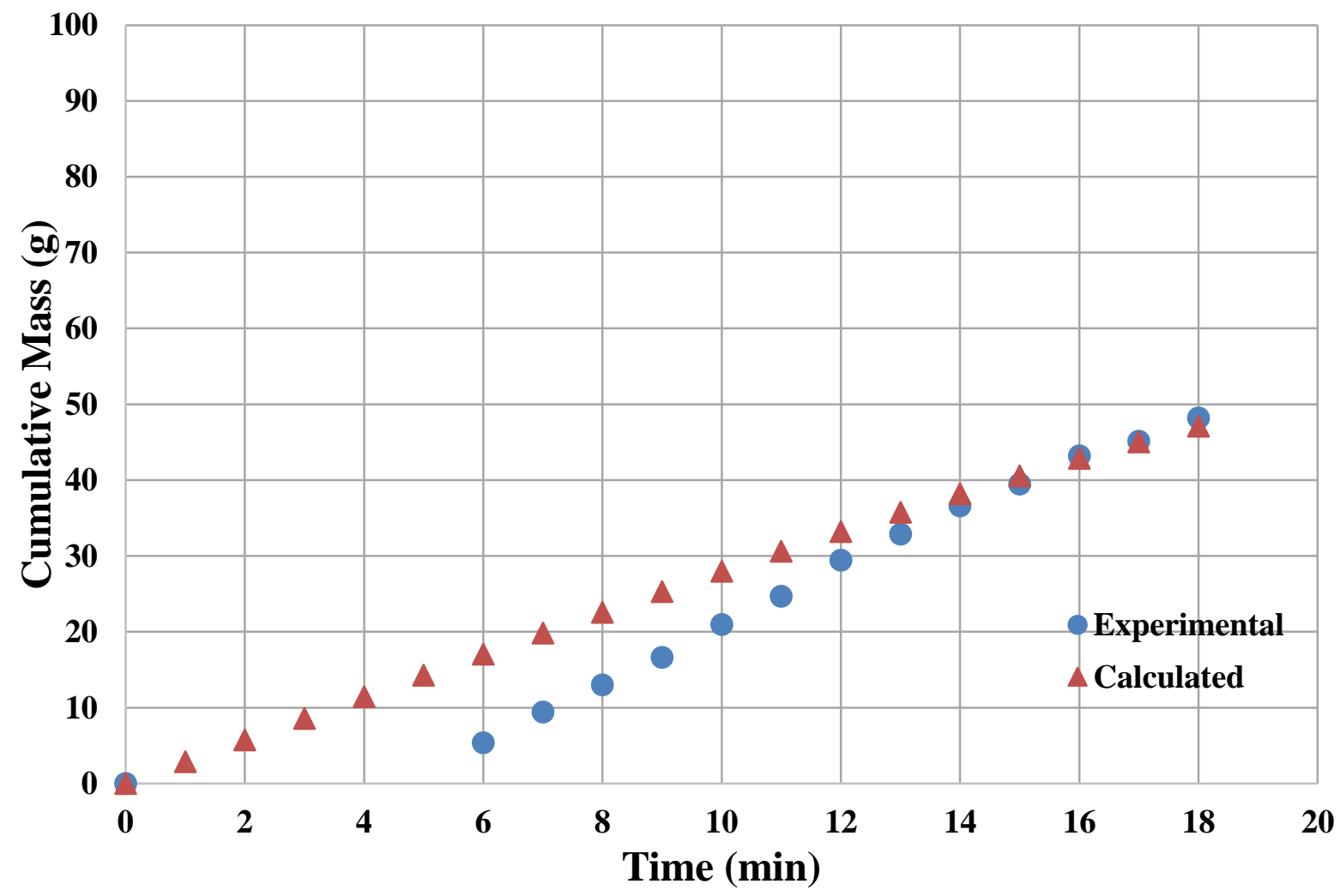

Figure 5.11 Model Validation at 3.44 MPa using 0.1 wt \% polymer concentration 


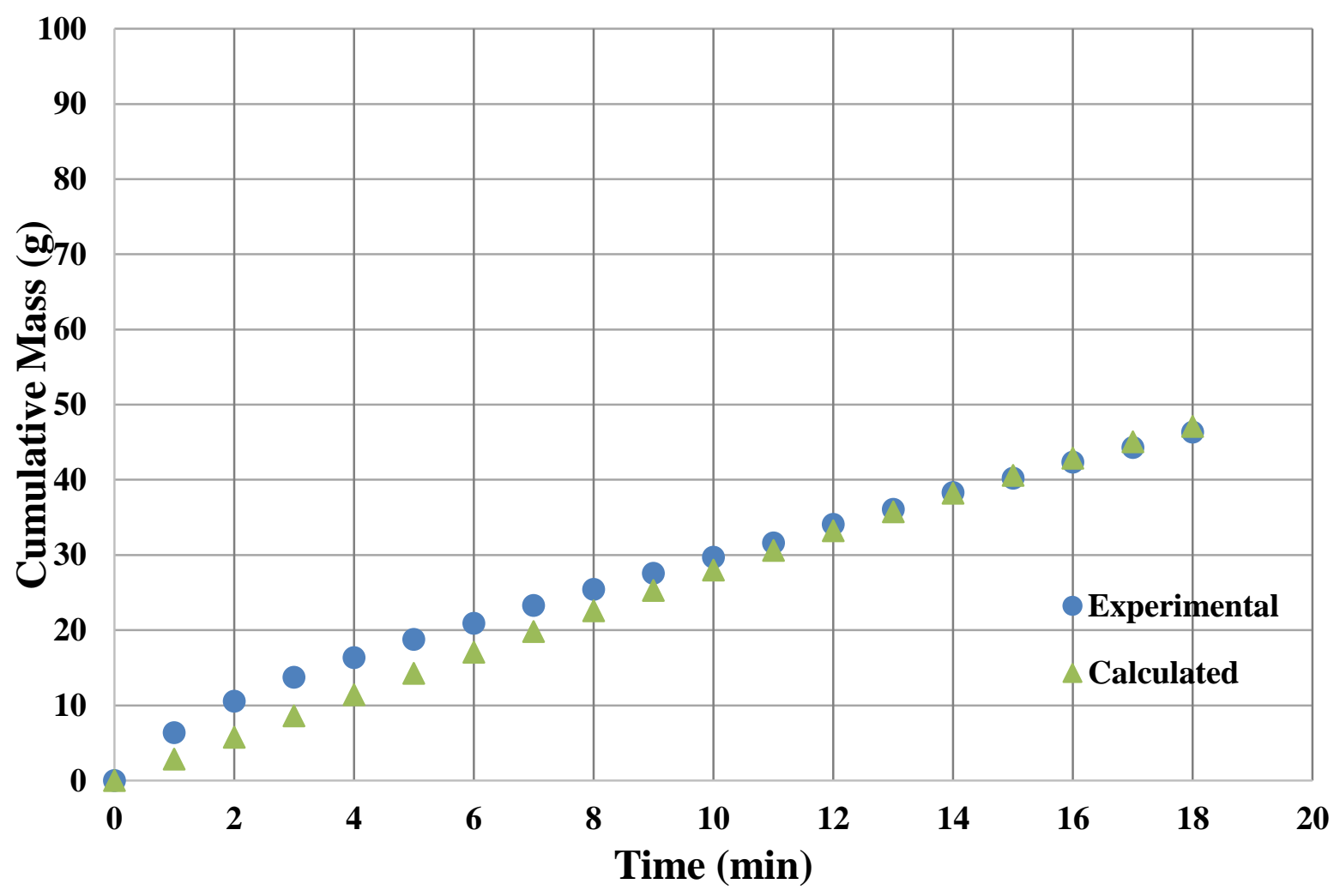

Figure 5.12 Model Validation at 3.44 MPa using 0.2 wt \% polymer concentration

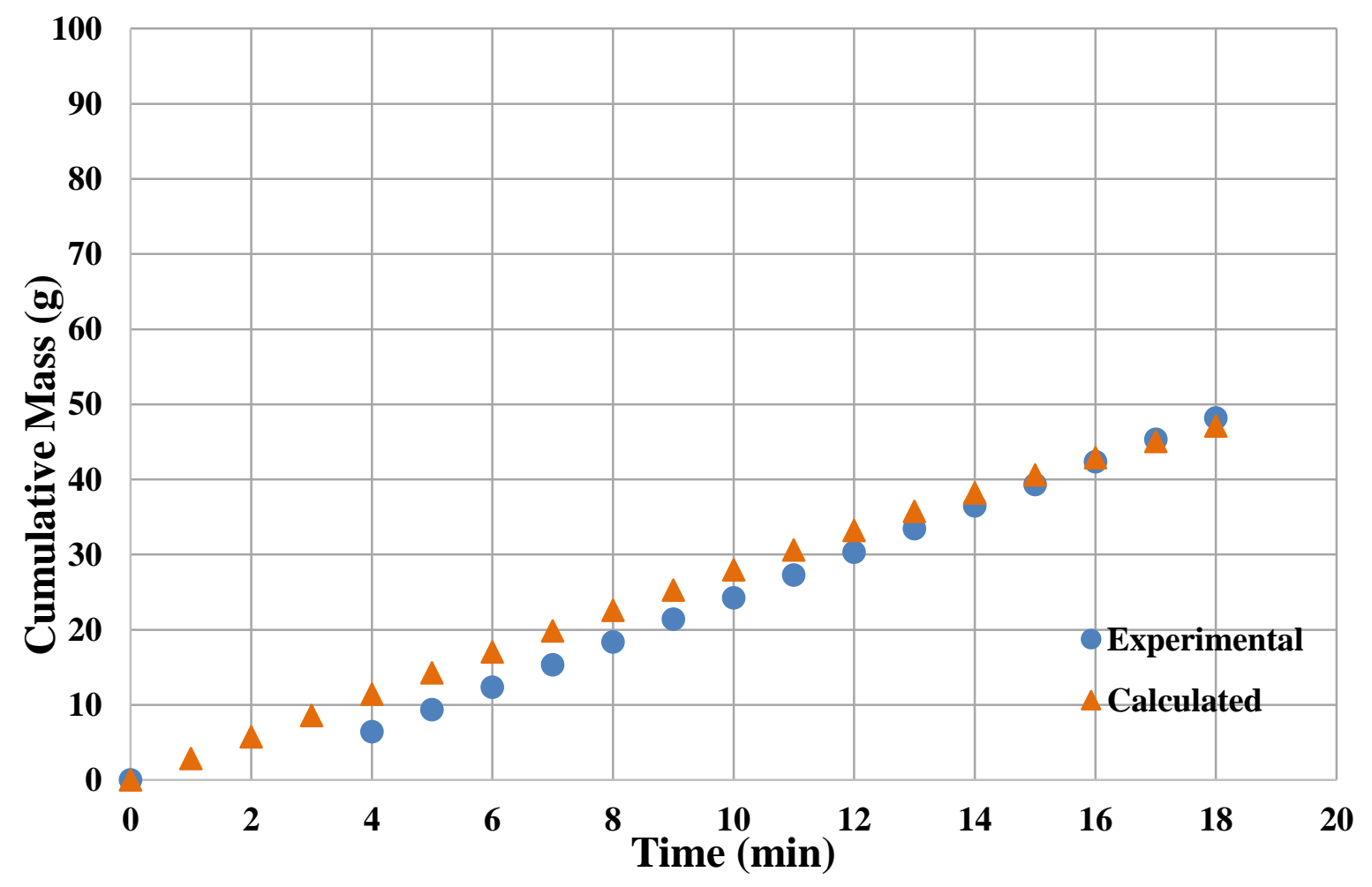

Figure 5.13 Model Validation at 3.44 MPa using 0.3 wt \% polymer concentration 


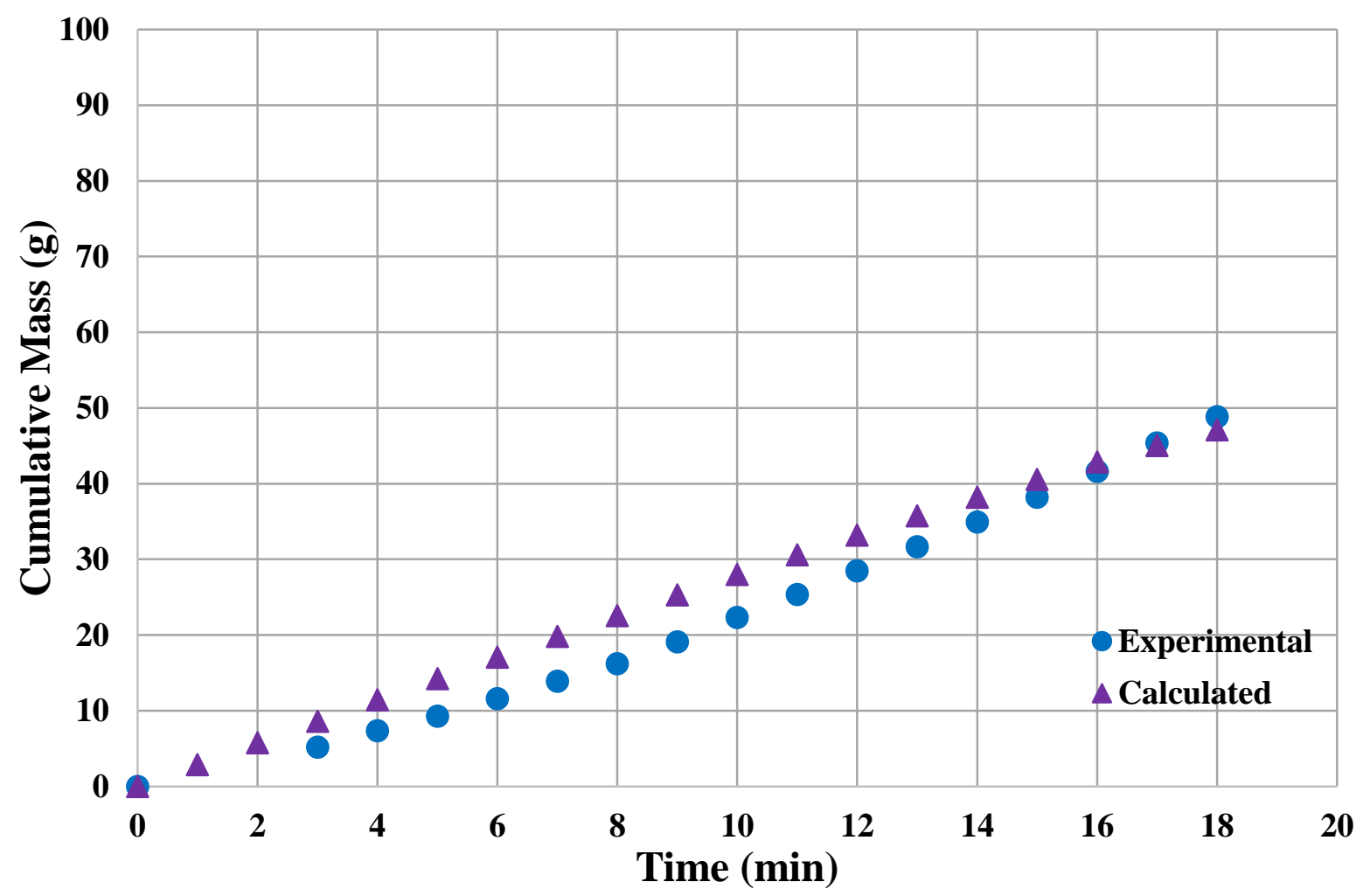

Figure 5.14 Model Validation at 3.44 MPa using 0.4 wt \% polymer concentration

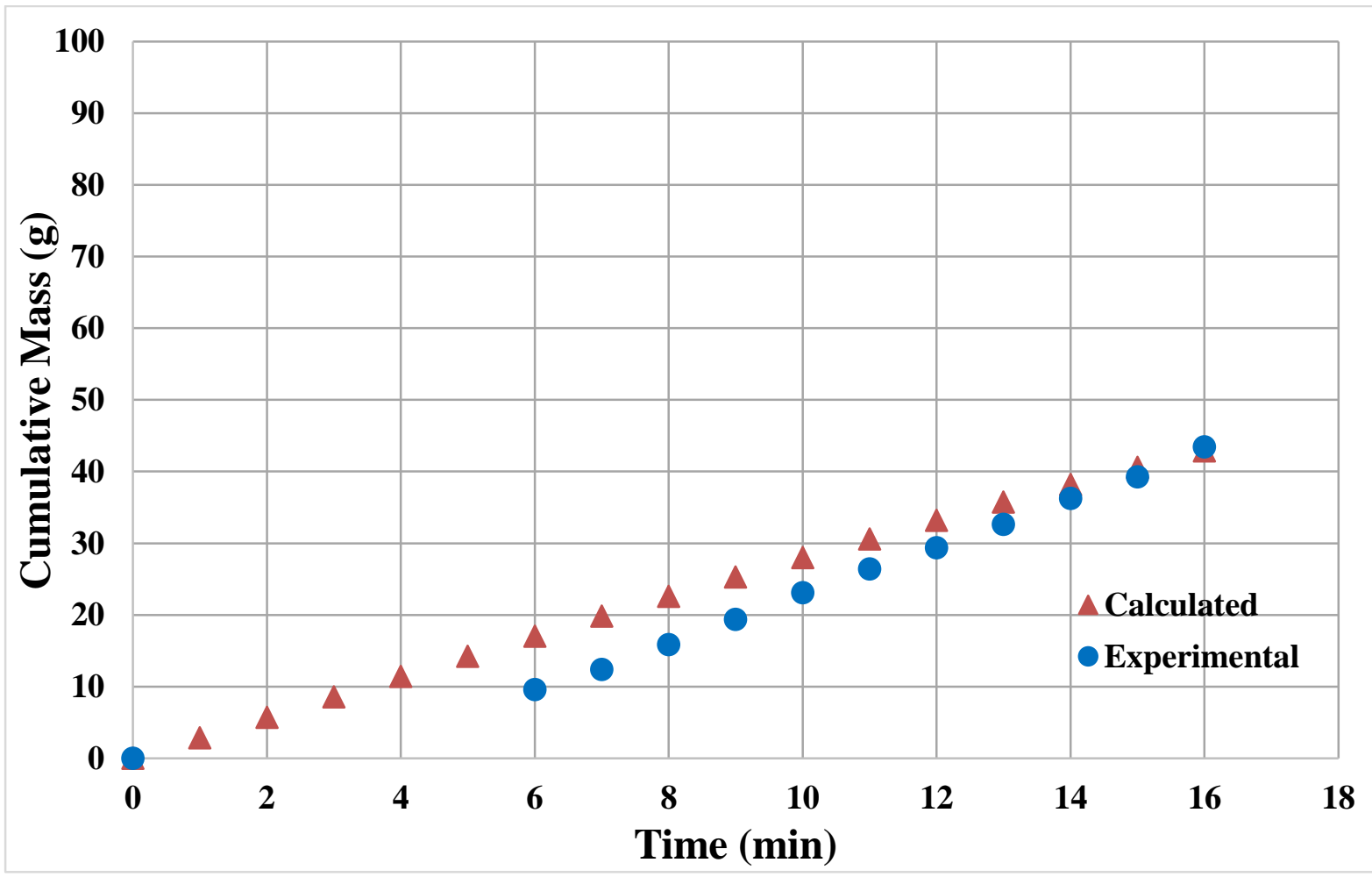

Figure 5.15 Model Validation at 3.44 MPa using 0.5 wt \% polymer concentration 


\section{Conclusions}

\subsection{Conclusions}

1. A novel technique was developed in this research work, polymeric solution injection using different concentrations (0.1-0.5 wt \%) with periodic pressure variation between 2.41 and 3.44 MPa was conducted first time for enhanced oil recovery at room temperature in a laboratory scale polymer flooding process. The developed technique is a combination of experimental-modelling approach.

2. A one-dimensional black oil model was mathematically formulated in conjunction with Darcy's law to predict the oil production rates. The model contains a set of partial differential equations that describes the oleic and aqueous phase flow as well as the pressure and polymer concentration. 
3. Different set of experiments were conducted to study the effects of constant minimum and maximum pressure 1.03 $\mathrm{MPa}$ and $3.44 \mathrm{MPa}$ as well as periodic pressure variations were examined experimentally. A polymer solution with different concentrations 0.1 , $0.2,0.3,0.4,0.5 \mathrm{wt} \%$ was injected at a pressure in the range of 2.41-3.44 MPa into a lab-scale physical reservoir model of porosity $38 \%$. Experiments with periodic pressure variations were performed at least three times and the standard deviation between these experiments were found to be in the range of $\pm 0.124-0.275 \%$ OOIP.

4. A numerical algorithm was used to integrate the model discretized scaled differential equations to predict production rates. The model prediction with $3.44 \mathrm{MPa}$ was close enough with the experimental production rates but not in conjunction with minimum constant pressure $1.03 \mathrm{MPa}$.

5. The experiments with maximum constant pressure $3.44 \mathrm{MPa}$, an oil recovery of $41.92 \%$ OOIP was obtained with 0.1 wt $\%$ polymeric solution injection. On the other hand, periodic pressure variation between 2.41 and $3.44 \mathrm{MPa}$ enhanced the heavy oil recovery to $80 \%$ OOIP using $0.4 \mathrm{wt} \%$ polymer solution. This recovery is $100 \%$ more than that with constant pressure injection. Overall, the oil recovery using partially hydrolyzed polyacrylamide solution at constant pressure $1.03 \mathrm{MPa}$ and periodic injection pressure between 2.41 and $3.44 \mathrm{MPa}$ is a promising technique for oil heavy recovery from conventional and non-conventional heavy oil reservoirs.

\subsection{Recommendations for Future Work}

1. The mathematical model developed in this research work could be applied to predict the simulated oil production rates with minimum constant pressure $1.03 \mathrm{MPa}$ and periodic pressure injection between 2.41 to $3.44 \mathrm{MPa}$.

2. Periodic optimal control and the computational algorithm can be developed and applied on the black oil model in which the pressure versus time can be used as a control function to enhance heavy oil production.

3. To investigate the pilot scale application of periodic pressure injection on large physical reservoir models with and without fractures. 


\section{Appendix A}

Sample of porous medium permeability calculation

The permeability $(K)$ was calculated by applying the following equation (El-Haj, 2010):

$K=\frac{Q \mu L}{A \Delta P} \times 1.01325 \times 10^{12}$

where $Q$ is the volumetric flow rate $\left(\mathrm{m}^{3} / \mathrm{s}\right)$ of the brine through the porous media, $A$ is the cross-sectional area $\left(\mathrm{m}^{2}\right)$ of the fluid flow through the medium, $\mu$ is the viscosity (Pa s) of the brine, and $\Delta P$ is the differential pressure $(\mathrm{Pa})$ across the length of the core $L(\mathrm{~m})$. The corresponding values of all these parameters are listed in Table A for a specific size range of glass beads 0.594-0.419 mm. By substituting all these values in the Equation above gives the absolute permeability.

Table A. Data for calculations

\begin{tabular}{|c|c|}
\hline Parameter & Value \\
\hline$Q\left(\mathrm{~m}^{3} / \mathrm{s}\right)$ & $1.66 \times 10^{-8}$ \\
\hline$\mu_{\text {brine }} @ 25^{\circ} \mathrm{C}(\mathrm{Pa} \mathrm{s})$ & $1.02 \times 10^{-3}$ \\
\hline$L(\mathrm{~m})$ & 0.3 \\
\hline $\mathrm{A}\left(\mathrm{m}^{2}\right)$ & $4.9 \times 10^{-4}$ \\
\hline$\Delta P(\mathrm{~Pa})$ & 1200 \\
\hline
\end{tabular}

$K=\frac{1.66 \times 10^{-8} \times 1.02 \times 10^{-3} \times 0.3}{4.9 \times 10^{-4} \times 1200} \times 1.01325 \times 10^{12}$

$K=8.75$ Darcy 


\section{Appendix B}

Table B. Parameters Used in Equation (32) in the Power Law Model Obtained from the Flow Curve of FLOPAAM3630 Solution at Various Concentrations

\begin{tabular}{cccc}
\hline $\begin{array}{c}\text { Concentration } \\
(\mathrm{ppm})\end{array}$ & $\begin{array}{c}\text { Power law index } \\
(\mathrm{n})\end{array}$ & $\begin{array}{c}\text { Consistency index } \\
(\mathrm{K})\end{array}$ & $\mathrm{r}^{2}$ coefficient \\
\hline 1000 & 0.7866 & 0.05394 & 0.8495 \\
2000 & 0.6869 & 0.1139 & 0.9471 \\
3000 & 0.5389 & 0.3201 & 0.9843 \\
4000 & 0.4569 & 0.6606 & 0.9896 \\
5000 & 0.3015 & 2.29 & 0.9988 \\
\hline
\end{tabular}




\section{Appendix C}

Table C. Parameters Obtained from the Flow Curve of FLOPAAM 3630 (4000 ppm) at Various NaCl Concentrations

\begin{tabular}{c|c|c|c}
\hline $\begin{array}{c}\text { Concentration } \\
(\mathrm{ppm})\end{array}$ & $\begin{array}{c}\text { Power law index } \\
(\mathrm{n})\end{array}$ & $\begin{array}{c}\text { Consistency index } \\
(\mathrm{K})\end{array}$ & $\mathrm{r}^{2}$ coefficient \\
\hline 2000 & 0.4767 & 0.5866 & 0.9883 \\
3000 & 0.4808 & 0.5805 & 0.9819 \\
\hline
\end{tabular}




\section{Appendix D}

\section{Derivation of Polymer Flooding Model}

\section{Pressure Equation Derivation}

First starting with the oleic phase equation and expanding the both sides of the Equation

$h \frac{\partial}{\partial t}\left(\varphi \frac{S_{\mathrm{o}}}{B_{\mathrm{o}}}\right)=\nabla \cdot\left[\frac{K K_{\mathrm{ro}} h}{B_{\mathrm{o}} \mu_{\mathrm{o}}} \nabla \mathrm{P}\right]$

Now expanding the L.H.S of the oleic phase flow Equation

$h\left[\frac{1}{B_{\mathrm{o}}} S_{\mathrm{o}} \frac{\partial \varphi}{\partial t}+\varphi S_{\mathrm{o}}\left(-\frac{1}{B_{o}^{2}}\right) \frac{\partial B_{\mathrm{o}}}{\partial P} \frac{\partial P}{\partial t}+\frac{\varphi}{B_{\mathrm{o}}} \frac{\partial S_{\mathrm{o}}}{\partial t}\right]=\nabla \cdot\left[\frac{K K_{\mathrm{ro}} h}{B_{\mathrm{o}} \mu_{\mathrm{o}}} \nabla \mathrm{P}\right]$

$h\left[\frac{S_{\mathrm{o}}}{B_{\mathrm{o}}} \frac{\partial \varphi}{\partial t}-\frac{\varphi S_{\mathrm{o}}}{B_{\mathrm{o}}^{2}} \frac{\partial B_{\mathrm{o}}}{\partial P} \frac{\partial P}{\partial t}+\frac{\varphi}{B_{\mathrm{o}}} \frac{\partial S_{\mathrm{o}}}{\partial t}\right]=\nabla \cdot\left[\frac{K K_{\mathrm{ro}} h}{B_{\mathrm{o}} \mu_{\mathrm{o}}} \nabla \mathrm{P}\right]$

Now taking the aqueous phase Equation which is written as follows;

$h \frac{\partial}{\partial t}\left(\varphi \frac{S_{\mathrm{w}}}{B_{\mathrm{w}}}\right)=\nabla \cdot\left[\frac{K K_{\mathrm{rw}} h}{B_{\mathrm{w}} \mu_{\mathrm{p}} R_{\mathrm{k}}} \nabla \mathrm{P}\right]$

$h\left[\frac{1}{B_{\mathrm{w}}} S_{\mathrm{w}} \frac{\partial \varphi}{\partial t}+\varphi S_{\mathrm{w}}\left(-\frac{1}{B_{\mathrm{w}}^{2}}\right) \frac{\partial B_{\mathrm{w}}}{\partial P} \frac{\partial P}{\partial t}+\frac{\varphi}{B_{\mathrm{w}}} \frac{\partial S_{\mathrm{w}}}{\partial t}\right]=\nabla \cdot\left[\frac{K K_{\mathrm{rw}} h}{B_{\mathrm{w}} \mu_{\mathrm{p}} R_{\mathrm{k}}} \nabla \mathrm{P}\right]$

(D.2)

Multiply by $\left(\frac{B_{\mathrm{o}}}{h}\right)$ on both sides of the Equation (D.1) and $\left(\frac{B_{\mathrm{W}}}{h}\right)$ on the both sides of the Equation (D.2) we get;

$\left[S_{\mathrm{o}} \frac{\partial \varphi}{\partial t}-\varphi \frac{S_{\mathrm{o}}}{B_{\mathrm{o}}} \frac{\partial B_{\mathrm{o}}}{\partial P} \frac{\partial P}{\partial t}+\varphi \frac{\partial S_{\mathrm{o}}}{\partial t}\right]=\nabla \cdot\left[\frac{K K_{\mathrm{ro}}}{\mu_{\mathrm{o}}} \nabla \mathrm{P}\right]$

where as $\rho_{\mathrm{o}}=\frac{\rho_{\mathrm{osc}}}{B_{\mathrm{o}}}=>B_{\mathrm{o}}=\frac{\rho_{\mathrm{osc}}}{\rho_{\mathrm{o}}}$

Similarly, the aqueous phase Equation becomes;

$$
\begin{aligned}
& {\left[S_{\mathrm{w}} \frac{\partial \varphi}{\partial t}-\varphi \frac{S_{\mathrm{w}}}{B_{\mathrm{w}}} \frac{\partial B_{\mathrm{w}}}{\partial P} \frac{\partial P}{\partial t}+\varphi \frac{\partial S_{\mathrm{w}}}{\partial t}\right]=\nabla \cdot\left[\frac{K K_{\mathrm{rw}}}{R_{\mathrm{k}} \mu_{\mathrm{p}}} \nabla \mathrm{P}\right]} \\
& \therefore \rho_{\mathrm{w}}=\frac{\rho_{\mathrm{wsc}}}{B_{\mathrm{w}}}=>B_{\mathrm{w}}=\frac{\rho_{\mathrm{wsc}}}{\rho_{\mathrm{w}}}
\end{aligned}
$$


Adding Equation (D.2) and (D.3) we get: -

$$
\begin{aligned}
& {\left[\frac{\partial \varphi}{\partial t}\left(S_{\mathrm{o}}+S_{\mathrm{w}}\right)+\varphi C_{\mathrm{o}} S_{\mathrm{o}} \frac{\partial P}{\partial t}+\varphi S_{\mathrm{w}} C_{\mathrm{w}} \frac{\partial P}{\partial t}+\varphi\left(\frac{\partial S_{\mathrm{o}}}{\partial t}+\frac{\partial S_{\mathrm{w}}}{\partial t}\right)\right]=\nabla \cdot\left[\frac{K K_{\mathrm{ro}}}{\mu_{\mathrm{o}}} \nabla \mathrm{P}\right]+} \\
& \nabla \cdot\left[\frac{K K_{\mathrm{rw}}}{\mu_{\mathrm{p}} R_{\mathrm{k}}} \nabla \mathrm{P}\right] \\
& \therefore S_{\mathrm{o}}+S_{\mathrm{w}}=1 \quad C_{\mathrm{o}}=-\frac{1}{B_{\mathrm{o}}} \frac{\partial B_{\mathrm{o}}}{\partial P} \quad \frac{\partial S_{\mathrm{o}}}{\partial t}+\frac{\partial S_{\mathrm{w}}}{\partial t}=0 \quad C_{\mathrm{w}}=-\frac{1}{B_{\mathrm{w}}} \frac{\partial B_{\mathrm{w}}}{\partial P} \\
& {\left[\frac{\partial \varphi}{\partial t}+\varphi \frac{\partial P}{\partial t}\left(C_{\mathrm{o}} S_{\mathrm{o}}+C_{\mathrm{w}} S_{\mathrm{w}}\right)+0\right]=\nabla \cdot\left[\frac{K K_{\mathrm{ro}}}{\mu_{\mathrm{o}}} \nabla \mathrm{P}\right]+\nabla \cdot\left[\frac{K K_{\mathrm{rw}}}{\mu_{\mathrm{p}} R_{\mathrm{k}}} \nabla \mathrm{P}\right]} \\
& \therefore \frac{\partial \varphi}{\partial t}=\frac{\partial \varphi}{\partial P} \frac{\partial P}{\partial t} \\
& {\left[\frac{\partial \varphi}{\partial p} \frac{\partial P}{\partial t}+\varphi \frac{\partial P}{\partial t}\left(C_{\mathrm{o}} S_{\mathrm{o}}+C_{\mathrm{w}} S_{\mathrm{w}}\right)\right]=\nabla \cdot\left[\frac{K K_{\mathrm{ro}}}{\mu_{\mathrm{o}}} \nabla \mathrm{P}\right]+\nabla \cdot\left[\frac{K K_{\mathrm{rw}}}{\mu_{\mathrm{p}} R_{\mathrm{k}}} \nabla \mathrm{P}\right]} \\
& {\left[\frac{\partial P}{\partial t}\left(\frac{\partial \varphi}{\partial P}+\varphi\left(C_{\mathrm{o}} S_{\mathrm{o}}+C_{\mathrm{w}} S_{\mathrm{w}}\right)\right]=\nabla \cdot\left[\frac{K K_{\mathrm{ro}}}{\mu_{\mathrm{o}}} \nabla \mathrm{P}\right]+\nabla \cdot\left[\frac{K K_{\mathrm{rw}}}{\mu_{\mathrm{p}} R_{\mathrm{k}}} \nabla \mathrm{P}\right]\right.} \\
& \varphi \frac{\partial P}{\partial t}\left[\frac{1}{\varphi} \frac{\partial \varphi}{\partial P}+C_{\mathrm{o}} S_{\mathrm{o}}+C_{\mathrm{w}} S_{\mathrm{w}}\right]=\nabla \cdot\left[\frac{K K_{\mathrm{ro}}}{\mu_{\mathrm{o}}} \nabla \mathrm{P}\right]+\nabla \cdot\left[\frac{K K_{\mathrm{rw}}}{\mu_{\mathrm{p}} R_{\mathrm{k}}} \nabla \mathrm{P}\right] \\
& \therefore C_{\mathrm{T}}=\left[\frac{1}{\varphi} \frac{\partial \varphi}{\partial P}+C_{\mathrm{o}} S_{\mathrm{o}}+C_{\mathrm{w}} S_{\mathrm{w}}\right] \\
& \varphi C_{\mathrm{T}} \frac{\partial P}{\partial t}=\nabla \cdot\left[\frac{K K_{\mathrm{ro}}}{\mu_{\mathrm{o}}} \nabla \mathrm{P}_{\mathrm{o}}\right]+\nabla \cdot\left[\frac{K K_{\mathrm{rw}}}{\mu_{\mathrm{p}} R_{\mathrm{k}}} \nabla \mathrm{P}_{\mathrm{w}}\right] \\
& \varphi C_{\mathrm{T}} \frac{\partial P}{\partial t}=\nabla \cdot\left[\frac{K K_{\mathrm{ro}}}{\mu_{\mathrm{o}}} \nabla \mathrm{P}_{\mathrm{o}}\right]+\nabla \cdot\left[\frac{K K_{\mathrm{rw}}}{\mu_{\mathrm{p}} R_{\mathrm{k}}}\left(\nabla \mathrm{P}_{\mathrm{o}}-\nabla \mathrm{P}_{\mathrm{c}}\right)\right] \\
& \therefore \mathrm{P}_{\mathrm{c}}=\mathrm{P}_{\mathrm{o}}-\mathrm{P}_{\mathrm{w}} \text {, where } \mathrm{P}_{\mathrm{c}} \text { is the capillary pressure and } \\
& \therefore \nabla \mathrm{P}_{\mathrm{c}}=\nabla \mathrm{P}_{\mathrm{o}}-\nabla \mathrm{P}_{\mathrm{w}}=\nabla \mathrm{P}_{\mathrm{w}}=\nabla \mathrm{P}_{\mathrm{o}}-\nabla \mathrm{P}_{\mathrm{c}} \\
& \varphi C_{\mathrm{T}} \frac{\partial P}{\partial t}=\nabla \cdot\left[\frac{K K_{\mathrm{ro}}}{\mu_{\mathrm{o}}} \nabla \mathrm{P}_{\mathrm{o}}\right]+\nabla \cdot\left[\frac{K K_{\mathrm{rw}}}{\mu_{\mathrm{p}} R_{\mathrm{k}}}\left(\nabla \mathrm{P}_{\mathrm{o}}-\frac{\partial \mathrm{P}_{\mathrm{c}}}{\partial \mathrm{S}_{\mathrm{w}}} \nabla \boldsymbol{S}_{\mathrm{w}}\right)\right] \\
& \therefore \frac{\partial \mathrm{P}_{\mathrm{c}}}{\partial \mathrm{S}_{\mathrm{w}}} \nabla \boldsymbol{S}_{\mathrm{w}}=0
\end{aligned}
$$

The capillary pressure effect is considered to be negligible then the equation takes the form as;

$$
\varphi C_{\mathrm{T}} \frac{\partial P}{\partial t}=\nabla \cdot\left[\frac{K K_{\mathrm{ro}}}{\mu_{\mathrm{o}}} \nabla \mathrm{P}_{\mathrm{o}}\right]+\nabla \cdot\left[\frac{K K_{\mathrm{rw}}}{\mu_{\mathrm{p}} R_{\mathrm{k}}} \nabla \mathrm{P}_{\mathrm{o}}\right]
$$




\section{Derivation of Pressure Equation in Cylindrical Coordinates}

Now solving the pressure Equation (D.4):

$\varphi C_{\mathrm{T}} \frac{\partial P}{\partial t}=\nabla \cdot\left[\frac{K K_{\mathrm{ro}}}{\mu_{\mathrm{o}}} \nabla \mathrm{P}\right]+\nabla \cdot\left[\frac{K K_{\mathrm{rw}}}{\mu_{\mathrm{p}} R_{\mathrm{k}}} \nabla \mathrm{P}\right]$

Now expanding the R.H.S of the above Equation

$\nabla \cdot\left[\frac{K K_{\mathrm{ro}}}{\mu_{\mathrm{o}}} \nabla \mathrm{P}\right]$

$=\frac{K K_{\mathrm{ro}}}{\mu_{\mathrm{o}}} \nabla \cdot(\nabla \mathrm{P})+\nabla \mathrm{P} \cdot \nabla \underbrace{\left(\frac{K K_{\mathrm{ro}}}{\mu_{\mathrm{o}}}\right)}_{\alpha}$

$=\frac{K K_{\mathrm{ro}}}{\mu_{\mathrm{o}}} \nabla \cdot(\nabla \mathrm{P})+\nabla \mathrm{P} \cdot \nabla(\alpha)$

$=\frac{K K_{\mathrm{ro}}}{\mu_{\mathrm{o}}} \nabla^{2} \mathrm{P}+\nabla \mathrm{P} \cdot \nabla(\alpha)$

$=\frac{K K_{\mathrm{ro}}}{\mu_{\mathrm{o}}}\left[\frac{1}{r} \frac{\partial}{\partial r}\left(r \frac{\partial P}{\partial r}\right)+\frac{1}{r^{2}} \frac{\partial^{2} P}{\partial \theta^{2}}+\frac{\partial^{2} P}{\partial z^{2}}\right]+\left[\hat{r} \frac{\partial P}{\partial r}+\frac{1}{r} \hat{\theta} \frac{\partial P}{\partial \theta}+\hat{z} \frac{\partial P}{\partial z}\right] \cdot\left[\hat{r} \frac{\partial \alpha}{\partial r}+\frac{1}{r} \hat{\theta} \frac{\partial \alpha}{\partial \theta}+\hat{z} \frac{\partial \alpha}{\partial z}\right]$

$=\frac{K K_{\mathrm{ro}}}{\mu_{\mathrm{o}}}\left[\frac{\partial^{2} P}{\partial z^{2}}\right]+\left[\frac{\partial P}{\partial z}\right]\left[\frac{\partial \alpha}{\partial z}\right]$

$\alpha=\alpha\left[K_{\mathrm{ro}}\left(S_{\mathrm{o}}(z)\right)\right]$

$\frac{\partial \alpha}{\partial z}=\left[\frac{\partial \alpha}{\partial K_{\mathrm{ro}}} \frac{\partial K_{\mathrm{ro}}}{\partial S_{\mathrm{o}}} \frac{\partial S_{\mathrm{o}}}{\partial z}\right]$

$\alpha=\frac{K K_{\mathrm{ro}}}{\mu_{\mathrm{o}}}$

1. $\frac{\partial \alpha}{\partial K_{\mathrm{ro}}}=\frac{\partial}{\partial K_{\mathrm{ro}}}\left(\frac{K K_{\mathrm{ro}}}{\mu_{\mathrm{o}}}\right)$

$\frac{\partial \alpha}{\partial K_{\mathrm{ro}}}=\frac{K}{\mu_{0}}$

2. $\frac{\partial K_{\mathrm{ro}}}{\partial S_{\mathrm{o}}}=\frac{\partial}{\partial S_{\mathrm{o}}}\left[K_{\mathrm{ro}, \mathrm{cw}}\left(\frac{1-S_{\mathrm{w}}-S_{\mathrm{or}}}{1-S_{\mathrm{wc}}-S_{\mathrm{or}}}\right)^{n_{\mathrm{o}}}\right]$

$\therefore S_{\mathrm{o}}+S_{\mathrm{w}}=1=>\quad S_{\mathrm{o}}=1-S_{\mathrm{w}}$ 
$\frac{\partial K_{\mathrm{ro}}}{\partial S_{0}}=\left(\frac{n_{o} K_{\mathrm{ro}, \mathrm{cw}}}{1-S_{\mathrm{wc}}-S_{\mathrm{or}}}\right)\left(\frac{S_{\mathrm{o}}-S_{\mathrm{or}}}{1-S_{\mathrm{wc}}-S_{\mathrm{or}}}\right)^{n_{o}-1}$

Now inserting values of Equation (D.6) and (D.7) into (D.5), we get the following equation below

$\frac{\partial \alpha}{\partial z}=\left[\frac{K}{\mu_{\mathrm{o}}}\left(\frac{n_{o} K_{\mathrm{ro}, \mathrm{cw}}}{1-S_{\mathrm{wc}}-S_{\mathrm{or}}}\right)\left(\frac{S_{\mathrm{o}}-S_{\mathrm{or}}}{1-S_{\mathrm{wc}}-S_{\mathrm{or}}}\right)^{n_{o}-1} \frac{\partial S_{\mathrm{o}}}{\partial z}\right]$

By inserting Equations (D.8) into (D.6) the resulting equation becomes;

$\nabla \cdot\left[\frac{K K_{\mathrm{ro}}}{\mu_{\mathrm{o}}} \nabla \mathrm{P}\right]=\frac{K K_{\mathrm{ro}}}{\mu_{\mathrm{o}}}\left[\frac{\partial^{2} P}{\partial z^{2}}\right]+\left[\frac{K}{\mu_{\mathrm{o}}}\left(\frac{n_{\mathrm{o}} K_{\mathrm{ro}, \mathrm{cw}}}{1-S_{\mathrm{wc}}-S_{\mathrm{or}}}\right)\left(\frac{S_{\mathrm{o}}-S_{\mathrm{or}}}{1-S_{\mathrm{wc}}-S_{\mathrm{or}}}\right)^{n_{o}-1} \frac{\partial S_{\mathrm{o}}}{\partial z} \frac{\partial P}{\partial z}\right]$

Now expanding the term $\nabla \cdot\left[\frac{K K_{\mathrm{rw}}}{\mu_{\mathrm{p}} R_{\mathrm{k}}} \nabla \mathrm{P}\right]$

$=\frac{K K_{\mathrm{rw}}}{R_{\mathrm{k}} \mu_{\mathrm{p}}} \nabla \cdot(\nabla \mathrm{P})+\nabla \mathrm{P} \cdot \nabla \underbrace{\left(\frac{K K_{\mathrm{rw}}}{R_{\mathrm{k}} \mu_{\mathrm{p}}}\right)}_{\beta}$

$=\frac{K K_{\mathrm{rw}}}{R_{\mathrm{k}} \mu_{\mathrm{p}}} \nabla \cdot(\nabla \mathrm{P})+\nabla \mathrm{P} \cdot \nabla(\beta)$

$=\frac{K K_{\mathrm{rw}}}{R_{\mathrm{k}} \mu_{\mathrm{p}}} \nabla^{2} \mathrm{P}+\nabla \mathrm{P} \cdot \nabla(\beta)$

$=\frac{K K_{\mathrm{rw}}}{R_{\mathrm{k}} \mu_{\mathrm{p}}}\left[\frac{1}{r} \frac{\partial}{\partial r}\left(r \frac{\partial P}{\partial r}\right)+\frac{1}{r^{2}} \frac{\partial^{2} P}{\partial \theta^{2}}+\frac{\partial^{2} P}{\partial z^{2}}\right]+\left[\hat{r} \frac{\partial P}{\partial r}+\frac{1}{r} \hat{\theta} \frac{\partial P}{\partial \theta}+\hat{z} \frac{\partial P}{\partial z}\right] \cdot\left[\hat{r} \frac{\partial \beta}{\partial r}+\frac{1}{r} \hat{\theta} \frac{\partial \beta}{\partial \theta}+\hat{z} \frac{\partial \beta}{\partial z}\right]$

$=\frac{K K_{\mathrm{rw}}}{R_{\mathrm{k}} \mu_{\mathrm{p}}}\left[\frac{\partial^{2} P}{\partial z^{2}}\right]+\left[\frac{\partial P}{\partial z}\right]\left[\frac{\partial \beta}{\partial z}\right]$

$\beta=\beta\left[K_{\mathrm{rw}}\left(S_{\mathrm{w}}(z)\right), R_{\mathrm{k}}(C(z)), \mu_{\mathrm{p}}(C(z))\right]$

$\frac{\partial \beta}{\partial z}=\left[\frac{\partial \beta}{\partial K_{\mathrm{rw}}} \frac{\partial K_{\mathrm{rw}}}{\partial S_{\mathrm{w}}} \frac{\partial S_{\mathrm{w}}}{\partial z}+\frac{\partial \beta}{\partial R_{\mathrm{k}}} \frac{\partial R_{\mathrm{k}}}{\partial C} \frac{\partial C}{\partial z}+\frac{\partial \beta}{\partial \mu_{\mathrm{p}}} \frac{\partial \mu_{\mathrm{p}}}{\partial C} \frac{\partial C}{\partial z}\right]$

$\beta=\frac{K K_{\mathrm{rw}}}{R_{\mathrm{k}} \mu_{\mathrm{p}}}$

1. $\frac{\partial \beta}{\partial K_{\mathrm{rw}}}=\frac{\partial}{\partial K_{\mathrm{rw}}}\left(\frac{K K_{\mathrm{rw}}}{R_{\mathrm{k}} \mu_{\mathrm{p}}}\right)$

$\frac{\partial \beta}{\partial K_{\mathrm{rw}}}=\frac{K}{R_{\mathrm{k}} \mu_{\mathrm{p}}}$ 
2. $\quad \frac{\partial K_{\mathrm{rw}}}{\partial S_{\mathrm{w}}}=\frac{\partial}{\partial S_{\mathrm{w}}}\left[K_{\mathrm{rw}, \mathrm{ro}}\left(\frac{S_{\mathrm{W}}-S_{\mathrm{wc}}}{1-S_{\mathrm{wc}}-S_{\mathrm{or}}}\right)^{n_{w}}\right]$

$\frac{\partial K_{\mathrm{rw}}}{\partial S_{\mathrm{w}}}=\left(\frac{n_{w} K_{\mathrm{rw}, \mathrm{ro}}}{1-S_{\mathrm{wc}}-S_{\mathrm{or}}}\right)\left(\frac{S_{\mathrm{w}}-S_{\mathrm{wc}}}{1-S_{\mathrm{wc}}-S_{\mathrm{or}}}\right)^{n_{w^{-1}}}$

3. $\frac{\partial \beta}{\partial R_{\mathrm{k}}}=\frac{\partial}{\partial R_{\mathrm{k}}}\left(\frac{K K_{\mathrm{rw}}}{R_{\mathrm{k}} \mu_{\mathrm{p}}}\right)$

$\frac{\partial \beta}{\partial R_{\mathrm{k}}}=-\frac{K K_{\mathrm{rw}}}{R_{\mathrm{k}}^{2} \mu_{\mathrm{p}}}$

4. $\frac{\partial R_{\mathrm{k}}}{\partial C}=\frac{\partial}{\partial C}\left(1+\frac{\left(R_{\mathrm{kmax}}-1\right) \cdot b_{\mathrm{rk}} \cdot C}{1+b_{\mathrm{rk}} \cdot C}\right)$

$\frac{\partial R_{\mathrm{k}}}{\partial C}=\left(\frac{\left(R_{\mathrm{kmax}} b_{\mathrm{rk}}-b_{\mathrm{rk}}\right)}{\left(1+b_{\mathrm{rk}} \cdot C\right)^{2}}\right)$

5. $\frac{\partial \beta}{\partial \mu_{\mathrm{p}}}=\frac{\partial}{\partial \mu_{\mathrm{p}}}\left(\frac{K K_{\mathrm{rw}}}{R_{\mathrm{k}} \mu_{\mathrm{p}}}\right)$

$\frac{\partial \beta}{\partial \mu_{\mathrm{p}}}=-\frac{K K_{\mathrm{rw}}}{\mu_{\mathrm{p}}^{2} R_{\mathrm{k}}}$

6. $\frac{\partial \mu_{\mathrm{p}}}{\partial C}=\frac{\partial}{\partial C}\left[\mu_{\mathrm{w}}\left(1+\left(a p_{1} C+a p_{2} C^{2}+a p_{3} C^{3}\right)\right)\right]$

$\frac{\partial \mu_{\mathrm{p}}}{\partial C}=\left(\mu_{\mathrm{w}} a p_{1}+2 \mu_{\mathrm{w}} a p_{2} \cdot C+3 \mu_{\mathrm{w}} a p_{3} \cdot C^{2}\right)$

Now inserting all the derivatives of the above Equations (D.11-16) into the Equation below and we get the following relation;

$\frac{\partial \beta}{\partial z}=\left[\frac{\partial \beta}{\partial K_{\mathrm{rw}}} \frac{\partial K_{\mathrm{rw}}}{\partial S_{\mathrm{w}}} \frac{\partial S_{\mathrm{w}}}{\partial z}+\frac{\partial \beta}{\partial R_{\mathrm{k}}} \frac{\partial R_{\mathrm{k}}}{\partial C} \frac{\partial C}{\partial z}+\frac{\partial \beta}{\partial \mu_{\mathrm{p}}} \frac{\partial \mu_{\mathrm{p}}}{\partial C} \frac{\partial C}{\partial z}\right]$

$\frac{\partial \beta}{\partial z}=\left[\frac{K}{R_{\mathrm{k}} \mu_{\mathrm{p}}}\left(\frac{n_{w} K_{\mathrm{rw}, \mathrm{ro}}}{1-S_{\mathrm{wc}}-S_{\mathrm{or}}}\right)\left(\frac{S_{\mathrm{w}}-S_{\mathrm{wc}}}{1-S_{\mathrm{wc}}-S_{\mathrm{or}}}\right)^{n_{w}-1} \frac{\partial S_{\mathrm{w}}}{\partial z}-\frac{K k_{\mathrm{rw}}}{R_{\mathrm{k}}^{2} \mu_{\mathrm{p}}}\left(\frac{\left(R_{\mathrm{kmax}} b_{\mathrm{rk}}-b_{\mathrm{rk}}\right)}{\left(1+b_{\mathrm{rk}} \cdot C\right)^{2}}\right) \frac{\partial C}{\partial z}-\right.$

$\left.\frac{K K_{\mathrm{rw}}}{\mu_{\mathrm{p}}^{2} R_{\mathrm{k}}}\left(\mu_{\mathrm{w}} a p_{1}+2 \mu_{\mathrm{w}} a p_{2} \cdot C+3 \mu_{\mathrm{w}} a p_{3} \cdot C^{2}\right) \frac{\partial C}{\partial z}\right]$ 


$$
\begin{aligned}
& \varphi C_{\mathrm{T}} \frac{\partial P}{\partial t}=\frac{K K_{\mathrm{ro}}}{\mu_{\mathrm{o}}}\left[\frac{\partial^{2} P}{\partial z^{2}}\right]+\left[\frac{K}{\mu_{\mathrm{o}}}\left(\frac{n_{o} K_{\mathrm{ro}, \mathrm{cw}}}{1-S_{\mathrm{wc}}-S_{\mathrm{or}}}\right)\left(\frac{S_{\mathrm{o}}-S_{\mathrm{or}}}{1-S_{\mathrm{wc}}-S_{\mathrm{or}}}\right)^{n_{o}-1} \frac{\partial S_{\mathrm{o}}}{\partial z} \frac{\partial P}{\partial z}\right]+\frac{K K_{\mathrm{rw}}}{R_{\mathrm{k}} \mu_{\mathrm{p}}}\left[\frac{\partial^{2} P}{\partial z^{2}}\right]+ \\
& {\left[\frac{K}{R_{\mathrm{k}} \mu_{\mathrm{p}}}\left(\frac{n_{w} K_{\mathrm{rw}, \mathrm{ro}}}{1-S_{\mathrm{wc}}-S_{\mathrm{or}}}\right)\left(\frac{S_{\mathrm{w}}-S_{\mathrm{wc}}}{1-S_{\mathrm{wc}}-S_{\mathrm{or}}}\right)^{n_{w}-1} \frac{\partial S_{\mathrm{w}}}{\partial z} \frac{\partial P}{\partial z}-\frac{K K_{\mathrm{rw}}}{R_{\mathrm{k}}^{2} \mu_{\mathrm{p}}}\left(\frac{\left(R_{\mathrm{kmax}} b_{\mathrm{rk}}-b_{\mathrm{rk}}\right)}{\mu_{\mathrm{rw}}}\right) \frac{\partial C}{\partial z} \frac{\partial P}{\partial z}-\right.} \\
& \frac{\partial P}{\partial t}=\frac{\left.K K_{\mathrm{rk}} \cdot C\right)^{2}}{\mu_{\mathrm{o}} \varphi C_{\mathrm{T}}}\left[\frac{\partial^{2} P}{\partial z^{2}}\right]+\left[\frac{K}{\mu_{\mathrm{o}} \varphi C_{\mathrm{T}}}\left(\frac{n_{o} K_{\mathrm{ro}, \mathrm{cw}}}{1-S_{\mathrm{wc}}-S_{\mathrm{or}}}\right)\left(\frac{S_{\mathrm{o}}-S_{\mathrm{or}}}{1-S_{\mathrm{wc}}-S_{\mathrm{or}}}\right)^{n_{o}-1} \frac{\partial S_{\mathrm{o}}}{\partial z} \frac{\partial P}{\partial z}\right]+\frac{K K_{\mathrm{rw}}}{R_{\mathrm{k}} \mu_{\mathrm{p}} \varphi C_{\mathrm{T}}}\left[\frac{\partial^{2} P}{\partial z^{2}}\right]+ \\
& {\left[\frac{K}{R_{\mathrm{k}} \mu_{\mathrm{p}} \varphi C_{\mathrm{T}}}\left(\frac{n_{w} K_{\mathrm{rw}, \mathrm{ro}}}{1-S_{\mathrm{wc}}-S_{\mathrm{or}}}\right)\left(\frac{S_{\mathrm{w}}-S_{\mathrm{wc}}}{1-S_{\mathrm{wc}}-S_{\mathrm{or}}}\right)^{n_{w}-1} \frac{\partial S_{\mathrm{w}}}{\partial z} \frac{\partial P}{\partial z}-\frac{K K_{\mathrm{rw}}}{R_{\mathrm{k}} \mu_{\mathrm{p}} \varphi C_{\mathrm{T}}} \frac{\partial C}{\partial z} \frac{\partial P}{\partial z}\left(\left(\frac{\left(R_{\mathrm{kmax}} b_{\mathrm{rk}}-b_{\mathrm{rk}}\right)}{R_{\mathrm{k}}\left(1+b_{\mathrm{rk}} \cdot C\right)^{2}}\right)+\right.\right.} \\
& \left.\left.\left(\frac{\left(\mu_{\mathrm{w}} a p_{1}+2 \mu_{\mathrm{w}} a p_{2} \cdot C+3 \mu_{\mathrm{w}} a p_{3} \cdot C^{2}\right)}{\mu_{\mathrm{p}}}\right)\right)\right]
\end{aligned}
$$

\section{Derivation of Oleic Flow Equation}

Consider the two dimensional flow of fluid through a porous medium. Let ' $\varphi$ ' be the porosity of the medium and ' $h$ ' denotes the thickness of the reservoir bed. The density of the fluid is represented by ' $\rho$ ' which is flowing with a superficial velocity ' $v$ '. By applying the general mass balance equation across the control element of the core, we get;

\section{General Mass Balance:}

$\left[\begin{array}{c}\text { Rate of Mass } \\ \text { into the element } \\ a t^{\prime} r^{\prime}\end{array}\right]-\left[\begin{array}{c}\text { Rate of Mass } \\ \text { out of the element } \\ a t^{\prime} r+\Delta r^{\prime}\end{array}\right]+\left[\begin{array}{c}\text { Rate of Mass } \\ \text { into the element } \\ a t^{\prime} z^{\prime}\end{array}\right]-$

$$
\left[\begin{array}{c}
\text { Rate of Mass } \\
\text { out of the element } \\
\text { at }{ }^{\prime} z+\Delta z^{\prime}
\end{array}\right]=\left[\begin{array}{c}
\text { Rate of } \\
\text { Accumulation }
\end{array}\right]
$$

\section{$\underline{\text { Rate of fluid mass enters the element at ' } r \text { ': }}$}

$\rho\left(r, z^{\prime}\right) \cdot v_{r}\left(r, z^{\prime}\right) \cdot h\left(r, z^{\prime}\right) \cdot \Delta z=\Delta z\left(h \rho v_{r}\right)_{r, z^{\prime}}$

\section{$\underline{\text { Rate of fluid mass leaves the element at ' } r+\Delta r \text { ': }}$}

$\rho\left(r+\Delta r, z^{\prime}\right) \cdot v_{r}\left(r+\Delta r, z^{\prime}\right) \cdot h\left(r+\Delta r, z^{\prime}\right) \cdot \Delta z=\Delta z\left(h \rho v_{r}\right)_{r+\Delta r, z^{\prime}}$

\section{Rate of fluid mass enters the element at ' $z$ ':}


$\rho\left(r^{\prime}, z\right) \cdot v_{z}\left(r^{\prime}, z\right) \cdot h\left(r^{\prime}, z\right) \cdot \Delta r=\Delta r\left(h \rho v_{z}\right)_{r^{\prime}, z}$

$\underline{\text { Rate of fluid mass leaves the element at ' } z+\Delta z \text { ': }}$

$\rho\left(r^{\prime}, z+\Delta z\right) \cdot v_{z}\left(r^{\prime}, z+\Delta z\right) \cdot h\left(r^{\prime}, z+\Delta z\right) \cdot \Delta r=\Delta r\left(h \rho v_{z}\right)_{r^{\prime}, z+\Delta z}$

\section{$\underline{\text { Rate of accumulation: }}$}

$h \frac{\partial}{\partial t}\left(\varphi \rho S_{n}\right) \Delta r \Delta z$

where ' $S_{n}{ }^{\prime}$ is the phase saturation or non-wetting phase saturation.

$$
\left[\Delta z\left(h \rho v_{r}\right)_{r}-\Delta z\left(h \rho v_{r}\right)_{r+\Delta r}\right]+\left[\Delta r\left(h \rho v_{z}\right)_{z}-\Delta r\left(h \rho v_{z}\right)_{z+\Delta z}\right]=h \frac{\partial}{\partial t}\left(\varphi \rho S_{n}\right) \Delta r \Delta z
$$

Rearranging and dividing by ' $\Delta r \Delta z^{\prime}$ and taking the limit $\Delta r \rightarrow 0, \Delta z \rightarrow 0$.

$-\frac{\partial}{\partial r}\left(h \rho v_{r}\right)-\frac{\partial}{\partial z}\left(h \rho v_{z}\right)=h \frac{\partial}{\partial t}\left(\varphi \rho S_{n}\right)$

\section{According to Darcy's law:}

$\widehat{Q}=\frac{K A}{\mu} \frac{\Delta P}{L}($ For horizontal System $)$

where ' $\Delta P^{\prime}$ is the applied pressure drop across the sample, ' $\mu$ ' is the fluid viscosity and ' $K$ ' is the intrinsic or absolute permeability

$v=\frac{\hat{Q}}{A}=-\frac{K}{\mu} \frac{\Delta P}{L}$

$\therefore \hat{Q}=$ volumetric flow rate

$\therefore v=$ superficial flow velocity

Note: - "Negative sign" indicates that the pressure decreases in the direction of flow.

Darcy's law for ' $r$ - and $z$-dimension is given as follows;

$v_{r}=-\frac{K}{\mu} \frac{\partial P}{\partial r}$

$v_{z}=-\frac{K}{\mu} \frac{\partial P}{\partial z}$ 
inserting Equation (D.20), and (D.21) into (D.19), the resulting Equation becomes;

$-\frac{\partial}{\partial r}\left(h \rho\left(-\frac{K}{\mu} \frac{\partial P}{\partial r}\right)\right)-\frac{\partial}{\partial z}\left(h \rho\left(-\frac{K}{\mu} \frac{\partial P}{\partial z}\right)\right)=h \frac{\partial}{\partial t}\left(\varphi \rho S_{n}\right)$

$\frac{\partial}{\partial r}\left(h \rho \frac{K}{\mu} \frac{\partial P}{\partial r}\right)+\frac{\partial}{\partial z}\left(h \rho \frac{K}{\mu} \frac{\partial P}{\partial z}\right)=h \frac{\partial}{\partial t}\left(\varphi \rho S_{n}\right)$

The above equation is the general equation for both the aqueous phase and oleic phase flow.

Now consider the equation specifically for the flow of oleic phase through the medium.

$\frac{\partial}{\partial r}\left(h \rho_{\mathrm{o}} \frac{K_{\mathrm{o}}}{\mu_{\mathrm{o}}} \frac{\partial P}{\partial r}\right)+\frac{\partial}{\partial z}\left(h \rho_{\mathrm{o}} \frac{K_{\mathrm{o}}}{\mu_{\mathrm{o}}} \frac{\partial P}{\partial z}\right)=h \frac{\partial}{\partial t}\left(\varphi \rho_{\mathrm{o}} S_{\mathrm{o}}\right)$

$\therefore K_{\mathrm{ro}}=\frac{K_{\mathrm{o}}}{K} \leq 1 \Rightarrow K_{\mathrm{o}}=K K_{\mathrm{ro}}$

$\therefore K_{\mathrm{rw}}=\frac{K_{\mathrm{w}}}{K} \leq 1 \Rightarrow K_{\mathrm{w}}=K K_{\mathrm{rw}}$

The simultaneous flow of the two fluids causes to interfere with the flow of each other, therefore this effective permeability's must be less than or equal to the single fluid permeability, ' $\mathrm{K}$ ' of the medium.

$\frac{\partial}{\partial r}\left(h \rho_{\mathrm{o}} \frac{K K_{\mathrm{ro}}}{\mu_{\mathrm{o}}} \frac{\partial P}{\partial r}\right)+\frac{\partial}{\partial z}\left(h \rho_{\mathrm{o}} \frac{K K_{\mathrm{ro}}}{\mu_{\mathrm{o}}} \frac{\partial P}{\partial z}\right)=h \frac{\partial}{\partial t}\left(\varphi \rho_{\mathrm{o}}\left(1-S_{\mathrm{w}}\right)\right)$

$\therefore S_{\mathrm{o}}+S_{\mathrm{w}}=1=>1-S_{\mathrm{w}}$

$S_{\mathrm{o}}=$ Phase saturation of oil

$S_{\mathrm{w}}=$ Phase saturation of water

$\frac{\partial}{\partial r}\left(h \rho_{\mathrm{o}} \frac{K K_{\mathrm{ro}}}{\mu_{\mathrm{o}}} \frac{\partial P}{\partial r}\right)+\frac{\partial}{\partial z}\left(h \rho_{\mathrm{o}} \frac{K K_{\mathrm{ro}}}{\mu_{\mathrm{o}}} \frac{\partial P}{\partial z}\right)=h \frac{\partial}{\partial t}\left(\varphi \rho_{\mathrm{o}}\left(1-S_{\mathrm{w}}\right)\right)$

\section{Formation Volume Factor:}

Ratio of volume of the fluid measure at reservoir conditions to the volume of the same fluid at the standard conditions.

$B(P, T)=\frac{V(P, T)}{V_{S C}}$ 
Let ' $W$ ' be the weight of the fluid, because $V=\frac{W}{\rho}$ and $V_{s c}=\frac{W}{\rho_{s c}}$, whereas ' $\rho_{s c}$ ' is the density at standard conditions. So, $\rho=\frac{\rho_{\text {sc }}}{B}$. Similarly, for oil it becomes $\rho_{\mathrm{o}}=\frac{\rho_{\mathrm{osc}}}{\mathrm{B}_{\mathrm{o}}}$.

$B_{\mathrm{o}}=\frac{\rho_{\mathrm{osc}}}{\rho_{\mathrm{o}}}$

$B_{\mathrm{o}}=$ Oil formation volume $\frac{\text { res } \mathrm{m}^{3}}{\text { std } \mathrm{m}^{3}}$

$\frac{\partial}{\partial r}\left(h \rho_{\mathrm{osc}} \frac{K K_{\mathrm{ro}}}{\mu_{\mathrm{o}} B_{\mathrm{o}}} \frac{\partial P}{\partial r}\right)+\frac{\partial}{\partial z}\left(h \rho_{\mathrm{osc}} \frac{K K_{\mathrm{ro}}}{\mu_{\mathrm{o}} B_{\mathrm{o}}} \frac{\partial P}{\partial z}\right)=h \frac{\partial}{\partial t}\left(\varphi \rho_{\mathrm{osc}} \frac{\left(1-S_{\mathrm{W}}\right)}{B_{\mathrm{o}}}\right)$

$\frac{\partial}{\partial r}\left(h \frac{K K_{\mathrm{ro}}}{\mu_{\mathrm{o}} B_{\mathrm{o}}} \frac{\partial P}{\partial r}\right)+\frac{\partial}{\partial z}\left(h \frac{K K_{\mathrm{ro}}}{\mu_{\mathrm{o}} B_{\mathrm{o}}} \frac{\partial P}{\partial z}\right)=h \frac{\partial}{\partial t}\left(\varphi \frac{\left(1-S_{\mathrm{W}}\right)}{B_{\mathrm{o}}}\right)$

Finally, the equation for the oleic phase becomes;

$\frac{\partial}{\partial r}\left(\frac{K K_{\mathrm{ro}} h}{\mu_{0} B_{0}} \frac{\partial P}{\partial r}\right)+\frac{\partial}{\partial z}\left(\frac{K K_{\mathrm{ro}} h}{\mu_{0} B_{0}} \frac{\partial P}{\partial z}\right)=h \frac{\partial}{\partial t}\left(\frac{\varphi\left(1-S_{\mathrm{W}}\right)}{B_{0}}\right)$

\section{Oleic Flow Equation Derivation in Cylindrical Coordinates}

The flow equation for oil phase can be written as;

$$
\begin{aligned}
& h \frac{\partial}{\partial t}\left(\varphi \frac{S_{\mathrm{o}}}{B_{\mathrm{o}}}\right)=\nabla \cdot\left[\frac{K K_{\mathrm{ro}} h}{B_{\mathrm{o}} \mu_{\mathrm{o}}} \nabla \mathrm{P}\right] \\
& h \frac{\partial}{\partial t}\left(\varphi \frac{S_{\mathrm{o}}}{B_{\mathrm{o}}}\right)=\frac{K K_{\mathrm{ro}} h}{B_{\mathrm{o}} \mu_{\mathrm{o}}} \nabla \cdot(\nabla \mathrm{P})+\nabla \mathrm{P} \cdot \nabla \underbrace{\left(\frac{K K_{\mathrm{ro}} h}{B_{\mathrm{o}} \mu_{\mathrm{o}}}\right)}_{\lambda} \\
& h \frac{\partial}{\partial t}\left(\varphi \frac{S_{\mathrm{o}}}{B_{\mathrm{o}}}\right)=\frac{K K_{\mathrm{ro}} h}{B_{\mathrm{o}} \mu_{\mathrm{o}}} \nabla \cdot(\nabla \mathrm{P})+\nabla \mathrm{P} \cdot \nabla(\lambda) \\
& h \frac{\partial}{\partial t}\left(\varphi \frac{S_{\mathrm{o}}}{B_{\mathrm{o}}}\right)=\frac{K K_{\mathrm{ro}} h}{B_{\mathrm{o}} \mu_{\mathrm{o}}} \nabla^{2} \mathrm{P}+\nabla \mathrm{P} \cdot \nabla(\lambda) \\
& h \frac{\partial}{\partial t}\left(\varphi \frac{S_{\mathrm{o}}}{B_{\mathrm{o}}}\right)=\frac{K K_{\mathrm{ro}} h}{B_{\mathrm{o}} \mu_{\mathrm{o}}}\left[\frac{1}{r} \frac{\partial}{\partial r}\left(r \frac{\partial P}{\partial r}\right)+\frac{1}{r^{2}} \frac{\partial^{2} P}{\partial \theta^{2}}+\frac{\partial^{2} P}{\partial z^{2}}\right]+\left[\hat{r} \frac{\partial P}{\partial r}+\frac{1}{r} \hat{\theta} \frac{\partial P}{\partial \theta}+\hat{z} \frac{\partial P}{\partial z}\right] \cdot\left[\hat{r} \frac{\partial \lambda}{\partial r}+\right. \\
& \left.\frac{1}{r} \hat{\theta} \frac{\partial \lambda}{\partial \theta}+\hat{z} \frac{\partial \lambda}{\partial z}\right] \\
& h \frac{\partial}{\partial t}\left(\varphi \frac{S_{\mathrm{o}}}{B_{\mathrm{o}}}\right)=\frac{K K_{\mathrm{ro}} h}{B_{\mathrm{o}} \mu_{\mathrm{o}}}\left[\frac{\partial^{2} P}{\partial z^{2}}\right]+\left[\frac{\partial P}{\partial z}\right]\left[\frac{\partial \lambda}{\partial z}\right]
\end{aligned}
$$


Now simplifying $\left[\frac{\partial \lambda}{\partial z}\right]$

$\lambda=\lambda\left[K_{\mathrm{ro}}\left(S_{\mathrm{o}}(z)\right), B_{\mathrm{o}}(P(z))\right]$

$\frac{\partial \lambda}{\partial Z}=\left[\frac{\partial \lambda}{\partial K_{\mathrm{ro}}} \frac{\partial K_{\mathrm{ro}}}{\partial S_{\mathrm{o}}} \frac{\partial S_{\mathrm{o}}}{\partial Z}+\frac{\partial \lambda}{\partial B_{\mathrm{o}}} \frac{\partial B_{\mathrm{o}}}{\partial P} \frac{\partial P}{\partial Z}\right]$

$\lambda=\frac{K K_{\mathrm{ro}} h}{B_{\mathrm{o}} \mu_{\mathrm{o}}}$

1. $\frac{\partial \lambda}{\partial K_{\mathrm{ro}}}=\frac{\partial}{\partial K_{\mathrm{ro}}}\left(\frac{K K_{\mathrm{ro}} h}{B_{\mathrm{o}} \mu_{\mathrm{o}}}\right)$

$\frac{\partial \lambda}{\partial K_{\mathrm{ro}}}=\frac{K h}{B_{0} \mu_{0}}$

2. $\frac{\partial K_{\mathrm{ro}}}{\partial S_{\mathrm{o}}}=\frac{\partial}{\partial S_{\mathrm{o}}}\left[K_{\mathrm{ro}, \mathrm{cw}}\left(\frac{1-S_{\mathrm{W}}-S_{\mathrm{or}}}{1-S_{\mathrm{wc}}-S_{\mathrm{or}}}\right)^{n_{\mathrm{o}}}\right]$

$\therefore S_{\mathrm{o}}+S_{\mathrm{w}}=1=>\quad S_{\mathrm{o}}=1-S_{\mathrm{w}}$

$\frac{\partial K_{\mathrm{ro}}}{\partial S_{0}}=\left(\frac{n_{o} K_{\mathrm{ro}, \mathrm{cw}}}{1-S_{\mathrm{wc}}-S_{\mathrm{or}}}\right)\left(\frac{S_{\mathrm{o}}-S_{\mathrm{or}}}{1-S_{\mathrm{wc}}-S_{\mathrm{or}}}\right)^{n_{o}-1}$

3. $\frac{\partial \lambda}{\partial B_{\mathrm{o}}}=\frac{\partial}{\partial B_{\mathrm{o}}}\left(\frac{K K_{\mathrm{ro}} h}{B_{\mathrm{o}} \mu_{\mathrm{o}}}\right)$

$\frac{\partial \lambda}{\partial B_{\mathrm{o}}}=-\left(\frac{K K_{\mathrm{ro}} h}{B_{0}^{2} \mu_{\mathrm{o}}}\right)$

$\frac{\partial \lambda}{\partial z}=\left[\frac{\partial \lambda}{\partial K_{\mathrm{ro}}} \frac{\partial K_{\mathrm{ro}}}{\partial S_{\mathrm{o}}} \frac{\partial S_{\mathrm{o}}}{\partial z}+\frac{\partial \lambda}{\partial B_{\mathrm{o}}} \frac{\partial B_{\mathrm{o}}}{\partial P} \frac{\partial P}{\partial z}\right]$

$\frac{\partial \lambda}{\partial z}=\left[\frac{K h}{B_{\mathrm{o}} \mu_{\mathrm{o}}}\left(\frac{n_{o} K_{\mathrm{ro}, \mathrm{cw}}}{1-S_{\mathrm{wc}}-S_{\mathrm{or}}}\right)\left(\frac{S_{\mathrm{o}}-S_{\mathrm{or}}}{1-S_{\mathrm{wc}}-S_{\mathrm{or}}}\right)^{n_{O}-1} \frac{\partial S_{\mathrm{o}}}{\partial z}-\frac{K K_{\mathrm{ro}} h}{B_{\mathrm{o}}^{2} \mu_{\mathrm{o}}} \frac{\partial B_{\mathrm{o}}}{\partial P} \frac{\partial P}{\partial z}\right]$

$\frac{\partial \lambda}{\partial Z}=\left[\frac{K h}{B_{o} \mu_{o}}\left(\frac{n_{o} k_{r o, c w}}{1-S_{w c}-S_{o r}}\right)\left(\frac{S_{o}-S_{o r}}{1-S_{w c}-S_{o r}}\right)^{n_{o}-1} \frac{\partial S_{o}}{\partial Z}+\frac{K K_{r o} h}{B_{o} \mu_{o}} C_{o} \frac{\partial P}{\partial z}\right]$

$h \frac{\partial}{\partial t}\left(\varphi \frac{S_{\mathrm{o}}}{B_{\mathrm{o}}}\right)=\frac{K K_{\mathrm{ro}} h}{B_{\mathrm{o}} \mu_{\mathrm{o}}}\left[\frac{\partial^{2} P}{\partial z^{2}}\right]+\left[\frac{\partial P}{\partial z}\right]\left[\frac{K h}{B_{o} \mu_{o}}\left(\frac{n_{o} K_{r o, c w}}{1-S_{w c}-S_{o r}}\right)\left(\frac{S_{o}-S_{o r}}{1-S_{w c}-S_{o r}}\right)^{n_{o}-1} \frac{\partial S_{o}}{\partial z}+\frac{K K_{r o} h}{B_{o} \mu_{o}} C_{o} \frac{\partial P}{\partial z}\right]$

$h \frac{\partial}{\partial t}\left(\varphi \frac{S_{\mathrm{o}}}{B_{\mathrm{o}}}\right)=\frac{K K_{\mathrm{ro}} h}{B_{\mathrm{o}} \mu_{\mathrm{o}}}\left[\frac{\partial^{2} P}{\partial z^{2}}\right]+\left[\frac{K h}{B_{\mathrm{o}} \mu_{\mathrm{o}}}\left(\frac{n_{\mathrm{o}} K_{\mathrm{ro}, \mathrm{cw}}}{1-S_{\mathrm{wc}}-S_{\mathrm{or}}}\right)\left(\frac{S_{\mathrm{o}}-S_{\mathrm{or}}}{1-S_{\mathrm{wc}}-S_{\mathrm{or}}}\right)^{n_{o}-1} \frac{\partial S_{\mathrm{o}}}{\partial z} \frac{\partial P}{\partial z}+\frac{K K_{\mathrm{ro}} h}{B_{\mathrm{o}} \mu_{\mathrm{o}}} C_{\mathrm{o}} \frac{\partial^{2} P}{\partial z^{2}}\right]$ 
$\therefore C_{\mathrm{o}}=-\frac{1}{B_{\mathrm{o}}} \frac{\partial B_{\mathrm{o}}}{\partial P}$

Now expanding the L.H.S of the above equation $h \frac{\partial}{\partial t}\left(\varphi \frac{S_{\mathrm{o}}}{B_{\mathrm{o}}}\right)$

$h\left[\frac{1}{B_{\mathrm{o}}} S_{\mathrm{o}} \frac{\partial \varphi}{\partial t}+\varphi S_{\mathrm{o}}\left(-\frac{1}{B_{\mathrm{o}}^{2}}\right) \frac{\partial B_{\mathrm{o}}}{\partial P} \frac{\partial P}{\partial t}+\frac{\varphi}{B_{\mathrm{o}}} \frac{\partial S_{\mathrm{o}}}{\partial t}\right]$

$h\left[\frac{S_{\mathrm{o}}}{B_{\mathrm{o}}} \frac{\partial \varphi}{\partial t}-\frac{\varphi S_{\mathrm{o}}}{B_{\mathrm{o}}^{2}} \frac{\partial B_{\mathrm{o}}}{\partial P} \frac{\partial P}{\partial t}+\frac{\varphi}{B_{\mathrm{o}}} \frac{\partial S_{\mathrm{o}}}{\partial t}\right]=\frac{K K_{\mathrm{ro}} h}{B_{\mathrm{o}} \mu_{\mathrm{o}}}\left[\frac{\partial^{2} P}{\partial z^{2}}\right]+$

$\left[\frac{K h}{B_{\mathrm{o}} \mu_{\mathrm{o}}}\left(\frac{n_{\mathrm{o}} K_{\mathrm{ro}, \mathrm{cw}}}{1-S_{\mathrm{wc}}-S_{\mathrm{or}}}\right)\left(\frac{S_{\mathrm{o}}-S_{\mathrm{or}}}{1-S_{\mathrm{wc}}-S_{\mathrm{or}}}\right)^{n_{o}-1} \frac{\partial S_{\mathrm{o}}}{\partial z} \frac{\partial P}{\partial z}+\frac{K K_{\mathrm{ro}} h}{B_{\mathrm{o}} \mu_{\mathrm{o}}} C_{\mathrm{o}} \frac{\partial^{2} P}{\partial z^{2}}\right]$

Multiply by $\left(\frac{B_{0}}{h}\right)$ on both sides of the Equation (D.28) to get the resulting equation;

$\left[S_{\mathrm{o}} \frac{\partial \varphi}{\partial t}-\varphi \frac{S_{\mathrm{o}}}{B_{\mathrm{o}}} \frac{\partial B_{\mathrm{o}}}{\partial P} \frac{\partial P}{\partial t}+\varphi \frac{\partial S_{\mathrm{o}}}{\partial t}\right]=\frac{K K_{\mathrm{ro}}}{\mu_{\mathrm{o}}}\left[\frac{\partial^{2} P}{\partial z^{2}}\right]+\left[\frac{K}{\mu_{\mathrm{o}}}\left(\frac{n_{\mathrm{o}} K_{\mathrm{ro}, \mathrm{cw}}}{1-S_{\mathrm{wc}}-S_{\mathrm{or}}}\right)\left(\frac{S_{\mathrm{o}}-S_{\mathrm{or}}}{1-S_{\mathrm{wc}}-S_{\mathrm{or}}}\right)^{n_{o}-1} \frac{\partial S_{\mathrm{o}}}{\partial z} \frac{\partial P}{\partial z}+\right.$

$\left.\frac{K K_{\mathrm{ro}}}{\mu_{\mathrm{o}}} C_{o} \frac{\partial^{2} P}{\partial z^{2}}\right]$

$\left[S_{\mathrm{o}} \frac{\partial \varphi}{\partial t}+\varphi S_{\mathrm{o}} C_{\mathrm{o}} \frac{\partial P}{\partial t}+\varphi \frac{\partial S_{\mathrm{o}}}{\partial t}\right]=\frac{K K_{\mathrm{ro}}}{\mu_{\mathrm{o}}}\left[\frac{\partial^{2} P}{\partial z^{2}}\right]+\left[\frac{K}{\mu_{\mathrm{o}}}\left(\frac{n_{o} K_{\mathrm{ro}, \mathrm{cw}}}{1-S_{\mathrm{wc}}-S_{\mathrm{or}}}\right)\left(\frac{S_{\mathrm{o}}-S_{\mathrm{or}}}{1-S_{\mathrm{wc}}-S_{\mathrm{or}}}\right)^{n_{\mathrm{o}}-1} \frac{\partial S_{\mathrm{o}}}{\partial z} \frac{\partial P}{\partial z}+\right.$

$\left.\frac{K K_{\mathrm{ro}}}{\mu_{\mathrm{o}}} C_{\mathrm{o}} \frac{\partial^{2} P}{\partial z^{2}}\right]$

$\therefore C_{\mathrm{o}}=-\frac{1}{B_{\mathrm{o}}} \frac{\partial B_{\mathrm{O}}}{\partial P} \quad \frac{\partial \varphi}{\partial t}=\frac{\partial \varphi}{\partial P} \frac{\partial P}{\partial t}$

$\left[S_{\mathrm{o}} \frac{\partial \varphi}{\partial P} \frac{\partial P}{\partial t}+\varphi S_{\mathrm{o}} C_{\mathrm{o}} \frac{\partial P}{\partial t}+\varphi \frac{\partial S_{\mathrm{o}}}{\partial t}\right]=\frac{K K_{\mathrm{ro}}}{\mu_{\mathrm{o}}}\left[\frac{\partial^{2} P}{\partial z^{2}}\right]+\left[\frac{K}{\mu_{\mathrm{o}}}\left(\frac{n_{o} K_{\mathrm{ro}, \mathrm{cw}}}{1-S_{\mathrm{wc}}-S_{\mathrm{or}}}\right)\left(\frac{S_{\mathrm{o}}-S_{\mathrm{or}}}{1-S_{\mathrm{wc}}-S_{\mathrm{or}}}\right)^{n_{o}-1} \frac{\partial S_{\mathrm{o}}}{\partial z} \frac{\partial P}{\partial z}+\right.$

$\left.\frac{K K_{\mathrm{ro}}}{\mu_{\mathrm{o}}} C_{\mathrm{o}} \frac{\partial^{2} P}{\partial z^{2}}\right]$

$\frac{\partial P}{\partial t}\left(S_{\mathrm{o}} \frac{\partial \varphi}{\partial P}+\varphi S_{\mathrm{o}} C_{\mathrm{o}}\right)+\varphi \frac{\partial S_{\mathrm{o}}}{\partial t}=\frac{K K_{\mathrm{ro}}}{\mu_{\mathrm{o}}}\left[\frac{\partial^{2} P}{\partial z^{2}}\right]+\left[\frac{K}{\mu_{\mathrm{o}}}\left(\frac{n_{o} K_{\mathrm{ro}, \mathrm{cw}}}{1-S_{\mathrm{wc}}-S_{\mathrm{or}}}\right)\left(\frac{S_{\mathrm{o}}-S_{\mathrm{or}}}{1-S_{\mathrm{wc}}-S_{\mathrm{or}}}\right)^{n_{o}-1} \frac{\partial S_{\mathrm{o}}}{\partial z} \frac{\partial P}{\partial z}+\right.$

$\left.\frac{K K_{\text {ro }}}{\mu_{\mathrm{o}}} C_{\mathrm{o}} \frac{\partial^{2} P}{\partial z^{2}}\right]$

Now introducing the rock compressibility which is defined by the equation above;

$\therefore C_{\mathrm{R}}=\frac{1}{\varphi} \frac{\partial \varphi}{\partial P}$ 
After integration it is given as;

$\phi=\varphi_{\mathrm{r}} e^{C_{\mathrm{R}}\left(P-P_{\mathrm{r}}\right)}$

where $\varphi_{\mathrm{r}}$ is the porosity at reference pressure. Similarly, it is approximated by;

$\phi \approx \varphi_{\mathrm{r}}\left(1+C_{\mathrm{R}}\left(P-P_{\mathrm{r}}\right)\right)$

$\frac{\partial \varphi}{\partial P}=\varphi_{\mathrm{r}} C_{\mathrm{R}}$

$S_{\mathrm{o}} \frac{\partial P}{\partial t}\left(\varphi_{\mathrm{r}} C_{\mathrm{R}}+\varphi C_{\mathrm{o}}\right)+\varphi \frac{\partial S_{\mathrm{o}}}{\partial t}=\frac{K K_{\mathrm{ro}}}{\mu_{\mathrm{o}}}\left[\frac{\partial^{2} P}{\partial z^{2}}\right]+\left[\frac{K}{\mu_{\mathrm{o}}}\left(\frac{n_{o} K_{\mathrm{ro}, \mathrm{cw}}}{1-S_{\mathrm{wc}}-S_{\mathrm{or}}}\right)\left(\frac{S_{\mathrm{o}}-S_{\mathrm{or}}}{1-S_{\mathrm{wc}}-S_{\mathrm{or}}}\right)^{n_{o}-1} \frac{\partial S_{\mathrm{o}}}{\partial z} \frac{\partial P}{\partial z}+\right.$

$\left.\frac{K K_{\mathrm{ro}}}{\mu_{\mathrm{o}}} C_{o} \frac{\partial^{2} P}{\partial z^{2}}\right]$

$\varphi S_{\mathrm{o}} C_{\mathrm{f}} \frac{\partial P}{\partial t}+\varphi \frac{\partial S_{\mathrm{o}}}{\partial t}=\frac{K K_{\mathrm{ro}}}{\mu_{\mathrm{o}}}\left[\frac{\partial^{2} P}{\partial z^{2}}\right]+\left[\frac{K}{\mu_{\mathrm{o}}}\left(\frac{n_{o} K_{\mathrm{ro}, \mathrm{cw}}}{1-S_{\mathrm{wc}}-S_{\mathrm{or}}}\right)\left(\frac{S_{\mathrm{o}}-S_{\mathrm{or}}}{1-S_{\mathrm{wc}}-S_{\mathrm{or}}}\right)^{n_{o}-1} \frac{\partial S_{\mathrm{o}}}{\partial z} \frac{\partial P}{\partial z}+\frac{K K_{\mathrm{ro}}}{\mu_{\mathrm{o}}} C_{\mathrm{o}} \frac{\partial^{2} P}{\partial z^{2}}\right]$

$\therefore C_{\mathrm{f}}=\frac{\varphi_{\mathrm{r}}}{\varphi} C_{\mathrm{R}}+C_{\mathrm{o}}$

where $C_{\mathrm{R}}$, and $C_{\mathrm{o}}$ are the compressibility's of rock and oil. As we can see the term $\varphi S_{\mathrm{o}} C_{\mathrm{f}} \frac{\partial P}{\partial t} \ll \varphi \frac{\partial S_{\mathrm{o}}}{\partial t}$ it will be neglected and the final resulting equation will become;

$\frac{\partial S_{\mathrm{o}}}{\partial t}=\frac{K K_{\mathrm{ro}}}{\mu_{\mathrm{o}} \varphi}\left[\frac{\partial^{2} P}{\partial z^{2}}\right]+\left[\frac{K}{\mu_{\mathrm{o}} \varphi}\left(\frac{n_{\mathrm{o}} K_{\mathrm{ro}, \mathrm{cw}}}{1-S_{\mathrm{wc}}-S_{\mathrm{or}}}\right)\left(\frac{S_{\mathrm{o}}-S_{\mathrm{or}}}{1-S_{\mathrm{wc}}-S_{\mathrm{or}}}\right)^{n_{0}-1} \frac{\partial S_{\mathrm{o}}}{\partial z} \frac{\partial P}{\partial z}+\frac{K K_{\mathrm{ro}}}{\mu_{\mathrm{o}} \varphi} C_{\mathrm{o}} \frac{\partial^{2} P}{\partial z^{2}}\right]$ 


\section{Derivation of Aqueous Flow Equation}

The flow equation for the water phase is derived as follows;

\section{General Mass Balance:}

$\left[\begin{array}{c}\text { Rate of Mass } \\ \text { into the element } \\ a t^{\prime} r^{\prime}\end{array}\right]-\left[\begin{array}{c}\text { Rate of Mass } \\ \text { out of the element } \\ a t^{\prime} r+\Delta r^{\prime}\end{array}\right]+\left[\begin{array}{c}\text { Rate of Mass } \\ \text { into the element } \\ a t^{\prime} z^{\prime}\end{array}\right]-$

$\left[\begin{array}{c}\text { Rate of Mass } \\ \text { out of the element } \\ \text { at }{ }^{\prime} z+\Delta z^{\prime}\end{array}\right]=\left[\begin{array}{c}\text { Rate of } \\ \text { Accumulation }\end{array}\right]$

\section{$\underline{\text { Rate of fluid mass enters the element at ' } r \text { ': }}$}

$\rho\left(r, z^{\prime}\right) \cdot v_{r}\left(r, z^{\prime}\right) \cdot h\left(r, z^{\prime}\right) \cdot \Delta z=\Delta z\left(h \rho v_{r}\right)_{r, z^{\prime}}$

\section{Rate of fluid mass leaves the element at ' $r+\Delta r$ ':}

$\rho\left(r+\Delta r, z^{\prime}\right) \cdot v_{r}\left(r+\Delta r, z^{\prime}\right) \cdot h\left(r+\Delta r, z^{\prime}\right) \cdot \Delta z=\Delta z\left(h \rho v_{r}\right)_{r+\Delta r, z^{\prime}}$

\section{Rate of fluid mass enters the element at ' $z$ ':}

$\rho\left(r^{\prime}, z\right) \cdot v_{z}\left(r^{\prime}, z\right) \cdot h\left(r^{\prime}, z\right) \cdot \Delta r=\Delta r\left(h \rho v_{z}\right)_{r^{\prime}, z}$

$\underline{\text { Rate of fluid mass leaves the element at ' } z+\Delta z \text { ': }}$

$\rho\left(r^{\prime}, z+\Delta z\right) \cdot v_{z}\left(r^{\prime}, z+\Delta z\right) \cdot h\left(r^{\prime}, z+\Delta z\right) \cdot \Delta r=\Delta r\left(h \rho v_{z}\right)_{r^{\prime}, z+\Delta z}$

\section{Rate of accumulation:}

$h \frac{\partial}{\partial t}\left(\varphi \rho S_{n}\right) \Delta r \Delta z$

where ' $S_{n}{ }^{\prime}$ is the phase saturation or non-wetting phase saturation.

$$
\left[\Delta z\left(h \rho v_{r}\right)_{r}-\Delta z\left(h \rho v_{r}\right)_{r+\Delta r}\right]+\left[\Delta r\left(h \rho v_{z}\right)_{z}-\Delta r\left(h \rho v_{z}\right)_{z+\Delta z}\right]=h \frac{\partial}{\partial t}\left(\varphi \rho S_{n}\right) \Delta r \Delta z
$$

Rearranging and dividing by ' $\Delta r \Delta z^{\prime}$ and taking the limit $\Delta r \rightarrow 0, \Delta z \rightarrow 0$.

$$
-\frac{\partial}{\partial r}\left(h \rho v_{r}\right)-\frac{\partial}{\partial z}\left(h \rho v_{z}\right)=h \frac{\partial}{\partial t}\left(\varphi \rho S_{n}\right)
$$




\section{According to Darcy's law:}

Darcy's law states that "The velocity of flow of a fluid through a porous medium is proportional to the pressure gradient in the direction of flow".

$\widehat{Q}=\frac{K A}{\mu} \frac{\Delta P}{L}($ For horizontal System $)$

where ${ }^{\prime} \Delta P^{\prime}$ the applied pressure drop across the cylindrical core, ' $\mu$ ' is the fluid viscosity and ${ }^{\prime} K$ ' is the intrinsic or absolute permeability.

$v=\frac{\hat{Q}}{A}=-\frac{K}{\mu} \frac{\Delta P}{L}$

$\therefore \hat{Q}=$ volumetric flow rate

$\therefore v=$ superficial flow velocity

Note: - "Negative sign" indicates that the pressure decreases in the direction of flow.

Darcy's law for ' $r$ - and $z$-dimension is given as follows;

$v_{r}=-\frac{K}{\mu} \frac{\partial P}{\partial r}$

$v_{z}=-\frac{K}{\mu} \frac{\partial P}{\partial z}$

For aqueous phase the velocity can be written as;

$\therefore v_{r}=-\frac{K_{w}}{\mu} \frac{\partial P}{\partial r}$

$\therefore v_{z}=-\frac{K_{w}}{\mu} \frac{\partial P}{\partial z}$

inserting Equation (D.32), and (D.33) into Equation (D.31) and the resulting Equation becomes;

$-\frac{\partial}{\partial r}\left(h \rho\left(-\frac{K}{\mu} \frac{\partial P}{\partial r}\right)\right)-\frac{\partial}{\partial z}\left(h \rho\left(-\frac{K}{\mu} \frac{\partial P}{\partial z}\right)\right)=h \frac{\partial}{\partial t}\left(\varphi \rho S_{n}\right)$

$\frac{\partial}{\partial r}\left(h \rho \frac{K}{\mu} \frac{\partial P}{\partial r}\right)+\frac{\partial}{\partial z}\left(h \rho \frac{K}{\mu} \frac{\partial P}{\partial z}\right)=h \frac{\partial}{\partial t}\left(\varphi \rho S_{n}\right)$ 
The above equation is the general equation for both the aqueous phase and oleic phase flow. Now consider the equation specifically for the flow of water phase through the medium.

$$
\begin{aligned}
& \frac{\partial}{\partial r}\left(h \rho_{\mathrm{w}} \frac{K_{\mathrm{w}}}{\mu_{\mathrm{w}}} \frac{\partial P}{\partial r}\right)+\frac{\partial}{\partial z}\left(h \rho_{\mathrm{w}} \frac{K_{\mathrm{w}}}{\mu_{\mathrm{w}}} \frac{\partial P}{\partial z}\right)=h \frac{\partial}{\partial t}\left(\varphi \rho_{\mathrm{w}} S_{\mathrm{w}}\right) \\
& \therefore K_{\mathrm{rw}}=\frac{K_{\mathrm{w}}}{K} \leq 1 \Rightarrow K_{\mathrm{w}}=K K_{\mathrm{rw}}
\end{aligned}
$$

The simultaneous flow of the two fluids causes to interfere with the flow of each other, therefore this effective permeability's must be less than or equal to the single fluid permeability, ' $\mathrm{K}$ ' of the medium.

$\frac{\partial}{\partial r}\left(h \rho_{\mathrm{w}} \frac{K K_{\mathrm{rw}}}{\mu_{\mathrm{w}}} \frac{\partial P}{\partial r}\right)+\frac{\partial}{\partial z}\left(h \rho_{\mathrm{w}} \frac{K K_{\mathrm{rw}}}{\mu_{\mathrm{w}}} \frac{\partial P}{\partial z}\right)=h \frac{\partial}{\partial t}\left(\varphi \rho_{\mathrm{w}} S_{\mathrm{w}}\right)$

$S_{\mathrm{w}}=$ Phase saturation of water

$\frac{\partial}{\partial r}\left(h \rho_{\mathrm{w}} \frac{K K_{\mathrm{rw}}}{\mu_{w}} \frac{\partial P}{\partial r}\right)+\frac{\partial}{\partial z}\left(h \rho_{\mathrm{w}} \frac{K K_{\mathrm{rw}}}{\mu_{w}} \frac{\partial P}{\partial z}\right)=h \frac{\partial}{\partial t}\left(\varphi \rho_{\mathrm{w}} S_{\mathrm{w}}\right)$

\section{Formation Volume Factor:}

Ratio of volume of the fluid measure at reservoir conditions to the volume of the same fluid at the standard conditions.

$B(P, T)=\frac{V(P, T)}{V_{\mathrm{sc}}}$

Let ' $W$ ' be the weight of the fluid, $V=\frac{W}{\rho}, V_{\mathrm{sc}}=\frac{W}{\rho_{\mathrm{sc}}}$, whereas ' $\rho_{\mathrm{sc}}$ ' is the density at standard conditions. So, $\rho=\frac{\rho_{\mathrm{Sc}}}{B}$ similarly for aqueous phase it becomes;

$$
\begin{aligned}
& \rho_{\mathrm{w}}=\frac{\rho_{\mathrm{wsc}}}{B_{\mathrm{w}}} \\
& B_{\mathrm{w}}=\frac{\rho_{\mathrm{wsc}}}{\rho_{\mathrm{w}}} \\
& B_{\mathrm{w}}=\text { water formation volume } \frac{\text { res } m^{3}}{\text { std } m^{3}} \\
& \frac{\partial}{\partial r}\left(h \rho_{\mathrm{wsc}} \frac{K K_{\mathrm{rw}}}{\mu_{\mathrm{p}} B_{\mathrm{w}}} \frac{\partial P}{\partial r}\right)+\frac{\partial}{\partial z}\left(h \rho_{\mathrm{wsc}} \frac{K K_{\mathrm{rw}}}{\mu_{\mathrm{p}} B_{\mathrm{w}}} \frac{\partial P}{\partial z}\right)=h \frac{\partial}{\partial t}\left(\varphi \rho_{\mathrm{wsc}} \frac{S_{\mathrm{w}}}{B_{\mathrm{w}}}\right)
\end{aligned}
$$


$\frac{\partial}{\partial r}\left(h \frac{K K_{\mathrm{rw}}}{\mu_{\mathrm{p}} B_{\mathrm{w}}} \frac{\partial P}{\partial r}\right)+\frac{\partial}{\partial z}\left(h \frac{K K_{\mathrm{rw}}}{\mu_{\mathrm{p}} B_{\mathrm{w}}} \frac{\partial P}{\partial z}\right)=h \frac{\partial}{\partial t}\left(\varphi \frac{S_{\mathrm{w}}}{B_{\mathrm{w}}}\right)$

The polymer is dissolved in the aqueous phase. So, the viscosity of polymeric solution is taken into account instead of considering the viscosity of water alone. The addition of water-soluble polymers reduces the permeability to water flow to a greater extent than to oil or gas flow. Due to this, the permeability reduction factor ' $R_{k}{ }^{\prime}$ is taken into consideration.

$\frac{\partial}{\partial r}\left(\frac{K K_{\mathrm{rw}} h}{\mu_{\mathrm{p}} B_{\mathrm{w}} R_{\mathrm{k}}} \frac{\partial P}{\partial r}\right)+\frac{\partial}{\partial z}\left(\frac{K K_{\mathrm{rw}} h}{\mu_{\mathrm{p}} B_{\mathrm{w}} R_{\mathrm{k}}} \frac{\partial P}{\partial z}\right)=h \frac{\partial}{\partial t}\left(\frac{\varphi S_{\mathrm{w}}}{B_{\mathrm{w}}}\right)$

\section{Derivation of Aqueous Flow Equation in Cylindrical Coordinates}

The flow equation for aqueous phase can be written as;

$$
\begin{aligned}
& h \frac{\partial}{\partial t}\left(\varphi \frac{S_{\mathrm{w}}}{B_{\mathrm{w}}}\right)=\nabla \cdot\left[\frac{K K_{\mathrm{rw}} h}{B_{\mathrm{w}} \mu_{\mathrm{p}} R_{\mathrm{k}}} \nabla \mathrm{P}\right] \\
& h \frac{\partial}{\partial t}\left(\varphi \frac{S_{\mathrm{w}}}{B_{\mathrm{w}}}\right)=\frac{K K_{\mathrm{rw}} h}{B_{\mathrm{w}} R_{\mathrm{k}} \mu_{\mathrm{p}}} \nabla \cdot(\nabla \mathrm{P})+\nabla \mathrm{P} \cdot \nabla \underbrace{\left.\frac{K K_{\mathrm{rw}} h}{B_{\mathrm{w}} R_{\mathrm{k}} \mu_{\mathrm{p}}}\right)}_{\gamma}
\end{aligned}
$$$$
h \frac{\partial}{\partial t}\left(\varphi \frac{S_{\mathrm{w}}}{B_{\mathrm{w}}}\right)=\frac{K K_{\mathrm{rw}} h}{B_{\mathrm{w}} R_{\mathrm{k}} \mu_{\mathrm{p}}} \nabla \cdot(\nabla \mathrm{P})+\nabla \mathrm{P} \cdot \nabla(\gamma)
$$$$
h \frac{\partial}{\partial t}\left(\varphi \frac{S_{\mathrm{w}}}{B_{\mathrm{w}}}\right)=\frac{K K_{\mathrm{rw}} h}{B_{\mathrm{w}} R_{\mathrm{k}} \mu_{\mathrm{p}}} \nabla^{2} \mathrm{P}+\nabla \mathrm{P} . \nabla(\gamma)
$$$$
h \frac{\partial}{\partial t}\left(\varphi \frac{S_{\mathrm{w}}}{B_{\mathrm{w}}}\right)=\frac{K K_{\mathrm{rw}} h}{B_{\mathrm{w}} R_{\mathrm{k}} \mu_{\mathrm{p}}}\left[\frac{1}{r} \frac{\partial}{\partial r}\left(r \frac{\partial P}{\partial r}\right)+\frac{1}{r^{2}} \frac{\partial^{2} P}{\partial \theta^{2}}+\frac{\partial^{2} P}{\partial z^{2}}\right]+\left[\hat{r} \frac{\partial P}{\partial r}+\frac{1}{r} \hat{\theta} \frac{\partial P}{\partial \theta}+\hat{z} \frac{\partial P}{\partial z}\right] \cdot\left[\hat{r} \frac{\partial \gamma}{\partial r}+\right.
$$$$
\left.\frac{1}{r} \hat{\theta} \frac{\partial \gamma}{\partial \theta}+\hat{z} \frac{\partial \gamma}{\partial z}\right]
$$$$
h \frac{\partial}{\partial t}\left(\varphi \frac{S_{\mathrm{w}}}{B_{\mathrm{W}}}\right)=\frac{K K_{\mathrm{rw}} h}{B_{\mathrm{w}} R_{\mathrm{k}} \mu_{\mathrm{p}}}\left[\frac{\partial^{2} P}{\partial z^{2}}\right]+\left[\frac{\partial P}{\partial z}\right]\left[\frac{\partial \gamma}{\partial z}\right]
$$

$$
\gamma=\gamma\left[K_{\mathrm{rw}}\left(S_{\mathrm{w}}(z)\right), B_{\mathrm{w}}(P(z)) R_{\mathrm{k}}(C(z)), \mu_{\mathrm{p}}(C(z))\right]
$$

$\frac{\partial \gamma}{\partial z}=\left[\frac{\partial \gamma}{\partial K_{\mathrm{rw}}} \frac{\partial K_{\mathrm{rw}}}{\partial S_{\mathrm{w}}} \frac{\partial S_{\mathrm{w}}}{\partial z}+\frac{\partial \gamma}{\partial B_{\mathrm{w}}} \frac{\partial B_{\mathrm{w}}}{\partial P} \frac{\partial P}{\partial z}+\frac{\partial \gamma}{\partial R_{\mathrm{k}}} \frac{\partial R_{\mathrm{k}}}{\partial C} \frac{\partial C}{\partial z}+\frac{\partial \gamma}{\partial \mu_{\mathrm{p}}} \frac{\partial \mu_{\mathrm{p}}}{\partial C} \frac{\partial C}{\partial z}\right]$

$$
\gamma=\frac{K K_{\mathrm{rw}} h}{B_{\mathrm{w}} R_{\mathrm{k}} \mu_{\mathrm{p}}}
$$


1. $\frac{\partial \gamma}{\partial K_{\mathrm{rw}}}=\frac{\partial}{\partial K_{\mathrm{rw}}}\left(\frac{K K_{\mathrm{rw}} h}{B_{\mathrm{w}} R_{\mathrm{k}} \mu_{\mathrm{p}}}\right)$

$\frac{\partial \gamma}{\partial K_{\mathrm{rw}}}=\frac{K h}{B_{\mathrm{W}} R_{\mathrm{k}} \mu_{\mathrm{p}}}$

2. $\frac{\partial K_{\mathrm{rw}}}{\partial S_{\mathrm{w}}}=\frac{\partial}{\partial S_{\mathrm{w}}}\left[K_{\mathrm{rw}, \mathrm{ro}}\left(\frac{S_{\mathrm{w}}-S_{\mathrm{wc}}}{1-S_{\mathrm{wc}}-S_{\mathrm{or}}}\right)^{n_{w}}\right]$

$\frac{\partial K_{\mathrm{rw}}}{\partial S_{\mathrm{w}}}=\left(\frac{n_{w} K_{\mathrm{rw}, \mathrm{ro}}}{1-S_{\mathrm{wc}}-S_{\mathrm{or}}}\right)\left(\frac{S_{\mathrm{w}}-S_{\mathrm{wc}}}{1-S_{\mathrm{wc}}-S_{\mathrm{or}}}\right)^{n_{w}-1}$

$\frac{\partial \gamma}{\partial B_{\mathrm{w}}}=\frac{\partial}{\partial B_{\mathrm{w}}}\left(\frac{K K_{\mathrm{rw}} h}{B_{\mathrm{w}} R_{\mathrm{k}} \mu_{\mathrm{p}}}\right)$

$\frac{\partial \gamma}{\partial B_{\mathrm{w}}}=-\left(\frac{K K_{\mathrm{rw}} h}{R_{\mathrm{k}} B_{\mathrm{w}}^{2} \mu_{\mathrm{p}}}\right)$

3. $\frac{\partial \gamma}{\partial R_{\mathrm{k}}}=\frac{\partial}{\partial R_{\mathrm{k}}}\left(\frac{K K_{\mathrm{rw}} h}{B_{\mathrm{w}} R_{\mathrm{k}} \mu_{\mathrm{p}}}\right)$

$\frac{\partial \gamma}{\partial R_{\mathrm{k}}}=-\frac{K K_{\mathrm{rw}} h}{B_{\mathrm{w}} R_{\mathrm{k}}^{2} \mu_{\mathrm{p}}}$

4. $\frac{\partial R_{\mathrm{k}}}{\partial C}=\frac{\partial}{\partial C}\left(1+\frac{\left(R_{\mathrm{kmax}}-1\right) \cdot b_{\mathrm{rk}} \cdot C}{1+b_{\mathrm{rk}} \cdot C}\right)$

$\frac{\partial R_{\mathrm{k}}}{\partial C}=\left(\frac{\left(R_{\mathrm{kmax}} b_{\mathrm{rk}}-b_{\mathrm{rk}}\right)}{\left(1+b_{\mathrm{rk}} \cdot C\right)^{2}}\right)$

5. $\frac{\partial \gamma}{\partial \mu_{\mathrm{p}}}=\frac{\partial}{\partial \mu_{\mathrm{p}}}\left(\frac{K K_{\mathrm{rw}} h}{B_{\mathrm{w}} R_{\mathrm{k}} \mu_{\mathrm{p}}}\right)$

$\frac{\partial \gamma}{\partial \mu_{\mathrm{p}}}=-\frac{K K_{\mathrm{rw}} h}{B_{\mathrm{w}} \mu_{\mathrm{p}}^{2} R_{\mathrm{k}}}$

6. $\frac{\partial \mu_{\mathrm{p}}}{\partial C}=\frac{\partial}{\partial C}\left[\mu_{\mathrm{w}}\left(1+\left(a p_{1} C+a p_{2} C^{2}+a p_{3} C^{3}\right)\right)\right]$

$\frac{\partial \mu_{\mathrm{p}}}{\partial c}=\left(\mu_{\mathrm{w}} a p_{1}+2 \mu_{\mathrm{w}} a p_{2} \cdot C+3 \mu_{\mathrm{w}} a p_{3} \cdot C^{2}\right)$

Now inserting all the derivatives of the Equations (D.37-43) into Equation (D.36) and we get the following relation;

$\frac{\partial \gamma}{\partial z}=\left[\frac{\partial \gamma}{\partial K_{\mathrm{rw}}} \frac{\partial K_{\mathrm{rw}}}{\partial S_{\mathrm{w}}} \frac{\partial S_{\mathrm{w}}}{\partial z}+\frac{\partial \gamma}{\partial B_{w}} \frac{\partial B_{\mathrm{w}}}{\partial P} \frac{\partial P}{\partial z}+\frac{\partial \gamma}{\partial R_{\mathrm{k}}} \frac{\partial R_{\mathrm{k}}}{\partial C} \frac{\partial C}{\partial z}+\frac{\partial \gamma}{\partial \mu_{\mathrm{p}}} \frac{\partial \mu_{\mathrm{p}}}{\partial C} \frac{\partial C}{\partial z}\right]$ 


$$
\begin{aligned}
& \frac{\partial \gamma}{\partial z}=\left[\left[\frac{K h}{B_{\mathrm{w}} R_{\mathrm{k}} \mu_{\mathrm{p}}}\left(\frac{n_{w} K_{\mathrm{rw}, \mathrm{ro}}}{1-S_{\mathrm{wc}}-S_{\mathrm{or}}}\right)\left(\frac{S_{\mathrm{w}}-S_{\mathrm{wc}}}{1-S_{\mathrm{wc}}-S_{\mathrm{or}}}\right)^{n_{w}-1} \frac{\partial S_{\mathrm{w}}}{\partial z}+\frac{K K_{\mathrm{rw}} h}{B_{\mathrm{w}} R_{\mathrm{k}} \mu_{\mathrm{p}}} C_{\mathrm{w}} \frac{\partial P}{\partial z}-\right.\right. \\
& \left.\left.\frac{K K_{\mathrm{rw}} h}{B_{\mathrm{w}} R_{\mathrm{k}}^{2} \mu_{\mathrm{p}}}\left(\frac{\left(R_{\mathrm{kmax}} b_{\mathrm{rk}}-b_{\mathrm{rk}}\right)}{\left(1+b_{\mathrm{rk}} \cdot C\right)^{2}}\right) \frac{\partial C}{\partial z}-\frac{K K_{\mathrm{rw}} h}{B_{\mathrm{w}} \mu_{\mathrm{p}}^{2} R_{\mathrm{k}}}\left(\mu_{\mathrm{w}} a p_{1}+2 \mu_{\mathrm{w}} a p_{2} \cdot C+3 \mu_{\mathrm{w}} a p_{3} \cdot C^{2}\right) \frac{\partial C}{\partial z}\right]\right]
\end{aligned}
$$

Now expanding the L.H.S of the aqueous phase equation

$$
h\left[\frac{1}{B_{\mathrm{w}}} S_{\mathrm{w}} \frac{\partial \varphi}{\partial t}+\varphi S_{\mathrm{w}}\left(-\frac{1}{B_{\mathrm{w}}^{2}}\right) \frac{\partial B_{\mathrm{w}}}{\partial P} \frac{\partial P}{\partial t}+\frac{\varphi}{B_{\mathrm{w}}} \frac{\partial S_{\mathrm{w}}}{\partial t}\right]=\frac{K K_{\mathrm{rw}} h}{B_{\mathrm{w}} R_{\mathrm{k}} \mu_{\mathrm{p}}}\left[\frac{\partial^{2} P}{\partial z^{2}}\right]+\left[\frac{\partial P}{\partial z}\right]\left[\frac{\partial \gamma}{\partial z}\right]
$$

Multiply by $\left(\frac{B_{\mathrm{w}}}{h}\right)$ on both sides of the equation to get the resulting equation;

$$
\begin{aligned}
& {\left[S_{\mathrm{w}} \frac{\partial \varphi}{\partial t}-\varphi \frac{S_{\mathrm{w}}}{B_{\mathrm{w}}} \frac{\partial B_{\mathrm{w}}}{\partial P} \frac{\partial P}{\partial t}+\varphi \frac{\partial S_{\mathrm{w}}}{\partial t}\right]=\frac{K K_{\mathrm{rw}}}{R_{\mathrm{k}} \mu_{\mathrm{p}}}\left[\frac{\partial^{2} P}{\partial z^{2}}\right]+} \\
& {\left[\left[\frac{K}{R_{\mathrm{k}} \mu_{\mathrm{p}}}\left(\frac{n_{w} K_{\mathrm{rw}, \mathrm{ro}}}{1-S_{\mathrm{wc}}-S_{\mathrm{or}}}\right)\left(\frac{S_{\mathrm{w}}-S_{\mathrm{wc}}}{1-S_{\mathrm{wc}}-S_{\mathrm{or}}}\right)^{n_{w}-1} \frac{\partial S_{\mathrm{w}}}{\partial z} \frac{\partial P}{\partial z}+\frac{K K_{\mathrm{rw}}}{R_{\mathrm{k}} \mu_{\mathrm{p}}} C_{\mathrm{w}} \frac{\partial^{2} P}{\partial z^{2}}-\right.\right.}
\end{aligned}
$$$$
\left.\left.\frac{K K_{\mathrm{rw}}}{R_{\mathrm{k}}^{2} \mu_{\mathrm{p}}}\left(\frac{\left(R_{\mathrm{kmax}} b_{\mathrm{rk}}-b_{\mathrm{rk}}\right)}{\left(1+b_{\mathrm{rk}} \cdot C\right)^{2}}\right) \frac{\partial C}{\partial z} \frac{\partial P}{\partial z}-\frac{K K_{\mathrm{rw}}}{\mu_{\mathrm{p}}^{2} R_{\mathrm{k}}}\left(\mu_{\mathrm{w}} a p_{1}+2 \mu_{\mathrm{w}} a p_{2} \cdot C+3 \mu_{\mathrm{w}} a p_{3} \cdot C^{2}\right) \frac{\partial C}{\partial z} \frac{\partial P}{\partial z}\right]\right]
$$

$$
\left[S_{\mathrm{w}} \frac{\partial \varphi}{\partial t}+\varphi S_{\mathrm{w}} C_{\mathrm{w}} \frac{\partial P}{\partial t}+\varphi \frac{\partial S_{\mathrm{w}}}{\partial t}\right]=\frac{K K_{\mathrm{rw}}}{R_{\mathrm{k}} \mu_{\mathrm{p}}}\left[\frac{\partial^{2} P}{\partial z^{2}}\right]+
$$$$
\left[\left[\frac{K}{R_{\mathrm{k}} \mu_{\mathrm{p}}}\left(\frac{n_{w} K_{\mathrm{rw}, \mathrm{ro}}}{1-S_{\mathrm{wc}}-S_{\mathrm{or}}}\right)\left(\frac{S_{\mathrm{w}}-S_{\mathrm{wc}}}{1-S_{\mathrm{wc}}-S_{\mathrm{or}}}\right)^{n_{W}-1} \frac{\partial S_{\mathrm{w}}}{\partial z} \frac{\partial P}{\partial z}+\frac{K K_{\mathrm{rw}}}{R_{\mathrm{k}} \mu_{\mathrm{p}}} C_{\mathrm{w}} \frac{\partial^{2} P}{\partial z^{2}}-\right.\right.
$$$$
\left.\left.\frac{K K_{\mathrm{rw}}}{R_{\mathrm{k}}^{2} \mu_{\mathrm{p}}}\left(\frac{\left(R_{\mathrm{kmax}} b_{\mathrm{rk}}-b_{\mathrm{rk}}\right)}{\left(1+b_{\mathrm{rk}} \cdot C\right)^{2}}\right) \frac{\partial C}{\partial z} \frac{\partial P}{\partial z}-\frac{K K_{\mathrm{rw}}}{\mu_{\mathrm{p}}^{2} R_{\mathrm{k}}}\left(\mu_{\mathrm{w}} a p_{1}+2 \mu_{\mathrm{w}} a p_{2} \cdot C+3 \mu_{\mathrm{w}} a p_{3} \cdot C^{2}\right) \frac{\partial C}{\partial z} \frac{\partial P}{\partial z}\right]\right]
$$

$\therefore C_{\mathrm{w}}=-\frac{1}{B_{\mathrm{w}}} \frac{\partial B_{\mathrm{W}}}{\partial P} \quad \frac{\partial \varphi}{\partial t}=\frac{\partial \varphi}{\partial P} \frac{\partial P}{\partial t}$

$$
\left[S_{\mathrm{w}} \frac{\partial \varphi}{\partial P} \frac{\partial P}{\partial t}+\varphi S_{\mathrm{w}} C_{\mathrm{w}} \frac{\partial P}{\partial t}+\varphi \frac{\partial S_{\mathrm{w}}}{\partial t}\right]=\frac{K K_{\mathrm{rw}}}{R_{\mathrm{k}} \mu_{\mathrm{p}}}\left[\frac{\partial^{2} P}{\partial z^{2}}\right]+
$$$$
\left[\left[\frac{K}{R_{\mathrm{k}} \mu_{\mathrm{p}}}\left(\frac{n_{w} K_{\mathrm{rw}, \mathrm{ro}}}{1-S_{\mathrm{wc}}-S_{\mathrm{or}}}\right)\left(\frac{S_{\mathrm{w}}-S_{\mathrm{wc}}}{1-S_{\mathrm{wc}}-S_{\mathrm{or}}}\right)^{n_{w}-1} \frac{\partial S_{\mathrm{w}}}{\partial z} \frac{\partial P}{\partial z}+\frac{K K_{\mathrm{rw}}}{R_{\mathrm{k}} \mu_{\mathrm{p}}} C_{\mathrm{w}} \frac{\partial^{2} P}{\partial z^{2}}-\right.\right.
$$

$\left.\left.\frac{K K_{\mathrm{rw}}}{R_{\mathrm{k}}^{2} \mu_{\mathrm{p}}}\left(\frac{\left(R_{\mathrm{kmax}} b_{\mathrm{rk}}-b_{\mathrm{rk}}\right)}{\left(1+b_{\mathrm{rk}} \cdot C\right)^{2}}\right) \frac{\partial C}{\partial z} \frac{\partial P}{\partial z}-\frac{K K_{\mathrm{rw}}}{\mu_{\mathrm{p}}^{2} R_{\mathrm{k}}}\left(\mu_{\mathrm{w}} a p_{1}+2 \mu_{\mathrm{w}} a p_{2} \cdot C+3 \mu_{\mathrm{w}} a p_{3} \cdot C^{2}\right) \frac{\partial C}{\partial z} \frac{\partial P}{\partial z}\right]\right]$ 


$$
\begin{aligned}
& \frac{\partial P}{\partial t}\left(S_{\mathrm{w}} \frac{\partial \varphi}{\partial P}+\varphi S_{\mathrm{w}} C_{\mathrm{w}}\right)+\varphi \frac{\partial S_{\mathrm{w}}}{\partial t}=\frac{K K_{\mathrm{rw}}}{R_{\mathrm{k}} \mu_{\mathrm{p}}}\left[\frac{\partial^{2} P}{\partial z^{2}}\right]+ \\
& {\left[\left[\frac{K}{R_{\mathrm{k}} \mu_{\mathrm{p}}}\left(\frac{n_{w} K_{\mathrm{rw}, \mathrm{ro}}}{1-S_{\mathrm{wc}}-S_{\mathrm{or}}}\right)\left(\frac{S_{\mathrm{w}}-S_{\mathrm{wc}}}{1-S_{\mathrm{wc}}-S_{\mathrm{or}}}\right)^{n_{w}-1} \frac{\partial S_{\mathrm{w}}}{\partial z} \frac{\partial P}{\partial z}+\frac{K K_{\mathrm{rw}}}{R_{\mathrm{k}} \mu_{\mathrm{p}}} C_{\mathrm{w}} \frac{\partial^{2} P}{\partial z^{2}}-\right.\right.} \\
& \left.\left.\frac{K K_{\mathrm{rw}}}{R_{\mathrm{k}}^{2} \mu_{p}}\left(\frac{\left(R_{\mathrm{kmax}} b_{\mathrm{rk}}-b_{\mathrm{rk}}\right)}{\left(1+b_{\mathrm{rk}} \cdot C\right)^{2}}\right) \frac{\partial C}{\partial z} \frac{\partial P}{\partial z}-\frac{K K_{\mathrm{rw}}}{\mu_{\mathrm{p}}^{2} R_{\mathrm{k}}}\left(\mu_{\mathrm{w}} a p_{1}+2 \mu_{\mathrm{w}} a p_{2} \cdot C+3 \mu_{\mathrm{w}} a p_{3} \cdot C^{2}\right) \frac{\partial C}{\partial z} \frac{\partial P}{\partial z}\right]\right]
\end{aligned}
$$

Now introducing the rock compressibility which is defined by the equation below;

$\therefore C_{\mathrm{R}}=\frac{1}{\varphi} \frac{\partial \varphi}{\partial P}$

After integration it is given as;

$\phi=\varphi_{\mathrm{r}} e^{C_{\mathrm{R}}\left(P-P_{\mathrm{r}}\right)}$

where $\varphi_{\mathrm{r}}$ is the porosity at reference pressure. Similarly, it is approximated by;

$\phi \approx \varphi_{\mathrm{r}}\left(1+C_{\mathrm{R}}\left(P-P_{\mathrm{r}}\right)\right)$

$\frac{\partial \varphi}{\partial P}=\varphi_{\mathrm{r}} C_{\mathrm{R}}$

$S_{\mathrm{w}} \frac{\partial P}{\partial t}\left(\varphi_{\mathrm{r}} C_{\mathrm{R}}+\varphi C_{\mathrm{w}}\right)+\varphi \frac{\partial S_{\mathrm{w}}}{\partial t}=\frac{K K_{\mathrm{rw}}}{R_{\mathrm{k}} \mu_{\mathrm{p}}}\left[\frac{\partial^{2} P}{\partial z^{2}}\right]+$

$\left[\left[\frac{K}{R_{\mathrm{k}} \mu_{\mathrm{p}}}\left(\frac{n_{w} K_{\mathrm{rw}, \mathrm{ro}}}{1-S_{\mathrm{wc}}-S_{\mathrm{or}}}\right)\left(\frac{S_{\mathrm{w}}-S_{\mathrm{wc}}}{1-S_{\mathrm{wc}}-S_{\mathrm{or}}}\right)^{n_{w}-1} \frac{\partial S_{\mathrm{w}}}{\partial z} \frac{\partial P}{\partial z}+\frac{K K_{\mathrm{rw}}}{R_{\mathrm{k}} \mu_{\mathrm{p}}} C_{\mathrm{w}} \frac{\partial^{2} P}{\partial z^{2}}-\right.\right.$

$\left.\left.\frac{K K_{\mathrm{rw}}}{R_{\mathrm{k}}^{2} \mu_{\mathrm{p}}}\left(\frac{\left(R_{\mathrm{kmax}} b_{\mathrm{rk}}-b_{\mathrm{rk}}\right)}{\left(1+b_{\mathrm{rk}} \cdot C\right)^{2}}\right) \frac{\partial C}{\partial z} \frac{\partial P}{\partial z}-\frac{K K_{\mathrm{rw}}}{\mu_{\mathrm{p}}^{2} R_{\mathrm{k}}}\left(\mu_{\mathrm{w}} a p_{1}+2 \mu_{\mathrm{w}} a p_{2} \cdot C+3 \mu_{\mathrm{w}} a p_{3} \cdot C^{2}\right) \frac{\partial C}{\partial z} \frac{\partial P}{\partial z}\right]\right]$

$\varphi S_{\mathrm{w}} C_{\mathrm{fw}} \frac{\partial P}{\partial t}+\varphi \frac{\partial S_{\mathrm{w}}}{\partial t}=\frac{K K_{\mathrm{rw}}}{R_{\mathrm{k}} \mu_{p}}\left[\frac{\partial^{2} P}{\partial z^{2}}\right]+\left[\left[\frac{K}{R_{\mathrm{k}} \mu_{\mathrm{p}}}\left(\frac{n_{w} K_{\mathrm{rw}, \mathrm{ro}}}{1-S_{\mathrm{wc}}-S_{\mathrm{or}}}\right)\left(\frac{S_{\mathrm{w}}-S_{\mathrm{wc}}}{1-S_{\mathrm{wc}}-S_{\mathrm{or}}}\right)^{n_{w}-1} \frac{\partial S_{\mathrm{w}}}{\partial z} \frac{\partial P}{\partial z}+\right.\right.$

$\frac{K K_{\mathrm{rw}}}{R_{\mathrm{k}} \mu_{p}} C_{\mathrm{w}} \frac{\partial^{2} P}{\partial z^{2}}-\frac{K K_{\mathrm{rw}}}{R_{\mathrm{k}}^{2} \mu_{\mathrm{p}}}\left(\frac{\left(R_{\mathrm{kmax}} b_{\mathrm{rk}}-b_{\mathrm{rk}}\right)}{\left(1+b_{\mathrm{rk}} \cdot C\right)^{2}}\right) \frac{\partial C}{\partial z} \frac{\partial P}{\partial z}-\frac{K K_{\mathrm{rw}}}{\mu_{\mathrm{p}}^{2} R_{\mathrm{k}}}\left(\mu_{\mathrm{w}} a p_{1}+2 \mu_{\mathrm{w}} a p_{2} \cdot C+\right.$

$\left.\left.\left.3 \mu_{\mathrm{w}} a p_{3} . C^{2}\right) \frac{\partial C}{\partial z} \frac{\partial P}{\partial z}\right]\right]$

where $C_{\mathrm{R}}$, and $C_{\mathrm{w}}$ are the compressibility's of rock and water. As we can see the term $\varphi S_{\mathrm{w}} C_{\mathrm{fw}} \frac{\partial P}{\partial t} \ll \varphi \frac{\partial S_{\mathrm{w}}}{\partial t}$ it will be neglected and the final resulting equation will become; 
$\varphi \frac{\partial S_{\mathrm{w}}}{\partial t}=\frac{K K_{\mathrm{rw}}}{R_{\mathrm{k}} \mu_{\mathrm{p}}}\left[\frac{\partial^{2} P}{\partial z^{2}}\right]+\left[\left[\frac{K}{R_{\mathrm{k}} \mu_{\mathrm{p}}}\left(\frac{n_{w} K_{\mathrm{rw}, \mathrm{ro}}}{1-S_{\mathrm{wc}}-S_{\mathrm{or}}}\right)\left(\frac{S_{\mathrm{w}}-S_{\mathrm{wc}}}{1-S_{\mathrm{wc}}-S_{\mathrm{or}}}\right)^{n_{w}-1} \frac{\partial S_{\mathrm{w}}}{\partial z} \frac{\partial P}{\partial z}+\frac{K K_{\mathrm{rw}}}{R_{\mathrm{k}} \mu_{\mathrm{p}}} C_{\mathrm{w}} \frac{\partial^{2} P}{\partial z^{2}}-\right.\right.$

$\left.\left.\frac{K K_{\mathrm{rw}}}{R_{\mathrm{k}}^{2} \mu_{\mathrm{p}}}\left(\frac{\left(R_{\mathrm{kmax}} b_{\mathrm{rk}}-b_{\mathrm{rk}}\right)}{\left(1+b_{\mathrm{rk}} \cdot C\right)^{2}}\right) \frac{\partial C}{\partial z} \frac{\partial P}{\partial z}-\frac{K K_{\mathrm{rw}}}{\mu_{\mathrm{p}}^{2} R_{\mathrm{k}}}\left(\mu_{\mathrm{w}} a p_{1}+2 \mu_{\mathrm{w}} a p_{2} \cdot C+3 \mu_{\mathrm{w}} a p_{3} \cdot C^{2}\right) \frac{\partial C}{\partial z} \frac{\partial P}{\partial z}\right]\right]$

$\frac{\partial S_{\mathrm{w}}}{\partial t}=\frac{K K_{\mathrm{rw}}}{R_{\mathrm{k}} \mu_{\mathrm{p}} \varphi}\left[\frac{\partial^{2} P}{\partial z^{2}}\right]+\left[\frac{K}{R_{\mathrm{k}} \mu_{\mathrm{p}} \varphi}\left(\frac{n_{w} K_{\mathrm{rw}, \mathrm{ro}}}{1-S_{\mathrm{wc}}-S_{\mathrm{or}}}\right)\left(\frac{S_{\mathrm{w}}-S_{\mathrm{wc}}}{1-S_{\mathrm{wc}}-S_{\mathrm{or}}}\right)^{n_{w}-1} \frac{\partial S_{\mathrm{w}}}{\partial z} \frac{\partial P}{\partial z}+\frac{K K_{\mathrm{rw}}}{R_{\mathrm{k}} \mu_{\mathrm{p}} \varphi} C_{\mathrm{w}} \frac{\partial^{2} P}{\partial z^{2}}-\right.$

$\left.\frac{K K_{\mathrm{rw}}}{R_{\mathrm{k}} \mu_{\mathrm{p}} \varphi} \frac{\partial P}{\partial z} \frac{\partial C}{\partial z}\left(\frac{\left(R_{\mathrm{kmax}} b_{\mathrm{rk}}-b_{\mathrm{rk}}\right)}{R_{\mathrm{k}}\left(1+b_{\mathrm{rk}} \cdot C\right)^{2}}\right)+\left(\frac{\left(\mu_{\mathrm{w}} a p_{1}+2 \mu_{\mathrm{w}} a p_{2} \cdot C+3 \mu_{\mathrm{w}} a p_{3} \cdot C^{2}\right)}{\mu_{p}}\right)\right]$

\section{Derivation of Polymer Component Flow Equation}

The general form of the diffusion-convection equation of polymer is given as;

$$
\begin{aligned}
& D \nabla^{2} \mathrm{C}-v \cdot \nabla \mathrm{C}=\varphi \frac{\partial C}{\partial t} \\
& D=\text { diffusivity } \\
& \mathrm{C}=\text { concentration }
\end{aligned}
$$

Now solving the equation for polymer which adsorbs onto the rock surface is given by generalized Fick's law of diffusion and adsorption. The general mass balance takes the form;

$\left[\begin{array}{c}\text { Rate of Mass } \\ \text { into the element } \\ a t^{\prime} r^{\prime}\end{array}\right]-\left[\begin{array}{c}\text { Rate of Mass } \\ \text { out of the element } \\ a t^{\prime} r+\Delta r^{\prime}\end{array}\right]+\left[\begin{array}{c}\text { Rate of Mass } \\ \text { into the element } \\ a t^{\prime} z^{\prime}\end{array}\right]-$

$\left[\begin{array}{c}\text { Rate of Mass } \\ \text { out of the element } \\ \text { at }{ }^{\prime} z+\Delta z^{\prime}\end{array}\right]=\left[\begin{array}{c}\text { Rate of } \\ \text { Accumulation }\end{array}\right]$

\section{Rate of fluid mass enters the element at ' $r$ ':}

$J_{i}\left(r, z^{\prime}\right) \cdot h\left(r, z^{\prime}\right) \cdot \varphi_{p}\left(r, z^{\prime}\right) \cdot \Delta z=\Delta z\left(h \varphi_{p} J_{i}\right)_{r, z^{`}}$

\section{$\underline{\text { Rate of fluid mass leaves the element at ' } r+\Delta r \text { ': }}$}

$J_{i}\left(r+\Delta r, z^{\prime}\right) \cdot h\left(r+\Delta r, z^{\prime}\right) \cdot \varphi_{p}\left(r+\Delta r, z^{\prime}\right) \cdot \Delta z=\Delta z\left(h \varphi_{p} J_{i}\right)_{r+\Delta r, z^{\prime}}$

\section{Rate of fluid mass enters the element at ' $z$ ':}

$J_{i}\left(r^{\prime}, z\right) \cdot h\left(r^{\prime}, z\right) \cdot \varphi_{p}\left(r^{\prime}, z\right) \cdot \Delta r=\Delta r\left(h \varphi_{p} J_{i}\right)_{r_{, z}}$ 
$\underline{\text { Rate of fluid mass leaves the element at ' } z+\Delta z^{\prime} \text { : }}$

$J_{i}\left(r^{\prime}, z+\Delta z\right) \cdot h\left(r^{\prime}, z+\Delta z\right) \cdot \varphi_{p}\left(r^{\prime}, z+\Delta z\right) \cdot \Delta r=\Delta r\left(h \varphi_{p} J_{i}\right)_{r^{\prime}, z+\Delta z}$

\section{$\underline{\text { Rate of accumulation: }}$}

$h \frac{\partial}{\partial t}(C \varphi) \Delta r \Delta z$

where, $J_{i}=-D \nabla \mathbf{C}=>-D \frac{\partial \mathrm{C}}{\partial r}$ for $r-$ direction

$-D \frac{\partial \mathrm{C}}{\partial z}$ for $z-$ direction

$\left[\Delta z\left(h \varphi_{\mathrm{p}} J_{i}\right)_{r}-\Delta z\left(h \varphi_{\mathrm{p}} J_{i}\right)_{r+\Delta r}\right]+\left[\Delta r\left(h \varphi_{\mathrm{p}} J_{i}\right)_{z}-\Delta r\left(h \varphi_{\mathrm{p}} J_{i}\right)_{z+\Delta z}\right]=h \frac{\partial}{\partial t}(C \varphi) \Delta r \Delta z$

Rearranging and dividing by ' $\Delta r \Delta z^{\prime}$ and taking the limit $\Delta r \rightarrow 0, \Delta z \rightarrow 0$.

$$
\begin{aligned}
& -\frac{\partial}{\partial r}\left(h \varphi_{\mathrm{p}} J_{i}\right)-\frac{\partial}{\partial z}\left(h \varphi_{\mathrm{p}} J_{i}\right)=h \frac{\partial}{\partial t}(C \varphi) \\
& -\frac{\partial}{\partial r}\left(h \varphi_{\mathrm{p}}\left(-D \frac{\partial C}{\partial r}\right)\right)-\frac{\partial}{\partial z}\left(h \varphi_{\mathrm{p}}\left(-D \frac{\partial C}{\partial z}\right)\right)=h \frac{\partial}{\partial t}(C \varphi) \\
& \frac{\partial}{\partial r}\left(D h \varphi_{\mathrm{p}} \frac{\partial C}{\partial r}\right)+\frac{\partial}{\partial z}\left(D h \varphi_{\mathrm{p}} \frac{\partial C}{\partial z}\right)=h \frac{\partial}{\partial t}(C \varphi) \\
& \frac{\partial}{\partial r}\left(D h \varphi_{\mathrm{p}} \frac{\partial C}{\partial r}\right)+\frac{\partial}{\partial z}\left(D h \varphi_{\mathrm{p}} \frac{\partial C}{\partial z}\right)=h \frac{\partial}{\partial t}(\varphi C)
\end{aligned}
$$

\section{Bulk Flow Equation: -}

$\left[\begin{array}{c}\text { Rate of Mass } \\ \text { into the element } \\ a t^{\prime} r^{\prime}\end{array}\right]-\left[\begin{array}{c}\text { Rate of Mass } \\ \text { out of the element } \\ a t^{\prime} r+\Delta r^{\prime}\end{array}\right]+\left[\begin{array}{c}\text { Rate of Mass } \\ \text { into the element } \\ a t^{\prime} z^{\prime}\end{array}\right]-$

$\left[\begin{array}{c}\text { Rate of Mass } \\ \text { out of the element } \\ \text { at }{ }^{\prime} z+\Delta z^{\prime}\end{array}\right]=\left[\begin{array}{c}\text { Rate of } \\ \text { Accumulation }\end{array}\right]$

\section{$\underline{\text { Rate of fluid mass enters the element at ' } r \text { ': }}$}

$C\left(r, z^{\prime}\right) \cdot v_{r}\left(r, z^{\prime}\right) \cdot h\left(r, z^{\prime}\right) \cdot \Delta z=\Delta z\left(h C v_{r}\right)_{r, z^{\prime}}$

$\underline{\text { Rate of fluid mass leaves the element at ' } r+\Delta r^{\prime} \text { : }}$ 
$C\left(r+\Delta r, z^{\prime}\right) \cdot v_{r}\left(r+\Delta r, z^{\prime}\right) \cdot h\left(r+\Delta r, z^{\prime}\right) \cdot \Delta z=\Delta z\left(h C v_{r}\right)_{r+\Delta r, z^{\prime}}$

\section{$\underline{\text { Rate of fluid mass enters the element at ' } z \text { ': }}$}

$C\left(r^{\prime}, z\right) \cdot v_{z}\left(r^{\prime}, z\right) \cdot h\left(r^{\prime}, z\right) \cdot \Delta r=\Delta r\left(h C v_{z}\right)_{r^{\prime}, z}$

\section{Rate of fluid mass leaves the element at ' $z+\Delta z$ :}

$C\left(r^{\prime}, z+\Delta z\right) \cdot v_{z}\left(r^{\prime}, z+\Delta z\right) \cdot h\left(r^{\prime}, z+\Delta z\right) \cdot \Delta r=\Delta r\left(h C v_{z}\right)_{r^{\prime}, z+\Delta z}$

\section{Rate of accumulation:}

$h \frac{\partial}{\partial t}(C \varphi) \Delta r \Delta z$

$\left[\Delta z\left(h C v_{r}\right)_{r}-\Delta z\left(h C v_{r}\right)_{r+\Delta r}\right]+\left[\Delta r\left(h C v_{z}\right)_{z}-\Delta r\left(h C v_{z}\right)_{z+\Delta z}\right]=h \frac{\partial}{\partial t}(C \varphi) \Delta r \Delta z$

Rearranging and dividing by ' $\Delta r \Delta z^{\prime}$ and taking the limit $\Delta r \rightarrow 0, \Delta z \rightarrow 0$.

$-\frac{\partial}{\partial r}\left(h C v_{r}\right)-\frac{\partial}{\partial z}\left(h C v_{z}\right)=h \frac{\partial}{\partial t}(C \varphi)$

$-\frac{\partial}{\partial r}\left(h C\left(-\frac{K_{\mathrm{W}}}{\mu_{\mathrm{p}}} \frac{\partial P}{\partial r}\right)\right)-\frac{\partial}{\partial z}\left(h C\left(-\frac{K_{\mathrm{w}}}{\mu_{\mathrm{p}}} \frac{\partial P}{\partial z}\right)\right)=h \frac{\partial}{\partial t}(C \varphi)$

$\therefore K_{\mathrm{rw}}=\frac{K_{\mathrm{w}}}{K} \leq 1 \Rightarrow K_{\mathrm{w}}=K K_{\mathrm{rw}}$

$\frac{\partial}{\partial r}\left(h C \frac{K K_{\mathrm{rw}}}{\mu_{\mathrm{p}}} \frac{\partial P}{\partial r}\right)+\frac{\partial}{\partial z}\left(h C \frac{K K_{\mathrm{rw}}}{\mu_{\mathrm{p}}} \frac{\partial P}{\partial z}\right)=h \frac{\partial}{\partial t}(\varphi C)$

$\frac{\partial}{\partial r}\left(D h \varphi_{\mathrm{p}} \frac{\partial C}{\partial r}\right)+\frac{\partial}{\partial r}\left(h C \frac{K K_{\mathrm{rw}}}{\mu_{\mathrm{p}} R_{\mathrm{k}}} \frac{\partial P}{\partial r}\right)+\frac{\partial}{\partial z}\left(D h \varphi_{\mathrm{p}} \frac{\partial C}{\partial z}\right)+\frac{\partial}{\partial z}\left(h C \frac{K K_{\mathrm{rw}}}{\mu_{\mathrm{p}} R_{\mathrm{k}}} \frac{\partial P}{\partial z}\right)=h \frac{\partial}{\partial t}(\varphi C)$

The addition of water-soluble polymers reduces the permeability to water flow to a greater extent than to oil or gas flow. Due to this, the permeability reduction factor ' $R_{k}{ }^{\prime}$ is taken into consideration.

$\frac{\partial}{\partial r}\left(D h \varphi_{\mathrm{p}} \frac{\partial C}{\partial r}\right)+\frac{\partial}{\partial r}\left(\frac{K K_{\mathrm{rw}} h C}{\mu_{\mathrm{p}} R_{\mathrm{k}}} \frac{\partial P}{\partial r}\right)+\frac{\partial}{\partial z}\left(D h \varphi_{\mathrm{p}} \frac{\partial C}{\partial z}\right)+\frac{\partial}{\partial z}\left(\frac{K K_{\mathrm{rw}} h C}{\mu_{\mathrm{p}} R_{\mathrm{k}}} \frac{\partial P}{\partial z}\right)=h \frac{\partial}{\partial t}(\varphi C)$ 


\section{Polymer Flow Equation in Cylindrical Coordinates}

$\nabla \cdot\left(D h \varphi_{\mathrm{p}} \nabla \mathbf{C}\right)+\nabla \cdot\left(\frac{K K_{\mathrm{rw}} h C}{\mu_{\mathrm{p}} R_{\mathrm{k}}} \nabla \mathrm{P}\right)=h \frac{\partial}{\partial t}(\varphi C)$

$\therefore \varphi_{\mathrm{p}}=f_{\mathrm{a}} \varphi$

So,

$\nabla \cdot\left(D h f_{\mathrm{a}} \varphi \nabla \mathbf{C}\right)+\nabla \cdot\left(\frac{K K_{\mathrm{rw}} h C}{\mu_{\mathrm{p}} R_{\mathrm{k}}} \nabla \mathrm{P}\right)=h \frac{\partial}{\partial t}(\varphi C)$

Expanding R.H.S of the above equation;

$\nabla .\left[D h f_{\mathrm{a}} \varphi \nabla \mathbf{C}\right]$

$=D h f_{\mathrm{a}} \varphi \nabla \cdot(\nabla \mathbf{C})+\nabla C \cdot \nabla(\underbrace{D h f_{\mathrm{a}} \varphi}_{\lambda})$

$=D h f_{\mathrm{a}} \varphi\left[\frac{1}{r} \frac{\partial}{\partial r}\left(r \frac{\partial C}{\partial r}\right)+\frac{1}{r^{2}} \frac{\partial^{2} C}{\partial \theta^{2}}+\frac{\partial^{2} C}{\partial z^{2}}\right]+\left[\hat{r} \frac{\partial C}{\partial r}+\frac{1}{r} \hat{\theta} \frac{\partial C}{\partial \theta}+\hat{z} \frac{\partial C}{\partial z}\right] \cdot\left[\hat{r} \frac{\partial \lambda}{\partial r}+\frac{1}{r} \hat{\theta} \frac{\partial \lambda}{\partial \theta}+\hat{z} \frac{\partial \lambda}{\partial z}\right]$

$=D h f_{\mathrm{a}} \varphi\left[\frac{\partial^{2} C}{\partial z^{2}}\right]+\left[\frac{\partial C}{\partial z}\right]\left[\frac{\partial \lambda}{\partial z}\right]$

$\lambda=D h f_{\mathrm{a}} \varphi$

$\lambda=\lambda[\varphi(P(z))]$

$\frac{\partial \lambda}{\partial z}=\left[\frac{\partial \lambda}{\partial \varphi} \frac{\partial \varphi}{\partial P} \frac{\partial P}{\partial z}\right]$

$\frac{\partial \lambda}{\partial z}=\left[\left(D h f_{\mathrm{a}}\right)\left(\varphi_{r} C_{R}\right) \frac{\partial P}{\partial z}\right]$

$\frac{\partial \lambda}{\partial z}=\left[\left(D h f_{\mathrm{a}}\right)\left(\varphi_{\mathrm{r}} C_{\mathrm{R}}\right) \frac{\partial P}{\partial z}\right]$

$\left(\frac{\partial C}{\partial z}\right)\left(\frac{\partial \lambda}{\partial z}\right)=\left[\left(D h f_{\mathrm{a}}\right)\left(\varphi_{\mathrm{r}} C_{\mathrm{R}}\right) \frac{\partial C}{\partial z} \frac{\partial P}{\partial z}\right]$

The final equation for $\nabla .\left[D h f_{\mathrm{a}} \varphi \nabla \mathbf{C}\right]$ becomes;

$D h f_{\mathrm{a}} \varphi\left[\frac{\partial^{2} C}{\partial \mathrm{z}^{2}}\right]+\left[\left(D h f_{\mathrm{a}} \varphi_{\mathrm{r}} C_{\mathrm{R}}\right) \frac{\partial C}{\partial z} \frac{\partial P}{\partial z}\right]$ 
Now solving $\nabla \cdot\left[\frac{K K_{\mathrm{rw}} h C}{\mu_{\mathrm{p}} R_{\mathrm{k}}} \nabla \mathrm{P}\right]$

$=\frac{K K_{\mathrm{rw}} h C}{\mu_{\mathrm{p}} R_{\mathrm{k}}} \nabla \cdot(\nabla \mathrm{P})+\nabla \mathrm{P} \cdot \nabla \underbrace{\left(\frac{K K_{\mathrm{rw}} h C}{\mu_{\mathrm{p}} R_{\mathrm{k}}}\right)}_{\gamma}$

$=\frac{K K_{\mathrm{rw}} h C}{\mu_{\mathrm{p}} R_{\mathrm{k}}} \nabla^{2} \mathrm{P}+\nabla \mathrm{P} \cdot \nabla(\gamma)$

$=\frac{K K_{\mathrm{rw}} h C}{\mu_{\mathrm{p}} R_{\mathrm{k}}}\left[\frac{1}{r} \frac{\partial}{\partial r}\left(r \frac{\partial P}{\partial r}\right)+\frac{1}{r^{2}} \frac{\partial^{2} P}{\partial \theta^{2}}+\frac{\partial^{2} P}{\partial z^{2}}\right]+\left[\hat{r} \frac{\partial P}{\partial r}+\frac{1}{r} \hat{\theta} \frac{\partial P}{\partial \theta}+\hat{z} \frac{\partial P}{\partial z}\right] \cdot\left[\hat{r} \frac{\partial \gamma}{\partial r}+\frac{1}{r} \hat{\theta} \frac{\partial \gamma}{\partial \theta}+\hat{z} \frac{\partial \gamma}{\partial z}\right]$

$=\frac{K K_{\mathrm{rw}} h C}{\mu_{\mathrm{p}} R_{\mathrm{k}}}\left[\frac{\partial^{2} P}{\partial z^{2}}\right]+\left[\frac{\partial P}{\partial z}\right]\left[\frac{\partial \gamma}{\partial z}\right]$

$\gamma=\gamma\left[K_{\mathrm{rw}}\left(S_{\mathrm{w}}(z)\right), R_{\mathrm{k}}(C(z)), \mu_{\mathrm{p}}(C(z))\right]$

$\frac{\partial \gamma}{\partial z}=\left[\frac{\partial \gamma}{\partial K_{\mathrm{rw}}} \frac{\partial K_{\mathrm{rw}}}{\partial S_{\mathrm{w}}} \frac{\partial S_{\mathrm{w}}}{\partial z}+\frac{\partial \gamma}{\partial R_{\mathrm{k}}} \frac{\partial R_{\mathrm{k}}}{\partial C} \frac{\partial C}{\partial z}+\frac{\partial \gamma}{\partial \mu_{\mathrm{p}}} \frac{\partial \mu_{\mathrm{p}}}{\partial C} \frac{\partial C}{\partial z}\right]$

$\gamma=\frac{K K_{\mathrm{rw}} h C}{\mu_{\mathrm{p}} R_{\mathrm{k}}}$

1. $\frac{\partial \gamma}{\partial K_{\mathrm{rw}}}=\frac{\partial}{\partial K_{\mathrm{rw}}}\left(\frac{K K_{\mathrm{rw}} h C}{\mu_{\mathrm{p}} R_{\mathrm{k}}}\right)$

$\frac{\partial \gamma}{\partial K_{\mathrm{rw}}}=\frac{K h C}{\mu_{\mathrm{p}} R_{\mathrm{k}}}$

2. $\frac{\partial K_{\mathrm{rw}}}{\partial S_{\mathrm{w}}}=\frac{\partial}{\partial S_{\mathrm{w}}}\left[K_{\mathrm{rw}, \mathrm{ro}}\left(\frac{S_{\mathrm{w}}-S_{\mathrm{wc}}}{1-S_{\mathrm{wc}}-S_{\mathrm{or}}}\right)^{n_{w}}\right]$

$\frac{\partial K_{\mathrm{rw}}}{\partial S_{\mathrm{w}}}=\left(\frac{n_{w} K_{\mathrm{rw}, \mathrm{ro}}}{1-S_{\mathrm{wc}}-S_{\mathrm{or}}}\right)\left(\frac{S_{\mathrm{w}}-S_{\mathrm{wc}}}{1-S_{\mathrm{wc}}-S_{\mathrm{or}}}\right)^{n_{w}-1}$

3. $\frac{\partial \gamma}{\partial R_{\mathrm{k}}}=\frac{\partial}{\partial R_{\mathrm{k}}}\left(\frac{K K_{\mathrm{rw}} h C}{\mu_{\mathrm{p}} R_{\mathrm{k}}}\right)$

$\frac{\partial \gamma}{\partial R_{\mathrm{k}}}=-\frac{K K_{\mathrm{rw}} h C}{R_{\mathrm{k}}^{2} \mu_{\mathrm{p}}}$

4. $\frac{\partial R_{\mathrm{k}}}{\partial C}=\frac{\partial}{\partial C}\left(1+\frac{\left(R_{\mathrm{kmax}}-1\right) \cdot b_{\mathrm{rk}} \cdot C}{1+b_{\mathrm{rk}} \cdot C}\right)$ 
$\frac{\partial R_{\mathrm{k}}}{\partial C}=\left(\frac{\left(R_{\mathrm{kmax}} b_{\mathrm{rk}}-b_{\mathrm{rk}}\right)}{\left(1+b_{\mathrm{rk}} \cdot C\right)^{2}}\right)$

5. $\quad \frac{\partial \gamma}{\partial \mu_{\mathrm{p}}}=\frac{\partial}{\partial \mu_{\mathrm{p}}}\left(\frac{K K_{\mathrm{rw}} h C}{R_{\mathrm{k}} \mu_{\mathrm{p}}}\right)$

$\frac{\partial \gamma}{\partial \mu_{\mathrm{p}}}=-\frac{K K_{\mathrm{rw}} h C}{\mu_{\mathrm{p}}^{2} R_{\mathrm{k}}}$

6. $\frac{\partial \mu_{\mathrm{p}}}{\partial C}=\frac{\partial}{\partial C}\left[\mu_{\mathrm{w}}\left(1+\left(a p_{1} C+a p_{2} C^{2}+a p_{3} C^{3}\right)\right)\right]$

$\frac{\partial \mu_{\mathrm{p}}}{\partial c}=\left(\mu_{\mathrm{w}} a p_{1}+2 \mu_{\mathrm{w}} a p_{2} \cdot C+3 \mu_{\mathrm{w}} a p_{3} \cdot C^{2}\right)$

Now inserting all the derivatives of the above relations into the equation below and we get the following relation;

$\frac{\partial \gamma}{\partial z}=\left[\frac{\partial \gamma}{\partial K_{\mathrm{rw}}} \frac{\partial K_{\mathrm{rw}}}{\partial S_{\mathrm{w}}} \frac{\partial S_{\mathrm{w}}}{\partial z}+\frac{\partial \gamma}{\partial R_{\mathrm{k}}} \frac{\partial R_{\mathrm{k}}}{\partial C} \frac{\partial C}{\partial z}+\frac{\partial \gamma}{\partial \mu_{\mathrm{p}}} \frac{\partial \mu_{\mathrm{p}}}{\partial C} \frac{\partial C}{\partial z}\right]$

$\frac{\partial \gamma}{\partial z}=\left[\left[\frac{K h C}{R_{\mathrm{k}} \mu_{\mathrm{p}}}\left(\frac{n_{w} K_{\mathrm{rw}, \mathrm{ro}}}{1-S_{\mathrm{wc}}-S_{\mathrm{or}}}\right)\left(\frac{S_{\mathrm{w}}-S_{\mathrm{wc}}}{1-S_{\mathrm{wc}}-S_{\mathrm{or}}}\right)^{n_{w}-1} \frac{\partial S_{\mathrm{w}}}{\partial z}-\frac{K K_{\mathrm{rw}} h C}{R_{\mathrm{k}}^{2} \mu_{\mathrm{p}}}\left(\frac{\left(R_{\mathrm{kmax}} b_{\mathrm{rk}}-b_{\mathrm{rk}}\right)}{\left(1+b_{\mathrm{rk}} \cdot C\right)^{2}}\right) \frac{\partial C}{\partial z}-\right.\right.$

$\left.\left.\frac{K K_{\mathrm{rw}} h C}{\mu_{\mathrm{p}}^{2} R_{\mathrm{k}}}\left(\mu_{\mathrm{w}} a p_{1}+2 \mu_{\mathrm{w}} a p_{2} \cdot C+3 \mu_{\mathrm{w}} a p_{3} \cdot C^{2}\right) \frac{\partial C}{\partial z}\right]\right]$

$\left[\frac{\partial P}{\partial z}\right]\left[\frac{\partial \gamma}{\partial z}\right]=\left[\left[\frac{K h C}{R_{\mathrm{k}} \mu_{\mathrm{p}}}\left(\frac{n_{w} K_{\mathrm{rw}, \mathrm{ro}}}{1-S_{\mathrm{wc}}-S_{\mathrm{or}}}\right)\left(\frac{S_{\mathrm{w}}-S_{\mathrm{wc}}}{1-S_{\mathrm{wc}}-S_{\mathrm{or}}}\right)^{n_{w}-1} \frac{\partial S_{\mathrm{w}}}{\partial z} \frac{\partial P}{\partial z}-\right.\right.$

$\left.\left.\frac{K K_{\mathrm{rw}} h C}{R_{\mathrm{k}} \mu_{\mathrm{p}}} \frac{\partial C}{\partial z} \frac{\partial P}{\partial z}\left(\frac{\left(R_{\mathrm{kmax}} b_{\mathrm{rk}}-b_{\mathrm{rk}}\right)}{R_{k}\left(1+b_{\mathrm{rk}} \cdot C\right)^{2}}\right)+\left(\frac{\mu_{\mathrm{w}} a p_{1}+2 \mu_{\mathrm{w}} a p_{2} \cdot C+3 \mu_{\mathrm{w}} a p_{3} \cdot C^{2}}{\mu_{\mathrm{p}}}\right)\right]\right]$

The final equation for $\nabla \cdot\left[\frac{K K_{\mathrm{rw}} h C}{R_{\mathrm{k}} \mu_{\mathrm{p}}} \nabla \mathrm{P}\right]$ is given as;

$\nabla \cdot\left[\frac{K K_{\mathrm{rw}} h C}{R_{\mathrm{k}} \mu_{\mathrm{p}}} \nabla \mathrm{P}\right]=\frac{K K_{\mathrm{rw}} h C}{R_{\mathrm{k}} \mu_{\mathrm{p}}}\left[\frac{\partial^{2} P}{\partial z^{2}}\right]+\left[\frac{K h C}{R_{\mathrm{k}} \mu_{\mathrm{p}}}\left(\frac{n_{w} K_{\mathrm{rw}, \mathrm{ro}}}{1-S_{\mathrm{wc}}-S_{\mathrm{or}}}\right)\left(\frac{S_{\mathrm{w}}-S_{\mathrm{wc}}}{1-S_{\mathrm{wc}}-S_{\mathrm{or}}}\right)^{n_{w}-1} \frac{\partial S_{\mathrm{w}}}{\partial z} \frac{\partial P}{\partial z}-\right.$

$\left.\frac{K K_{\mathrm{rw}} h C}{R_{\mathrm{k}} \mu_{\mathrm{p}}}\left(\frac{\partial C}{\partial z}\right)\left(\frac{\partial P}{\partial z}\right)\left(\left(\frac{\left(R_{\mathrm{kmax}} b_{\mathrm{rk}}-b_{\mathrm{rk}}\right)}{R_{k}\left(1+b_{\mathrm{rk}} \cdot C\right)^{2}}\right)+\left(\frac{\mu_{\mathrm{w}} a p_{1}+2 \mu_{\mathrm{w}} a p_{2} \cdot C+3 \mu_{\mathrm{w}} a p_{3} \cdot C^{2}}{\mu_{\mathrm{p}}}\right)\right)\right]$

Now expanding the L.H.S of the equation, we get; 
$=h \frac{\partial}{\partial t}(\varphi C)$

$h \varphi \frac{\partial C}{\partial t}$

$\left[h \varphi \frac{\partial C}{\partial t}\right]=D h f_{\mathrm{a}} \varphi\left[\frac{\partial^{2} C}{\partial z^{2}}\right]+\left(D h f_{\mathrm{a}}\right)\left(\varphi_{\mathrm{r}} C_{\mathrm{R}}\right) \frac{\partial C}{\partial z} \frac{\partial P}{\partial z}+\frac{K K_{\mathrm{rw}} h C}{R_{\mathrm{k}} \mu_{\mathrm{p}}}\left[\frac{\partial^{2} P}{\partial z^{2}}\right]+$

$\left[\frac{K h C}{R_{\mathrm{k}} \mu_{\mathrm{p}}}\left(\frac{n_{w} K_{\mathrm{rw}, \mathrm{ro}}}{1-S_{\mathrm{wc}}-S_{\mathrm{or}}}\right)\left(\frac{S_{\mathrm{W}}-S_{\mathrm{wc}}}{1-S_{\mathrm{wc}}-S_{\mathrm{or}}}\right)^{n_{w}-1} \frac{\partial S_{\mathrm{w}}}{\partial z} \frac{\partial P}{\partial z}-\frac{K K_{\mathrm{rw}} h C}{R_{\mathrm{k}} \mu_{\mathrm{p}}}\left(\frac{\partial C}{\partial z}\right)\left(\frac{\partial P}{\partial z}\right)\left(\left(\frac{\left(R_{\mathrm{kmax}} b_{\mathrm{rk}}-b_{\mathrm{rk}}\right)}{R_{k}\left(1+b_{\mathrm{rk}} \cdot C\right)^{2}}\right)+\right.\right.$

$\left.\left.\left(\frac{\mu_{\mathrm{w}} a p_{1}+2 \mu_{\mathrm{w}} a p_{2} \cdot C+3 \mu_{\mathrm{W}} a p_{3} \cdot C^{2}}{\mu_{\mathrm{p}}}\right)\right)\right]$

Multiplying by $\left(\frac{1}{h \varphi}\right)$ on the both sides of the above equation and the final resulting equation takes the form as given below;

$\frac{\partial C}{\partial t}=D f_{\mathrm{a}}\left[\frac{\partial^{2} C}{\partial z^{2}}\right]+\frac{D f_{\mathrm{a}} \varphi_{\mathrm{r}} C_{\mathrm{R}}}{\varphi} \frac{\partial C}{\partial z} \frac{\partial P}{\partial z}+\frac{K K_{\mathrm{rw}} C}{R_{\mathrm{k}} \mu_{\mathrm{p}} \varphi}\left[\frac{\partial^{2} P}{\partial z^{2}}\right]+$

$\left[\frac{K C}{R_{\mathrm{k}} \mu_{\mathrm{p}} \varphi}\left(\frac{n_{w} K_{\mathrm{rw}, \mathrm{ro}}}{1-S_{\mathrm{wc}}-S_{\mathrm{or}}}\right)\left(\frac{S_{\mathrm{w}}-S_{\mathrm{wc}}}{1-S_{\mathrm{wc}}-S_{\mathrm{or}}}\right)^{n_{w}-1} \frac{\partial S_{\mathrm{w}}}{\partial z} \frac{\partial P}{\partial z}-\frac{K K_{\mathrm{rw}} C}{R_{\mathrm{k}} \mu_{\mathrm{p}} \varphi}\left(\frac{\partial C}{\partial z}\right)\left(\frac{\partial P}{\partial z}\right)\left(\left(\frac{\left(R_{\mathrm{kmax}} b_{\mathrm{rk}}-b_{\mathrm{rk}}\right)}{R_{\mathrm{k}}\left(1+b_{\mathrm{rk}} \cdot C\right)^{2}}\right)+\right.\right.$

$\left.\left.\left(\frac{\mu_{\mathrm{w}} a p_{1}+2 \mu_{\mathrm{w}} a p_{2} \cdot C+3 \mu_{\mathrm{w}} a p_{3} \cdot C^{2}}{\mu_{\mathrm{p}}}\right)\right)\right]$

(D.57) 


\section{REFERENCES}

Abukhalifeh, H. 2010. Determination of concentration-dependent dispersion of propane in vapor extraction of heavy oil (Vol. 72, No. 05).

Adams, D. M. 1982. Experiences with waterflooding Lloydminster heavy-oil reservoirs. Journal of Petroleum Technology, 34(08), 1-643.

Ali, S. F. 2003. Heavy oil—ever more mobile. Journal of Petroleum Science and Engineering, $37(1), 5-9$.

Ancheyta, J. 2016. Deactivation of Heavy Oil Hydroprocessing Catalysts: Fundamentals and Modeling. John Wiley \& Sons.

Anderson, W. G. 1987. Wettability literature survey-part 6: the effects of wettability on waterflooding. Journal of Petroleum Technology, 39(12), 1-605.

Aldousary, S. 2015. Role of Surfactant Flooding in Enhanced Oil Recovery.

Algharaib, M., Alajmi, A., \& Gharbi, R. 2014. Improving polymer flood performance in high salinity reservoirs. Journal of Petroleum Science and Engineering, 115, 17-23.

Al-Mutairi, S. M., \& Kokal, S. L. 2011, January. EOR potential in the middle east: current and future trends. In SPE EUROPEC/EAGE Annual Conference and Exhibition. Society of Petroleum Engineers.

Alvarado, V., \& Manrique, E. 2010. Enhanced oil recovery: field planning and development strategies. Gulf Professional Publishing.

Alvarado, V., \& Manrique, E. 2010. Enhanced oil recovery: an update review. Energies, 3(9), 1529-1575.

Aronofsky, J. 1952. Mobility ratio-its influence on flood patterns during water encroachment. Journal of Petroleum Technology, 4(01), 15-24.

Asghari, K., \& Nakutnyy, P. 2008, January. Experimental results of polymer flooding of heavy oil reservoirs. In Canadian International Petroleum Conference. Petroleum Society of Canada.

BP. 2017. BP Statistical Review of World Energy June 2017 (66th ed.).

CAPP. 2017. 2017 Crude Oil Forecast, Markets and Transportation. Retrieved from http://www.capp.ca/publications-and-statistics/crude-oil-forecast.

Chang, H. L., Zhang, Z. Q., Wang, Q. M., Xu, Z. S., Guo, Z. D., Sun, H. Q., ... \& Qiao, Q. 2006. Advances in polymer flooding and alkaline/surfactant/polymer processes as developed and applied in the People's Republic of China. Journal of petroleum technology, 58(02), 8489. 
Chatzis, I., \& Morrow, N. R. 1984. Correlation of capillary number relationships for sandstone. Society of Petroleum Engineers Journal, 24(05), 555-562.

Clifford, P. J., \& Sorbie, K. S. 1985, January. The effects of chemical degradation on polymer flooding. In SPE Oilfield and Geothermal Chemistry Symposium. Society of Petroleum Engineers.

Cossé, R. 1993. Basics of reservoir engineering: oil and gas field development techniques. Éditions Technip.

Delamaide, E., Zaitoun, A., Renard, G., \& Tabary, R. 2014. Pelican Lake field: first successful application of polymer flooding in a heavy-oil reservoir. SPE Reservoir Evaluation \& Engineering, 17(03), 340-354.

Donaldson, E. C., Chilingarian, G. V., \& Yen, T. F. (Eds.). 1989. Enhanced oil recovery, II: Processes and operations. Elsevier.

EOR Surveys. 2017. Oil and Gas Journal. N.p. Penwell Corp.

ExxonMobil. 2016. The Outlook for Energy: A View to 2040.

Garrouch, A. A., \& Gharbi, R. C. 2006, January. A novel model for viscoelastic fluid flow in porous media. In SPE Annual Technical Conference and Exhibition. Society of Petroleum Engineers.

Green, D. W., \& Willhite, G. P. 1998. Enhanced oil recovery (Vol. 6, pp. 143-154). Richardson, TX: Henry L. Doherty Memorial Fund of AIME, Society of Petroleum Engineers. Han, D. K., Yang, C. Z., Zhang, Z. Q., Lou, Z. H., \& Chang, Y. I. 1999. Recent development of enhanced oil recovery in China. Journal of Petroleum Science and Engineering, 22(1), 181188.

Healy, R. N., \& Reed, R. L. 1974. Physsicochemical aspects of microemulsion flooding. Society of Petroleum Engineers Journal, 14(05), 491-501.

Hovendick, M. D. 1989. Development and results of the Hale/Mable leases cooperative polymer EOR injection project, vacuum (Grayburg-San Andres) field, Lea County, New Mexico. SPE Reservoir Engineering, 4(03), 363-372.

International Energy Agency. 2014. World Energy Outlook 2014. IEA.

Juárez, J. A. 2016. Deactivation of Heavy Oil Hydroprocessing Catalysts: Fundamentals and Modeling. Hoboken, New Jersey: Wiley.

Johnson Jr, C. E. 1976. Status of caustic and emulsion methods. Journal of Petroleum Technology, 28(01), 85-92. 
Kamari, A., Safiri, A., \& Mohammadi, A. H. 2015. Compositional model for estimating asphaltene precipitation conditions in live reservoir oil systems. Journal of Dispersion Science and Technology, 36(3), 301-309.

Kaminsky, R. D., Wattenbarger, R. C., Szafranski, R. C., \& Coutee, A. 2007, January. Guidelines for polymer flooding evaluation and development. In International petroleum technology conference. International Petroleum Technology Conference.

Kang, X., Zhang, J., Sun, F., Zhang, F., Feng, G., Yang, J., ... \& Xiang, W. 2011, January. A review of polymer EOR on offshore heavy oil field in Bohai Bay, China. In SPE enhanced oil recovery conference. Society of Petroleum Engineers.

Kasrale, M., Sammon, P. H., \& Jespersen, P. J. 1993. Field development options for a waterflooded heavy-oil reservoir. Journal of Petroleum Technology, 45(09), 888-894.

Knight, B. L., \& Rhudy, J. S. 1977. Recovery of high-viscosity crudes by polymer flooding. Journal of Canadian Petroleum Technology, 16(04).

Ko, S., Domier, D. B., \& MacDermott, R. N. 1995, January. Waterflood optimization of the Buffalo Coulee Bakken heavy oil pool of Southwestern Saskatchewan. In SPE International Heavy Oil Symposium. Society of Petroleum Engineers.

Kumar, M., Hoang, V. T., Satik, C., \& Rojas, D. H. 2008. High-mobility-ratio waterflood performance prediction: challenges and new insights. SPE Reservoir Evaluation \& Engineering, 11(01), 186-196.

Lake, L. W. 1989. Enhanced oil recovery. Prentice Hall, New Jersey, Cap, 9, 361-371.

Lee, K. S. 2009. Effects of various design parameters on the performance of polymer flooding processes. Energy Sources, Part A: Recovery, Utilization, and Environmental Effects, 31(20), 1791-1801.

Let, M. S., Priscilla, K., Manichand, R. N., \& Seright, R. S. 2012, January. Polymer Flooding a 500-cp Oil. In SPE Improved Oil Recovery Symposium. Society of Petroleum Engineers.

Levitt, D., Jouenne, S., Bondino, I., Santanach-Carreras, E., \& Bourrel, M. 2013, July. Polymer flooding of heavy oil under adverse mobility conditions. In SPE enhanced oil recovery conference. Society of Petroleum Engineers.

Li, H.-P., Zhao, H.T., Chen, H., Zhao, P.C., 2006a. Field application of hydrophobicallyassociating-polymer-based gel for profile modification in Zhongyuan oilfields. Oilfield chemistry $23(1), 54-58$. 
Li, H.-P., Zhao, H.T., Zhao, P.C., Chen, H., 2006b. Laboratory study of hydrophobicallyassociating-polymer-based gel as a profiling agent in high-temperature and high-salinity Zhongyuan oilfields. Oilfield chemistry 23 (1), 50-53.

Lie, K. A., Nilsen, H. M., Rasmussen, A. F., \& Raynaud, X. 2014. Fast simulation of polymer injection in heavy-oil reservoirs on the basis of topological sorting and sequential splitting. SPE Journal, 19(06), 991.

Lindley, J. 1927. Chemical Flooding (Polymer).

http://www.netl.doe.gov

Littman, W. 1998. Polymer Flooding: Developments in Petroleum Science.

Lozanski, W. R., \& Martin, I. 1970. Taber South-Canada's first polymer flood. Journal of Canadian Petroleum Technology, 9(02).

Lu, X., Wang, Y., \& Zhang, Y. 2006, January. Strategies and Techniques for a Giant Sandstone Oilfield Development: A Road Map to Maximize Recovery. In SPE Asia Pacific Oil \& Gas Conference and Exhibition. Society of Petroleum Engineers.

Ma, S. 2005. Enhanced heavy oil recovery by dilute alkaline flooding. ProQuest.

Maitin, B. K., \& Volz, H. 1981, January. Performance of Deutsche Texaco Ag's Oerrel and Hankensbuettel Polymer Floods. In SPE/DOE Enhanced Oil Recovery Symposium. Society of Petroleum Engineers.

Manning, R. K., Pope, G. A., Lake, L. W., \& Paul, G. W. 1983. A technical survey of polymer flooding projects. Bartlesville Project Office, US Department of Energy.

Manichand, R. N., Mogollon, J. L., Bergwijn, S. S., Graanoogst, F., \& Ramdajal, R. 2010, January. Preliminary assessment of Tambaredjo heavy oilfield polymer flooding pilot test. In SPE Latin American and Caribbean Petroleum Engineering Conference. Society of Petroleum Engineers.

Meyer, R. F., \& Attanasi, E. D. 2003. Heavy oil and bitumen-strategic petroleum resources. USGS Fact Sheets. US Geological Survey, Reston, VA.

Miller, K. A., \& Holub, A. J. 2000, January. Applying Canadian Heavy Oil Technology to an Argentine Heavy Oil Reservoir. In Canadian International Petroleum Conference. Petroleum Society of Canada.

Mohammadi, S., Masihi, M., \& Ghazanfari, M. H. 2012. Characterizing the role of shale geometry and connate water saturation on performance of polymer flooding in heavy oil Reservoirs: experimental observations and numerical simulations. Transport in porous media, 91(3), 973-998. 
Mohammadpoor, M., \& Torabi, F. 2012, January. An extensive review on the effective sequence of heavy oil recovery. In SPE heavy oil conference Canada. Society of Petroleum Engineers.

Mungan, N. 1964. Role of wettability and interfacial tension in water flooding. Society of Petroleum Engineers Journal, 4(02), 115-123.

Mungan, N. 1981. Enhanced oil recovery using water as a driving fluid. Part 7. Field applications of carbon dioxide flooding. World Oil;(United States), 193(4).

Needham, R. B., \& Doe, P. H. 1987. Polymer flooding review. Journal of Petroleum Technology, 39(12), 1-503.

Oefelein, F. H., \& Walker, J. W. 1964. California Flood Yields Profitable Recovery of Heavy Oil from Multilayered Reservoir. Journal of Petroleum Technology, 16(05), 509-514.

Oilfield Review January 2016. 2016, January. Retrieved from http://www.slb.com/resources/oilfield_review/en/2016/or2016_Jan.aspx.

Okoye, C. U. 1982. An experimental investigation of tertiary recovery of oil by alkaline steam flooding (Doctoral dissertation).

Okoye, C. U., \& Tiab, D. 1982, January. Enhanced Recovery of Oil by Alkaline Steam Flooding. In SPE Annual Technical Conference and Exhibition. Society of Petroleum Engineers.

Paterson, L., Hornof, V., \& Neale, G. 1984. Water fingering into an oil-wet porous medium saturated with oil at connate water saturation. Revue de l'Institut Français du Pétrole, 39(4), $517-521$.

Pye, D. J. 1964. Improved secondary recovery by control of water mobility. Journal of Petroleum technology, 16(08), 911-916.

Ramirez, W. F. 1987. Application of optimal control theory to enhanced oil recovery (Vol. 21). Elsevier.

Rudin, J., \& Wasan, D. T. 1992. Mechanisms for lowering of interfacial tension in alkali/acidic oil systems 1. Experimental studies. Colloids and surfaces, 68(1-2), 67-79.

Saboorian-Jooybari, H., Dejam, M., \& Chen, Z. 2016. Heavy oil polymer flooding from laboratory core floods to pilot tests and field applications: Half-century studies. Journal of Petroleum Science and Engineering, 142, 85-100.

Salama, D., \& Kantzas, A. 2006. Experiment observations of miscible displacement of heavy oil with hydrocarbon solvents. Journal of petroleum technology, 58(4), 102-104.

Sandiford, B. B. 1964. Laboratory and field studies of water floods using polymer solutions to increase oil recoveries. Journal of Petroleum Technology, 16(08), 917-922. 
Saskatchewan Energy and Mines (SEM), 1998. Reservoir Annual.

Schumacher, M. M. (Ed.). 1980. Enhanced recovery of residual and heavy oils (No. 174). Noyes Publications.

Seright, R. 2010. Potential for polymer flooding reservoirs with viscous oils. SPE Reservoir Evaluation \& Engineering, 13(04), 730-740.

Shaw, R. A., \& Stright Jr, D. H. 1977. Performance of Taber South Polymer Flood. Journal of Canadian Petroleum Technology, 16(01).

Sheng, J. 2011. Modern chemical enhance oil recovery: theory and practice. Gulf Professional. Sheng, J. (Ed.). 2013. Enhanced oil recovery field case studies. Gulf Professional Publishing. Sheng, J. J., Leonhardt, B., \& Azri, N. 2015. Status of polymer-flooding technology. Journal of Canadian Petroleum Technology, 54(02), 116-126.

Singhal, A. 2011. Preliminary review of IETP projects using polymers. Engineering Report, Calgary, Alberta, Canada: Premier Reservoir Engineering Services LTD.

Solatpour, R. 2015. Experimental Studies on Polymer and Alkaline-Surfactant-Polymer Flooding to Improve Heavy Oil Recovery (Doctoral dissertation, Faculty of Graduate Studies and Research, University of Regina).

Sorbie, K. S. 1991. Polymer-Improved oil recovery, Blackie and Son Ltd. Glasgow and London.

Sparlin, D. D. 1976. An Evaluation of Polyacrylamides for Reducing Water Production (includes associated papers 6561 and 6562). Journal of Petroleum Technology, 28(08), 906914.

Speight, J. G. 2013. Enhanced recovery methods for heavy oil and tar sands. Elsevier.

Speight, J. G. (Ed.). 1999. The desulfurization of heavy oils and residua. CRC Press.

Speight, J. G. 2009. Enhanced recovery methods for heavy oil and tar sands. Elsevier.

Squires, F. 1917. U.S. Patent No. 1,238,355. Washington, DC: U.S. Patent and Trademark Office.

Szabo, M. T. 1975. Laboratory investigations of factors influencing polymer flood performance. Society of Petroleum Engineers Journal, 15(04), 338-346.

Taber, J. J., Martin, F. D., \& Seright, R. S. 1997. EOR screening criteria revisited - part 2: applications and impact of oil prices. SPE Reservoir Engineering, 12(03), 199-206.

Thomas, S., \& Ali, S. M. 1999, January. Micellar flooding and ASP-chemical methods for enhanced oil recovery. In Annual Technical Meeting. Petroleum Society of Canada.

Thomas, S. 2008. Enhanced oil recovery-an overview. Oil \& Gas Science and TechnologyRevue de l'IFP, 63(1), 9-19. 
Urbissinova, T., Trivedi, J. J., \& Kuru, E. 2010, January. Effect of Elasticity during Viscoelastic Polymer Flooding-A Possible Mechanism of Increasing the Sweep Efficiency. In SPE western regional meeting. Society of Petroleum Engineers.

Uren, L. C., \& Fahmy, E. H. 1927. Factors influencing the recovery of petroleum from unconsolidated sands by waterflooding. Transactions of the AIME, 77(01), 318-335.

Veil, J. A., Quinn, J. J., \& Garcia, J. 2009, January. Water issues relating to heavy oil production. In SPE Americas E\&P Environmental and Safety Conference. Society of Petroleum Engineers.

Visiongain. 2014. Chemical Enhanced Oil Recovery (EOR) Market Forecast 2014--2024. Visiongain Ltd.

Wang, D., Cheng, J., Li, Q., Li, L. Z., Zhao, C. J., \& Hong, J. C. 1999. An alkaline biosurfactant polymer flooding pilots in Daqing Oil Field. paper SPE, 57304.

Wang, D., Cheng, J., Yang, Q., Wenchao, G., Qun, L., \& Chen, F. 2000, January. Viscouselastic polymer can increase microscale displacement efficiency in cores. In SPE annual technical conference and exhibition. Society of Petroleum Engineers.

Wang, J., \& Dong, M. 2007, January. A laboratory study of polymer flooding for improving heavy oil recovery. In Canadian International Petroleum Conference. Petroleum Society of Canada.

Wang, D., Seright, R. S., Shao, Z., \& Wang, J. 2008. Key aspects of project design for polymer flooding at the Daqing Oilfield. SPE Reservoir Evaluation \& Engineering, 11(06), 1117.

Wang, D., Wang, G., \& Xia, H. 2011, January. Large scale high visco-elastic fluid flooding in the field achieves high recoveries. In SPE Enhanced Oil Recovery Conference. Society of Petroleum Engineers.

Wassmuth, F. R., Green, K., Hodgins, L., \& Turta, A. T. 2007, January. Polymer flood technology for heavy oil recovery. In Canadian international petroleum conference. Petroleum Society of Canada.

Wassmuth, F. R., Green, K., Arnold, W., \& Cameron, N. 2009. Polymer flood application to improve heavy oil recovery at East Bodo. Journal of Canadian Petroleum Technology, 48(02), 55-61.

Wassmuth, F. R., Green, K., \& Bai, J. 2012, January. Associative Polymers Outperform Regular Polymers Displacing Heavy Oil in Heterogeneous Systems. In SPE Heavy Oil Conference Canada. Society of Petroleum Engineers. 
Wever, D. A. Z., Picchioni, F., \& Broekhuis, A. A. 2011. Polymers for enhanced oil recovery: a paradigm for structure-property relationship in aqueous solution. Progress in Polymer Science, 36(11), 1558-1628.

Yin, H., Wang, D., \& Zhong, H. 2006, January. Study on flow behaviors of viscoelastic polymer solution in micropore with dead end. In SPE Annual Technical Conference and Exhibition. Society of Petroleum Engineers.

Zaitoun, A. L. A. I. N., Tabary, R., Fossey, J. P., \& Boyle, T. 1998. Implementing a HeavyOil Horizontal Well Polymer Flood in Western Canada. Manuscript, (191), 27-30.

Zhao, F.-L., 1991. Chemistry in Oil Production. University of Petroleum, China

Zhang, J., Wang, K., He, F., \& Zhang, F. 1999, January. Ultimate evaluation of the alkali/polymer combination flooding pilot test in XingLongTai oil field. In SPE Asia Pacific Improved Oil Recovery Conference. Society of Petroleum Engineers.

Zhang, Y., Huang, S. S., \& Luo, P. 2010. Coupling immiscible CO2 technology and polymer injection to maximize EOR performance for heavy oils. Journal of Canadian Petroleum Technology, 49(05), 25-33.

Zhou, H., Huang, R.H., 1997. Study on the solution properties of water-soluble hydrophobically associating Acrylamide/n-Octylacrylate copolymers. Oilfield chemistry 14 (3), 252-256. 